UNIVERSIDADE DE SÃO PAULO

ESCOLA DE ENFERMAGEM

MARIA LUCIA HABIB PASCHOAL

\title{
ESTUDO DO CONSUMO DE MATERIAIS DE UM \\ CENTRO CIRÚRGICO APÓS A IMPLEMENTAÇÃO DE UM SISTEMA DE GESTÃO INFORMATIZADO
}




\section{MARIA LUCIA HABIB PASCHOAL}

\section{ESTUDO DO CONSUMO DE MATERIAIS DE UM CENTRO CIRÚRGICO APÓS A IMPLEMENTAÇÃO DE UM SISTEMA DE GESTÃO INFORMATIZADO}

Tese apresentada ao Programa de Pós-Graduação em Enfermagem da Escola de Enfermagem da Universidade de São Paulo, para obtenção do título de Doutor em Enfermagem.

Área de concentração:

Enfermagem

Orientadora:

Profa. Dra. Valéria Castilho 
Autorizo a reprodução total ou parcial deste trabalho, por qualquer meio convencional ou eletrônico, para fins de estudo e pesquisa, desde que citada a fonte.

Assinatura:

Data:

1

Catalogação na Publicação (CIP)

Biblioteca "Wanda de Aguiar Horta"

Escola de Enfermagem da Universidade de São Paulo

Paschoal, Maria Lucia Habib.

Estudo do consumo de materiais de um centro cirúrgico após a implementação de um sistema de gestão informatizado. / Maria Lucia Habib Paschoal. - São Paulo, 2009.

$190 \mathrm{p}$.

Tese (Doutorado) - Escola de Enfermagem da Universidade de São Paulo.

Orientadora: $\operatorname{Prof}^{\mathrm{a}}$ Dr$^{\mathrm{a}}$ Valéria Castilho.

1. Administração de materiais no hospital 2. Just in time 3.

Controle de estoques (automação) 4. Centro cirúrgico hospitalar.

I. Título. 
Maria Lucia Habib Paschoal

Estudo do consumo de materiais de um centro cirúrgico após a implementação de um sistema de gestão informatizado.

Tese apresentada ao Programa de PósGraduação em Enfermagem da Escola de Enfermagem da Universidade de São Paulo, para obtenção do título de Doutor em Enfermagem.

Aprovado em:

Banca Examinadora

Prof. Dr. Instituição:

Julgamento: Assinatura:

Prof. Dr. Instituição: Julgamento: Assinatura:

Prof. Dr. Instituição:

Julgamento: Assinatura:

Prof. Dr. Instituição:

Julgamento: Assinatura:

Prof. Dr. Instituição:

Julgamento: Assinatura: 
Aos meus mestres queridos, meus pais, José e Munira, onde tudo começou, os ensinamentos para toda vida.

Amo vocês...... 


\section{AGRADECIMENTO ESPECIAL}

Ao Professor Doutor Paulo Andrade Lotufo, pelo acolhimento na Superintendência do HU-USP, apoio e incentivo que me proporcionou, pela confiança e, principalmente, por acreditar e sempre estar junto a este projeto para seu pleno sucesso, depositando total confiança. Meu respeito, minha admiração e eterna gratidão!

À Professora Doutora Raquel Rapone Gaidzinski, por proporcionar sempre uma palavra de apoio....., pela oportunidade de desenvolvimento profissional e o incentivo para o ingresso no nível de doutorado. Raquel, meu muito obrigada!

À Professora Doutora Valeria Castilho pela disponibilidade, prontamente me aceitando como sua aluna, pelo carinho, amizade, respeito, dedicação e incentivo com que orientou este trabalho. 


\section{AGRADECIMENTOS}

À minha irmã, Tatinha, e meu cunhado, Luiz, pela compreensão da minha ausência em determinados momentos devido ao meu empenho nesta jornada.

À Maria Augusta, minha sobrinha, meu tesouro..., pela compreensão e o carinho demonstrado.

À amiga, Andréa, pela amizade, pela implementação do SGM, pelas contribuições durante a realização deste trabalho, pelo apoio tão fundamental.....

Aos Professores Doutores Vera Lúcia Mira Gonçalves e Antônio Robles Junior, pelas sugestões no exame de qualificação, contribuindo para a análise de dados deste trabalho.

À Instituição HU-USP, pela oportunidade e apoio, tornando possível a realização do estudo proposto.

À Filomena, Lea e a todos da Superintendência do HU-USP, pela compreensão e lugar para escrever.

À Rosana Alves Vieira, Diretora Administrativa do HU-USP, pelo apoio de sempre.

À Andréa Wertchko, Diretora do Serviço de material do HU-USP, e sua equipe, pela confiança e consideração.

Ao Mauricio Lanzini, chefe do setor de Almoxarifado do HU-USP, e sua equipe, pela disponibilidade e colaboração. 
Ao Stanley Galvão e André Britto, meus fieis escudeiros no desenvolvimento do novo Sistema de Gestão de Materiais, por tudo e pela implantação do SGM, tornando possível a realização do estudo proposto. Muito obrigada!

Ao Allan Clempe e Leandro Coelho Gouveia, pela atenção, gentileza e obtenção dos dados do SGM para realizar a coleta de dados.

À Rosangela Ferreira Magalhães e Maria Regina Pimentel, pela dedicação e apoio, minha eterna gratidão.

À Karina, enfermeira responsável pelo material do Departamento de Enfermagem do HU-USP, pela dedicação nos cadastros dos materiais médico-hospitalares do SGM.

A todos aqueles que participaram das reuniões periódicas para que o SGM pudesses ser implementado: Alexandre, Claudia, Luiz, Ricardo, Rosangela, Stanley, Brito, Allan, Leandro, Andréa Wertchko, Rosana, Mauricio, Andréa, Rosangela F. Magalhães, meu respeito e admiração.

A todos os profissionais da L.F.Consultoria em Informática, pelo apoio, profissionalismo e compromisso que desenvolveram o SGM no HU-USP.

A todos os profissionais do Centro Cirúrgico, de enfermagem, cirurgiões e anestesiologistas, obrigada!

À Creuza Maria Roveri Dalbo, pela descrição estatística dos resultados.

Ao Jair Santos, pela criatividade e o carinho dispensado.

À Jane Maria Ribeiro do Prado, pela eficiência e disponibilidade na composição final do trabalho.

À Professora Katumi Ussami, pela revisão extremamente cuidadosa do texto.

À Kazuko Kimura, amiga do grupo SOL, pela disponibilidade e a contribuição em inglês. 
À Maria Alice Rangel Rebello, pela cuidadosa revisão bibliográfica.

Ao Serviço de Biblioteca da Escola de Enfermagem da USP, em especial Andréia Wojcicki pela ficha catalográfica.

Enfim, a todos aqueles que diretamente ou indiretamente colaboraram para a realização deste trabalho.

A todos, muito obrigada! 
Paschoal MLH. Estudo do consumo de materiais de um centro cirúrgico após a implementação de um sistema de gestão informatizado [tese] São Paulo (SP): Escola de Enfermagem. Universidade de São Paulo; 2009.

\section{RESUMO}

Neste estudo, foi comparada a eficácia de dois modelos de gestão de materiais: o primeiro foi o modelo tradicional, com controle manual e com reposição de estoque baseado em cotas preestabelecidas, adotado pelo Hospital Universitário da Universidade de São Paulo (HU-USP), desde 1981; e o segundo modelo, implementado em 2008, com gestão informatizada e reposição de estoque segundo os princípios do just in time. Assim, os objetivos específicos foram comparar a quantidade e o custo dos materiais médicohospitalares consumidos e em estoque antes e após a implantação do Sistema de Gestão de Materiais informatizado (SGM) e, identificar o consumo dos kits cirúrgicos e anestésicos após a implantação do novo sistema. Trata-se de um estudo comparativo com abordagem quantitativa, desenvolvido no Centro Cirúrgico do HU-USP. Para a coleta de dados, foram utilizados quatro instrumentos: planilha de movimento cirúrgico e a caracterização do paciente; planilha de consumo do material; planilha de kits cirúrgicos e anestésicos; e a planilha de dados sobre estoque de materiais. A população foi constituída por 400 itens de materiais médico-hospitalares do setor de Centro Cirúrgico, no período de fevereiro a maio de 2007 e fevereiro a maio de 2008. Os resultados mostraram que o consumo de materiais do Centro Cirúrgico em 2008 reduziu $8,13 \%$ em relação ao ano de 2007 e o custo total dos materiais consumidos tiveram um acréscimo de 2,20\%, não tendo representação estatística significativa. Quanto aos kits de procedimentos cirúrgicos e anestésicos, nos quatro meses estudados no ano de $2008,64,7 \%$ do consumo de materiais fizeram parte do kit e $35,3 \%$ foram materiais avulsos consumidos durante a cirurgia. Foram utilizados 81tipos de kits sendo que, 54 (66,6\%) apresentaram um consumo de material abaixo de 51,9\%. Houve uma redução de materiais em estoque no Centro Cirúrgico em 2008 de 26,22\% em relação ao ano de 2007 e uma redução de $12,46 \%$ do custo.

PALAVRAS-CHAVE: Administração de materiais no hospital. Just in time. Controle de estoques (automação). Centro cirúrgico hospitalar. 
Paschoal MLH. Study on the use of hospital medical materials of a surgical center after the implementation of an automated management system [Thesis]. São Paulo (SP): Nursing School. University of São Paulo; 2009.

\begin{abstract}
This study involved the comparison of the efficiency of two models of management of hospital medical materials: the first was the traditional model, manually controlled and with stock reposition based on pre-determined quotas adopted by the Hospital Universitário of the University of São Paulo (HU-USP) since 1981; the second model, implemented in 2008, was under an automated management and stock reposition system following the just-in-time parameters. The specific objectives of the study were thus (1) to compare the volume and the cost of the hospital medical materials used with the ones remained in stock before and after the implementation of the automated System of Management of Materials (SGM-Sistema de Gestão de Materiais); and (2) to determine the use of surgical kits and anesthetics also after the implementation of the new system. It also focused on a quantitative approach adopted in the Surgical Center of HUUSP. To achieve a comprehensive result, four types of Control Sheets were used to assemble the data: the surgical activity and the status of the patient; the volume of the material used; the surgical kits and anesthetics; and on the data of the stock of materials. The analysis involved 400 items of hospital medical materials of the Surgical Center sector in the month-periods of February to May of 2007 and of 2008 . The results indicated an $8.13 \%$ reduction in the use of materials in the Surgical Center in 2008 as compared to 2007, and an increase of $2.20 \%$ in the total cost of material, the latter considered to be of no statistical significance. As far as the kits of surgical procedures and anesthetics are concerned, in the four-month period of $2008,64.7 \%$ of the use of materials was out of the kit, and $35.3 \%$ represented other assorted materials used during the surgeries. 81 types of kits were used of which $54(66.6 \%)$ decreased $51.9 \%$ in the use of kit-related materials. In 2008 there was a $26.22 \%$ stock reduction of materials in the Surgical Center as compared to 2007 and a $12.46 \%$ cost reduction.
\end{abstract}

KEYWORDS: Management of hospital medical materials. Just-in-time. Control of stock (automation) Hospital surgical center. 


\section{LISTA DE FIGURAS}

Figura 1. Atividades do gerenciamento de materiais, segundo Barbieri e Machline, São Paulo - 2006

Figura 2. Classificação de materiais, segundo Vecina Neto e Reinhardt Filho, São Paulo -1998.

Figura 3. Ciclo acumulativo do sistema de distribuição de materiais por cota e reposição mensal, segundo Vecina Neto e Reinhardt

Filho, São Paulo -1998

Figura 4. Fluxo dos setores assistenciais e de estoque de materiais no Sistema Tradicional utilizado no HU-USP, São Paulo - 2008

Figura 5. Fluxo de distribuição de materiais utilizado no Sistema Tradicional, utilizado no HU-USP, São Paulo - 2008

Figura 6. Fluxo de Estoque e Área de Suprimentos de Materiais no SGM utilizado no HU-USP, São Paulo - 2008

Figura 7. Fluxo do Processo Global do SGM, HU-USP, São Paulo 2008 .70

Figura 8. Fluxo de Central de Unitarização do HU-USP, São Paulo 2008 73

Figura 9. Fluxo de Área de Estoque e logística de distribuição do material no HU-USP, São Paulo - 2008

Figura 10. Fluxo de Processo da Área de Suprimentos I, HU-USP, São Paulo - 2008 .

Figura 11. Distribuição do número de cirurgias de fevereiro a maio de 2007 e 2008, São Paulo - 2008

Figura 12. Total de itens consumidos em cada mês nos anos avaliados, São Paulo - 2008 
Figura 13. Custo total em cada mês nos anos avaliados, São Paulo 2008

Figura 14. Distribuição da quantidade de itens de materiais consumidos no ano de 2008, comparados ao ano de 2007, São Paulo 2008 103

Figura 15. Distribuição do custo do material consumido nos anos de 2007 e 2008. São Paulo - 2008 104

Figura 16. Quantidade de 5.000 a 45.000 unidades de materiais consumidos nos anos de 2007 e 2008, São Paulo - 2008 106

Figura 17. Quantidade de 1.000 a 5.000 unidades de materiais consumidos nos anos de 2007 e 2008, São Paulo - 2008

Figura 18. Quantidade de 500 a 999 unidades de materiais consumidos nos anos de 2007 e 2008, São Paulo - 2008

Figura 19. Quantidade de 300 a 499 unidades de materiais consumidos nos anos de 2007 e 2008, São Paulo - 2008

Figura 20. Quantidade de 200 a 299 unidades de materiais consumidos nos anos de 2007 e 2008, São Paulo - 2008

Figura 21. Quantidade de 100 a 199 unidades de materiais consumidos nos anos de 2007 e 2008, São Paulo - 2008

Figura 22. Quantidade dos fios cirúrgicos consumidos nos anos de 2007 e 2008, São Paulo - 2008 


\section{LISTA DE TABELAS}

Tabela 1 - Setores assistenciais, segundo custo anual de materiais médico- hospitalares e medicamentos de 2007(1), HU-USP2008

Tabela 2 - Número de cirurgias de fevereiro a maio de 2007 e 2008, São Paulo - 2008

Tabela 3 - Valores do número de cirurgias, média, desvio padrão, mediana, mínimo e máximo da idade dos pacientes, segundo os anos de estudo, São Paulo - 2008

Tabela 4 - Frequências absolutas e relativas das variáveis que caracterizam os pacientes, segundo o ano de estudo, São Paulo - 2008

Tabela 5 - Total de itens consumidos em cada mês nos anos de 2007 e 2008, São Paulo - 2008

Tabela 6 - Custo total em cada mês nos anos avaliados em 2007 e 2008, São Paulo - 2008

Tabela 7 - Valores do número de itens de materiais, média, desvio padrão, mediana, mínimo e máximo de materiais consumidos, segundo os anos de estudo, São Paulo - 2008 ....102

Tabela 8 - Distribuição de itens de material segundo a quantidade consumida no ano de 2008 comparada ao ano de 2007, São Paulo - 2008

Tabela 9 - Distribuição do número de itens de material e a porcentagem do custo por unidades consumidas no ano de 2007 e 2008, São Paulo - 2008

Tabela 10 - Relação do consumo e do custo dos materiais que apresentaram de 5.000 a 45.000 unidades consumidas nos anos de 2007 e 2008, São Paulo - 2008 
Tabela 11 - Relação do consumo e do custo dos materiais que apresentaram de 1.000 a 5.000 unidades consumidas nos anos de 2007 e 2008, São Paulo - 2008 109

Tabela 12 - Relação do consumo e do custo dos materiais que apresentaram de 500 a 999 unidades consumidas nos anos de 2007 e 2008, São Paulo - 2008

Tabela 13 - Relação do consumo e do custo dos materiais que apresentaram de 300 a 499 unidades consumidas nos anos de 2007 e 2008, São Paulo - 2008

Tabela 14 - Relação do consumo e do custo dos materiais que apresentaram de 200 a 299 unidades consumidas nos anos de 2007 e 2008, São Paulo - 2008

Tabela 15 - Relação do consumo e do custo dos materiais que apresentaram de 100 a 199 unidades consumidas nos anos de 2007 e 2008, São Paulo - 2008

Tabela 16 - Relação do consumo e do custo dos fios cirúrgicos nos anos de 2007 e 2008, São Paulo - 2008

Tabela 17 - Distribuição de itens consumidos em 2008, São Paulo 2008

Tabela 18 - Relação do consumo de materiais (\%) dos kits cirúrgicos e anestésicos em 2008, São Paulo - 2008

Tabela 19 - Distribuição mensal de itens estocados no Centro Cirúrgico nos anos de 2007 e 2008, São Paulo - 2008 


\section{LISTA DE APÊNDICES}

Apêndice 1 - Relação das unidades consumidas dos itens avaliados nos anos de 2007 e 2008 ..................................................155

Apêndice 2 - Instrumentos de coleta dos dados ........................................163

Apêndice 3 - Relação de cirurgias realizadas no período de coleta de

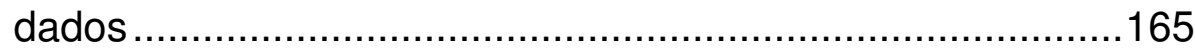




\section{LISTA DE ANEXOS}

Anexo 1 - Manual para o treinamento do Sistema de Gestão de Materiais - SGM (Centro Cirúrgico) .......................................175

Anexo 2 - Relação de materiais e seus custos unitários............................185

Anexo 3 - Aprovação da Câmara de Pesquisa do HU-USP .......................192 


\section{SUMÁRIO}

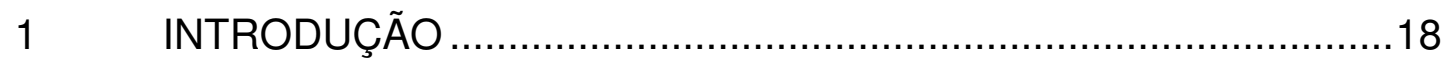

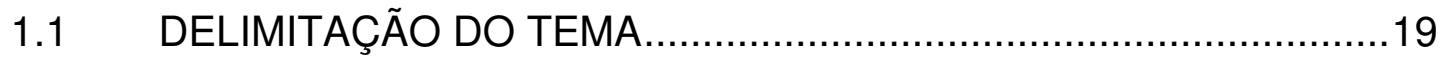

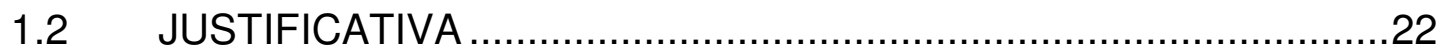

2 REVISÃO E DISCUSSÃO DA LITERATURA..................................25

2.1 GERENCIAMENTO DE MATERIAIS EM HOSPITAIS ...................26

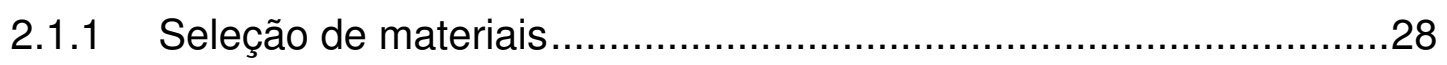

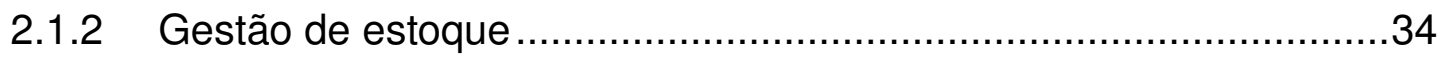

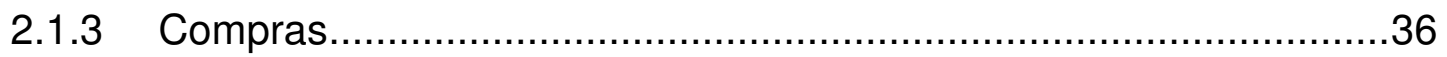

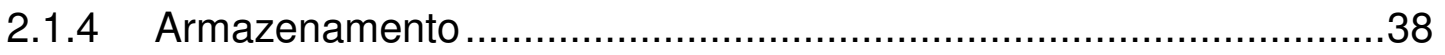

2.2 INFORMATIZAÇÃO DO GERENCIAMENTO DE MATERIAIS

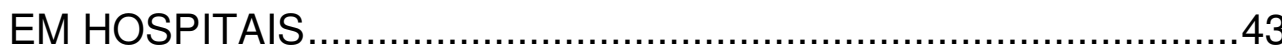

3 GERENCIAMENTO DE MATERIAIS DO HU-USP …...................48

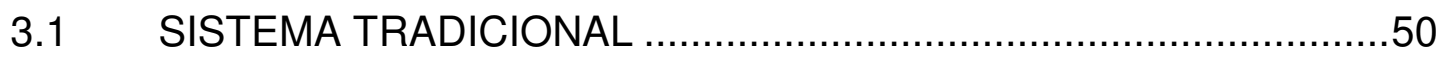

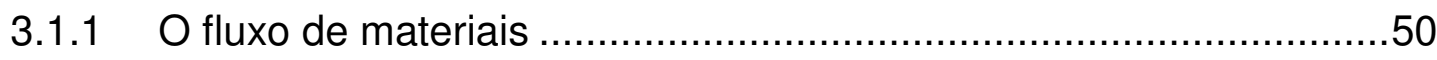

3.1.2 Levantamento de problemas decorrentes do Sistema Tradicional de gerenciamento de materiais......................................57

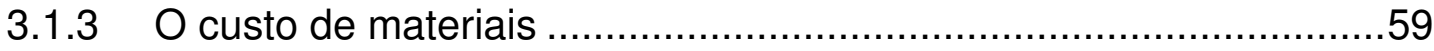

3.2 IMPLEMENTAÇÃO DO SISTEMA DE GESTÃO DE MATERIAIS INFORMATIZADO (SGM) .......................................61

3.2.1 A escolha do sistema e da ferramenta informacional......................61

3.2.2 Reestruturação do processo de logística de materiais no

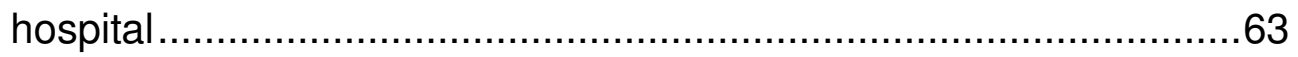

3.2.3 Desenvolvimento do Sistema de Gestão de Materiais (SGM) informatizado.....

3.2.4 Implantação do Sistema de Gerenciamento de Materiais (SGM) ....79

4 QUESTÃO DA PESQUISA 


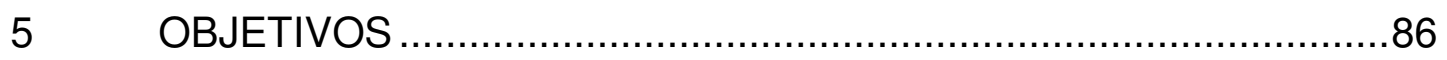

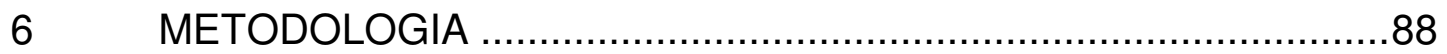

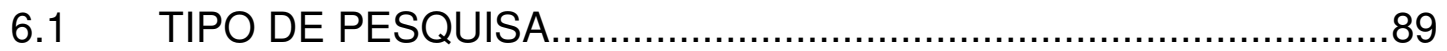

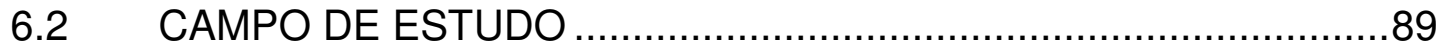

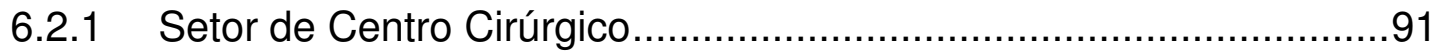

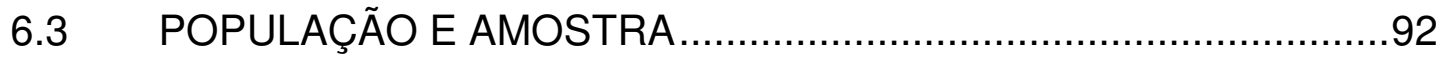

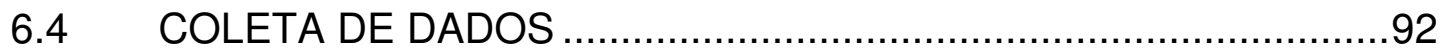

6.4.1 Instrumento de coleta de dados .................................................92

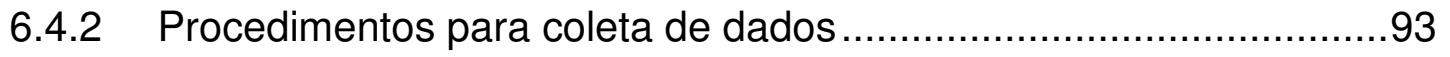

6.5 TRATAMENTO E ANÁLISE DOS DADOS.....................................94

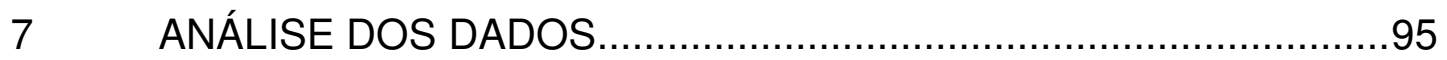

7.1 CARACTERIZAÇÃO DO MOVIMENTO CIRÚRGICO NO

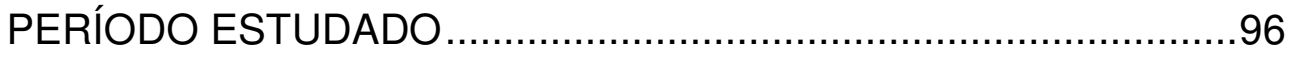

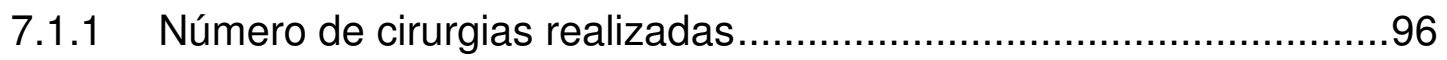

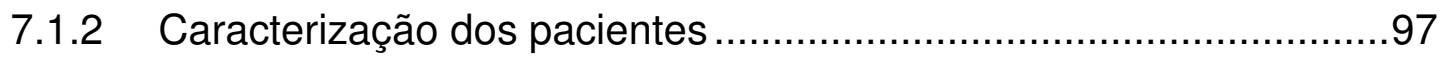

7.2 AVALIAÇÃO DO CONSUMO E DO CUSTO DO MATERIAL NO PERÍODO ESTUDADO ................................................................99

7.2.1 Comparação do consumo e do custo mensal do material................99

7.2.2 Comparação do consumo e do custo do material por item .............102

7.3 AVALIAÇÃO DO CONSUMO DOS KITS CIRÚRGICOS E

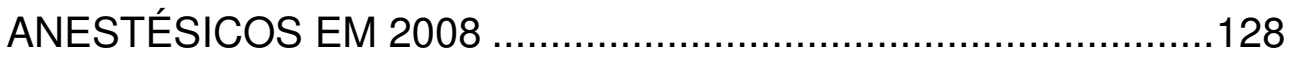

7.4 AVALIAÇÃO DO ESTOQUE DE MATERIAIS DO CENTRO CIRÚRGICO NO PERÍODO ESTUDADO ......................................134

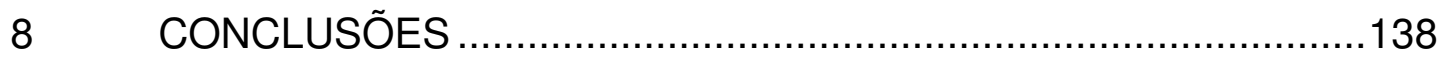

9 CONSIDERAÇÕES FINAIS ….............................................142

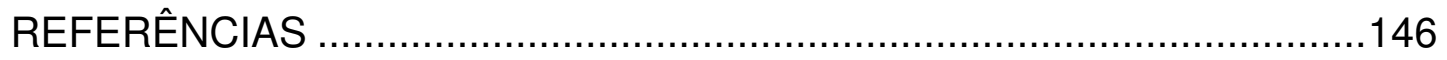

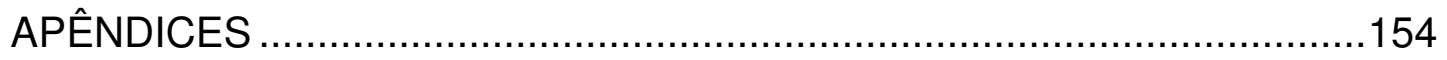

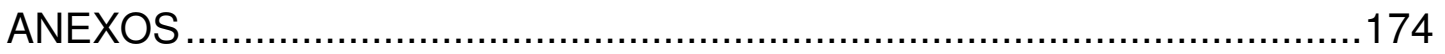




\subsection{DELIMITAÇÃO DO TEMA}

Os recursos materiais têm sido um tema que vem ganhando espaço nas discussões entre os profissionais da área de saúde, e, principalmente, entre os administradores hospitalares. Isto se deve à tendência de maior utilização desses recursos na atenção à saúde, influenciando o crescimento de seus custos, o que tem gerado a necessidade de uma reflexão constante sobre gastos, captação de recursos financeiros e otimização de resultados.

As empresas de saúde são consideradas organizações complexas, com profissionais especializados que desenvolvem atividades em grau de complexidades diferentes (Quinto Neto, Bittar, 2004). Estas atividades consomem uma diversidade de materiais, que tem contribuído para a elevação dos custos hospitalares (Lourenço, 2006).

Por outro lado, o contínuo avanço tecnológico tem impulsionado o aumento da complexidade assistencial e, consequentemente, maior consumo dos materiais.

Essa tendência de maior utilização de recursos em saúde tem sido observada nas instituições públicas e, também, no setor privado. Estas organizações, de um modo geral, estão sendo obrigadas a suprir o crescimento da demanda com o aumento da prestação da assistência ao paciente, porém, com a necessidade de redução de custos imposta pelos níveis de produção dos seus setores, pela quantidade de recursos financeiros disponíveis e pelos preços ditados pelo mercado.

No entanto, o crescimento dos custos em saúde não está relacionado somente com o crescimento da demanda e a universalização do acesso à saúde, mas a uma série de fatores, tais como: o aumento da expectativa de vida da população, a escassez de mão de obra qualificada, a má gestão das organizações por incapacidade administrativa dos profissionais de saúde e a falta de implantação de sistemas de controle de custos (Médici, 1990). 
Diante dessas questões, tem aumentado o interesse dos administradores de organizações de saúde em controlar custos e aprimorar os sistemas de gestão.

O controle de custo permite uma análise de custo do serviço prestado nas diversas áreas do hospital; do entendimento de seu comportamento quanto aos diversos níveis de movimento, como paciente, número de cirurgias, exames e outros; a identificação e a elaboração de estratégias de contenção de gastos; a redução de custos; a diminuição do desperdício e a identificação da rentabilidade de fontes pagadoras e sua negociação (Ching, 2001).

Francisco e Castilho (2002) apontam a necessidade de adoção de sistemas de gestão de custos, possibilitando aos serviços de saúde a contenção de gastos, com atenção à qualidade e ao envolvimento de todos os profissionais relacionados no desenvolvimento desses sistemas.

Em relação à composição dos custos hospitalares, observa-se que os materiais são fatores que mais elevam esses custos após o pessoal, reforçando a necessidade e a importância de dados e informações sobre os materiais e seus custos (Long, 2005).

No entanto, os líderes dos hospitais ainda são pouco informados e conscientizados sobre a capacidade e as contribuições que 0 gerenciamento de materiais tem para reduzir custos na assistência prestada ao paciente. O sistema de gestão de materiais é um dos grandes determinantes do planejamento financeiro de uma instituição, ou seja, é nesta área que se observa um grande gasto da receita e onde o capital poderá ser consumido (Long, 2005).

Assim, dada a complexidade das organizações hospitalares, com procedimentos diferenciados, atendimentos diversificados incorporando tecnologia e utilizando uma imensa variedade de materiais, controlar esses insumos e seus custos é fundamental. Atrelar o sistema de gestão de materiais a um sistema de informação automatizado torna-se essencial, pois permite obter facilidades e agilidade de informação para viabilizar todos os processos. 
Desta forma, os serviços de saúde necessitam adotar um sistema de gestão de materiais que, além de proporcionar recursos necessários ao processo produtivo, gere informações para tomada de decisões e subsidie a gestão de custos.

Para justificar a necessidade da informatização dessa área, além do que já foi exposto, observa-se que as instituições hospitalares possuem cerca de 3.000 a 6.000 itens de consumo, variando conforme as características de cada organização de saúde (Vecina Neto, Reinhardt Filho, 1998).

Portanto, quando se tem um grande número de itens de consumo, é possível compreender a necessidade de controle e informação sobre os recursos materiais que as organizações hospitalares apresentam, o que vem reforçar a importância de se ter um sistema informatizado de gestão de materiais, por meio de rede de computação institucional.

Nessa perspectiva, o gerenciamento de materiais tem como finalidade suprir os recursos materiais necessários para a organização de saúde, com qualidade, em quantidades adequadas, no tempo certo e, sobretudo, ao menor custo (Vecina Neto, Reinhardt Filho, 1998).

As instituições privadas, envolvidas no meio competitivo e preocupadas em manter espaço no mercado, têm avançado no desenvolvimento de sistemas informatizados de gestão de materiais que, além de permitirem maior controle na compra e distribuição de materiais, têm contribuído para a redução dos custos.

No entanto, não podemos dizer o mesmo sobre a rede pública, uma vez que vem apresentando iniciativas incipientes para o desenvolvimento de sistemas de controle de materiais. Alguns autores têm chamado a atenção para a necessidade de serem aprimorados esses sistemas, como se pode observar conforme a citação a seguir: 
A administração dos recursos de materiais tem sido motivo de preocupação nas organizações de saúde, tanto nas do setor público como nas do setor privado, que fazem parte da rede complementar do SUS. As do setor público, devido a orçamentos restritos, precisam de maior controle do consumo e dos custos para que não privem funcionários e pacientes do material necessário (Castilho, Gonçalves, 2005, p.157).

A pesquisadora deste estudo tem vivenciado essa problemática, no Hospital Universitário da Universidade de São Paulo (HU-USP), onde ocupa o cargo de assistente técnico de direção da Superintendência, responsável pela coordenação de gestão de equipamentos e materiais e do desenvolvimento e implantação de um novo Sistema de Gestão de Materiais informatizado (SGM).

Diante disso, pretendeu-se neste estudo conhecer o impacto deste novo sistema, implantado em 2008, sobre o consumo e o custo dos materiais médico-hospitalares do HU-USP, comparando-os com os gastos com o modelo tradicional adotado anteriormente.

\subsection{JUSTIFICATIVA}

Na dimensão estrutural, o aspecto mais importante que justifica a realização deste estudo é a escassez de literatura, principalmente no Brasil, sobre sistemas de gestão de materiais em hospitais, sobretudo aos modelos informatizados e a avaliação de seus resultados.

Já, na dimensão singular, justifica-se o desenvolvimento desse estudo sobre essa temática em um hospital universitário, público, integrante do Sistema Único de Saúde, que tem sido referência para outros hospitais.

O HU-USP é uma organização hospitalar geral, de ensino, de grande porte e com 243 leitos. 
Por se tratar de um hospital de ensino, inserido em uma Universidade, seu custeio apresenta algumas peculiaridades. Enquanto os recursos humanos são geridos pela própria Universidade não tendo o HUUSP governabilidade sobre esta questão, cabe ao Hospital Universitário administrar o custeio referente aos recursos materiais, despesas gerais, serviços e investimentos.

Atualmente, o HU-USP vem recebendo um montante fixo pelo Ministério da Saúde, acrescido de um aporte financeiro da Universidade, sendo que os gastos com os materiais de consumo correspondem a $49 \%$ do custeio do hospital, valor este acima dos relatos encontrados na literatura.

Alguns autores colocam que o gasto com esses recursos tem representado, em média, de $15 \%$ a $45 \%$ do orçamento das organizações hospitalares brasileiras (Castilho, Leite, 1991; Vecina Neto, Ferreira Júnior, 2001).

O HU trabalha com cerca de 3.000 itens referentes a materiais de consumo, com média de 1.500.000 unidades consumidas mensalmente, o que gera um custo anual de, aproximadamente, $R \$ 18.800 .000,00$.

Diante desses fatores, o gerenciamento de materiais do hospital em estudo passou a receber uma atenção maior por parte da administração do HU-USP. Percebeu-se a necessidade de se reestruturar essa área para atender os diferentes serviços com maior eficácia em relação à quantidade e à qualidade dos materiais, em tempo hábil e com menor custo.

Para resolver toda a problemática que envolve essa área, o hospital está reestruturando todo o processo de gerenciamento de materiais, desenvolvendo um Sistema de Gestão de Materiais informatizado (SGM).

Espera-se, como impacto dessa reestruturação, a redução de consumo de material e do seu estoque e, consequentemente, a diminuição dos custos. Isto possibilita o investimento em outras áreas, como em equipamentos médico-hospitalares e na estrutura predial com a finalidade de proporcionar melhores condições de trabalho e melhor qualidade de atendimento. $O$ impacto externo será a criação de um novo sistema de gestão de materiais, em uma instituição pública hospitalar, compromissada com resultados e com o Sistema Único de Saúde (SUS). 
Assim, esta pesquisa tem por finalidade comparar o consumo e o custo de materiais médico-hospitalares antes e após a implantação do novo sistema. Para este estudo, foi escolhido o setor de Centro Cirúrgico, primeiro setor assistencial do hospital a ser implantado o novo sistema. O Centro Cirúrgico apresenta o maior consumo de material médico hospitalar, com aproximadamente $17,54 \%$ do total gasto pelos 19 setores assistenciais do hospital. 
2 REVISÃO E DISCUSSÃO DA LITERATURA 


\subsection{GERENCIAMENTO DE MATERIAIS EM HOSPITAIS}

Os materiais são essenciais dentro das organizações de saúde e absorvem boa parte do seu orçamento, de modo que a sua administração se tornou uma necessidade.

Os materiais são produtos que podem ser armazenados ou que serão consumidos imediatamente após a sua chegada (Vecina Neto, Reinhardt Filho, 1998). Eles podem ser classificados em materiais de consumo e patrimoniais, sendo só o primeiro tratado integralmente pelo gerenciamento de materiais. Os materiais de consumo são: medicamentos, materiais médico-hospitalares, alimentos, material de escritório, de radiologia, de limpeza, de laboratório, etc. (Barbieri, Machline, 2006).

Gerenciamento, ou administração de materiais, compreende o processo gerencial para aquisição e disponibilização de materiais essenciais para a produção de serviços de saúde (Castilho, Gonçalves, 2005).

Para isso, é necessário estabelecer algumas ações, como: planejamento, controle, organização e outras atividades como fluxo de materiais e de informações. Na prática, existem muitas expressões utilizadas indistintamente e empregadas como sinônimos ao se referirem ao gerenciamento ou administração de materiais, suprimentos e logísticas, portanto é importante esclarecer alguns termos e suas diferenças.

Para Chiavenato (1991), a administração de materiais envolve todos os fluxos de materiais de uma organização, compreendendo: a programação, a compra, a recepção, o armazenamento, a movimentação de materiais, o transporte interno e o consumo dos materiais.

Segundo Barbiere e Machiline (2006), o suprimento nas organizações hospitalares envolve todas as atividades para o abastecimento dos materiais com o objetivo de satisfazer as necessidades dos usuários. As atividades típicas de suprimentos são, entre outras: seleções de materiais, compras, recebimento de materiais, gestão de estoque, armazenagem, etc. 
Já o conceito de logística é empregado para o armazenamento dos materiais e sua movimentação, ou seja, a distribuição física até o usuário, facilitando o fluxo de materiais, de tal forma que o usuário tenha acesso ao material na hora certa e a um custo razoável (Chiavenato, 1991; Gomes, Ribeiro, 2004; Pozo, 2007).

De acordo com uma definição do "Council of Logistics Management" amplamente conhecida, logística é:

O processo de planejamento, implementação e controle de fluxo eficiente e economicamente eficaz de matérias-primas, materiais em processo, produtos acabados e informações relacionadas com essas atividades, desde o ponto de origem até o ponto de consumo, com objetivo de atender às exigências dos clientes (Barbiere, Machline, 2006, p.4).

Resumindo, a logística consiste na visão estratégica para conduzir as atividades de gerenciamento de materiais realizadas pelos administradores, desde os fornecedores até a entrega do produto ao cliente externo à organização, bem como no desenho dos fluxos de materiais que constitui os suprimentos.

Assim, o gerenciamento ou administração de materiais consiste nas atividades operacionais relacionadas com os segmentos desse fluxo, que abastece ou supre a organização com os materiais, que tem como função: seleção de materiais, gestão de estoque, compras e armazenamento (Barbieri, Machiline, 2006; Vecina Neto, Reinhardt Filho, 1998). Estas quatro atividades apresentam um esquema lógico de interação entre elas e em todas as direções que compõe o gerenciamento de materiais de uma organização hospitalar. Primeiro é fundamental saber quais os materiais que a organização irá utilizar para depois decidir quanto e quando comprar, de quem e como comprar, como guardar e distribuir aos usuários (Figura 1). 


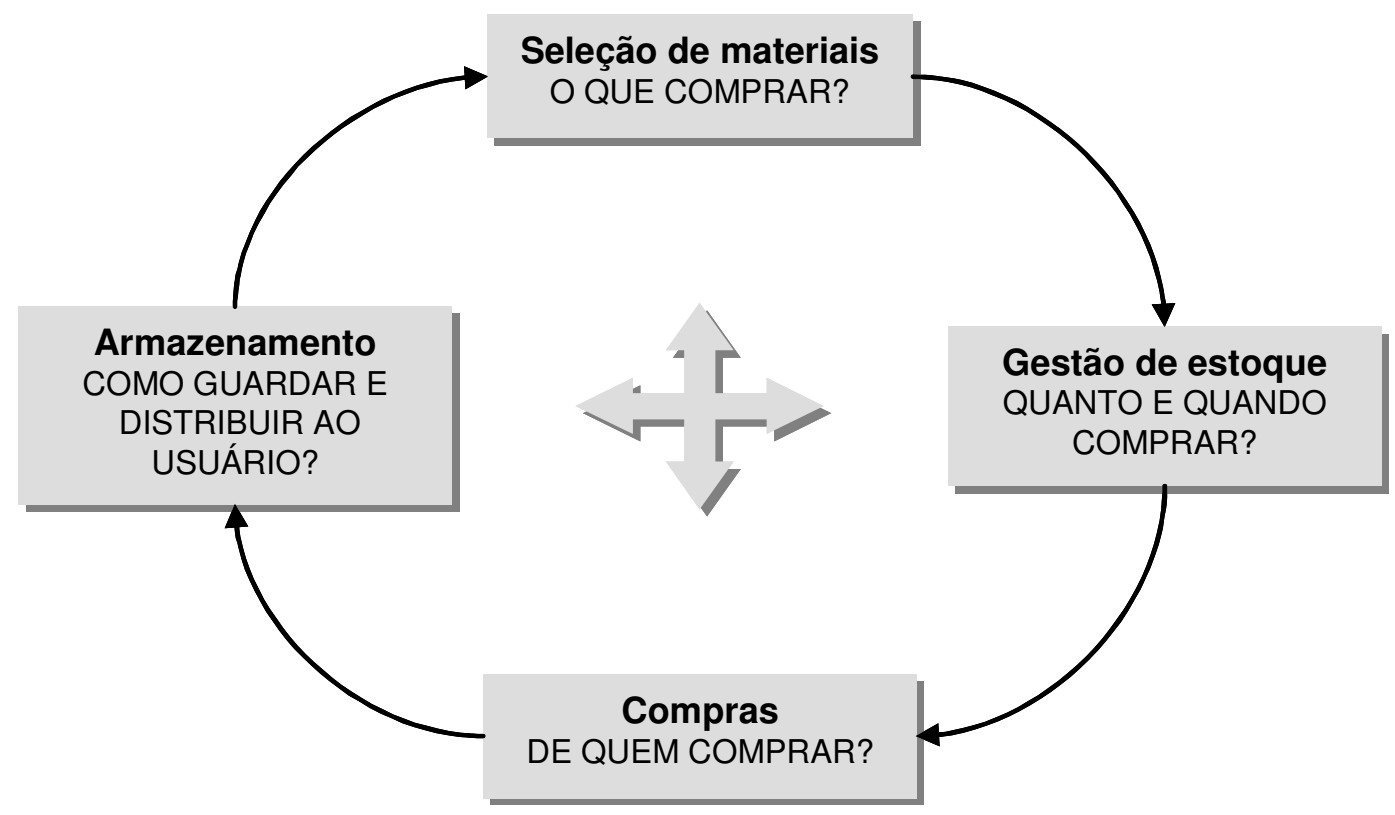

Figura 1. Atividades do gerenciamento de materiais, segundo Barbieri e Machline, São Paulo - 2006

\subsubsection{Seleção de materiais}

Também chamado de normalização e corresponde a escolha do material certo, cujos objetivos são:

- identificar o material correto para os usuários e para a organização hospitalar;

- estabelecer instrumentos de planejamento e de controle adequados;

- reduzir custos;

- melhorar o atendimento do serviço.

A organização de saúde, em conjunto com seus diversos usuários, deve escolher o material certo, considerando as características intrínsecas de cada material em face das necessidades dos usuários e dos administradores de materiais. A seleção de materiais deve ser conduzida por uma administração capaz de conciliar as divergências existentes e alcançar um consenso entre os diferentes profissionais e áreas envolvidas, como 
profissionais de saúde, compradores e a área financeira do hospital. (Barbieri, Machline, 2006).

A seleção de materiais ou normalização é responsável por estabelecer a relação entre a proposta assistencial e a área de apoio, ocorrendo o diálogo técnico entre as áreas meio e fim (Vecina Neto, Reinhardt Filho, 1998).

Cabe ressaltar que este processo é dinâmico, contínuo e multidisciplinar. Sendo assim, nada importa aos hospitais, se não existir um grupo responsável pela seleção e normalização de materiais regulamentados em forma de comissão ou resolução determinada pela administração maior.

Alguns autores referem à importância de criar uma comissão regulamentada e com o apoio irrestrito da administração superior para a normalização de materiais nas organizações de saúde (Vecina Neto, Reinhardt Filho, 1998; Lourenço, 2006). Esta comissão deve ser multidisciplinar, apresentar capacidade técnica e diálogo contínuo com o usuário, pois se trata da escolha de itens de padronização, processo pelo qual visa a seleção de materiais que serão comprados pelo hospital.

Lourenço (2006) cita, como exemplo de padronização em hospitais, a Comissão de Farmácia e Terapêutica (CFT) ou a Comissão de Padronização de Medicamentos (CPM), tendo como objetivo regulamentar a padronização de medicamentos utilizados no ambiente hospitalar. Com relação aos materiais de consumo, estes estão sendo geridos pela própria CPM ou estão sendo criadas Comissões de Padronização dos Materiais de Consumo Hospitalar, atribuídas pela necessidade de desenvolver este segmento de extrema importância organizacional.

Outro objetivo importante que pode ser atribuído às comissões de padronizações, além de selecionar e padronizar os materiais mais adequados para o hospital, é o estabelecimento de normatização dos materiais de consumo, ou seja, estabelecer normas e indicação de uso de determinado material para determinado tipo de procedimento.

De acordo Barbieri e Machline (2006), a padronização é uma forma de normalização. A International Organization for Standartization 
(ISO), citado por Barbieri e Machline (2006), considera como normalização "o processo de formulação e aplicação de regras para o tratamento ordenado de uma atividade especifica".

A padronização busca reduzir a variedade desnecessária de materiais para uma mesma finalidade e trata do processo de listagem, análise e escolha de tipos padronizados de materiais (Pozo,2007).

Após escolher os materiais, de acordo com o exposto acima, é necessário elaborar a especificação correta de cada material com definição objetiva e clara.

Castilho e Gonçalves (2005) conceituam especificação como sendo uma descrição técnica minuciosa do material, representada com precisão o que deseja adquirir, o que exige das instituições de saúde uma rigorosa análise do produto no que se refere às características de fabricação, utilização e desempenho.

A especificação pode ser entendida como uma identificação e descrição das características e propriedade de cada material. Nos hospitais, pouco se vê, como regra estabelecida, a existência regular da descrição atualizada de cada produto que a organização queira adquirir.

Uma adequada descrição permite minimizar erros e confusões com materiais similares. Para isso, devem ser observados os seguintes critérios (Barbieri, Machline, 2006):

- descrever o material do geral para o particular;

- conter dados para identificá-los de modo inequívoco;

- apresentar características concisas;

- usar terminologia padronizada.

A fase posterior à especificação corresponde a classificação e codificação dos materiais. Para Pozo (2007), classificar materiais consiste na codificação e estabelecer grupos ou famílias de materiais em uso na organização de saúde, de acordo com sua utilidade, natureza e função.

De acordo com Barbieri e Machline (2006), há diversos critérios para classificar os materiais: pelo valor de utilização, pela dificuldade de armazenamento, pela criticidade e pela dificuldade de aquisição entre 
outros. Duas das classificações mais importantes do ponto de vista de gestão de estoque são a classificação $A B C$ e a $X Y Z$.

Classificação ABC, também conhecida como Curva de Vilfredo Pareto e adaptada à administração de materiais, é utilizada para identificar os materiais em função dos valores que eles representam e de sua quantidade. Permite estabelecer formas de avaliação apropriadas à importância de cada item em relação ao valor total considerado. Muito utilizada em setores que necessitam tomar decisões envolvendo grandes estoques (Pozo, 2007; Barbieri,Machline, 2006). A maioria dos hospitais apresenta uma grande variedade de produtos, o que torna difícil para administração um padrão único de planejamento e controle do estoque. Tratarem com o mesmo grau de atenção a todos os itens pode ser insuficiente para uns e excessivo para outros.

Dessa forma, os materiais de consumo podem ser divididos em três classes (Lourenço, 2006; Castilho, Gonçalves, 2005; Pozo, 2007):

Classe A - pertence a esta classe um pequeno número de itens, mas com representatividade de um grande volume de recursos despendidos com os materiais. São os itens mais importantes e que devem receber toda atenção, pois representam em média $80 \%$ do valor monetário total e no máximo $20 \%$ dos itens existentes.

Classe B - são os itens intermediários que devem receber um tratamento menos rigoroso que os da classe A. Os dados classificados correspondem, em média, $15 \%$ do valor monetário total do estoque e, no máximo, 30\% dos itens.

Classe C - nesta classe entram os numerosos itens de pouca importância em termos de valor. A vigilância sobre esta classe pode se mais moderada, uma vez que o investimento representa aproximadamente $20 \%$ do custo total, porém mais de $50 \%$ dos itens formam sua estrutura. 
Nos hospitais, por trabalharem com grandes estoques e com alto investimento monetário, sugere-se a utilização da classificação $A B C$ para o gerenciamento de materiais, concentrando os esforços naqueles itens que representam muito valor, sem descuidar dos demais.

O objetivo desta classificação é fornecer informações para facilitar uma análise de itens de estoque e controles diferenciados, uma vez que devemos nos concentrar naqueles itens que trarão maiores benefícios para o alcance de metas determinadas pela instituição (Francischini, Gurgel, 2004).

Outra classificação que fornece informações para auxiliar na gestão de estoques é a Classificação $X Y Z$, importante para ser utilizada nas organizações hospitalares para a decisão de quando e o que comprar. A Classificação XYZ tem como critério o grau de criticidade ou imprescindibilidade do material para as atividades em que eles estarão sendo utilizados.

Classe $\mathbf{Z}$ - são os itens mais críticos, que quando faltam colocam em risco os pacientes e a organização. São materiais imprescindíveis à organização e que não são passíveis de substituição.

Classe $\mathbf{Y}$ - englobam materiais que apresentam um grau de criticidade médio, embora sejam vitais para as atividades do hospital, podem ser substituídos por equivalentes com relativa facilidade.

Classe $\mathbf{X}$ - pode faltar material sem acarretar prejuízos aos pacientes e para a organização, não pelo fato de não serem críticos para as atividades, mas pela possibilidade de serem substituídos com grande facilidade.

Assim, o objetivo da classificação $X Y Z$ é priorizar os materiais de consumo, com a finalidade de minimizar a falta de itens imprescindíveis à organização e elaborar possíveis alternativas de substituição, quando possível, para a prestação de assistência ao paciente (Lourenço, 2006).

Após a classificação dos produtos com critérios consistentes e sustentáveis para estabelecer os grupos de materiais, é fundamental 
elaborar a codificação. Para esta atividade costuma-se atribuir uma linguagem de símbolos aos materiais especificados.

Um tipo especial de codificação é o de código de barras, um código numérico convertido em combinações binárias formadas por barras claras e escuras. Atualmente, é o sistema mais utilizado em gerenciamento de estoques, cujo objetivo básico é identificar produtos e não classificá-los (Martins, Laugeni, 2000).

A automação hospitalar tem, no código de barras, um dos seus principais instrumentos; utiliza códigos padronizados por toda a cadeia logística, o que permite alcançar bons níveis de serviço com redução de custos. O material pode ser facilmente identificado eletronicamente pelos leitores ópticos sem a necessidade de digitação ou consultas a arquivos físicos. O código de barras utilizado no Brasil é o Código Nacional de Produtos, padrão EAN (European Article Numbering). O padrão EAN é administrado internacionalmente pela EAN International de Bruxelas e do Brasil, pela EAN Brasil - Associação Brasileira de Automação Comercial (Barbieri, Machline, 2006).

De acordo com Vecina Neto e Reinhardt Filho (1998), a outra maneira de identificar o produto e incorporar informações derivadas de uma classificação de materiais é dispor de outra estrutura de codificação; nenhum item tem mais do que um código, e um único código não abrange mais do que um item. Os materiais podem ser divididos em grupos, subgrupos e classes com codificação numérica, alfabética ou alfanumérica, como mostra o exemplo a seguir: fio cirúrgico nylon 4.0, agulha 2,4cm: código 02.11.435.

Estrutura

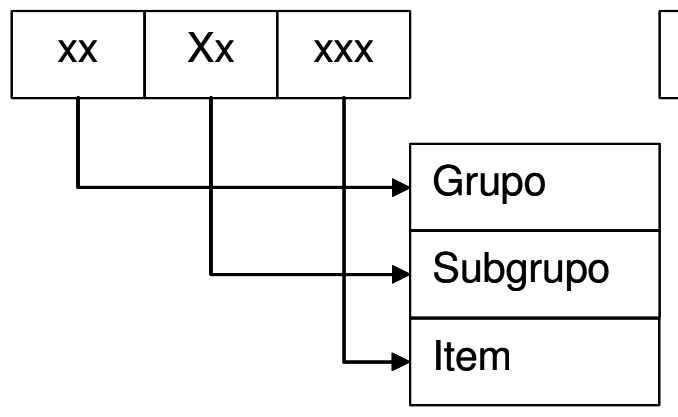

Exemplo

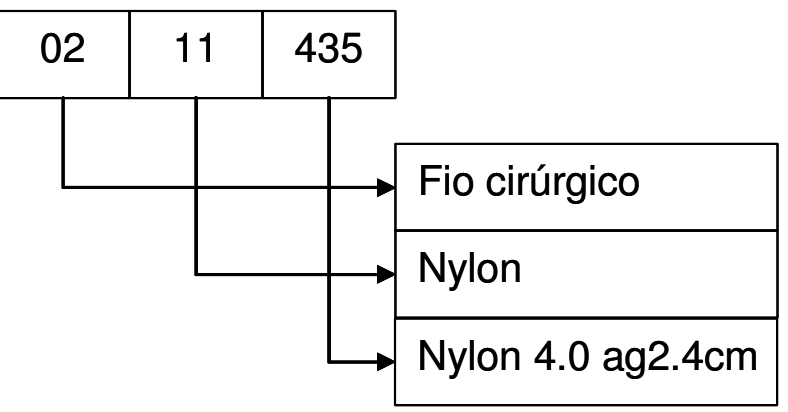

Figura 2. Classificação de materiais segundo Vecina Neto e Reinhardt Filho, São Paulo 1998. 


\subsubsection{Gestão de estoque}

Estoque é a composição de materiais que não são utilizados em determinado momento, mas que precisa existir para uma utilização posterior (Chiavenato,1991).

O controle de estoque compreende a função de valorização e administração de estoque, envolvendo a previsão da demanda e sistemas de reposição de materiais. A expressão "controle de estoques" é atribuída à necessidade de estipular os diversos níveis de materiais que a organização de saúde deve manter dentro de um custo mínimo possível (Pozo, 2007).

Dimensionar e controlar os estoques, sem dúvida, é um dos grandes desafios do gerenciamento de materiais nos hospitais, pois o nível de estoque de qualquer tipo de produto pode ser atingido pela qualidade e quantidade de informações sobre eles, tais como: previsão de consumo, processo de compra, prazos de entrega do produto, alteração de demanda, sazonalidade entre outros, que levam ao desperdício e ao capital empatado desnecessariamente.

Encontrar o ponto de equilíbrio, para que não haja excesso de materiais e nem a falta de um deles, é um dos problemas que o gerenciamento de estoques apresenta, visto que afeta de maneira bem definida o resultado financeiro da empresa. Por um lado, procura-se manter um volume alto de produtos para atender o usuário no momento certo e na quantidade certa; por outro, busca minimizar o investimento nos tipos de estoques, reduzindo o custo neste setor. Quando as empresas apresentam estoques elevados, acarreta a necessidade de elevado capital e elevados custos. No entanto, baixos estoques podem acarretar custos difíceis de contabilizar em face de atrasos de entrega, ausência de materiais e a insatisfação do usuário, no caso dos hospitais, podendo levar ao comprometimento da assistência prestada ao paciente (Pozo, 2007).

Assim, qualquer esquema pelo qual os estoques são reabastecidos deve responder duas questões básicas comentadas por vários autores: quanto repor e quando repor os estoques Necina Neto, Reinhardt Filho, 1998; Barbieri, Machline, 2006; Pozo, 2007). 
Desse modo, um dos papeis do controle de estoque é estabelecer "quando as ordens de compra devem ser emitidas" e "qual a quantidade a ser adquirida".

"Quando comprar" refere-se à renovação ou reposição de estoques, momento em que o processo de compra é desencadeado. Esse momento pode ocorrer em períodos fixos predeterminados ou em períodos variáveis com quantidades fixas ou variáveis. Sistemas de períodos variáveis permitem acolher modificações da demanda ou nos prazos de entrega do fornecimento de material, entretanto necessitam de decisões mais complexas e, portanto, mais exigentes em termos de recursos administrativos. Por essa razão, os sistemas comumente utilizados são os que fixam um dos parâmetros e mantém o outro variável, conseguindo, assim, lidar com a variabilidade da demanda e do fornecimento. Dentre estes, os mais conhecidos são o sistema do ponto de pedido e o sistema de revisão periódica (Barbieri, Machline, 2006).

O sistema de ponto de pedido trata-se do início de um processo de compra que ocorre sempre quando o estoque existente atingir um nível preestabelecido, também chamado de ponto de suprimento ou de encomenda. $O$ momento que desencadeia esse processo varia de acordo com a velocidade com que o nível de estoque existente atinge o ponto de pedido, e a quantidade a ser comprada é fixa (Pozo, 2007).

O sistema de revisão periódica é o inverso do sistema acima, período fixo e lotes variados. Neste sistema, o nível de estoques é revisto periodicamente, e as quantidades das ordens de compra são variáveis (Chiavenato, 1991).

"Quanto à quantidade a ser comprada" para a previsão das necessidades futuras, Vecina Neto e Ferreira Júnior (2001) consideram fundamentais os consumos históricos do registro na movimentação dos materiais.

Assim, o sistema de reposição de estoque, segundo Barbieri e Machline (2006), compreende o "conjunto articulado de informações processadas de operações capazes de garantir o suprimento de materiais necessários ao atendimento da demanda com o mínimo custo possível", 
incluindo informações sobre itens que devem ser estocados, demandas previstas, classificação dos itens e metas de redução de níveis de estoque.

Outro ponto a considerar, no momento da decisão do tipo de sistema a ser adotado na reposição de estoques, é a sazonalidade e a volubilidade da demanda hospitalar, atribuído ao perfil epidemiológico da população. Os números do consumo de materiais variam e implicam em uma média aritmética móvel do consumo verificado, com repercussão ao setor de compras que deve estar atento para essas alterações e considerálas, com a finalidade de reduzir a compra e consequentemente os custos (Lourenço, 2006).

\subsubsection{Compras}

É mais uma das atividades do gerenciamento de materiais. A área responsável por esta atividade é conhecida como setor de Compras e considerada uma atividade de apoio fundamental ao processo produtivo, suprindo as necessidades de materiais de uma organização.

O sistema de compras compreende o processo de seleção, avaliação e negociação com fornecedores e aquisição de materiais. Apresenta, como finalidade, a compra de todos os materiais para suprir as necessidades da empresa na qualidade correta, na quantidade certa, no prazo certo e ao preço correto, sobretudo na fonte adequada. Este setor é considerado um centro de lucro e não como um centro de custo, pois, quando bem administrado, pode trazer consideráveis economias e lucros para as empresas (Chiavenato, 1991; Pozo, 2007).

Qualquer que seja a finalidade da organização de saúde, o processo de compra envolve a localização de fornecedores e fontes de suprimentos que atendam às necessidades da empresa, obedecendo aos requisitos de qualidade e especificação do material, assim como os prazos exigidos. Entretanto, a condução desses processos difere de organização para organização. Nas instituições de saúde do setor privado, os materiais são adquiridos basicamente por compra direta. O setor de Compras negocia 
o que deseja direto com o fornecedor cadastrado, segue as diretrizes financeiras da empresa, obtendo um processo de aquisição rápido e ágil. Para as organizações públicas, é necessário seguir rigorosamente os processos de aquisição de materiais estabelecidos pela legislação, denominados licitação (Lourenço, 2006).

Para Administração Pública, a legislação que regulamenta as licitações é a Lei Federal n. 8.666/93 e suas alterações, que estabelece as normas gerais de licitação e contratos administrativos pertinentes a obras, serviços, compras, alienações e locações:

A Licitação destina-se a garantir a observância do princípio constitucional da isonomia e a selecionar a proposta mais vantajosa para administração, que será processada e julgada em estrita conformidade com os princípios básicos da legalidade, da impessoalidade, da moralidade, da igualdade, da publicidade e da probidade administrativa, da vinculação ao instrumento convocatório, do julgamento objetivo e dos que the são correlatos (Brasil, 2002a, p.2).

A Lei n.8.666/93 estabelece cinco modalidades de licitação comentadas a seguir:

Concorrência - modalidade utilizada entre quaisquer interessados que, na fase inicial de habilitação preliminar, comprovem possuir os requisitos mínimos de qualificação exigidos no edital para execução de seu projeto. Utilizadas, comumente para aquisição de altos valores previstos em lei.

Tomada de preço - utilizada para aquisição de valores médios, entre interessados e cadastrados ou que atendam a todas as exigências para cadastramento.

Convite - é a modalidade de licitação efetuada entre, no mínimo, três interessados do ramo pertinente ao seu objeto, escolhidos ou convidados pela unidade administrativa. Este tipo de modalidade contempla processos de aquisição de valores baixos. 
Concurso - esta modalidade não é aplicável aos processos de compra de bens materiais no ramo hospitalar (Brasil, 1993).

As compras realizadas nas organizações de saúde devem atender o princípio da padronização e o sistema de registro de preço previsto em lei, que caracteriza ser precedido de ampla pesquisa no mercado, com preços registrados e publicados trimestralmente para orientação da administração, na imprensa oficial.

E, por fim, uma outra modalidade de licitação muito utilizada na área hospitalar é o pregão previsto pela lei 10.520/2002. Esta modalidade trata-se da aquisição de bens e serviços comuns conforme disposto em regulamento, qualquer que seja o valor estimado da contratação, cuja disputa pelo fornecimento é realizada por meio de propostas e lances de valores mais baixos em uma sessão pública (Brasil, 2002b; Castilho, Gonçalves, 2005).

\subsubsection{Armazenamento}

É a última etapa do gerenciamento de materiais que envolvem todas as atividades de recebimento, guarda, preservação e distribuição de materiais aos usuários. As necessidades de materiais nem sempre são imediatas e constantes. Enquanto os materiais não são necessários ao processo produtivo, eles precisam ser armazenados para que no momento oportuno estejam disponíveis para serem utilizados. O local onde esse material fica alocado é chamado de "Almoxarifado". Segundo Vecina Neto e Reinhardt Filho (1998), a organização do setor de Almoxarifado reúne um conjunto de responsabilidades, tarefas e interrelacionamento capazes de gerar as atividades de: planejamento de localização, segurança e preservação de modo a operar o recebimento, armazenagem, entrega e controle dos materiais.

$O$ recebimento de materiais que 0 almoxarifado realiza nas empresas hospitalares consiste na conferência da quantidade, tipo, validade e lote de materiais, no ato da entrega, pelos fornecedores. $O$ 
armazenamento e a distribuição também são realizados por ele, e os materiais são, normalmente, armazenados em prateleiras e estrados que permitem ventilação adequada. São identificados, com código do sistema interno da empresa, por ordem numérica crescente (Lourenço, 2006). Para os critérios de estocagem, é levada em consideração a rotatividade do item, o volume de peso, a similaridade de produtos, sendo que, para os itens de valores representativos, costumam ser acondicionados em locais de maior segurança e controle (Chiavenato,1991).

A distribuição é vista como uma das atividades mais difícil e complexa do gerenciamento de materiais. Pode gerar graves problemas para a instituição hospitalar quando se trabalha com um sistema sem os instrumentos adequados para desempenhar as tarefas. É muito comum na área hospitalar apresentar um sistema convencional de distribuição de materiais, baseado em cotas e reposições mensais pelo almoxarifado, que estabelece um ciclo acumulativo levando a um desequilíbrio do sistema, como mostra a figura a seguir:

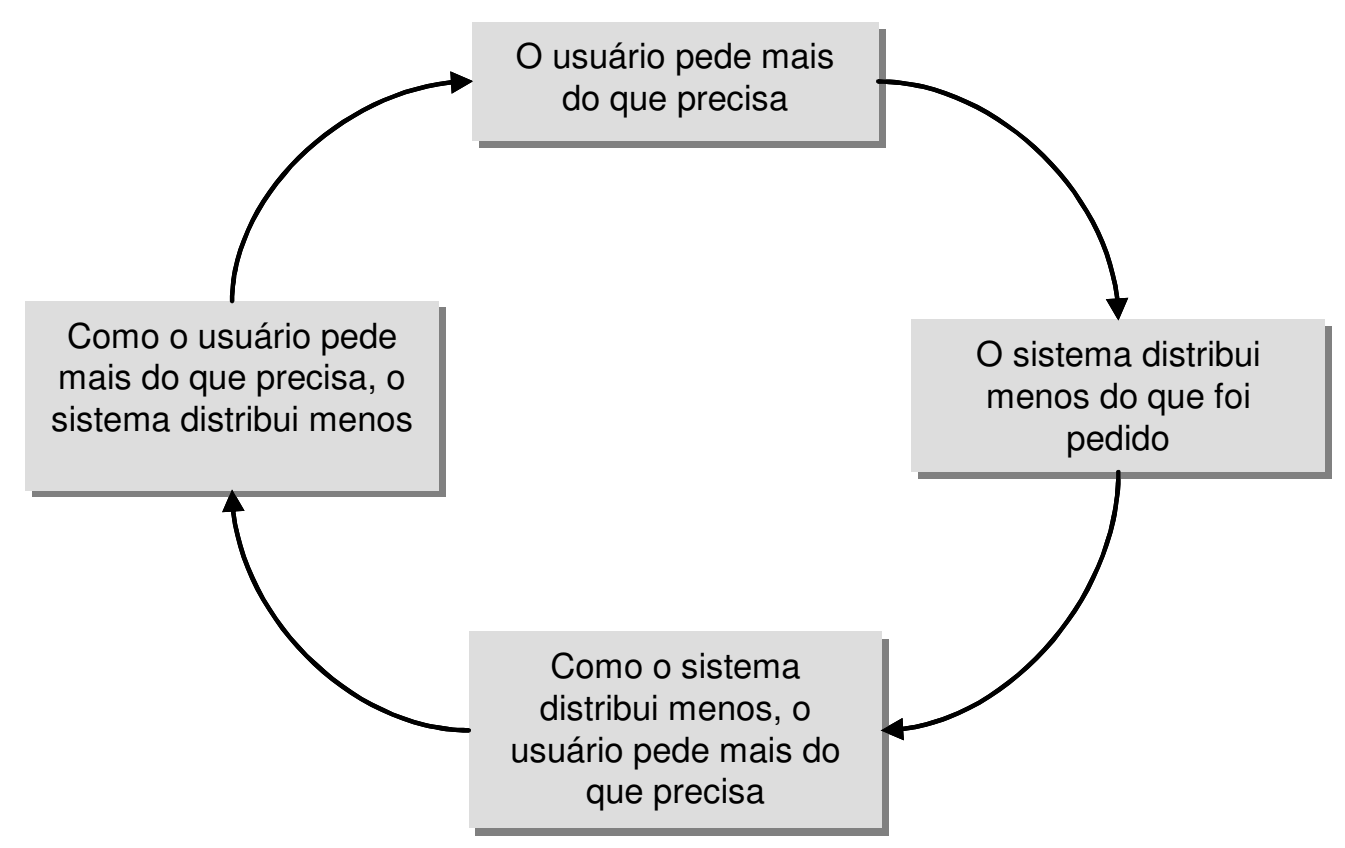

Figura 3. Ciclo acumulativo do sistema de distribuição de materiais por cota e reposição mensal, segundo Vecina Neto e Reinhardt Filho, São Paulo -1998. 
Quando não há confiança entre o usuário e o gerenciamento de materiais, instala-se o ciclo acima, levando a uma relação de sabotagem mútua e a criação de estoques periféricos (Vecina Neto, Reinhardt Filho, 1998).

Por consequência, é exigido um alto nível de profissionalização dos agentes responsáveis pela condução de todas as atividades da administração de materiais até agora mencionadas, incluindo o sistema de distribuição (Dutra, Neves, 2000).

Alguns princípios podem ser utilizados para subsidiar os gerentes das cadeias de suprimentos quanto ao sistema de distribuição de materiais. Esses princípios podem ser resumidos como os "4 Rs": responsividade (responsiveness), confiabilidade (reliability), resiliência (resilience) e relacionamentos (relationships). A responsividade é a capacidade de responder as exigências do usuário rapidamente. Para melhorar a confiabilidade, pode ser obtida mediante a reelaboração dos processos de trabalho, causando impacto no desempenho. A resiliência refere-se à capacidade de resistir a situações inesperadas, ou seja, a variabilidade da demanda, dependência de fornecedor com tempo de reposição longo ou um gargalo no processo de aquisição. E, por fim, o relacionamento, o gerenciamento de materiais, por definição, trata-se do gerenciamento das relações ao longo das áreas das organizações que embora sejam independentes, na realidade, são interdependentes. Cadeias de suprimentos bem sucedidas são aquelas regidas pela busca constante de soluções, baseadas na reciprocidade e confiança. Os temas da responsividade, confiança, resiliência e relacionamento formam a base para que seja bem sucedido o gerenciamento da cadeia de suprimentos e, por conseqüência, a distribuição de materiais (Christopher, 2007).

Alguns sistemas de distribuição que são comumente utilizados merecem ser mencionados:

No Sistema Convencional ou Tradicional, também chamado de sistema "empurrado", os produtos são adquiridos antes da demanda e posicionados nos almoxarifados como estoque de segurança. Com isso, ocorre a estocagem de materiais, dificultando os procedimentos, os 
controles e os manuseios, o que cria problemas de distribuição, acuracidade e tempo desperdiçado (Pozo, 2007).

O Sistema Tradicional, normalmente, trabalha com uma distribuição de materiais baseada em uma reposição periódica e uma cota de material preestabelecida pelo próprio usuário, o que propicia a formação de grandes estoques nas diversas áreas do hospital (Castilho, Leite, 1991).

O Just in Time (JIT) é um sistema que vem sendo discutido desde os anos 80 por indústrias ocidentais. Todavia, muitas empresas não entendem exatamente o que significa. As empresas confundem com um sistema ou artifício para redução de estoques, transferindo a responsabilidade para os fornecedores, ou simplesmente uma solução rápida para melhorar suas tarefas ineficientes. Na verdade, o JIT é muito mais do que isso, é tanto uma filosofia quanto uma técnica voltada para eliminação do desperdício no processo de compras à distribuição. Baseia-se na idéia de que, sempre que possível nenhuma atividade deve ocorrer em um sistema até que ocorra a necessidade para tal. Tem como princípio um fluxo organizado de produção, com muita atenção às regras e procedimentos de qualidade total, contínua melhoria do processo e estoques mínimos (Christopher, 2001; Pozo, 2007).

Christopher (2007) refere que o Just in Time é um conceito de "puxar", em que a demanda puxa os produtos em direção à área de consumo e, por trás disso, o fluxo de materiais também é determinado pela mesma demanda.

Este sistema, desenvolvido pelos japoneses, quando aplicado adequadamente, reduz ou elimina a maior parte dos desperdícios que ocorre em toda a cadeia de suprimentos. Entretanto, é necessário utilizar como estratégia de implantação três componentes básicos. O primeiro é o fluxo no processo de produção, criar onde não existe e melhorar os processos existentes. O segundo trata-se da qualidade, atitude da empresa quanto à ação de fazer certo da primeira vez. E o terceiro é o envolvimento profissional. Cada um deve estar conscientizado da importância da eliminação de desperdício e da solução dos problemas de produção que causam perdas. 
Outros autores classificam o sistema de distribuição de materiais, especificamente para hospitais, da seguinte forma: tradicional, estoque reduzido 1, estoque reduzido 2 e o JIT (Egbelu et al., 1998).

O Tradicional compreende um estoque central que mantém uma média alta de material. $\mathrm{O}$ fornecedor entrega o material no estoque central, e este realiza o suprimento para todas as áreas do hospital para um período predeterminado.

No Estoque reduzido 1 (Stoc-1), o estoque central é completamente eliminado. O distribuidor entrega o material, e o almoxarifado distribui diretamente para os subestoques das áreas do hospital repetidas vezes na semana.

O sistema de Estoque reduzido 2 (Stoc-2) é similar ao anterior, exceto que o hospital elimina o recebimento do material pelo Almoxarifado. O próprio fornecedor entrega todos os itens requisitados diretamente para todas as áreas do hospital, mantendo um estoque mínimo.

No JIT, o estoque central não é eliminado, ele mantém uma média baixa de material. $O$ fornecedor entrega 0 material com mais frequência e em pequenas quantidades no estoque central, conforme demanda, e o suprimento para todas as áreas do hospital é realizado por um período mínimo.

Independente do sistema adotado nas organizações hospitalares, seja convencional, JIT ou estoque reduzido, os parâmetros apresentados, como quantidade de material no estoque central, equipe para distribuição, o espaço de armazenamento, o custo do serviço em potencial para distribuir e a necessidade de responder em níveis de volatilidade na demanda podem alterar o custo total anual, sendo necessário uma análise criteriosa dos administradores hospitalares.

Para enfrentar esses desafios, as organizações de saúde precisam concentrar seus esforços para obter maior agilidade, a fim de responder em intervalos de tempos menores, tanto em termos de volume, como em variedade de materiais para os usuários.

Os avanços da última década no uso da tecnologia da informação, que permitem a captação de dados da demanda diretamente do 
local de consumo, estão proporcionando, cada vez mais, para as organizações, medidas mais ágeis e responsivas de consumo de material, que têm possibilitado aos administradores de materiais, fornecedores e usuários lidarem com os dados baseados em uma demanda real, em vez de depender de previsões passadas, convertendo posteriormente em previsões de estoque (Christopher, 2007).

Em uma pesquisa realizada sobre as atividades e diminuição de custos de logística de 201 hospitais nos Estados Unidos e na França, demonstrou que tanto os hospitais franceses como os americanos acreditam no uso da tecnologia de informação e no programa JIT para melhoria do gerenciamento de materiais (Aptel, Pourjalali, 2001).

Neste contexto, ainda se faz necessário uma atenção maior, por parte dos gestores hospitalares, quanto aos investimentos no gerenciamento de materiais, incluindo ferramentas de informatização, para melhores resultados financeiros, qualidade nos processos e maior produtividade (Bittar, 2005).

\subsection{INFORMATIZAÇÃO DO GERENCIAMENTO DE MATERIAIS EM HOSPITAIS}

A informatização na área de saúde é considerada uma ferramenta de trabalho com o objetivo de facilitar, agilizar e qualificar processos informacionais, visando melhoria à assistência e aos processos gerenciais de planejamento, monitoramento e avaliação dos serviços (Hadad et al., 2004).

O uso da tecnologia de informação (TI), no gerenciamento de materiais para compartilhar dados entre compradores, fornecedores e usuários, permite criar uma cadeia de suprimentos virtual baseada em informações e não em estoque. 
O gerenciamento de materiais tradicional baseia-se em um paradigma que identifica quantidades e localização espacial de estoque, tendo fórmulas complexas para apoiar este modelo de negócio. Paradoxalmente, as empresas, uma vez tendo conhecimento da demanda por meio da informação compartilhada, apresentam uma tendência de utilizar cada vez menos a premissa do Sistema Tradicional e utilizar a informação compartilhada e o alinhamento de todos os processos de uma cadeia de suprimentos. À medida que a tecnologia de informação permite que diferentes organizações em uma rede compartilhem, de forma colaborativa, informação sobre demanda real, estoque e capacidade, deixam de depender de pedidos e reposições imprecisas de materiais transmitidos pelo sistema tradicional (Christopher, 2007).

Para o gerenciamento de recursos materiais, é importante utilizar a tecnologia de informação como um elemento vital no planejamento, desenvolvimento, distribuição de produtos. Outro fator primordial é a conscientização e o envolvimento de todos os profissionais que participam deste processo, desde a aquisição até o consumo do material na instituição. Entretanto, são poucos os estudos que relatam sobre a informatização de gestão de materiais na área hospitalar, sendo necessário, portanto, desenvolver pesquisa sobre esse assunto.

A tecnologia de informação do processo logístico de materiais pouco se vê no Brasil. Este sistema foi implantado em algumas organizações de saúde privadas e mais estruturadas economicamente. No entanto, não há nenhuma referência na literatura nacional sobre essas experiências.

Rezende (2000) refere que o Sistema de Informação (SI) pode ser definido como o processo de transformação de dados em informações que podem ser utilizadas em tomadas de decisão da empresa e que proporciona a sustentação administrativa, visando à otimização dos resultados esperados. Ao se unir o SI com a TI, é criado grupo de telas e relatórios, gerando informações profícuas e oportunas aos administradores e usuários.

As tecnologias e os sistemas de informação permitem uma ligação e interação entre as atividades logísticas de uma empresa. Para 
isso, é necessária a utilização de equipamentos como computadores, palmtops, códigos de barra, entre outros (Gomes, Ribeiro, 2004).

O sistema informatizado, utilizando código de barra e leitoras ópticas para o gerenciamento de materiais nas organizações de saúde, tem sido utilizado em alguns países, como Estados Unidos, França e Canadá, como uma das formas encontradas para melhorar a situação do controle de material e dos custos. Nesse sistema, todo material adquirido pela instituição é codificado, distribuído e identificado pelo código de barras no momento de sua utilização. Com isso, acredita-se ser possível controlar o consumo e repor os materiais necessários nas unidades; obter rastreabilidade quanto à esterilização, lote e localização do produto; permitir o conhecimento do consumo real; planejar compras em quantidades adequadas; diminuir tempo de estoque e, consequentemente, eliminar desperdícios e reduzir custos das operações do gerenciamento de materiais.

O sistema eletrônico de código de barra no gerenciamento de materiais é parte inevitável quanto ao cuidado à saúde, pois a diversidade dos produtos e a preocupação de redução de custos são grandes. Pode-se entender o princípio do sistema de registro eletrônico de supermercado semelhante às necessidades que uma instituição hospitalar exige, porém com o diferencial de gerar soluções criativas, banco de dados mais ricos e melhores práticas (Kenneth, 1997).

O Summit Medical Center Oakland da Califórnia, nos Estados Unidos, mudou-se o modelo de gerenciamento focado no almoxarifado, onde se fazia apenas o inventário de materiais, para um novo modelo com o auxílio de um sistema informatizado, contendo todos os dados para aquisição, reposição, controle e consumo real dos insumos, registrados pelos profissionais, por meio de leitora de código de barra no momento do uso. Com a implantação do sistema informatizado de gestão de materiais com código de barra, os benefícios ficaram claros, quando compararam os resultados dos inventários no almoxarifado. Entre o ano de 1992 a 1996, encontraram uma diminuição do consumo de materiais, com redução de aproximadamente $49 \%$ dos custos (Darnell, 1996). 
O hospital St. Michel da cidade de Toronto adotou um sistema informatizado de processo de logística de materiais, em 2001, utilizando a tecnologia de código de barra para obter dados de consumo. Esse sistema permitiu a rastreabilidade e avaliação completa da cadeia de suprimentos de materiais, proporcionando maior tempo aos profissionais para o cuidado direto do paciente (King et al., 2005).

Esse sistema já está sendo utilizado por alguns hospitais brasileiros, porém, muitos, ainda, trabalham com controle manual de materiais, dentro do sistema tradicional de controle de estoque. A falta de reestruturação do gerenciamento de materiais e informatização favorece 0 desconhecimento do consumo real, a formação de estoques periféricos nas unidades, levando à compra inadequada de materiais para reposição no almoxarifado e um custo excessivo para a instituição.

A falta, a obsolescência ou a ineficiência no manuseio dos materiais podem trazer riscos ao paciente, interferindo em todo trabalho da equipe de saúde. Observa-se na prática que, frequentemente, há necessidade de dispensar boa parte do tempo para resolver problemas de material de consumo. Isto tudo é atribuído ao sistema deficitário de controle, armazenamento, distribuição e manuseio, advindo da ausência de informações de dados em tempo real.

Em vários hospitais brasileiros, foram encontrados problemas, tais como: compras mal dimensionadas e mal negociadas; miniestoques de materiais e medicamentos excessivos e desnecessários dispersos pelo hospital; estoques parados há mais de um ano e, na maioria, com prazo de validade vencido; falta de padronização; pessoal despreparado e ausência do sistema e tecnologia de informação no serviço de materiais (Paterno, 1992).

Outro aspecto observado nas organizações que trabalham com o Sistema Tradicional é o não envolvimento dos profissionais de saúde nessas questões. Em um estudo que analisou o preenchimento de 40 fichas de controle de gastos de material de consumo em cirurgia cardíaca, de um hospital governamental de ensino e pesquisa, foi observado que uma das dificuldades, em relação a essa atividade, era a falta de envolvimento dos 
profissionais de saúde, levando ao desconhecimento do gasto real nas cirurgias (Bittar, Castilho, 2003).

Outros autores, ao estudarem o conhecimento da equipe de enfermagem - um dos maiores usuários nas organizações hospitalares sobre o custo de alguns materiais de consumo, observaram que eles desconhecem o preço real desses materiais (Ortiz, Gaidzinski, 1999).

Diante desse cenário, há necessidade de adoção de sistemas de gerenciamento de materiais informatizados que auxiliem no controle de materiais e equipamentos, que gerem informações e que conscientizem e envolvam os funcionários nessas questões.

Embora já existam no mercado programas informatizados de gerenciamento de materiais hospitalares, eles necessitam de adaptação, segundo as necessidades de cada local, ou ainda, por não serem compatíveis, há necessidade de serem criados. 

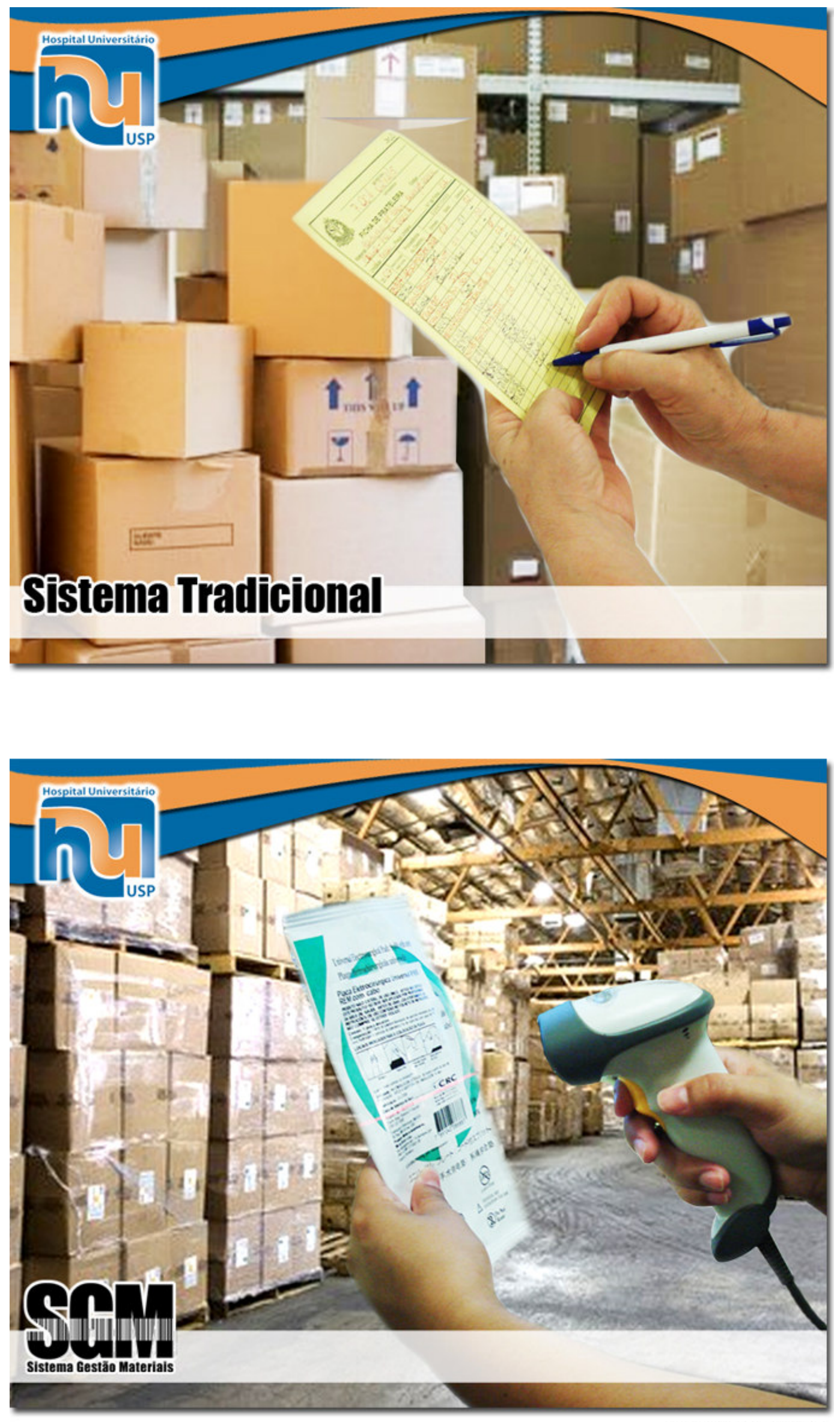


\subsection{SISTEMA TRADICIONAL}

\subsubsection{O fluxo de materiais}

O sistema adotado para o gerenciamento de materiais no $\mathrm{HU}$ USP, desde a sua implantação em 1981, foi pelo Sistema Tradicional que os materiais eram distribuídos aos usuários, conforme as cotas de material preestabelecidas com reposição em datas fixas.

Todas as atividades administrativas e operacionais relacionadas a materiais, como aquisição, recebimento, armazenagem, distribuição e controle físico dos materiais estocados eram realizados manualmente pelo setor de Compras e o Almoxarifado. Os demais setores, como as unidades assistenciais, administrativas e serviços de apoio, interagiam com o sistema, mantendo estoques nos respectivos setores. Havia participação efetiva desses mesmos setores na seleção do material solicitado, proporcionando suporte para o setor de Compras nos processos de aquisição.

O Almoxarifado utilizava o Sistema Tradicional baseado em um controle estatístico do estoque, que contava com novas aquisições, quando o nível de estoque atingia determinado ponto de pedido. Este sistema, frequentemente, resulta em níveis de estoque mais alto ou mais baixo do que o necessário, especialmente nos casos em que a demanda pode mudar ou aumentar muito em ocasiões específicas (Christopher, 2007).

O Almoxarifado é o setor responsável pela guarda e estoque dos materiais e também responsável pelo recebimento do material adquirido pelo setor de Compras. Após o recebimento, que abrange as fases de conferência fiscal, quantitativa e qualitativa, o material era armazenado no estoque central para ser solicitado periodicamente pelos diversos setores através das requisições de materiais.

Ao longo dos anos, houve a necessidade de se ter mais de um local de armazenagem devido à grande quantidade de itens cadastrados, da quantidade de material estocado por 2 a 3 meses e das características diferenciadas dos bens materiais que o hospital utiliza. Assim, os locais de armazenagem de materiais, considerados como estoques centrais, foram 
divididos em três setores: Farmácia, Serviço de Nutrição e o Almoxarifado. No Almoxarifado, eram armazenados os materiais variados, como materiais médico-hospitalares, de escritório, de uso geral, entre outros, necessários para o funcionamento do hospital.

O Almoxarifado apresentava-se como um Estoque Central que atendia todos os setores assistenciais do hospital, conforme o fluxo, como mostra a Figura 4, a seguir:

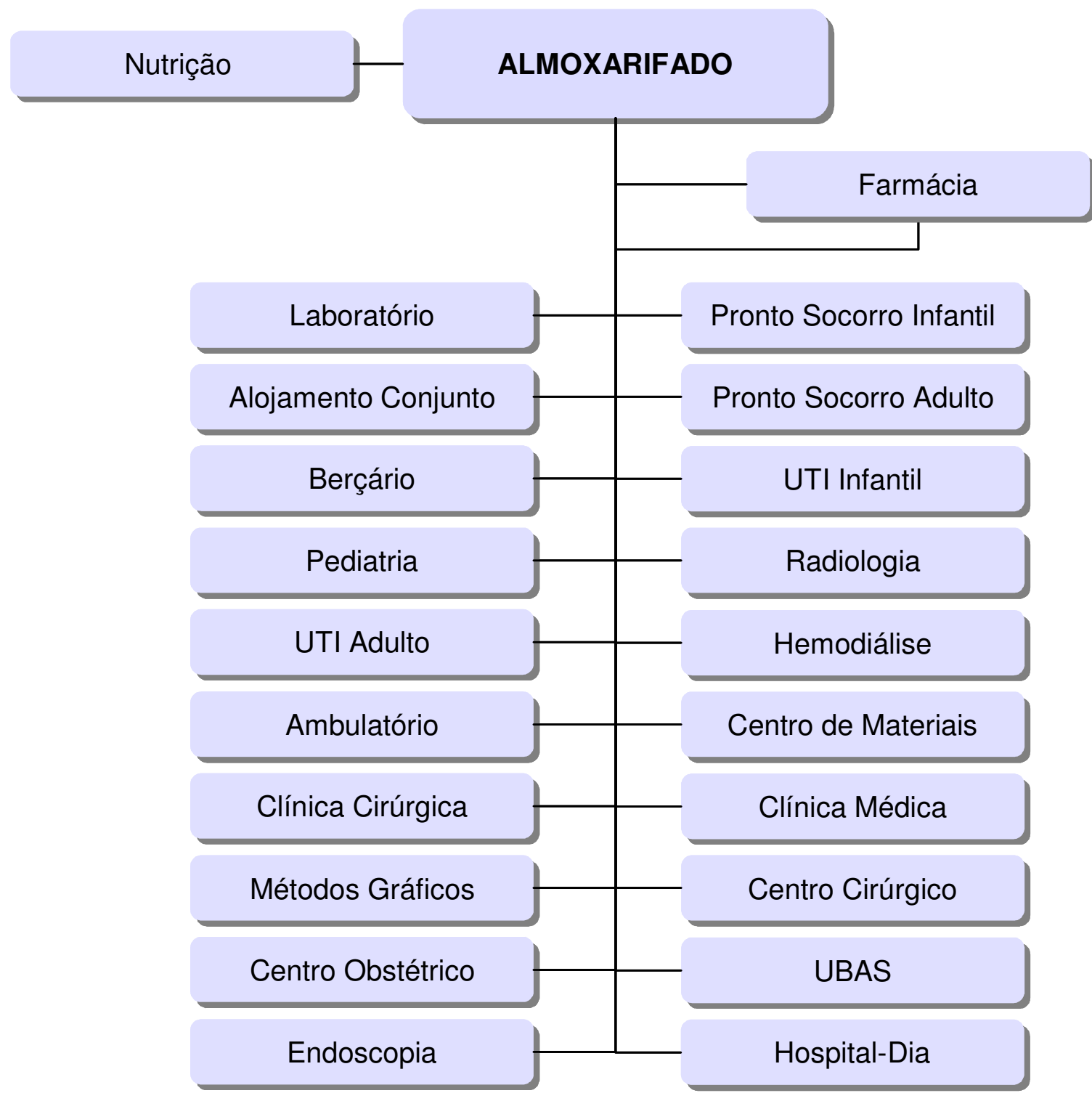

Figura 4. Fluxo dos setores assistenciais e de estoque de materiais no Sistema Tradicional utilizado no HU-USP, São Paulo - 2008 
O Estoque Central do Almoxarifado apresentava três áreas físicas para o armazenamento de materiais. Na primeira área, eram armazenados os materiais de grandes volumes e quantidades. Nas outras áreas, eram armazenados materiais, levando-se em consideração o espaço disponível para estocagem, tipos de materiais, número de itens estocados e o tipo de embalagem. Os materiais eram estocados em prateleiras e pallets formando várias fileiras com espaço suficiente para a movimentação dos materiais.

Para a localização dos materiais no estoque central, o Almoxarifado optou por trabalhar com o sistema de classificação dos materiais, agrupando-os de tal modo que cada gênero de material ocupasse um local respectivo, facilitando sua identificação e localização nesse local. Todo material era codificado por um sistema numérico. A primeira dezena representava o grupo do material, a segunda classificava o subgrupo e a terceira dezena tinha a função de melhor definir o item. A codificação substituía o nome do material e, com isso, todos os profissionais do almoxarifado e os demais conheciam o material pelo código e não pelo nome. O processo de trabalho deste setor era composto por atividades de recebimento de materiais, documentação do processo de compra e armazenamento no estoque central, que era realizado pelo gestor de estoque, separador e conferente.

As atividades do gestor de estoque compreendiam:

- controle da reposição de estoque fundamentado em um sistema de cartão amarelo, onde constavam entradas, saídas e quantidade do material em estoque, escrito manualmente pelo separador;

- preenchimento da requisição de ordem de compra do material para o setor de Compras;

- recebimento da solicitação de materiais dos setores hospitalares, chamada de requisição de estoque; 
- avaliação das quantidades de materiais requisitadas, realizando as alterações necessárias em caso de falta de materiais em estoque, promovendo a substituição do material ou diminuição da quantidade a ser entregue;

- distribuição das requisições para o separador.

Os separadores eram responsáveis por um determinado grupo de materiais e suas atividades contemplavam:

- separar o material, reconhecendo-o pelo código;

- registrar, no cartão amarelo do material, a quantidade; retirada e a quantidade em estoque.

- encaminhar o material separado ao conferente.

As atividades do conferente eram verificar todo material separado com a requisição enviada pelo setor solicitante.

Todos os setores do HU-USP solicitavam materiais ao Almoxarifado por meio de um impresso denominado requisição de estoque. Existiam dois tipos de requisições de estoque, a normal e a extra.

A normal era solicitar itens com previsão de cota mensal da sua unidade. O setor requisitante verificava em seu estoque a quantidade existente de material e solicitava a quantidade para atingir o estoque máximo permitido, até a próxima requisição mensal.

A extra compreendia a solicitação de itens, com ou sem previsão de cota mensal na unidade. O requisitante verificava a necessidade de solicitar novamente um item de sua previsão mensal por necessitar na unidade e detectar a ausência deste material no período que antecedia a nova requisição ou percebia a necessidade de utilizar um material que não possuísse em sua previsão mensal por tratar-se de procedimentos específicos e esporádicos. 
Em relação ao cronograma das solicitações dos materiais, todos os setores hospitalares seguiam as datas mensais preestabelecidas pelo setor de Almoxarifado para encaminhar as suas requisições de estoque. Este setor estabeleceu o prazo de três dias úteis para a distribuição dos itens solicitados em requisições do tipo normal. Nas requisições tipo extra, os itens eram distribuídos no mesmo dia (Lourenço, 2006).

Quando o setor solicitante recebia os materiais distribuídos pelo Almoxarifado, realizava uma conferência dos materiais entregues, e as requisições eram assinadas pela área que recebia os itens e arquivada no Almoxarifado. Para as requisições de itens que não eram atendidos em sua totalidade, atribuídos à falta desse material no estoque, essa requisição permanecia no setor de Almoxarifado até os materiais serem adquiridos, recebidos dos fornecedores e distribuídos para as áreas de acordo com as requisições pendentes.

$\mathrm{Na}$ figura 5, observa-se o fluxo de distribuição de materiais do setor de Almoxarifado para os setores hospitalares. 


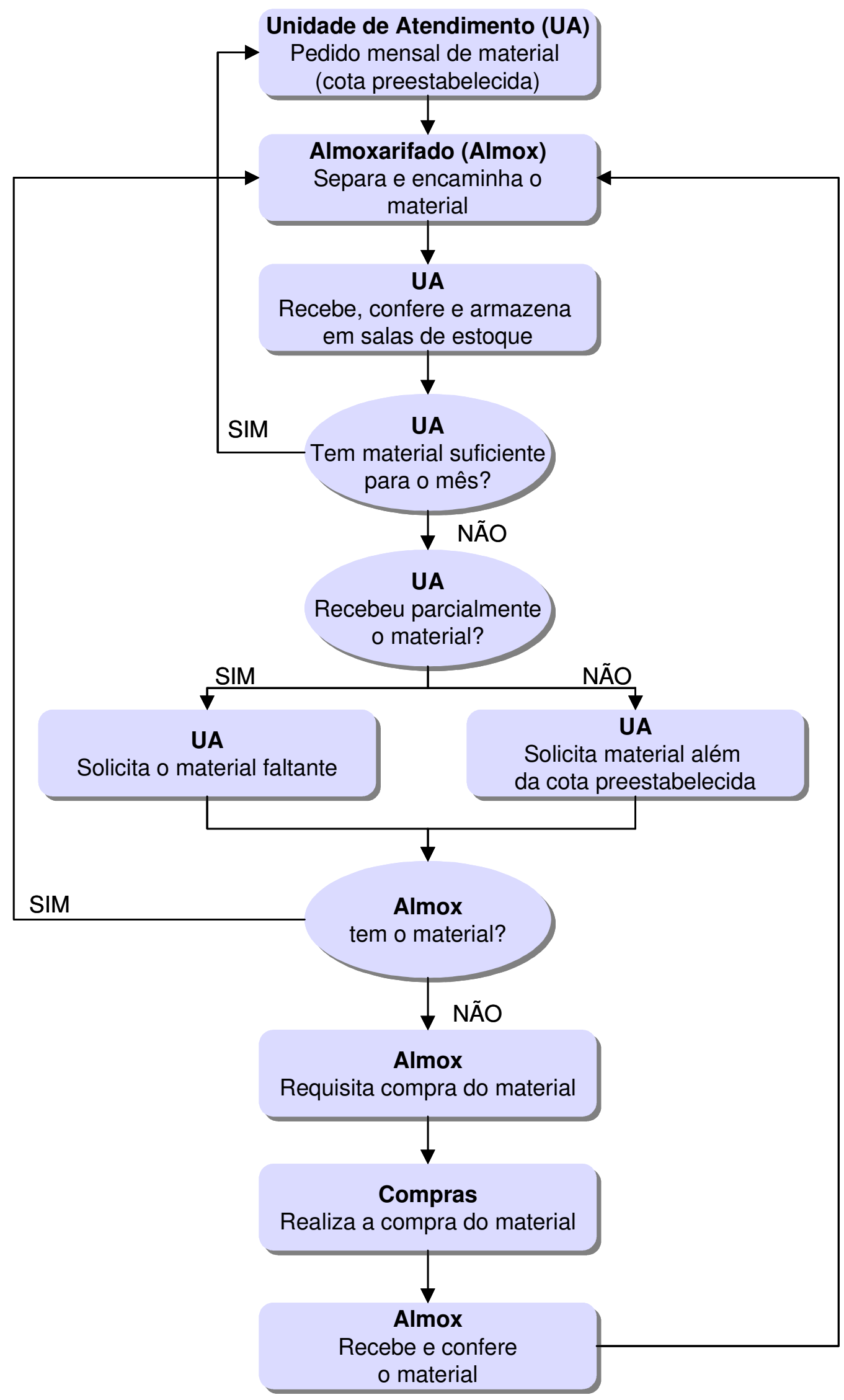

Figura 5. Fluxo de distribuição de materiais utilizado no Sistema Tradicional, utilizado no HU-USP, São Paulo - 2008 
Os setores hospitalares, ao receberem os materiais do Almoxarifado, realizavam o armazenamento em um local reservado para o estoque, e, durante o mês, os materiais eram dispostos em armários, gavetas e prateleiras para serem consumidos.

No Centro Cirúrgico, a disponibilidade dos materiais era diferente das demais áreas. Além da reposição diária do material em gavetas e prateleiras nas salas de operação (SO) e sala de recuperação anestésica (SRA), o Centro Cirúrgico realizava a montagem de kits cirúrgicos em uma área específica de armazenamento e preparo de materiais. Nessa área, chamada de guarda de materiais, ficava um técnico de enfermagem, responsável pelo estoque de todos os materiais recebidos do Almoxarifado e pela montagem dos kits para as cirurgias. Os kits eram montados para pronto uso, ou seja, poucas horas que antecediam as cirurgias, baseado em uma listagem de materiais médico-hospitalares necessários para cada procedimento cirúrgico.

O Centro Cirúrgico do HU-USP tinha, em sua rotina de trabalho, os kits padronizados por cirurgia, com o objetivo de prover materiais específicos em quantidade certa para os diferentes procedimentos cirúrgicos. Havia também a preocupação em controlar os materiais, evitar desperdícios com melhor adequação na utilização dos itens, um ambiente propenso a um menor risco de infecção do sítio cirúrgico e, consequentemente, prestar um atendimento de qualidade ao paciente. Entretanto, a área não conseguia obter dados reais do consumo de materiais em cirurgia, pois, na prática, existiam problemas como, montagem de kit manualmente e ausência de instrumentos de controle de gasto de materiais (Machado, Yamaguchi, Paschoal, 2007).

Essas dificuldades não foram observadas somente no Centro Cirúrgico, todos os setores hospitalares desconheciam o consumo real dos materiais, talvez justificado pela utilização de um sistema manual de gerenciamento de materiais, baseado em uma cota mensal pré-estabelecida, sem controle de gasto, de custo e de qualquer sistema que auxiliasse na decisão de quando comprar os materiais, evitando a imobilização de recursos. 
A ausência do controle de materiais, além de favorecer o acúmulo exagerado nos vários setores da instituição, favorece a perda de outros, por deterioração, obsoletismo, violação de sua integridade por estocagem inadequada, ou em demasia, bem como o seu desaparecimento (Horr et al., 1989).

Muitos problemas encontrados no dia-a-dia são relativos ao Sistema Tradicional de gerenciamento de materiais com o trabalho manual do Almoxarifado (controle, recebimento, pedido e entrega de material), a distribuição mensal de materiais baseado em cota preestabelecida e a perda do controle de estoque. Tal sistema acarreta a falta de alguns materiais e excesso de outros, levando ao comprometimento da assistência prestada (Toscan, 1990).

\subsubsection{Levantamento de problemas decorrentes do Sistema Tradicional de gerenciamento de materiais}

Os problemas decorrentes do Sistema Tradicional de gerenciamento de materiais observados no hospital foram relacionados à previsão, à organização e ao controle dos materiais.

Os problemas levantados relacionados à previsão de materiais foram:

- previsão mensal com cotas mal dimensionadas, ocasionando excesso de alguns itens e falta de outros no hospital;

- falta de padronização, tendo como consequência excesso de itens de materiais semelhantes para uma mesma finalidade técnica;

- grande quantidade de materiais e de alto custo sem critérios de indicação de uso;

- compras emergenciais com alto custo, para suprir a falta do material no hospital; 
- a área solicitava mais material do que necessitava e o setor de Almoxarifado entregava menos do que era solicitado, criando um círculo vicioso de distribuição de materiais, o que levou ao rompimento da relação de confiança no sistema tradicional e o hábito de criar estoques periféricos nas áreas (Ciclo acumulativo do sistema de distribuição de materiais de Vecina Neto e Reinhardt Filho, 1998).

Os problemas relacionados à organização de materiais encontrados foram:

- materiais, em abundância, armazenados em vários locais nas áreas como: gavetas, armários, prateleiras, favorecendo o desperdício;

- vários locais de estoque nas áreas, dificultando a localização do material;

- ausência de kits padronizados para o uso em procedimentos médicos e de enfermagem nas áreas de internação, atendimento ambulatorial e Pronto-Socorro, necessitando um gasto maior de tempo dos profissionais que, além de dificultar na assistência, contribuía para o desgaste físico do profissional.

Os problemas relacionados ao controle de materiais foram:

- controle de materiais realizado manualmente, ocasionando a perda do controle de estoque, ou seja, dificuldade do Almoxarifado identificar a necessidade de emissão de pedido de compra de materiais com nível abaixo do ponto de reposição;

- kits cirúrgicos sem avaliação periódica sistematizada, com quantidade de materiais mal dimensionada para a intervenção, apresentando falta de materiais, detectada durante a cirurgia, 
ou sobra excessiva de materiais, e ausência de registro do consumo real do material por procedimento;

- estoques periféricos nas áreas, isto é, além da cota estabelecida;

- ausência de registro do consumo real do material nas áreas hospitalares;

- falta de material no hospital;

- desperdício e extravio de material;

- material com prazo de validade vencida, obsoleto, sem uso e com embalagem deteriorada;

- falta de envolvimento dos profissionais de saúde na área de recursos materiais; a maioria dos profissionais desconhecia a importância do controle e do custo dos materiais.

\subsubsection{0 custo de materiais}

No ano de 2007, o custo de material médico-hospitalar e o medicamento foram de $R \$ 11.747 .059,08$, sendo o setor de Centro Cirúrgico o que mais consumiu, com $\mathrm{R} \$ 2.060 .991,69$ (17,54\%); em seguida a UTI Adulto, apresentando $\mathrm{R} \$ 1.921 .962,53$ (16,36\%); e depois Pronto-Socorro Adulto com $\mathrm{R} \$ 1.197 .201,37$ (10,19\%) do custo total anual de material gasto nos setores assistenciais da instituição.

Os demais setores assistenciais apresentaram um custo abaixo de $8,76 \%$ durante o ano, como mostra a Tabela 1. 
Tabela 1 - Setores assistenciais, segundo custo anual de materiais médicohospitalares e medicamentos de 2007(1), HU-USP- 2008

\begin{tabular}{lcc}
\hline \multicolumn{1}{c}{ UNIDADE } & CUSTO ANUAL (R $\$)$ & PORCENTAGEM \\
\hline Centro Cirúrgico & $2.060 .991,69$ & $17,54 \%$ \\
UTIAD & $1.921 .962,53$ & $16,36 \%$ \\
PSAD & $1.197 .201,37$ & $10,19 \%$ \\
Centro Obstétrico & $1.029 .118,46$ & $8,76 \%$ \\
UTIPED & $953.896,17$ & $8,12 \%$ \\
Clínica Médica & $875.799,78$ & $7,46 \%$ \\
Clínica Cirúrgica & $718.322,35$ & $6,11 \%$ \\
CME & $644.346,84$ & $5,49 \%$ \\
Radiologia & $485.445,45$ & $4,13 \%$ \\
Clínica Pediátrica & $421.587,73$ & $3,59 \%$ \\
PSINF & $235.438,92$ & $2,00 \%$ \\
Ambulatório & $231.569,00$ & $1,97 \%$ \\
Hemodiálise & $224.718,68$ & $1,91 \%$ \\
Berçário & $220.367,47$ & $1,88 \%$ \\
Endoscopia & $220.247,68$ & $1,87 \%$ \\
Alojamento Conjunto & $160.234,82$ & $1,36 \%$ \\
Hospital Dia & $55.281,72$ & $0,47 \%$ \\
Métodos Gráficos & $51.387,09$ & $0,44 \%$ \\
UBAS & $39.141,33$ & $0,33 \%$ \\
\hline TOTAL & $11.747 .059,08$ & $100,00 \%$ \\
\hline Hil & Almonte & \\
\hline
\end{tabular}

(1) Fonte fornecida pelo setor de Almoxarifado.

Finalizando, após todos esses anos utilizando o sistema tradicional de gerenciamento de materiais no HU-USP, observou-se um desgaste intenso por parte dos profissionais envolvidos, pois o sistema ficou desacreditado, com um custo de estoque elevado, sem condições de fornecimento de dados e controles confiáveis. 


\subsection{IMPLEMENTAÇÃO DO SISTEMA DE GESTÃO DE MATERIAIS INFORMATIZADO (SGM)}

\subsubsection{A escolha do sistema e da ferramenta informacional}

Diante dos problemas encontrados na utilização do Sistema Tradicional, citados anteriormente, a reestruturação do gerenciamento de materiais teve como finalidade conhecer a quantidade real e a eliminação de desperdícios no processo de obtenção, armazenamento e distribuição de materiais para toda a instituição, levando a redução de estoques e custos, proporcionando melhor assistência ao paciente e o envolvimento e a satisfação da equipe multiprofissional.

Para atingir essas finalidades, adotou-se um modelo pautado no sistema Just in Time, que estabelece um estoque mínimo, um consumo e uma reposição de materiais a partir de uma demanda real existente, com distribuição dos materiais com mais frequência e em pequenas quantidades nos setores do hospital. Para isso, foi desenvolvido um sistema de informação eletrônica para subsidiar a Gestão de Materiais e assim auxiliar nos processos de aquisição, estocagem, distribuição e controle dos materiais.

Devido à necessidade de obtenção de informações para subsidiar a tomada de decisão, é imprescindível, cada vez mais, a utilização de sistemas de informações. Desse modo, nas últimas décadas, surgiram vários segmentos de desenvolvimento de sistemas de informações, ou seja, grupos que desenvolvem software e que comercializam pacotes prontos, e grupos que desenvolvem sistemas dentro das organizações.

Para a tomada de decisão em adquirir um sistema pronto ou desenvolver um sistema de gestão de materiais internamente, é importante estabelecer a relação custo-benefício, pois uma das características que a informática traz, é o alto custo de desenvolvimento e implantação (Machado et al., 2004). 
Por essas razões, foi necessário, primeiramente, conhecer o que havia no mercado. O mercado oferece alguns sistemas para atender supermercados, empresas de saúde privadas e outras. No entanto, essas áreas apresentam processos de trabalhos diferentes dos desenvolvidos em hospitais públicos, principalmente, de ensino, inseridos em uma universidade. No HU-USP, o processo de compras tem peculiaridades e detalhes que regem a licitação pública, além de seguir as diretrizes da Universidade de São Paulo. O hospital realiza o processo de compra utilizando um programa de aquisição de materiais e bens, desenvolvido pela própria Universidade, chamado "Mercúrio". Esse programa apresenta especificidades próprias, contendo informações e dados necessários para aquisição de qualquer material.

Considerando as observações acima, o tempo necessário e o custo para realizar as adaptações de um sistema já construído às necessidades do hospital, optou-se pela criação de um sistema novo de gestão de materiais.

Para a criação do Sistema de Gestão de Materiais informatizado (SGM), seguiram-se as fases preconizadas para o desenvolvimento de um sistema de informação eletrônica (software) (Tamaki, 2007).

Essas fases foram:

a) o conhecimento de todos os processos de trabalho relacionados a gestão de materiais, utilizando, como estratégia, reuniões com todas as áreas do hospital para conhecer as necessidades, o trabalho cotidiano e as necessidades da instituição;

b) elaboração de proposta para modificação dos processos de trabalho relacionados a gestão de materiais, de acordo com as necessidades do setor, agregando-a ao desenvolvimento do software;

c) desenho de interface, ou seja, da elaboração dos campos e da apresentação da tela pela qual o usuário interage com o programa;

d) construção de uma versão preliminar (protótipo funcional), e o levantamento das funções e regras de negócios existentes em um sistema de informação, determinando seu comportamento, suas restrições e validações; 
e) implementação das funções e regras de negócio no sistema;

f) homologação da construção, junto ao usuário, com a preocupação de estar contemplando a dimensão do sistema com a necessidade do usuário;

g) treinamento do novo sistema de informação;

h) período de acompanhamento de aprendizado e de adaptação do usuário do novo sistema de informação.

Na perspectiva de criar um sistema de informação compatível e integrado aos sistemas preexistentes na instituição, foi utilizado o conceito de três camadas (apresentação, negócio, armazenamento de dados), as ferramentas de desenvolvimento NET (Dot Net) e o banco de dados Oracle (Conallen, 2002).

Para o novo Sistema de Gestão de Materiais, baseado no JIT, foi preciso construir o software simultaneamente à reestruturação do processo de logística de materiais no hospital.

\subsubsection{Reestruturação do processo de logística de materiais no hospital}

A reestruturação do processo de logística de materiais dentro do hospital foi realizada em duas etapas. A $1^{\text {a }}$ etapa compreendeu a reorganização do setor de Almoxarifado com seus locais de armazenagem dos materiais, denominados de estoques, até a criação de áreas específicas de distribuição de materiais para alguns setores do hospital, chamadas de Áreas de Suprimentos (AS). A $2^{\underline{a}}$ etapa objetivou a reestruturação do processo de trabalho de cada setor envolvendo desde as pequenas mudanças no fluxo do gerenciamento de materiais até a reorganização dos locais de acondicionamento.

$\mathrm{Na} 1^{\text {a }}$ etapa, envolveu a reorganização dos estoques do Almoxarifado, levando a uma reflexão sobre a estrutura física do Almoxarifado com locais adequados de armazenagem, a logística de distribuição dos materiais, a necessidade de uma área de produção de kit, o 
horário de funcionamento do Almoxarifado, os setores assistenciais especializados com seus materiais específicos e, por fim, a obtenção de um maior controle do material.

Assim, para a realização da $1^{\text {a }}$ etapa, como o Almoxarifado não apresenta condições quanto à estrutura física para absorver todas as demandas do novo SGM, e alguns setores serem especializados e críticos devido ao tipo de atendimento prestado ao paciente, optou-se por manter uma área de estoque central no Almoxarifado com a distribuição de materiais e criar em alguns setores assistenciais especializados áreas de armazenagem com produção de kit e distribuição, com funcionamento de 24 horas, chamadas de Áreas de Suprimentos (AS).

Neste novo SGM adotado pelo hospital, o estoque é chamado de Estoque Central que compreende as atividades de estocagem, separação, conferência, controle e distribuição dos materiais para todas as AS e demais setores hospitalares. Ficou determinado manter três estoques centrais e cinco Áreas de Suprimentos.

As áreas escolhidas para ter Estoque Central foram as mesmas áreas que já possuíam estoques e que recebiam materiais distintos entre elas, Farmácia, Serviço de Nutrição e Almoxarifado.

Farmácia - armazena, realiza o controle, a produção, a reposição e a distribuição de todos os medicamentos para os setores assistenciais e para as Áreas de Suprimentos.

Serviço de Nutrição - recebe, armazena, realiza o controle, a reposição e fornece todos os gêneros alimentícios para o hospital.

Almoxarifado - efetua o recebimento quantitativo e qualitativo, a unitarização, o armazenamento, o controle, a reposição e a distribuição de todos os materiais médico-hospitalares, materiais de escritório e materiais em geral. Ou seja, fornece materiais para todos os setores do hospital e para cinco AS.

As funções das AS compreendem o recebimento de materiais do estoque central do Almoxarifado e Farmácia, armazenagem, produção e distribuição de materiais. 
Para a escolha do local das AS, foram atribuídos critérios como: área física disponível, com menor investimento financeiro para adequação da área; setor considerado crítico e complexo pelo atendimento prestado aos pacientes; e o setor de maior impacto financeiro, com maior consumo e custo elevado de material.

Os cinco setores escolhidos para possuírem AS foram: Centro Cirúrgico (AS-I), Pronto-Socorro Adulto (AS-II), Pronto-Socorro Infantil (ASIII), Unidade de Terapia Intensiva Adulta (AS-IV) e Unidade de Terapia Intensiva Pediátrica (AS-V).

O Centro Cirúrgico é um setor crítico e de maior complexidade assistencial, com uma área física adequada para a AS, com recursos humanos capacitados e treinados para produção de kit, com maior consumo e custo anual de material dos setores assistenciais da instituição, conforme descrito anteriormente na Tabela 1. A Área de Suprimentos I (AS-I) agrega uma atividade diferente das demais AS, ela possui uma área de produção responsável por todos os kits hospitalares do HU.

A AS-I apresenta as seguintes atividades:

- recebimento de material do estoque central do Almoxarifado;

- recebimento de medicamentos injetáveis do estoque central da Farmácia;

- armazenamento de materiais em local apropriado;

- controle físico do material;

- produção de kit cirúrgico, kit de procedimento médico e de enfermagem;

- distribuição de materiais, de kits cirúrgicos e de medicamentos para o Centro Cirúrgico;

- distribuição de kit de procedimento médico e de enfermagem para as Áreas de Suprimentos II, III, IV, V e para os setores assistenciais do hospital que necessitarem.

O Pronto-Socorro Adulto e Infantil apresentam características e especificidades próprias para atendimento de emergência ao paciente, levando a necessidade de um maior controle do material e medicamento. 
As Unidades de Terapias Intensiva (UTI) Adulto e Pediátrico foram contempladas por apresentarem consumo de material significativo, principalmente, de medicamento e pela complexidade da assistência prestada ao paciente.

As Áreas de Suprimentos II, III, IV e V têm como atividades receber materiais, medicamentos e kits para serem consumidos nos seus respectivos setores como Pronto-Socorro Adulto e Infantil, UTI Adulto e Pediátrico.

A Figura 6 demonstra o fluxo de Estoques Centrais e Área de Suprimentos de materiais do SGM.

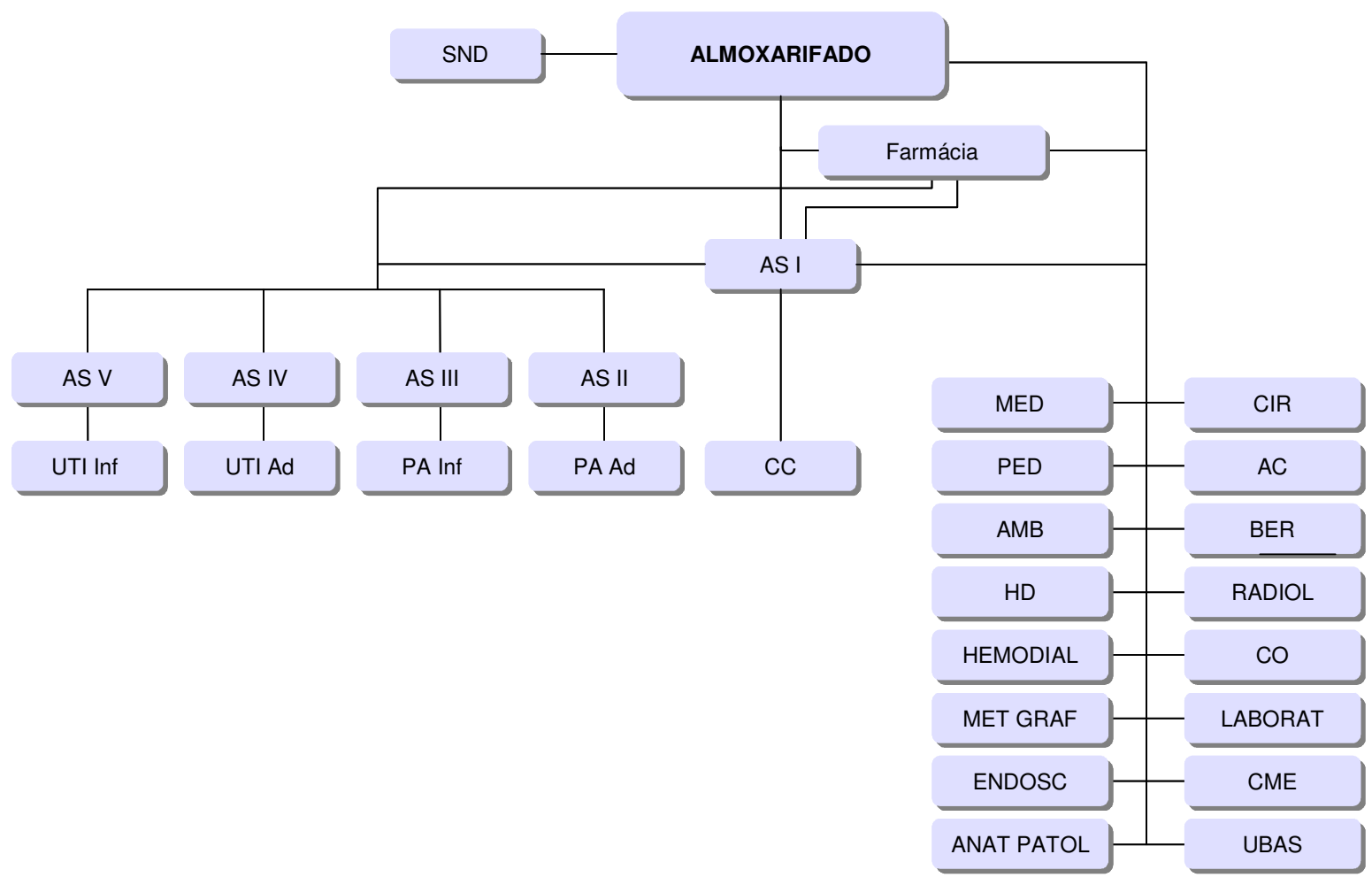

Figura 6. Fluxo de Estoque e Área de Suprimentos de Materiais no SGM utilizado no HUUSP, São Paulo - 2008 
$\mathrm{Na} 2^{\mathrm{a}}$ etapa, para reestruturar o processo de trabalho de cada setor e a organização do acondicionamento dos materiais, determinou que cada setor do hospital possuísse um único local para acondicionar os materiais para atender às necessidades dos pacientes e do próprio setor por um período de 24 horas.

Todos os setores reservaram uma sala em local centralizado e de fácil acesso para os profissionais, contendo estrutura para armários, câmara de refrigeração, para acondicionar medicamentos, e equipamentos como computadores, leitora de código de barra e impressora de etiquetas. Também foi necessária a aquisição de móveis apropriados para armazenagem e dispensação de materiais, pallets, carrinhos de transporte, caixas plásticas de vários tamanhos para acondicionamento de kit hospitalares e máquinas de fracionamento de medicação oral e injetável.

Os materiais e a elaboração do processo de trabalho do gerenciamento de materiais foram discutidos com as equipes interdisciplinares. Buscou-se também a experiência de outros hospitais, que já desenvolviam esse sistema de gerenciamento de materiais, soluções alternativas que poderiam satisfazer os requisitos do novo sistema de gestão de materiais e encontrar medidas facilitadoras para a dinâmica de trabalho diário do profissional.

Nos hospitais visitados, os setores assistenciais possuem poucos itens, pois a distribuição diária de materiais está diretamente endereçada para cada paciente. Para isso, é fundamental que as equipes de enfermagem informem aos estoques centrais e às áreas de suprimentos todos os materiais que o paciente precisará nas próximas 24 horas. Entretanto no HU-USP esta atividade não é possível ser realizada. Os setores envolvidos apresentam uma dinâmica de trabalho voltada totalmente para assistência direta ao paciente, não apresentando tempo e recursos humanos que possam informar o material necessário previamente.

Para controlar os materiais, evitar o desperdício e diminuir o consumo e, consequentemente, os custos, é preciso distribuir o material a partir de uma demanda, ou seja, enviar o material direto ao paciente. Porém, diante da impossibilidade do hospital realizar a tarefa de informar ao estoque 
central e à área de suprimento os materiais e kit para cada paciente, foi determinado trabalhar com o mínimo de material em cada unidade para 24 horas.

Foi adotado o estoque mínimo, conhecido também como estoque de segurança, que se trata de uma quantia de material estocado, além da quantidade de material armazenado para atender a demanda normal prevista, com a finalidade de reduzir o risco de falta, em decorrência de aumento imprevisto da demanda (Barbieri, Machline, 2006; Pozo, 2007).

Para viabilizar esta questão foram revisados os itens que cada setor possui, elaborados os kits de procedimentos médicos e de enfermagem, medicamentos injetáveis, acompanhados de seringas e agulhas, deixando apenas o mínimo de material nos setores para serem utilizados nos pacientes.

\subsubsection{Desenvolvimento do Sistema de Gestão de Materiais (SGM) informatizado}

O Sistema de Gestão de Materiais (SGM), desenvolvido com a criação do software e da reestruturação do processo de logística de materiais no HU-USP foi planejado contemplando três áreas consideradas igualmente importantes para o hospital, as áreas: de compras, de estoque e de produção.

A utilização das ferramentas de tecnologia da informação aplicadas à gestão de materiais foi um fator primordial para a operacionalização dos processos e seus gerenciamentos, que consiste em informatizar e integrar todas as operações do hospital.

Um importante fator, neste processo de automação, foi a implementação do código de barras que tem por definição simplificar a entrada de dados no sistema informatizado e facilitar as operações. Aliado ao sistema de identificação, foi necessário implantar um sistema denominado Troca Eletrônica de Dados (EDI - Eletronic Data Interchange), que permite as informações passarem a fluir ao longo do processo, 
propiciando a obtenção de dados importantes sobre as transações realizadas (Gonçalves, 2007).

O SGM está integrado com o sistema Mercúrio da Universidade de São Paulo; com o sistema de recepção, registro e agendamento do hospital; com o sistema de diagnóstico por imagem e laboratório; e com o sistema do hospital que dá entrada nas solicitações de serviço.

Para efetivação do SGM, toda troca de informação é realizada de forma estruturada, de acordo com os padrões preestabelecidos pelo $\mathrm{HU}$, envolvendo as três áreas de compras, estoque e produção, que se completam entre si, num ciclo contínuo e com retroalimentação a serem comentadas a seguir.

$\mathrm{Na}$ Figura 7, é demonstrado de maneira global todo processo do SGM que foi contemplado desde o processo de compra, entrada, unitarização, estocagem, produção e consumo, determinando todo o ciclo de vida de um material dentro do Hospital Universitário. Assim, ele compreende todas as fases de entrada do material no hospital desde a necessidade de compra até a sua reposição. 


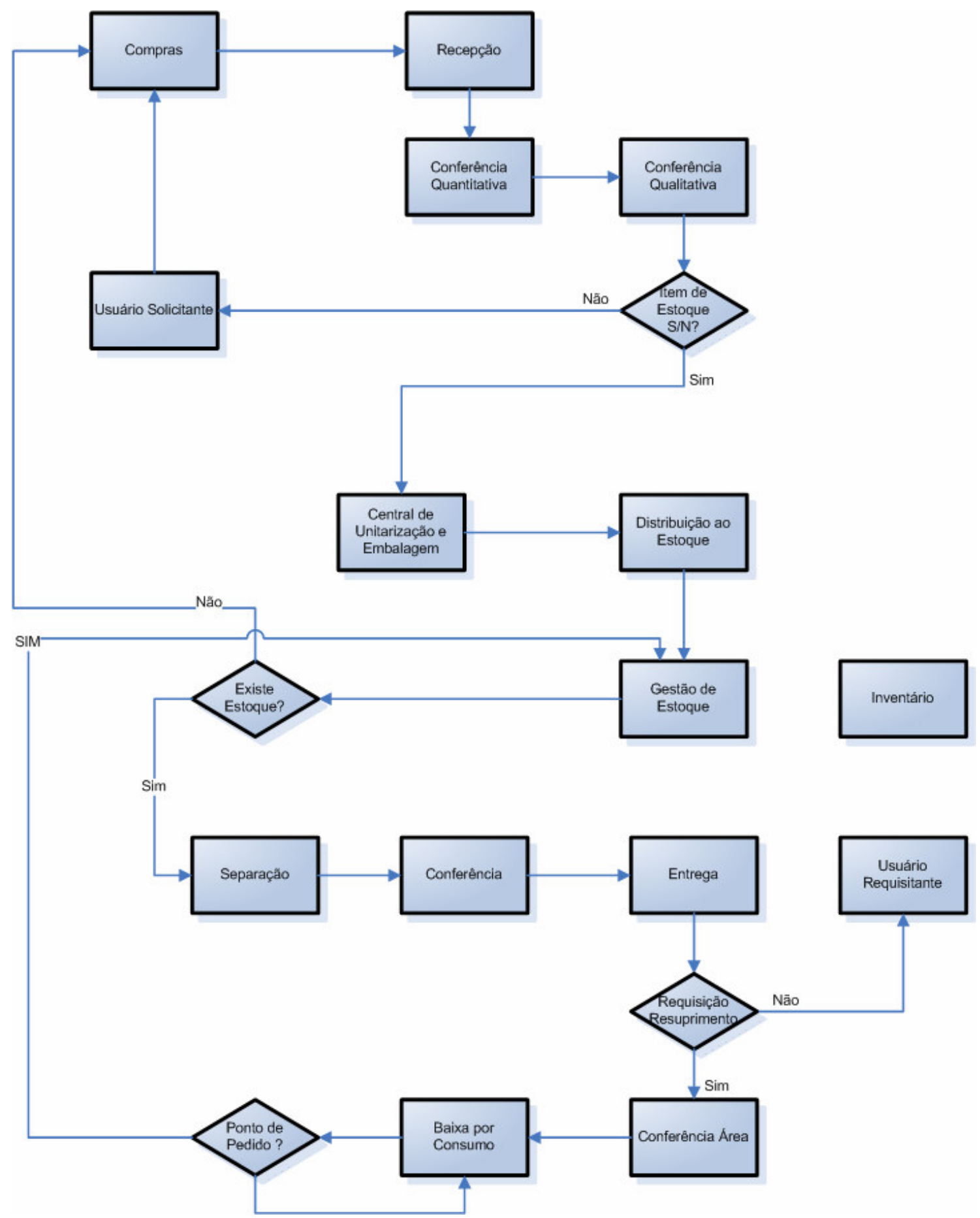

Figura 7. Fluxo do Processo Global do SGM, HU-USP, São Paulo - 2008 


\section{1. Área de Compras}

Para esta área, foram considerados os processos que envolvem desde a compra até a unitarização do material no hospital, cujo procedimento será detalhado a seguir.

Compras - foi realizado um cadastro de todos os itens no sistema, conforme suas características técnicas, determinadas em classes, subclasses e itens, permitindo uma descrição completa. Os itens possuem informações históricas necessárias para a gestão do estoque, tais como: ponto de reposição, quantidade máxima dispensada, movimentação mensal detalhada, custo unitário, custo médio, consumo mensal entre outras.

As necessidades de compras do hospital são controladas automaticamente pelo sistema, baseando-se em pontos de reposição, prazos de entrega, médias de consumo e a classificação $A B C$ e XYZ. Após a confirmação dos valores aprovados por item, o sistema realiza o processo de aquisição, conforme modalidade de compra adequada, transportando informações para o sistema de aquisição da Universidade (Sistema Mercúrio).

O SGM permite pesquisar e acompanhar as ordens de compra pendentes de várias formas: por número de ordem de compra, por fornecedor, por item, por data, etc. Qualquer local do hospital possibilita o profissional, desde que tenha acesso autorizado, a pesquisar e acompanhar o andamento do processo de Compras.

Recepção do material no hospital - o profissional responsável pelo recebimento do material no hospital, com a nota fiscal ou romaneio, localiza a ordem de compra no SGM e faz o lançamento do documento de entrada, preenchendo todos os campos necessários. Após o término do preenchimento, o sistema imprime uma cópia para ser colocado junto com a mercadoria para que possa ser executada as conferências quantitativas e qualitativas. 
- Conferência quantitativa: é executada por contagem de pacotes e amostragem. O responsável localiza os itens no sistema e informa o número do documento de entrada ou nota fiscal para registrar a quantidade contada e o motivo da divergência, quando houver.

- Conferência qualitativa: é realizada pelo setor responsável do material. A conferência pode ser parcial ou total e caso haja devolução, deverá ser registrado o motivo no sistema.

A continuidade do fluxo de materiais deve ser dado após todas as fases do recebimento do material concluídas, e enviado o material para a central de unitarização.

Unitarização e embalagem - o processo de unitarização inicia-se quando o responsável localiza o documento de entrada no sistema e solicita a impressão de etiquetas que deverão ser impressas de acordo com a quantidade dos itens descritos no documento de entrada. Após a etiquetagem, os profissionais devem executar a embalagem do produto, realizar a recontagem (Código de Barra) ou informar a nova quantidade embalada e destinar para a localização dentro do Estoque Central, conforme informado no sistema.

Para itens que não são controlados pelo estoque, o fluxo termina quando entrega o material ao solicitante, como mostra a Figura 8. 

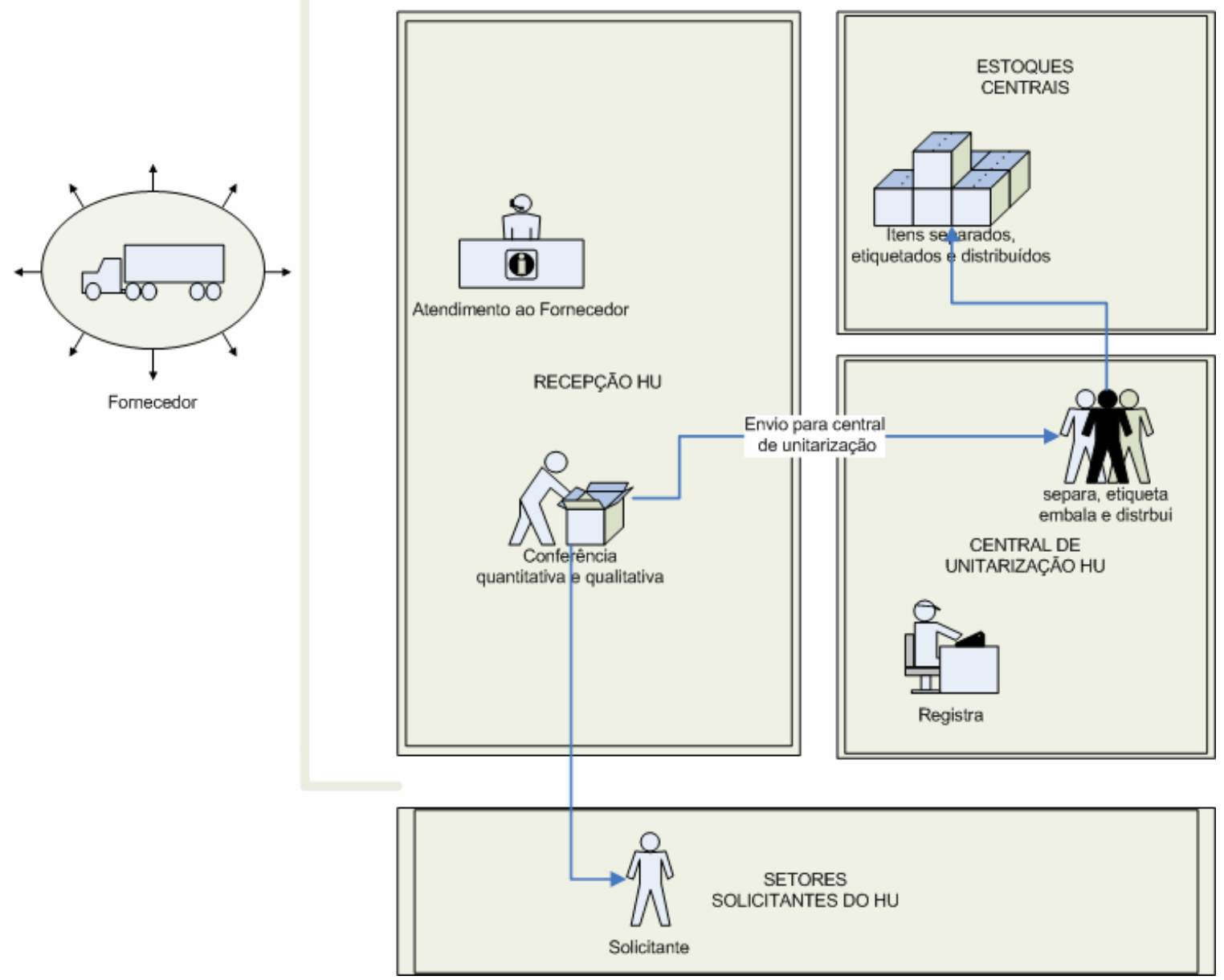

Figura 8. Fluxo de Central de Unitarização do HU-USP, São Paulo - 2008

\section{2. Área de Estoque}

Após a fase de unitarização, o material é enviado para o local de estoque para armazenamento.

O abastecimento de estoques e o atendimento de requisições estão relacionados com 80\% das tarefas diárias dos Estoques Centrais.

A rotina diária do Estoque Central inicia no relatório que indica o ressuprimento do material dos setores e Áreas de Suprimentos e termina quando o setor recebe o material e armazena-o em seu devido estoque, concluindo o ciclo da Àrea de Estoque, conforme demonstra a Figura 9, a seguir. 

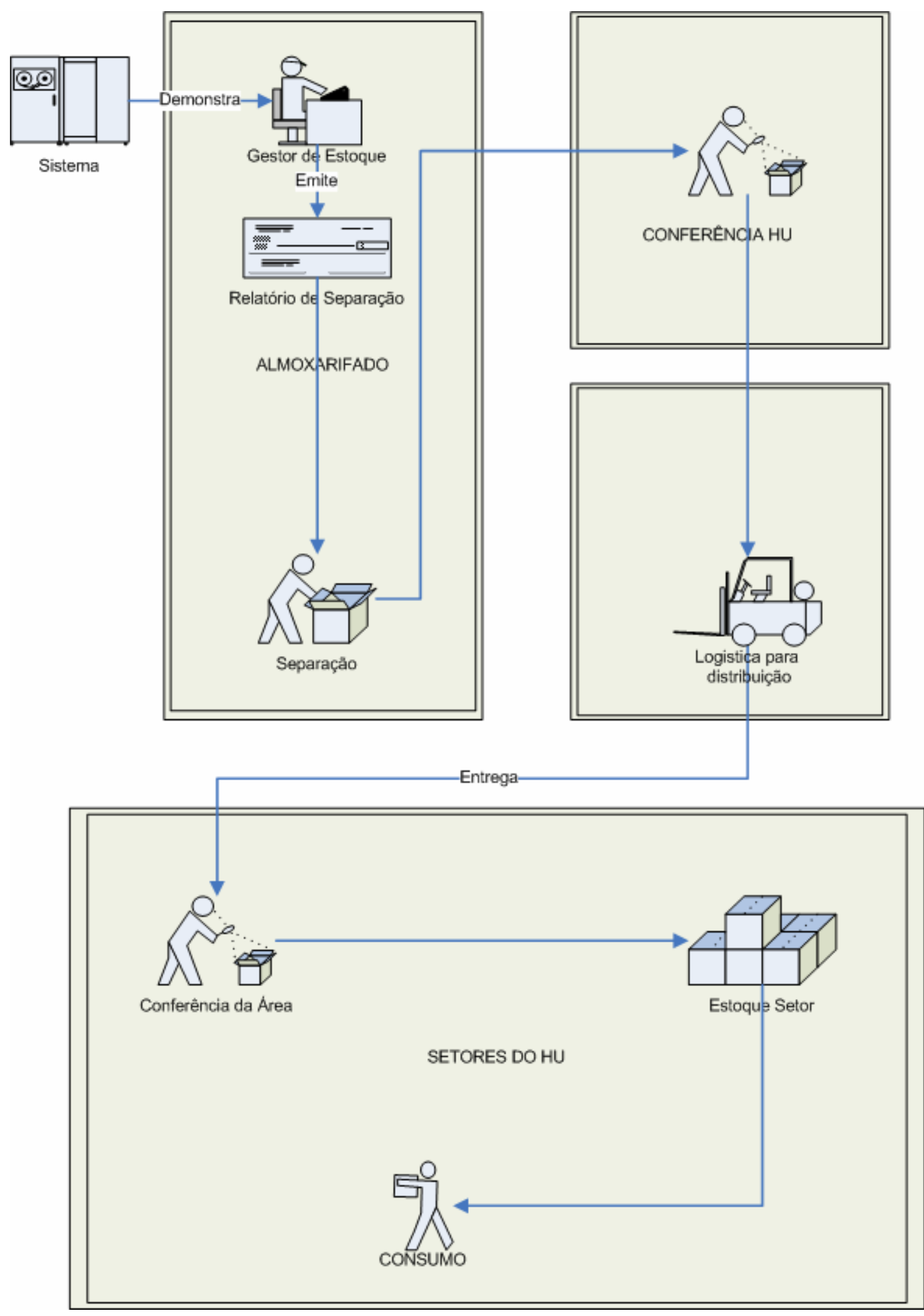

Figura 9. Fluxo de Área de Estoque e logística de distribuição do material no HU-USP, São Paulo - 2008 
Parece simples, porém, para que isso aconteça, devem ocorrer dois grupos de atividades: posições de quantidades em estoques sempre corretas e revisadas ("inventários") e o fluxo de baixa (consumo) pelos usuários dos setores. Dessa maneira, torna-se possível realizar a reposição do material por estoque mínimo.

Requisição de estoque mínimo - o gestor de estoque entra no sistema, localiza os itens faltantes por setor (o sistema apresenta ao gestor todos os itens faltantes nos estoques dos setores do $\mathrm{HU}$ naquele dia), ou por classe e subclasse (o gestor verifica os itens faltantes daquela classe em todos os estoques do $\mathrm{HU}$ ), seleciona os itens demonstrados e gera as listas para separação dos materiais de cada setor do $\mathrm{HU}$.

Separação - esta atividade contempla a separação de todos os itens pendentes de todos os setores e Área de Suprimentos.

Conferência - todos os itens separados deverão ser conferidos, onde o responsável deverá rever as quantidades de cada requisição, os lotes e embalar em pacotes com a devida identificação do setor e preparálos para distribuição.

Distribuição - a logística de distribuição de material deve ser realizada em um dia. Portanto, considerando os processos de separação, conferencia e distribuição, todos os setores recebem os itens com saldo abaixo do estoque mínimo em, no máximo, 48 horas.

Recebimento e conferência - os itens dos setores e das Áreas de Suprimentos devem ser recebidos, passar por uma conferência, onde irá verificar e lançar no sistema as quantidades, lotes e validades e posteriormente armazenar nos respectivos lugares.

Baixa de itens - esta atividade compreende o consumo do material. O consumo poderá ser ao paciente ou ao setor e registrado no sistema, em tempo real (on time). O material contém código de barras e, no momento do uso, o profissional do setor faz a leitura por meio de leitora óptica, informando ao SGM o item consumido, a quantidade e para qual paciente se destina. 
Lembrando-se que é o registro desse consumo que define a necessidade de ressuprimento dos itens no setor. Caso esta atividade não seja realizada no sistema, não haverá reabastecimento, o que poderá ocasionar a falta de material e problemas na compra do item.

Outra maneira de consumir o material é por meio da produção de kits hospitalares. Para a produção do kit, executam a baixa de itens, gerando um novo produto e que será tratado como um outro item de consumo.

Entende-se por produto o kit hospitalar que pode ser de medicamento, de cirurgia, de procedimento médico e de enfermagem.

Este processo de criação do kit hospitalar será detalhado como um processo diferenciado, respectivo da área de produção e que somente a Área de Suprimentos I do Centro Cirúrgico e o setor de Farmácia podem executar. Porém, nesta pesquisa será comentada a área de produção somente da Área de Suprimentos do Centro Cirúrgico.

\section{3. Área de produção}

Os fluxos da figura abaixo determinam o processo de trabalho da Área de Suprimentos do Centro Cirúrgico que executa a produção e transformação de itens, também conhecido como produto ou kit hospitalar. Basicamente existem três fluxos: 


\section{Processos referentes à Produção}
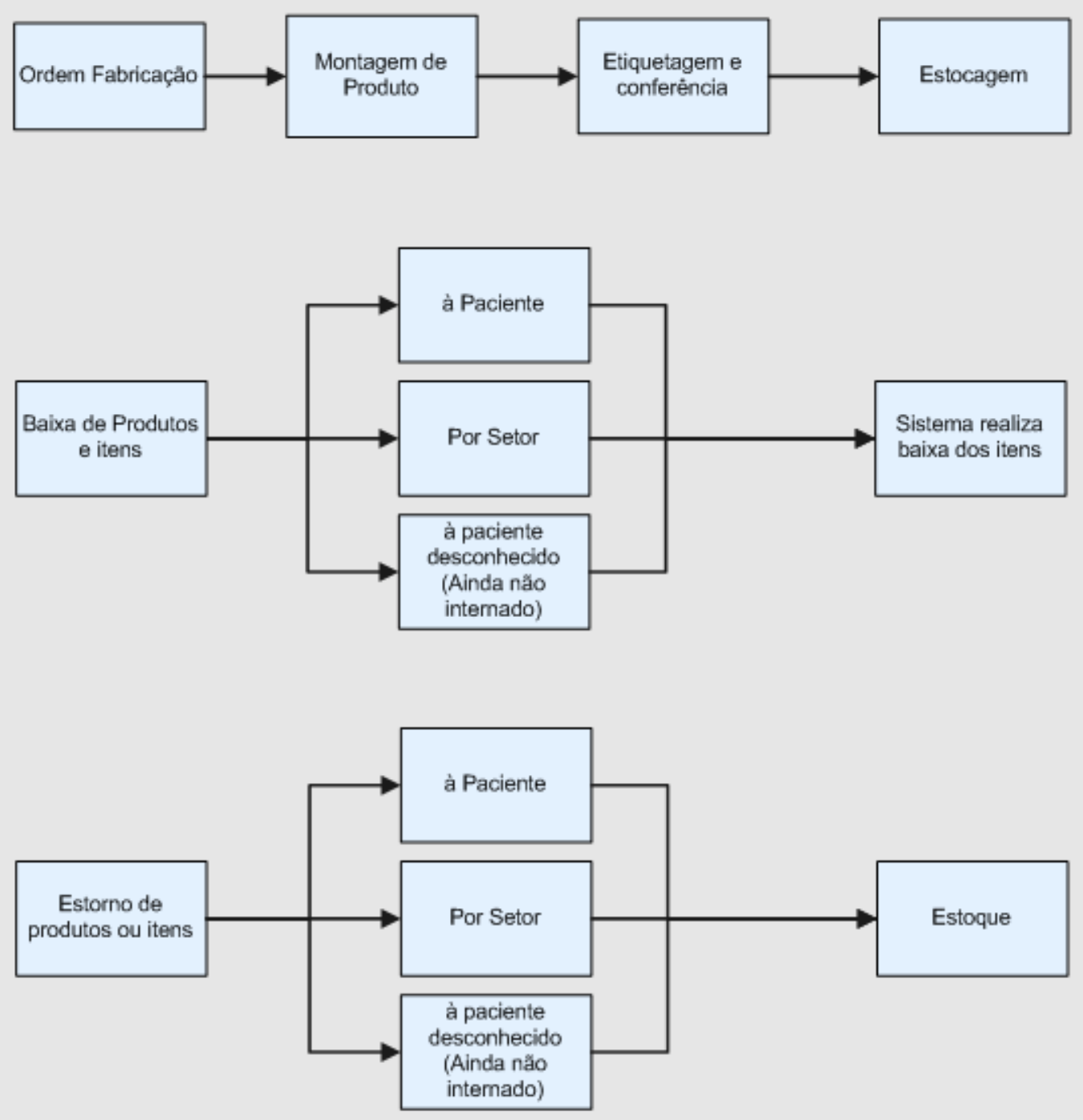

Figura 10. Fluxo de Processo da Área de Suprimentos I, HU-USP, São Paulo - 2008

Montagem do produto (kit) - esta atividade inicia-se com a ordem de fabricação. Baseado em uma programação cirúrgica é criada uma ordem de fabricação que determina qual é o produto $(k i t)$, e qual a quantidade a ser produzido. O profissional da AS-I deve separar os itens relacionados ao produto que deve ser montado, conferir e etiquetar com 
validade e lote. Após a montagem do produto,este será armazenado em um local do estoque indicado pelo sistema.

Baixa de produtos - deve ser realizada da mesma maneira que a baixa de um item de material, podendo ser à paciente, ao setor e à paciente desconhecido.

À paciente - o profissional da AS-I verifica a lista de pacientes do setor solicitante ou do agendamento de cirurgias, identifica o produto a ser entregue, emite a etiqueta "produto paciente" e dispensa ao solicitante 0 produto etiquetado com a identificação do paciente e do produto.

Ao setor - através de uma solicitação de item, o sistema demonstra os produtos existentes no estoque, o profissional da AS-I indica quais serão dispensados ao setor.

À paciente desconhecido - preocupados em atender os pacientes com risco eminente de vida, foi criada esta baixa para atender as cirurgias de emergências recebidas do setor de Pronto-Socorro, pois, na prática, não há tempo para fazer a internação antes da intervenção cirúrgica. Este caso tem o mesmo processo de baixa à paciente, porém, quando o paciente for identificado e internado, o profissional da AS-I deve alterar o registro de baixa.

Estorno de produtos - esta atividade foi contemplada no sistema tanto para itens como para produtos, pois pode acontecer de não consumir o material. Ela pode ser realizada à paciente e ao setor e à paciente desconhecido.

À paciente e ao setor - o profissional da AS-I recebe os itens devolvidos ou pertencentes ao produto (kit hospitalar) que não foram utilizados ou mesmo o produto inteiro.

À paciente desconhecido - esta atividade é a mesma do estorno à paciente, lembrando-se que o profissional da AS-I, além de receber os itens ou produto, terá que verificar se há mais de um paciente desconhecido registrado. 


\subsubsection{Implantação do Sistema de Gerenciamento de Materiais (SGM)}

A implantação do SGM iniciou desde a construção do próprio Sistema de Gestão de Materiais, com reuniões frequentes com todos os setores assistenciais. As reuniões tinham como objetivo discutir os problemas advindos do sistema tradicional utilizado no hospital, conhecer os processos de trabalho, rotinas e os desejos de cada setor. Foram apresentadas experiências de outros hospitais e todas as chefias participavam com sugestões e reflexões de como seria o novo sistema. Assim, foi ocorrendo a sensibilização e a conscientização de todos os envolvidos neste processo, com mudanças de paradigmas e quebra de culturas mantidas por muitos anos.

Para a implantação do SGM, foi realizada a padronização e a revisão de kits de procedimentos hospitalares. O setor de Centro Cirúrgico revisou todos os kits de cirurgia existentes (152), pois havia vários kits diferentes, compostos nos mesmos itens, subutilizados e sem padronização de linguagem. Foram alterados os conjuntos, elaborando kits que atendessem a vários procedimentos num mesmo grupo de especialidade. Assim alguns foram agrupados, outros, excluídos e outros sofreram pequenas alterações de acordo com a necessidade do serviço, reduzindo para 90 kits cirúrgicos (Machado, Yamaguchi, Paschoal, 2007).

Para os outros setores assistenciais, foram estabelecidos e padronizados os kits de procedimentos médicos e de enfermagem, como passagem de cateter de duplo lúmen e cateterismo vesical.

Outra atividade que antecedeu ao treinamento nos setores foi o cadastramento dos itens de materiais no SGM. Os materiais eram adquiridos e cadastrados sem padronização de linguagem, como, por exemplo, a cânula endotraqueal e a sonda de entubação traqueal, ambos os materiais são iguais. Para esta tarefa, foi discutido com os profissionais responsáveis de cada setor para fazerem a revisão e a padronização de todos os itens cadastrados no hospital e classificando-os em: classe, subclasse e item. 
O SGM é um sistema muito grande, complexo, abrangendo todos os setores e serviços, com mudança de cultura, no modo de pensar e agir sobre todos os materiais. Foi estabelecido para a implementação, iniciar com os Estoques Centrais (Almoxarifado, Nutrição e Farmácia), a Área de Suprimentos I, o setor de Compras e duas unidades, assistencial e administrativa (Centro Cirúrgico e Informática), com o objetivo de testar todo o ciclo do Sistema de Gestão de Materiais.

Como a metodologia de implantação empregada foi a mesma para todos os setores e serviços do hospital, será comentada somente a Área de Suprimentos I (AS-I), localizada no Centro Cirúrgico.

Metodologia de implantação do SGM:

- Elaboração de um cronograma de reuniões para todos os profissionais do Centro Cirúrgico para apresentar o sistema e prepará-los para o treinamento.

- Realização de uma revisão do cadastro de todos os profissionais para acessar o computador. Embora no hospital a informatização e o acesso aos microcomputadores são bastante disseminados, para alguns foi preciso receber um treinamento individual sobre noções básicas de informática e até aplicar como estratégia, jogos interativos para coordenação motora.

- Estabelecimento da data de inicio do SGM, o cronograma dos inventários e as reuniões semanais para o acompanhamento da implantação.

- Estabelecimento de uma equipe de profissionais fixos para assumir a AS-I e um grupo de profissionais do setor de Informática nos períodos da manhã, tarde e noite para ensinar, orientar, esclarecer dúvidas e dar aulas teóricas sobre o funcionamento das telas do sistema.

A equipe de profissionais estabelecida para assumir a AS-I foi composta de:

- Administrador de sistema - responsável pelo controle operacional, carga e manutenção das tabelas de parametrização que permite acesso e administra a utilização no sistema das operações dos demais usuários. 
- Técnico de enfermagem - responsável pela montagem de produtos (kits cirúrgicos), baixa (consumo) e estorno de itens de materiais e produtos, coordenação e controle de estoque de materiais.

- Enfermeiro - responsável por coordenar toda a equipe do Centro Cirúrgico e orientar quanto ao fluxo da Gestão de Materiais.

O SGM foi desenvolvido tendo a preocupação e o cuidado de construir um sistema flexível, não restritivo para o uso do material e telas com um protótipo de fácil utilização para que o usuário não tivesse resistência em fazer uso do sistema de informação.

O treinamento foi realizado para todos os profissionais de enfermagem, iniciando pela equipe fixa que foi definida para trabalhar na AS-I.

Eles receberam aulas teóricas sobre o SGM em pequenos grupos e aulas práticas das telas do sistema com acompanhamento da equipe de informática. O conteúdo do treinamento foi aplicado conforme o manual explicativo do SGM (Anexo 1).

O Conteúdo programático do manual do SGM do Centro Cirúrgico é composto de:

- solicitação, montagem de kit cirúrgico e anestésico;

- fornecimento de kit cirúrgico e anestésico para cirurgia (distribuição e baixa do kit para consumo);

- fornecimento de item avulso (distribuição e baixa do item para consumo);

- devolução de kits (devolução de materiais dos kits cirúrgicos e anestésicos que a AS-I produziu e dispensou);

- devolução de item avulso (devolução de materiais para a AS-I).

Todos apresentaram interesse em aprender e atender com rapidez e presteza às solicitações dos materiais para as cirurgias e contribuir com sugestões e mudanças de processo de trabalho, começando pelo local de armazenamento dos materiais. A equipe encontrou dificuldade em 
localizar os materiais, pois, com a revisão dos materiais para o cadastro, alguns materiais sofreram alteração do nome.

Embora a reestruturação do local de armazenagem de materiais e dos processos de trabalho desenvolvidos naquela área fosse de extrema necessidade para a implantação do novo sistema, não foi preciso sugerir, pois a própria equipe de enfermagem do Centro Cirúrgico detectou a necessidade e optou rever todos os processos, tomando algumas medidas.

Os materiais e instrumentais esterilizados vindos da Central de Material e Esterilização foram retirados da AS-I.

$\mathrm{Na}$ Área de Suprimentos I, ficou um local de armazenagem de materiais recebidos do Estoque Central do Almoxarifado, organizados em prateleiras, por ordem alfabética e identificada com os nomes antigos ao lado dos nomes atuais em letras grandes e legíveis, uma área de produção e uma área distinta para estoque e distribuição dos itens de materiais e produtos.

Outra medida tomada foi quanto à atitude de a equipe não permitir a entrada de pessoas além daquelas autorizadas naquela área. Foi delimitada a Área de Suprimentos I com barreira física e orientou-se a todos, da equipe médica e de enfermagem, sobre a nova rotina de solicitação de material para as cirurgias.

No primeiro inventário, a equipe realizou a contagem de todo o material existente no Centro Cirúrgico e cadastrou no SGM. A partir deste momento, nenhum material pôde ser consumido no Centro Cirúrgico sem informar ao sistema, entretanto, em alguns momentos, devido à extrema necessidade do material na sala de cirurgia e pela equipe não estar apta e ágil, foi dispensado algum material com anotação manual, para posterior alimentação no SGM. Não foi possível informar ao sistema os materiais anotados manualmente, pois não foram anotados todos os dados, impossibilitando sua localização no sistema para posterior registro de consumo. Esta situação foi corrigida pela equipe que percebeu que para 0 sistema funcionar, ou seja, não ter a falta do material é preciso que a quantidade de material existente no Centro Cirúrgico seja a mesma 
informada no SGM, pois a reposição é realizada automaticamente pelo sistema. Portanto é preciso alimentar o SGM On time, em tempo real.

No início, foi possível observar pequenas resistências em relação ao novo sistema. Esta situação era esperada entre as equipes, justificada pela mudança radical que o SGM traria para o Centro Cirúrgico, com o registro e controle dos materiais consumidos.

A equipe de enfermagem estava acostumada a realizar a montagem dos kits sem aplicar uma metodologia de produção, baseada na experiência vivenciada nas cirurgias. Colocava materiais além e aquém do que o kit cirúrgico pedia e acrescentava itens que não faziam parte. Foi reorientada e reforçada a importância de seguir passo a passo a montagem de produção que o sistema exigia para cada profissional que apresentava este problema.

Com isso, a equipe de enfermagem teve um acompanhamento, durante um certo tempo, para a montagem do kit, explicando as possíveis falhas que apresentariam se não seguisse a seqüência sugerida pelo sistema. Este problema foi visto como um período de adaptação necessário do funcionário ao SGM. Para isso, foi preciso primeiro observar o funcionamento do sistema, para depois acreditar e confiar. Para os funcionários mais resistentes, foram acompanhados por mais tempo no treinamento, e alguns foram convidados para serem agentes multiplicadores e apresentar o SGM para outros setores do hospital.

Para alguns profissionais da equipe de anestesiologia foi preciso um período maior para adaptação das mudanças derivadas do novo sistema implantado, pois estavam acostumados a ter todo o material em gavetas dentro da sala de operação (SO) e passaram a ter o material acondicionado em caixas plásticas. Para estes profissionais, os enfermeiros do setor optaram por conscientizar um a um, esclarecendo dúvidas sobre o SGM. A equipe cirúrgica recebeu o sistema de forma colaborativa, talvez porque sempre o material foi para a sala em forma de kit disposto em carro e agora acondicionado em caixas, não apresentando alterações para ele. 
4 QUESTÃO DA PESQUISA 
As questões de pesquisa são:

- Qual é a quantidade e o custo dos materiais médicohospitalares utilizados antes e após a implantação do Sistema de Gestão de Materiais (SGM) no setor de Centro Cirúrgico do HU-USP?

- Qual é a quantidade e o custo do estoque de materiais médico-hospitalares antes e após a implantação do Sistema de Gestão de Materiais (SGM) no setor de Centro Cirúrgico do HU-USP? 


\section{OBJETIVOS}




\section{Objetivo Geral}

- Comparar a eficácia do Sistema de Gestão de Materiais informatizado em relação ao Sistema Tradicional quanto ao consumo e estoque de materiais no setor de Centro Cirúrgico do HU-USP.

\section{Objetivos Específicos}

- Comparar o consumo e o custo dos materiais médicohospitalares antes e após a implantação do Sistema de Gestão de Materiais informatizado.

- Identificar o consumo de materiais dos kits cirúrgicos e anestésicos após a implantação do Sistema de Gestão de Materiais informatizado.

- Comparar a quantidade e o custo dos materiais médicohospitalares estocados antes e após a implantação do Sistema de Gestão de Materiais informatizado. 
6 METODOLOGIA 


\subsection{TIPO DE PESQUISA}

Trata-se de uma pesquisa comparativa com abordagem quantitativa.

Nessa pesquisa, foram comparados dois modelos de gestão de materiais, usualmente utilizados em organizações hospitalares. O primeiro é o modelo tradicional, com controle manual e com reposição de estoque por complementação de uma quantidade preestipulada (cota), adotado pelo HUUSP desde 1981. O segundo modelo, implementado em 2008, com gestão informatizada e reposição de estoque segundo os princípios do Just in Time.

As variáveis dependentes estudadas para comparar a eficácia dos dois modelos foram a quantidade e o custo dos materiais consumidos e estocados no setor de Centro Cirúrgico. As variáveis intervenientes levantadas foi o número de procedimentos cirúrgicos realizados no período do estudo, as intercorrências no intraoperatório e as características dos pacientes, uma vez que o consumo de material e, consequentemente, seu custo poderiam sofrer alterações dessas variáveis.

No período do estudo, não houve modificações na equipe médica cirúrgica e nem nas técnicas das cirurgias mais realizadas.

\subsection{CAMPO DE ESTUDO}

O estudo foi desenvolvido no setor do Centro Cirúrgico do Hospital Universitário da Universidade de São Paulo (HU-USP).

O HU-USP foi inaugurado em 1981 e tem por finalidade promover o ensino, a pesquisa e a extensão da assistência à saúde à comunidade.

Localizado no campus da USP, numa área física de $36.000 \mathrm{~m}^{2}$, na região do Butantã da cidade de São Paulo, o HU-USP dispõe de 243 leitos distribuídos nas quatro especialidades básicas: médica, cirúrgica, obstétrica e pediátrica. 
A população atendida pelo hospital é constituída pela comunidade USP que compreende corpo docente, discente e servidores da Universidade de São Paulo, incluindo seus dependentes. É referência secundária dentro da regionalização e do Sistema Único de Saúde (SUS), atendendo a população da zona Oeste de São Paulo, de aproximadamente 400.000 habitantes.

Os recursos financeiros são provenientes da dotação orçamentária da USP e dos serviços prestados ao Sistema Único de Saúde (SUS).

Os órgãos da Administração Superior do HU-USP são o Conselho Deliberativo (CD) e a Superintendência. O CD é composto pelos diretores da Faculdade de Medicina, Faculdade de Ciências Farmacêuticas, Faculdade de Saúde Pública, Faculdade de Odontologia, Escola de Enfermagem, Instituto de Psicologia, pelo superintendente do HU-USP, pelos representantes discente e não docente da USP e por um representante dos usuários do Distrito de Saúde do Butantã. O CD tem como finalidade definir diretrizes básicas da assistência médico-hospitalar, de pesquisa e de cooperação didática. A Superintendência, constituída por um superintendente e assessores, é o órgão de direção executiva que coordena, supervisiona e controla todas as atividades do HU-USP. Diretamente ligados à Superintendência, ficam o Departamento Médico (DM), o Departamento de Enfermagem (DE) e a Diretoria Administrativa (DA). Todos têm a finalidade de coordenar, supervisionar e controlar as atividades desenvolvidas nas áreas médicas, de enfermagem e administrativas a eles respectivamente subordinadas (Gualda, 2001;Universidade de São Paulo,2001).

A Diretoria Administrativa apresenta sob sua responsabilidade os setores de Compras, de Almoxarifado e de Finanças.

O Departamento Médico e o de Enfermagem subdividem-se em quatro divisões: Clínica Médica, Clínica Cirúrgica, Clínica Obstétrica e Clínica Pediátrica. Essas quatro divisões congregam treze setores, sendo o setor de Centro Cirúrgico subordinada à Divisão de Clínica Cirúrgica. 


\subsubsection{Setor de Centro Cirúrgico}

O setor de Centro Cirúrgico prevê recursos materiais e humanos para a realização do procedimento anestésico-cirúrgico e presta assistência a pacientes da Unidade de Internação, Ambulatório e Seção de Emergência. Mantém comunicação com as áreas acima citadas, através de um agendamento cirúrgico diário que estabelece cirurgias programadas, extraprogramas e urgências nas seguintes especialidades: geral, urológica, infantil, tórax, vascular, plástica, ortopedia, otorrinolaringologia, oftalmologia, ginecologia, endoscopia e buco-maxilo.

O agendamento cirúrgico é realizado em um sistema informatizado (módulo GCC - Gestão de Centro Cirúrgico) e possibilita o acesso à intenção cirúrgica por todos os usuários da rede. As cirurgias são agendadas pelo próprio cirurgião, e o material necessário para as intervenções é programado diretamente pelo enfermeiro do Centro Cirúrgico.

Considerando o movimento de cirurgias agendadas no hospital, a maioria é da especialidade de cirurgia geral, seguidas da ortopedia e ginecologia (Universidade de São Paulo,2007; Universidade de São Paulo,2008).

O Centro Cirúrgico realiza, em média, 420 cirurgias mensais e possui cerca de 490 itens de materiais, resultando em um custo anual de aproximadamente de $\mathrm{R} \$ 2.060 .000,00$.

O Centro Cirúrgico está localizado no segundo andar e dispõe de 9 salas de cirurgias ativadas, 7 leitos de recuperação anestésica, uma área física destinada para estoque de material de consumo e conta com a interação e o apoio do setor de Almoxarifado. Esta área de estoque de materiais possui, sob a supervisão e orientação do enfermeiro, um técnico de enfermagem, responsável para receber 0 material do setor de Almoxarifado, armazenar, produzir kit, controlar e dispensar o material necessário para as salas de cirurgias e sala de recuperação anestésica. 


\subsection{POPULAÇÃO E AMOSTRA}

A população do estudo foi constituída de 400 itens de materiais médico-hospitalares utilizados no setor de Centro Cirúrgico do HU-USP (Anexo 2).

Para o estudo do consumo e do estoque de material antes e após a implantação do SGM, foram analisados apenas 293 materiais, pois não foi possível obter todos os dados dos 400 itens no ano de 2007 (Apêndice1). Para o estudo do consumo de materiais dos 81 kits, trabalhou-se com os 400 itens.

\subsection{COLETA DE DADOS}

\subsubsection{Instrumento de coleta de dados}

Os instrumentos de coleta de dados foram elaborados em forma de planilhas.

A primeira planilha foi elaborada para o levantamento do movimento cirúrgico e a caracterização do paciente contendo data, nome da cirurgia, quantidade e porte da cirurgia, idade, sexo, classificação do grau de estado físico do paciente e intercorrência no intraoperatório (Apêndice 2).

A segunda planilha foi elaborada com o objetivo de levantar o consumo do material, compreendendo os seguintes dados: data, código, nome do material, quantidade do material consumido e o custo unitário (Apêndice 2).

A terceira planilha teve a finalidade de levantar os kits cirúrgicos e anestésicos e os materiais consumidos contendo a data, nome do kit, quantidade dispensada, estornada, consumida, nome e quantidade do material consumido do kit e o custo unitário do material que compõe o kit (Apêndice 2). 
Por fim, na quarta planilha constam os dados sobre o estoque de materiais, contendo data, nome do material estocado, quantidade mínima de material estocado, quantidade de abastecimento de material no estoque e o custo unitário do material (Apêndice 2).

\subsubsection{Procedimentos para coleta de dados}

A coleta de dados foi realizada após a aprovação da Câmara de Pesquisa do HU-USP (Anexo 3).

O período da coleta de dados foi de 01 de fevereiro a 31 de maio de 2007 e 01 de fevereiro a 31 de maio de 2008, totalizando um período de 4 meses anterior à implantação do Sistema de Gestão de Materiais e 4 meses após 44 dias do início da implantação do SGM.

Para a coleta de dados, os responsáveis do Almoxarifado, do Centro Cirúrgico e do Serviço de Informática receberam esclarecimentos sobre os objetivos do estudo e, assim, poderem auxiliar na coleta.

A fonte de consulta de dados dos materiais médico-hospitalares foram as planilhas com os registros de movimentação de material de consumo, fornecidas pelo Almoxarifado, Centro Cirúrgico e o Serviço de Informática.

Para o levantamento do custo dos materiais médico-hospitalares, foram utilizados registros do setor de Almoxarifado e Setor de Informática.

Para a obtenção de dados dos kits cirúrgicos e anestésicos, da cirurgia e da caracterização do paciente, foram consultadas ao sistema Apolo do Módulo de Gestão de Centro Cirúrgico informatizado (GCC) e ao serviço de Informática do Hospital. 


\subsection{TRATAMENTO E ANÁLISE DOS DADOS}

Os dados coletados foram inseridos em um banco de dados eletrônico do Programa Excel para tratamento e apresentação. Foi utilizada estatística descritiva para sintetizar e apresentar os dados em tabelas e figuras, utilizando-se a frequência absoluta e percentual.

Inicialmente, todas as variáveis foram analisadas descritivamente.

Para as variáveis quantitativas, esta análise foi feita através da observação: dos valores mínimos e máximos, do cálculo de médias, do desvio padrão e da mediana.

Para as variáveis qualitativas, calcularam-se frequências absolutas e relativas.

Para a comparação de médias de dois grupos, foi utilizado o teste t de Student, quando a suposição de normalidade dos dados foi rejeitada foi utilizado o teste não-paramétrico de Mann-Whitney.

Para a comparação dos momentos pré e pós-implantação do sistema, foi utilizado o teste não-paramétrico de Wilcoxon, pois a suposição de normalidade dos dados foi rejeitada.

Para se testar a homogeneidade entre as proporções, foi utilizado o teste qui-quadrado.

O nível de significância utilizado para os testes foi de $5 \%$. 
7 ANÁLISE DOS DADOS

(1) ANALE DOS DADOS 


\subsection{CARACTERIZAÇÃO DO MOVIMENTO CIRÚRGICO NO PERÍODO ESTUDADO}

\subsubsection{Número de cirurgias realizadas}

No período da coleta de dados, foi realizado um total de 3.036 cirurgias, sendo que 1.581 procedimentos foram realizados no ano de 2007 e 1.455 cirurgias foram realizadas em 2008. Sendo que as cirurgias que mais foram realizadas no HU-USP foram da especialidade de cirurgia geral. As cirurgias mais realizadas nos dois anos foram: apendicectomia com $76(4,8 \%)$ em 2007 e 94(6,5\%) em 2008; laparotomia exploradora com 63(4,0\%) em 2007 e 90(6,2\%) em 2008; colecistectomia vídeo laparoscópica com 81(5,1\%) em 2007 e 70(4,8\%) em 2008; e herniorrafia inguinal unilateral nos dois anos, respectivamente, com 55(3,65\%) e 56(3,8\%) (Apêndice 3).

$\mathrm{Na}$ Tabela 2, demonstra a quantidade de cirurgias distribuídas nos meses da coleta de dados.

Tabela 2 - Número de cirurgias de fevereiro a maio de 2007 e 2008, São Paulo 2008

\begin{tabular}{lrrr}
\hline \multicolumn{1}{c}{ MÊS } & 2007 & 2008 & \% DE REDUÇÃO \\
\hline Fevereiro & 353 & 333 & \\
Março & 435 & 380 & \\
Abril & 358 & 401 & \\
Maio & 435 & 341 & \\
\hline Média & $\mathbf{3 9 5 , 2 5}$ & $\mathbf{3 6 3 , 7 5}$ & \\
dp & $\mathbf{4 5 , 9 4}$ & $\mathbf{3 2 , 2 2}$ & $\mathbf{7 , 9 7}$ \\
Mediana & $\mathbf{3 9 6 , 5 0}$ & $\mathbf{3 6 0 , 5 0}$ & \\
\hline
\end{tabular}

O total de cirurgias realizadas em 2007 foi maior do que o total de cirurgias de 2008, entretanto ao comparar os valores da média, mediana e o desvio padrão não encontra diferença significativa entre o número de cirurgias dos anos de 2007 e 2008. 
Embora os dados não revelem uma diferença significativa entre o número de cirurgias, foi aplicado o teste não-paramétrico de Mann-Whitney para demonstrar de outra maneira o resultado acima, sendo obtido o seguinte valor:

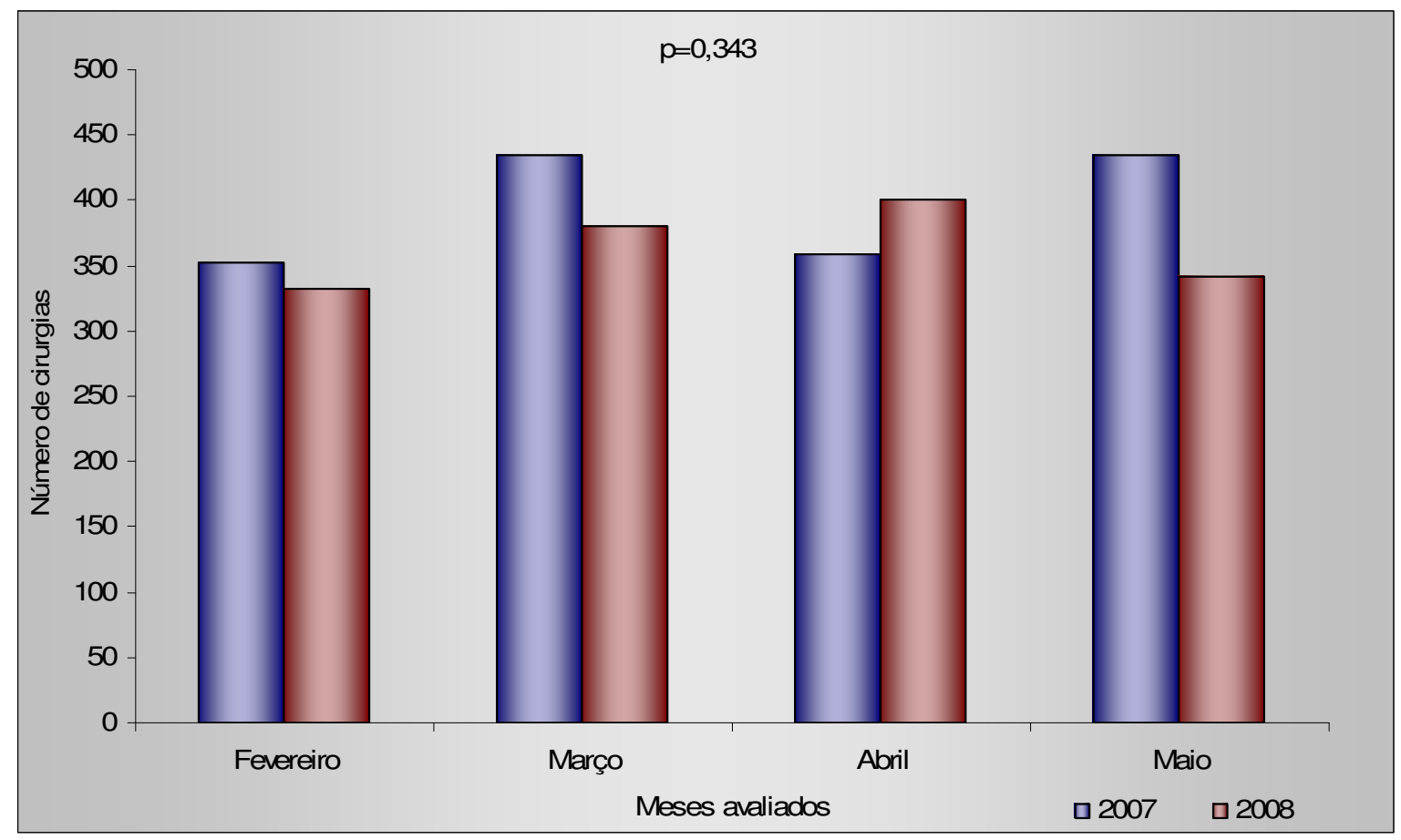

Figura 11. Distribuição do número de cirurgias de fevereiro a maio de 2007 e 2008, São Paulo - 2008

Na Figura 1, demonstra que, nos quatro meses da coleta de dados, ao aplicar o teste não-paramétrico de Mann-Whitney $(p=0,343)$ não há diferença estatística do número de cirurgias de 2007 e 2008.

Assim, apesar de que, numericamente, apresente uma quantidade diferente de cirurgias realizadas em 2007 e 2008, não foi encontrada diferença representativa entre o número de cirurgias.

\subsubsection{Caracterização dos pacientes}

Para a caracterização dos pacientes no período estudado, foram avaliadas as variáveis: idade, sexo, estado físico do paciente, porte de cirurgia e presença ou não de intercorrência durante a cirurgia. 
Na Tabela 3, observa-se que a idade média, nos 2 anos, foi 41,83 e 41,70 respectivamente, não havendo diferença em 2007 e 2008.

Tabela 3 - Valores do número de cirurgias, média, desvio padrão, mediana, mínimo e máximo da idade dos pacientes, segundo os anos de estudo, São Paulo - 2008

\begin{tabular}{cccccccc}
\hline ANO & $\begin{array}{c}\text { No } \\
\text { CIRURGIAS }\end{array}$ & MÉDIA & DP & MEDIANA & $\begin{array}{c}\text { IDADE } \\
\text { MíNIMA }\end{array}$ & $\begin{array}{c}\text { IDADE } \\
\text { MÁXIMA }\end{array}$ & P $^{*}$ \\
\hline 2007 & 1.581 & 41,83 & 24,34 & 42 & 1 mês & 99 anos & 0,882 \\
2008 & 1.455 & 41,70 & 23,85 & 42 & 1 mês & 98 anos & \\
\hline
\end{tabular}

$\left(^{\star}\right)$ nível descritivo de probabilidade do teste t de Student.

Para a variável sexo, há um predomínio do paciente masculino em ambos os anos, com $52 \%$ e $54 \%$ respectivamente.

Quanto ao estado físico, medido pela Classificação das Condições Físicas da American Society of Anesthesiologists (ASA), com escala de 1 a 6 , foram encontrados nos dois períodos, respectivamente, $52 \%$ e $55,6 \%$ dos pacientes na classificação 1 , na qual são graduados os pacientes saudáveis, sem distúrbio fisiológico, psicológico, bioquímico ou orgânico.

Em relação ao porte de cirurgias realizadas em 2007 e 2008, foram encontradas $52,0 \%$ e $52,4 \%$, respectivamente, de pequeno porte seguido de médio (36,5\% e 35,9\%) e de grande, com 11,5\% em 2007 e 11, $8 \%$ em 2008.

A Tabela 4 demonstra que, para essas três variáveis, não foi encontrada diferença significativa nos anos de 2007 e 2008.

Os anos diferem em relação à presença de intercorrência durante a cirurgia. O ano de 2008 apresenta uma porcentagem significativamente maior de casos (teste qui-quadrado de $<0,001$ ) do que o ano de 2007 . Foi levantado somente se havia presença de intercorrências ou não no intraoperatório, não sendo tratado o conteúdo para os casos que apresentaram sim. Talvez a justificativa para o dado encontrado na Tabela 6 possa ser atribuída a uma melhor notificação pelos médicos. 
Tabela 4 - Frequências absolutas e relativas das variáveis que caracterizam os pacientes, segundo o ano de estudo, São Paulo - 2008

\begin{tabular}{|c|c|c|c|c|c|c|}
\hline \multirow{3}{*}{ VARIÁVEL } & \multirow{3}{*}{ CATEGORIA } & \multicolumn{4}{|c|}{ ANO } & \multirow[b]{3}{*}{$p^{*}$} \\
\hline & & \multicolumn{2}{|c|}{2007} & \multicolumn{2}{|c|}{2008} & \\
\hline & & $\mathrm{n}$ & $\%$ & $n$ & $\%$ & \\
\hline \multirow{2}{*}{ Sexo } & Feminino & 758 & 47,9 & 669 & 46,0 & \multirow{2}{*}{0,278} \\
\hline & Masculino & 823 & 52,1 & 786 & 54,0 & \\
\hline \multirow{6}{*}{$\begin{array}{l}\text { Estado físico do } \\
\text { paciente }\end{array}$} & 1 & 594 & 55,6 & 492 & 52,0 & \multirow{6}{*}{0,223} \\
\hline & 2 & 338 & 31,6 & 331 & 35,0 & \\
\hline & 3 & 109 & 10,2 & 106 & 11,2 & \\
\hline & 4 & 23 & 2,2 & 11 & 1,2 & \\
\hline & 5 & 4 & 0,4 & 6 & 0,6 & \\
\hline & 6 & 1 & 0,1 & 1 & 0,1 & \\
\hline \multirow{3}{*}{ Porte de cirurgia } & Grande & 181 & 11,5 & 171 & 11,8 & \multirow{3}{*}{0,919} \\
\hline & Médio & 577 & 36,5 & 522 & 35,9 & \\
\hline & Pequeno & 821 & 52,0 & 762 & 52,4 & \\
\hline \multirow{2}{*}{ Intercorrências } & Sim & 55 & 3,5 & 122 & 8,4 & \multirow{2}{*}{$<0,001$} \\
\hline & Não & 1.524 & 96,5 & 1.331 & 91,6 & \\
\hline
\end{tabular}

${ }^{*}{ }^{*}$ nível descritivo de probabilidade do teste qui-quadrado.

\subsection{AVALIAÇÃO DO CONSUMO E DO CUSTO DO MATERIAL NO PERÍODO ESTUDADO}

No período de coleta de dados, foram levantados 400 itens de materiais. Destes, não foi possível obter dados de 107 materiais em 2007. Portanto, para a comparação dos materiais dos anos de 2007 e 2008 foram estudados apenas 293 itens de materiais.

\subsubsection{Comparação do consumo e do custo mensal do material}

Para a análise do consumo de materiais, foi comparado o número de itens nos quatro meses estudados de 2007 e de 2008.

$\mathrm{Na}$ Tabela 5, temos o consumo total, por mês, em cada ano, demonstrando uma tendência de diminuição (redução de 8,13\%), com exceção do mês de abril que apresentou um aumento do consumo do material (44.615 para 44.809) no ano de 2008, possivelmente devido ao 
aumento de cirurgias apresentadas neste mês. Entretanto, quando comparados os valores da média, desvio padrão, mediana e aplicado o teste não-paramétrico de Mann-Whitney $(p=0,486)$, não foi observada diferença estatística entre os consumos dos anos de 2007 e 2008.

Tabela 5 - Total de itens consumidos em cada mês nos anos de 2007 e 2008, São Paulo - 2008

\begin{tabular}{lrrr}
\hline \multicolumn{1}{c}{ MÊS } & 2007 & \multicolumn{1}{c}{2008} & \% DE REDUÇÃO \\
\hline Fevereiro & 36.947 & 32.207 & \\
Março & 50.418 & 40.721 & \\
Abril & 44.615 & 44.809 & \\
Maio & 47.034 & 46.724 & \\
\hline Média & $\mathbf{4 4 . 7 5 3 , 5 0}$ & $\mathbf{4 1 . 1 1 5 , 2 5}$ & $\mathbf{8 , 1 3}$ \\
dp & $5.722,70$ & $\mathbf{6 . 4 4 5 , 0 0}$ & \\
Mediana & $\mathbf{4 5 . 8 2 4 , 5 0}$ & $\mathbf{4 2 . 7 6 5 , 0 0}$ & \\
\hline
\end{tabular}

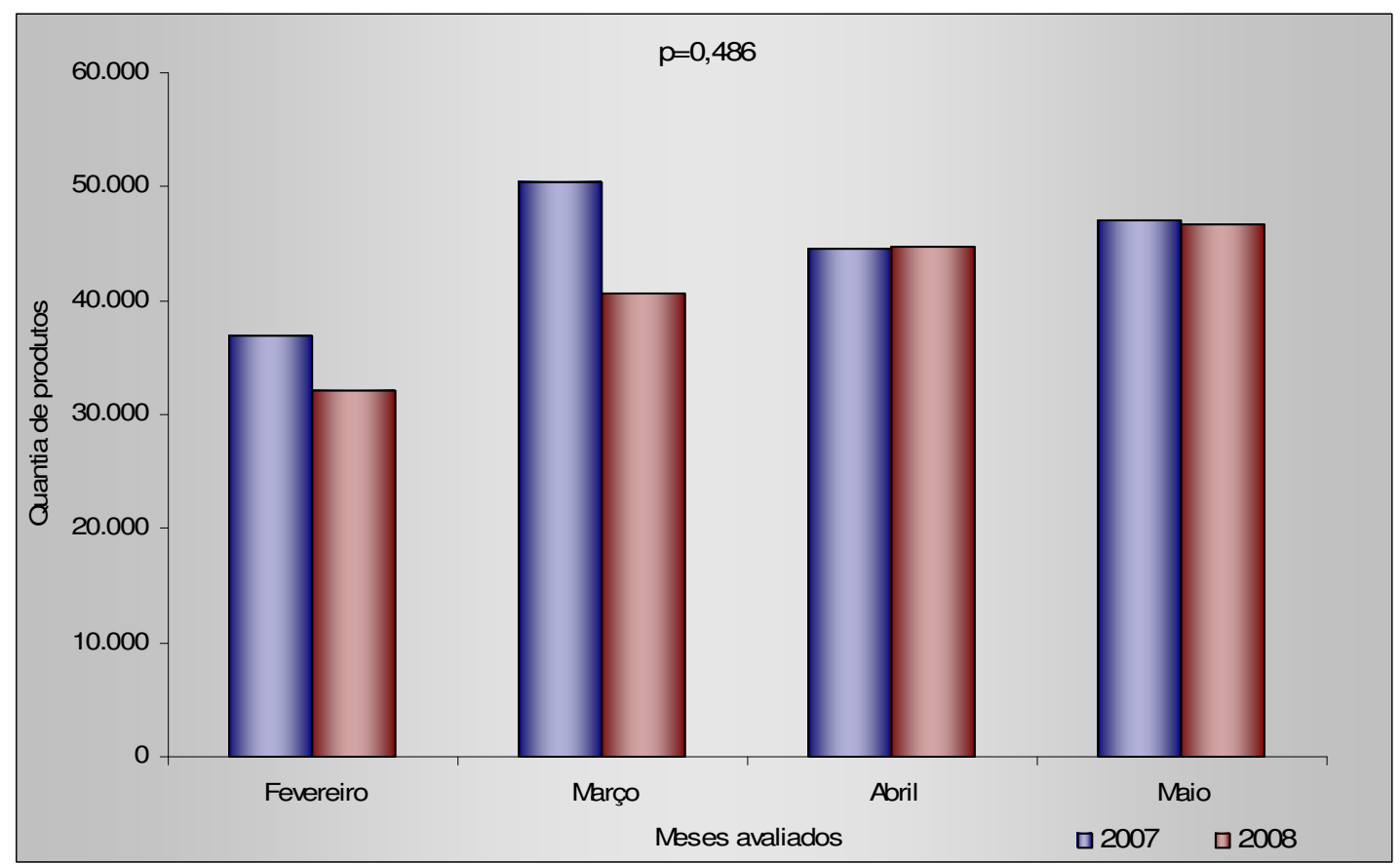

Figura 12. Total de itens consumidos em cada mês nos anos avaliados, São Paulo - 2008

Em relação ao valor monetário, foi demonstrado na Tabela 6 o custo do material por mês em cada ano (em $\mathrm{R} \$$ ). 
Tabela 6 - Custo total em cada mês nos anos avaliados em 2007 e 2008, São Paulo - 2008

\begin{tabular}{lccc}
\hline \multicolumn{1}{c}{ MÊS } & 2007 & 2008 & $\begin{array}{c}\text { \% DE } \\
\text { ACRÉSCIMO }\end{array}$ \\
\hline Fevereiro & $108.366,44$ & $99.667,96$ & \\
Março & $142.198,64$ & $131.614,80$ & \\
Abril & $108.513,72$ & $123.212,91$ & \\
Maio & $98.065,19$ & $112.738,40$ & \\
\hline Média & $\mathbf{9 1 . 8 3 0 , 2 0}$ & $\mathbf{9 3 . 8 4 8 , 4 1}$ & $\mathbf{2 , 2 0}$ \\
dp & $\mathbf{5 2 . 9 0 5 , 2 2}$ & $\mathbf{5 2 . 7 1 1 , 3 2}$ & \\
Mediana & $\mathbf{1 0 8 . 3 6 6 , 4 4}$ & $\mathbf{1 1 2 . 7 3 8 , 4 0}$ & \\
\hline
\end{tabular}

Observa-se que em dois meses houve uma redução nos custos e em dois meses um aumento,apresentando em média 2,20\% de acréscimo.

No entanto, comparando-se esses valores, não encontramos diferença estatística entre os custos dos anos de 2007 e 2008 (teste nãoparamétrico de Mann-Whitney, $p=0,686)$.

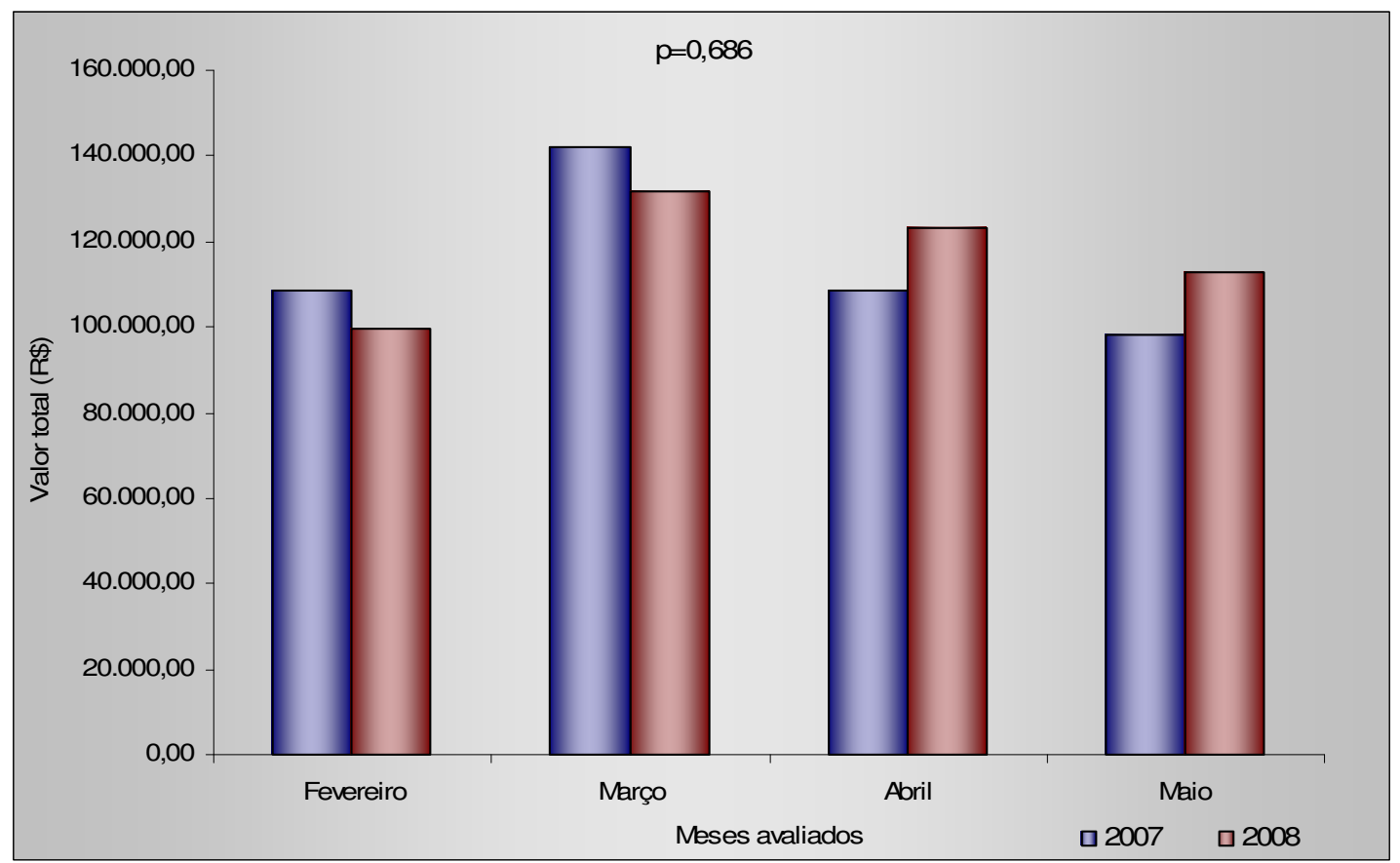

Figura 13. Custo total em cada mês nos anos avaliados, São Paulo - 2008 
Concluindo, quando comparados o consumo e o custo do material globalmente, mês a mês, não foram significativas as diferenças. Entretanto, ao analisar a Tabela 7, verifica-se que nos quatro meses estudados três apresentaram diminuição, ou seja, nos $75 \%$ dos meses, há uma diminuição do consumo de material em 2008. Essa tendência deve ser confirmada ou não pelo acompanhamento do consumo nos meses posteriores.

\subsubsection{Comparação do consumo e do custo do material por item}

Considerando o consumo dos 4 meses de cada ano em cada item de material, foi observada a quantia total do ano de 2007 e 2008 e comparadas entre si.

$\mathrm{Na}$ Tabela 7, temos o consumo médio total em cada ano.

Tabela 7 - Valores do número de itens de materiais, média, desvio padrão, mediana, mínimo e máximo de materiais consumidos, segundo os anos de estudo, São Paulo - 2008

\begin{tabular}{cccccccc}
\hline ANO & $\mathrm{n}$ & MÉDIA & $\mathrm{dp}$ & MÍNIMO & MÁXIMO & MEDIANA & $\mathrm{p}$ \\
\hline 2007 & 293 & 610,97 & $3.279,35$ & 0 & 41.000 & 53 & \\
2008 & 293 & 561,30 & $3.133,34$ & 0 & 42.625 & 37 & \\
\hline
\end{tabular}

Comparando-se estes valores de maneira pareada, isto é, item a item, foi observada a diferença entre os anos em cada item. Foi aplicado o teste não-paramétrico de Wilcoxon $(p<0,001)$ e foi possível detectar diferença estatística entre os consumos dos anos de 2007 e 2008. Portanto, a quantia média de itens consumidos em 2007 é significativamente maior que em 2008

Ao analisar o ano de 2008 na Tabela 8 e na Figura 14, foram observadas algumas diferenças em relação ao ano de 2007. 
Tabela 8 - Distribuição de itens de material segundo a quantidade consumida no ano de 2008 comparada ao ano de 2007, São Paulo - 2008

\begin{tabular}{lcc} 
& CONSUMO EM 2008 & \multicolumn{2}{c}{ ITENS DE MATERIAIS } \\
& total & $\%$ \\
\hline Redução & 177 & 60,41 \\
Aumento & 103 & 35,15 \\
Igual & 13 & 4,44 \\
\hline Total & 293 & 100,00 \\
\hline
\end{tabular}

Dos 293 itens de materiais analisados nos meses estudados, observou-se que o consumo de 177 (60,41\%) itens diminuiu no ano de 2008; houve aumento de 103 (35,15\%) itens em 2008; e 13 (4,44\%) mantiveram a mesma quantidade consumida em 2007 e 2008.

Pode-se observar na Figura 14, a representação gráfica desses números.

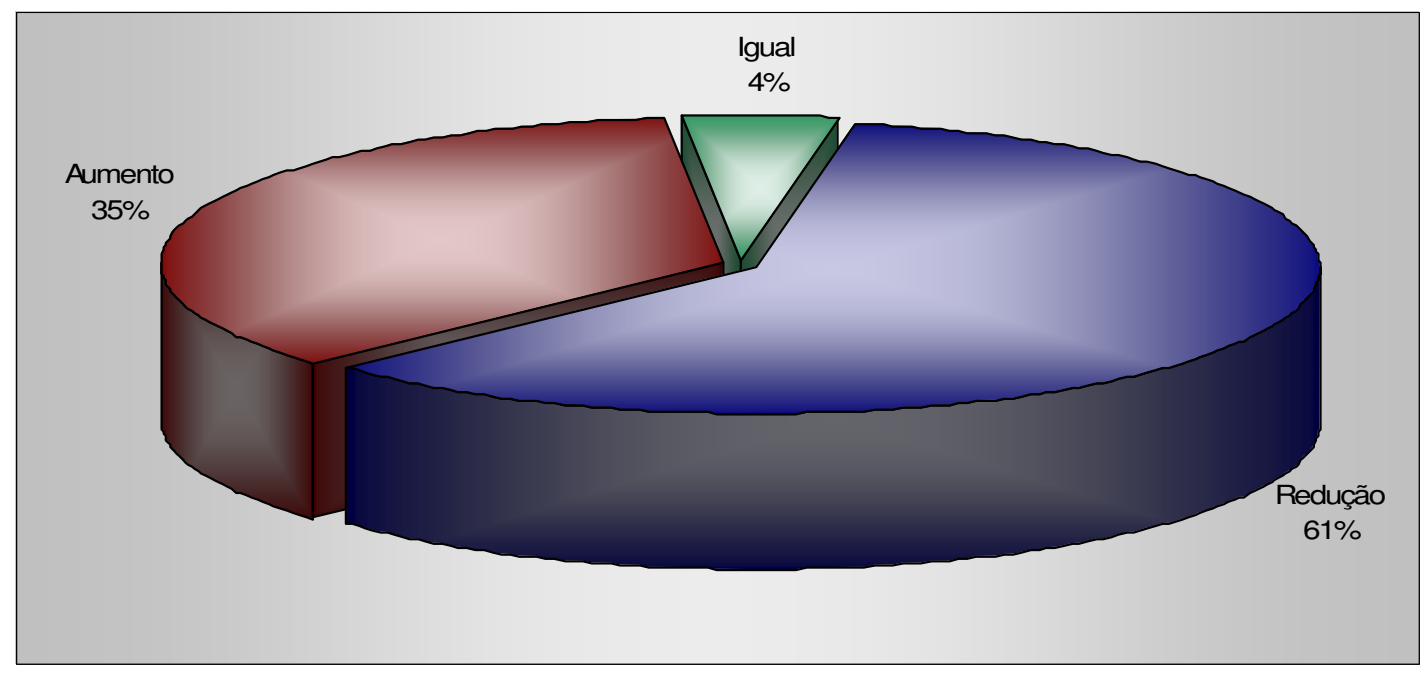

Figura 14. Distribuição da quantidade de itens de materiais consumidos no ano de 2008, comparados ao ano de 2007, São Paulo - 2008 
Quanto ao custo total desses itens, está representado na Figura 15.

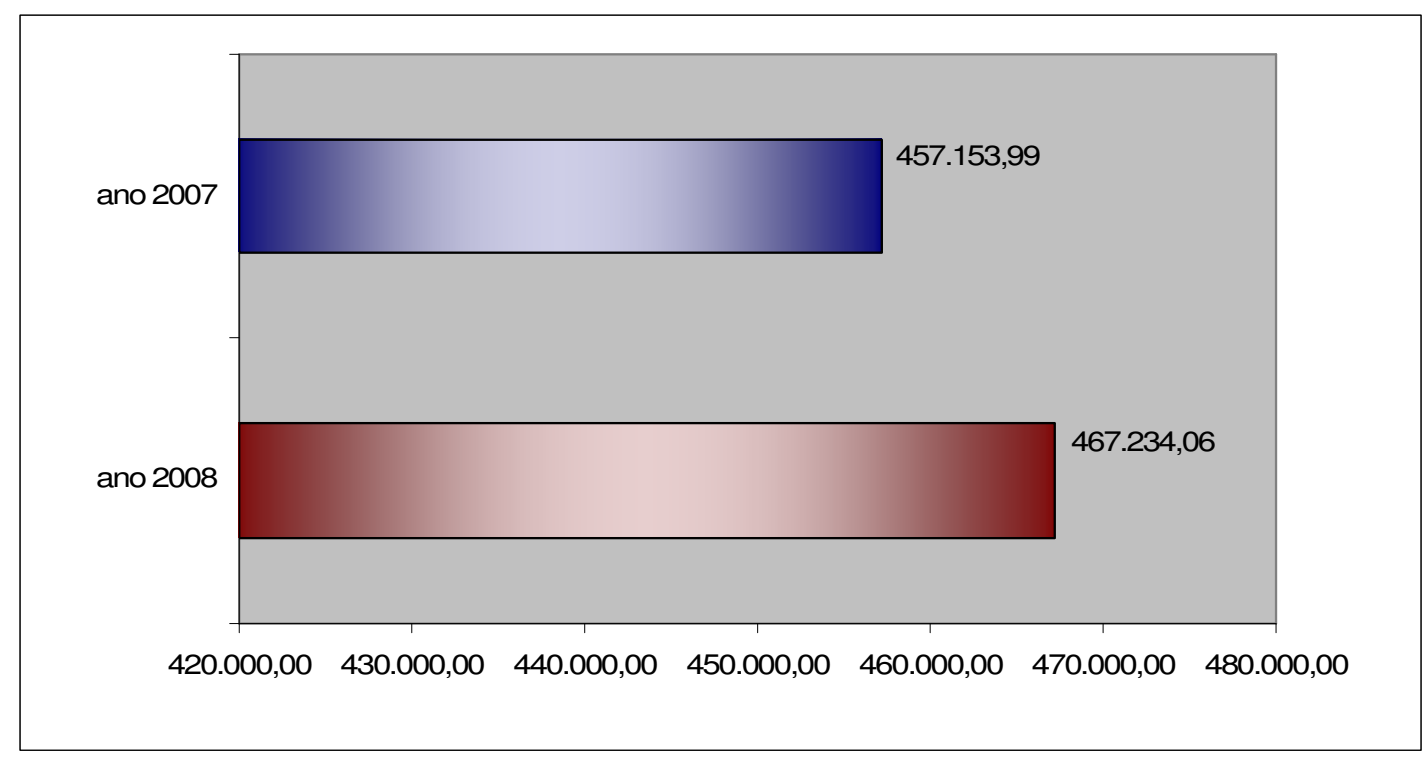

Figura 15. Distribuição do custo do material consumido nos anos de 2007 e 2008. São

Paulo - 2008

O valor monetário atribuído ao consumo dos materiais nos quatro meses de 2007 foi de $R \$ 457.153,99$ e o custo dos materiais consumidos nos quatro meses de 2008 foi de $R \$ 467.234,06$, mostrando um aumento de $\mathrm{R} \$ 10.080,07$. A diferença encontrada, embora não seja significativa estatisticamente, foi atribuída aos 103 itens (35,15\%) que tiveram aumento do consumo dos materiais e que representam unitariamente um custo maior.

Pode-se dizer que, ao implantar um Sistema de Gestão de Materiais informatizado, é possível conhecer o consumo real dos materiais, com uma tendência em diminuir o consumo e não necessariamente diminuir o custo.

A diferença do consumo de materiais pode ser atribuída ao controle efetivo que o SGM, implementado no hospital, de maneira sistêmica e informatizada, proporciona ao usuário. Ou seja, permite saber realmente "para quem, para que, quanto e o que" foi consumido de material. Com isso, há diminuição das perdas de materiais, pois diminui o desperdício no processo assistencial. 
Outro ponto relevante é a conscientização do usuário que somente abre um material quando tem a certeza que ele será consumido. Ao saber que existe um controle do material e que pode ter que justificar o uso, ele passa a pensar na real necessidade de sua utilização.

O Sistema de Gestão de Material informatizado, além de aprimorar o controle de material, devido à agilidade e praticidade, ele induz 0 profissional refletir suas atitudes no dia-a-dia do trabalho, devido a sua responsabilidade no processo.

Outro aspecto é que, a partir do momento que o usuário adquire confiança no SGM, ele deixa de solicitar o material em abundância para se sentir seguro ao prestar assistência ao paciente.

No sistema tradicional, além de não haver um controle mais efetivo sobre o gasto de material, deixava à disposição no setor uma grande quantidade de material. Assim, além de favorecer o uso indiscriminado pelo usuário, levava ao desperdício devido ao vencimento de prazos de validade.

Para se ter melhor compreensão do consumo de materiais, optouse estudar todos os itens que apresentaram acima de 100 a 45.000 unidades consumidas no período da coleta de dados, representados por 115 itens, mas que correspondem a $77,90 \%$ do custo em 2007 e $80,50 \%$ em 2008, num total de 293 materiais.

Os materiais que tiveram menos que 100 unidades consumidas (178 itens), embora dentre esses itens existam materiais com um valor unitário alto, como, por exemplo, grampeador de sutura mecânica $(R \$ 2.263,00)$ e fragmentador de tecidos laparoscópico para cirurgia ginecológica vídeo assistida ( $\mathrm{R} \$ 2.800,00)$, o consumo foi baixo, apresentando $22,10 \%$ do custo em 2007, e 19,50\% em 2008, como demonstra a Tabela 9. 
Tabela 9 - Distribuição do número de itens de material e a porcentagem do custo por unidades consumidas no ano de 2007 e 2008, São Paulo - 2008

\begin{tabular}{lccc}
\hline \multirow{2}{*}{ UNIDADES CONSUMIDAS } & ITENS & \multicolumn{2}{c}{ CUSTO \% } \\
\cline { 3 - 4 } 100 a 45.000 unidades consumidas & 115 & 77,90 & 80,50 \\
Menor que 100 unidades consumidas & 178 & 2008 & 2007 \\
\hline Total & 293 & 100,00 & 10,50 \\
\hline
\end{tabular}

No gráfico a seguir (Figura 16), foram apresentados, por ordem decrescente de consumo, os itens que apresentaram de 5.000 a 45.000 unidades consumidas nos quatro meses dos anos estudados. Observa-se que houve uma pequena diminuição do consumo dos materiais.

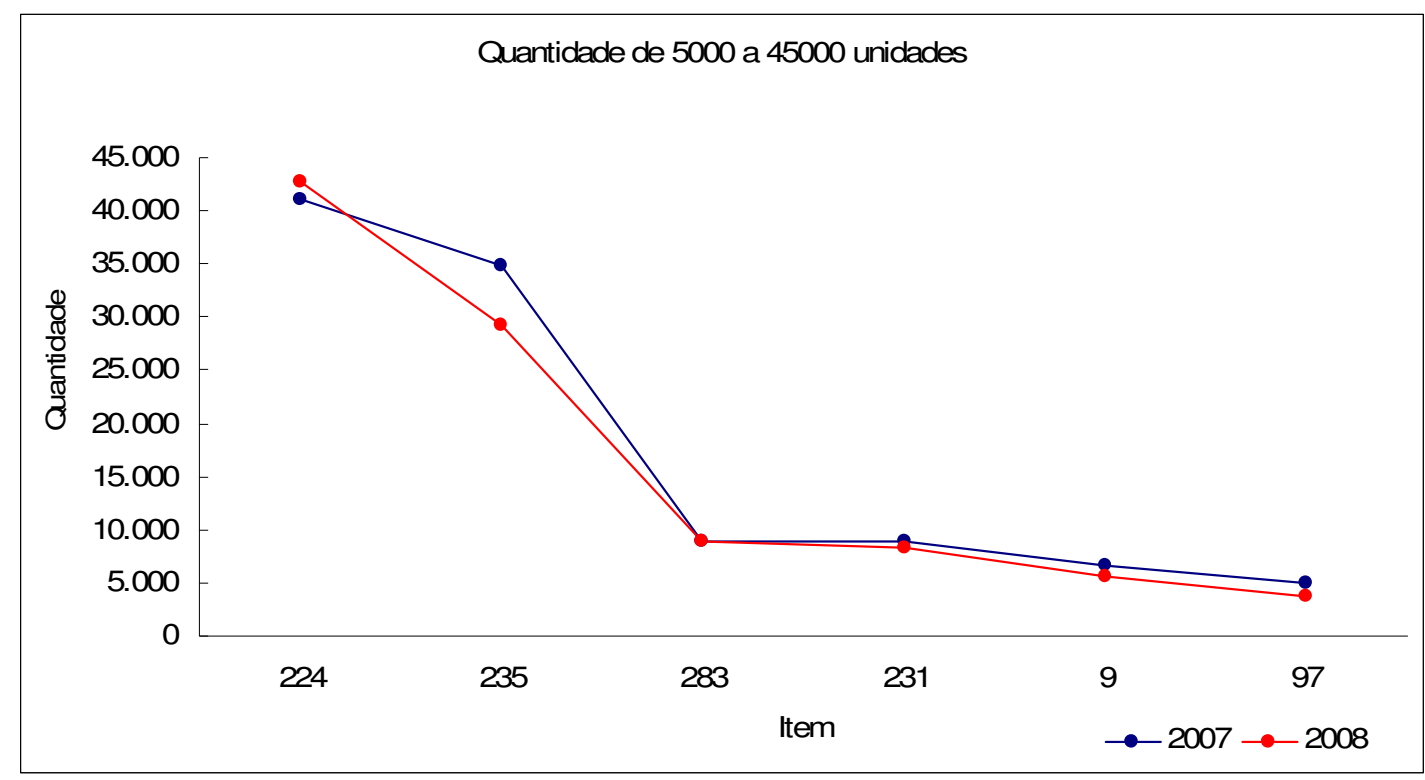

Figura 16. Quantidade de 5.000 a 45.000 unidades de materiais consumidos nos anos de 2007 e 2008, São Paulo - 2008

Os itens descritos no gráfico acima estão demonstrados na Tabela 10. 
Tabela 10 - Relação do consumo e do custo dos materiais que apresentaram de 5.000 a 45.000 unidades consumidas nos anos de 2007 e 2008, São

Paulo - 2008

\begin{tabular}{|c|c|c|c|c|c|c|}
\hline \multirow{2}{*}{ CÓDIGO } & \multirow{2}{*}{$\begin{array}{c}\text { DESCRIÇÃO DO } \\
\text { MATERIAL }\end{array}$} & \multicolumn{2}{|c|}{2007} & \multicolumn{2}{|c|}{2008} & \multirow{2}{*}{$\begin{array}{c}\% \text { da } \\
\text { diferença } \\
\text { dos anos }\end{array}$} \\
\hline & & $\begin{array}{c}\text { Consumo } \\
\text { Qt }\end{array}$ & Custo $R \$$ & $\begin{array}{c}\text { Consumo } \\
\text { Qt }\end{array}$ & Custo $\mathrm{R} \$$ & \\
\hline 224 & $\begin{array}{l}\text { Luva procedimento médio } \\
\text { não-estéril }\end{array}$ & 41.000 & $428.450,00$ & 42.625 & $445.431,25$ & 4 \\
\hline 235 & Prope descartável & 34.900 & $4.816,20$ & 29.150 & $4.022,70$ & -16 \\
\hline 283 & Touca descartável & 9.012 & 540,72 & 8.900 & 534,00 & -1 \\
\hline 231 & $\begin{array}{l}\text { Máscara cirúrgica } \\
\text { descartável }\end{array}$ & 9.000 & 585 & 8.350 & 542,75 & -7 \\
\hline 9 & $\begin{array}{l}\text { Agulha hipodérmica } \\
30 \mathrm{~mm} \times 8 \mathrm{~mm} \text { descartável }\end{array}$ & 6.700 & $27.737,18$ & 5.606 & $23.208,16$ & -16 \\
\hline 97 & $\begin{array}{l}\text { Compressa gaze branco } \\
45 \mathrm{~cm} \times 45 \mathrm{~cm} \text { campo } \\
\text { op.estéril }\end{array}$ & 5.000 & $35.909,09$ & 3.832 & $27.520,73$ & -23 \\
\hline
\end{tabular}

Os materiais que apresentam grande quantidade de consumo são aqueles que fazem parte da paramentação da equipe de profissionais do Centro Cirúrgico, e sua utilização está justificada pelo número de cirurgias agendadas. Quanto ao item prope descartável (-16\%), agulha hipodérmica ($16 \%$ ) e a compressa de gaze branco (-23\%), comumente conhecida como "compressa cirúrgica grande", são materiais que são utilizados em todos os procedimentos cirúrgicos. Pode ser observado que, mesmo sendo materiais que são utilizados em todos os procedimentos, apresentam uma diminuição no consumo e consequentemente no custo do material. Esta diminuição pode ser atribuída ao controle que o SGM oferece. A partir do momento que a equipe multiprofissional compartilha com o SGM percebe-se a importância de evitar o desperdício de materiais.

Ao analisar, em porcentagem, as diferenças do custo desse grupo de materiais, encontra-se um acréscimo de $4 \%$ nas luvas de procedimento não-estéril e uma redução para os demais itens. 
Em uma pesquisa realizada no mesmo hospital estudado, os materiais assistenciais representam em torno de $80 \%$ de todos os itens de materiais de consumo da instituição, e são os itens mais representativos em termos de custo. Dentre esses materiais, encontra-se a luva de procedimento não-estéril, classificada como o sétimo item de maior consumo na curva $A B C$ e um dos dez maiores valores de aquisição do ano (Lourenço, Castilho, 2006).

Considerando esse estudo e o que foi encontrado na Tabela 11, pode-se dizer que não houve diferença para o consumo de luvas de procedimento não-estéril ao implantar o SGM, o que nos leva a pensar em uma instituição hospitalar preocupada com a proteção do trabalhador e do paciente, porém há necessidade de uma investigação quanto ao critério de uso desse material.

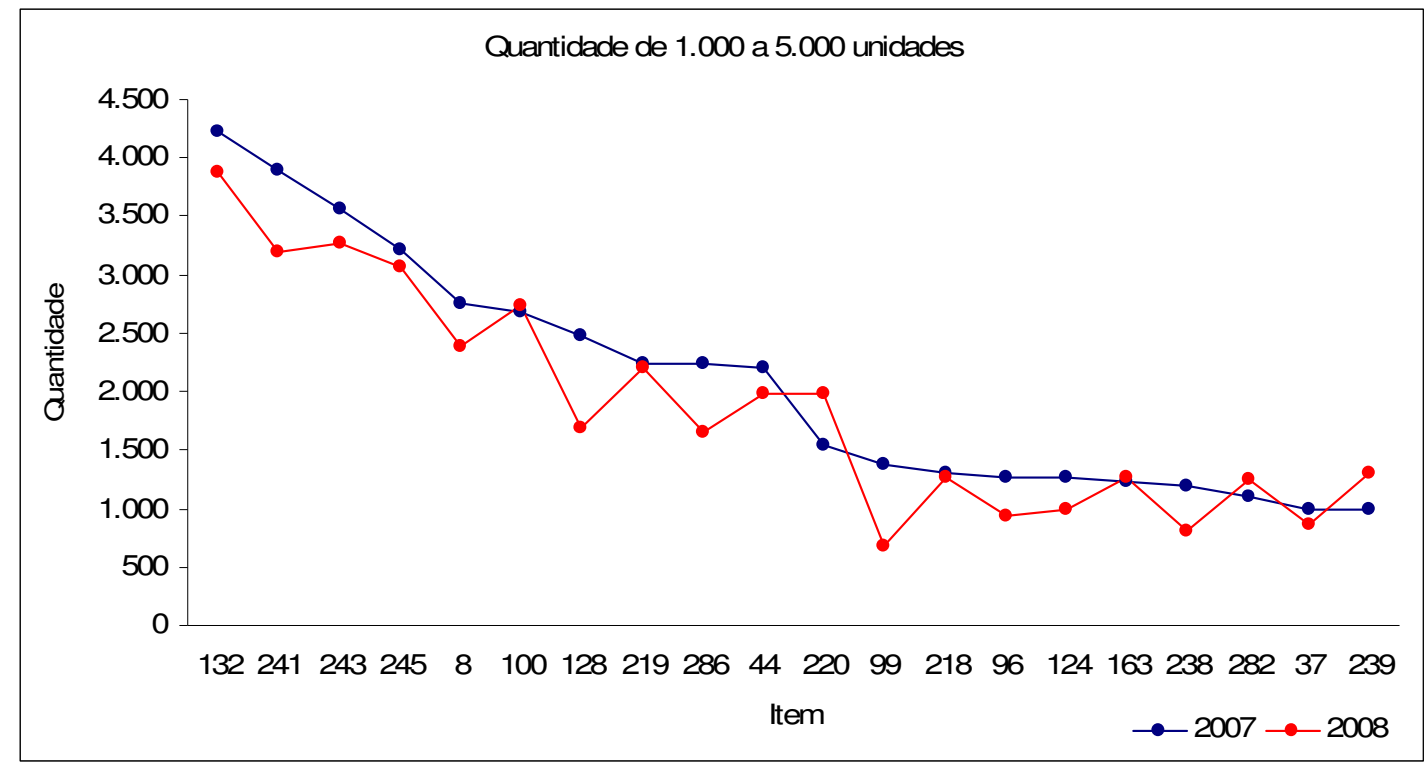

Figura 17. Quantidade de 1.000 a 5.000 unidades de materiais consumidos nos anos de 2007 e 2008, São Paulo - 2008

No gráfico acima, há dois itens de materiais que se destacam por terem apresentado um consumo maior em 2008 em relação a 2007. A luva cirúrgica 8,0 estéril (cód. 220) é considerada um material que pode variar o seu uso dependendo dos profissionais que compõem a equipe cirúrgica e dos alunos que estão fazendo estágio. O segundo item foi o saco para lixo 90L branco (cod. 239), utilizado dentro da sala de cirurgia, não havendo 
justificativa aparente, uma vez que foi encontrado o mesmo número de cirurgias em 2008 e 2007. Entretanto os 20 itens que apresentaram de 1.000 a 5.000 unidades consumidas 15 (75\%) apresentaram diminuição do consumo em 2008, após a implementação do SGM.

Tabela 11 - Relação do consumo e do custo dos materiais que apresentaram de 1.000 a 5.000 unidades consumidas nos anos de 2007 e 2008, São Paulo - 2008

\begin{tabular}{|c|c|c|c|c|c|c|}
\hline \multirow{2}{*}{ CÓDIGO } & \multirow{2}{*}{$\begin{array}{l}\text { DESCRIÇÃO DO } \\
\text { MATERIAL }\end{array}$} & \multicolumn{2}{|c|}{2007} & \multicolumn{2}{|c|}{2008} & \multirow{2}{*}{$\begin{array}{c}\% \text { da } \\
\text { diferença } \\
\text { dos anos }\end{array}$} \\
\hline & & $\begin{array}{c}\text { Consumo } \\
\text { Qt }\end{array}$ & Custo $\mathrm{R} \$$ & $\begin{array}{c}\text { Consumo } \\
\text { Qt }\end{array}$ & Custo $\mathrm{R} \$$ & \\
\hline 132 & Escova assepsia seca & 4.216 & $2.318,80$ & 3.867 & $2.126,85$ & -8 \\
\hline 241 & Seringa $10 \mathrm{ml}$ descartável & 3.900 & 621,79 & 3.204 & 510,82 & -18 \\
\hline 243 & Seringa $20 \mathrm{ml}$ descartável & 3.566 & 998,48 & 3.275 & 917,00 & -8 \\
\hline 245 & Seringa $5 \mathrm{ml}$ descartável & 3.206 & 320,60 & 3.065 & 306,50 & -4 \\
\hline 8 & $\begin{array}{l}\text { Agulha hipodérmica } \\
30 \mathrm{~mm} \times 7 \mathrm{~mm} \text { descartável }\end{array}$ & 2.750 & 159,66 & 2.385 & 138,47 & -13 \\
\hline 100 & $\begin{array}{l}\text { Compressa gaze } 7,5 \mathrm{~cm} \mathrm{x} \\
7,5 \mathrm{~cm} \text { filamento radiopaco }\end{array}$ & 2.690 & $1.667,80$ & 2.732 & $1.693,84$ & 2 \\
\hline 128 & Equipo macrogotas & 2.480 & 3697 & 1.695 & $2.526,78$ & -32 \\
\hline 219 & Luva cirúrgica 7,5 estéril & 2.250 & 998,10 & 2.198 & 975,03 & -2 \\
\hline 286 & $\begin{array}{l}\text { Tubo aspirador cirúrgico } \\
200 \mathrm{~cm} \text { estéril }\end{array}$ & 2.235 & $3.329,38$ & 1.652 & $2.460,91$ & -26 \\
\hline 44 & $\begin{array}{l}\text { Campo impermeável 110- } \\
150 \mathrm{~cm} \text { x 200-230cm mesa }\end{array}$ & 2.200 & $11.199,90$ & 1.989 & $10.125,73$ & -10 \\
\hline 220 & Luva cirúrgica 8,0 estéril & 1.550 & 687,83 & 1.981 & 879,09 & 28 \\
\hline 99 & $\begin{array}{l}\text { Compressa gaze branco } \\
7,5 \mathrm{~cm} \times 7,5 \mathrm{~cm} \text { estéril }\end{array}$ & 1.380 & 345 & 688 & 172,00 & -50 \\
\hline 218 & Luva cirúrgica 7,0 estéril & 1.300 & 575,8 & 1.260 & 558,08 & -3 \\
\hline 96 & $\begin{array}{l}\text { Compressa gaze branco } \\
30 \mathrm{~cm} \times 30 \mathrm{~cm} \text { campo op. }\end{array}$ & 1.264 & $6.058,09$ & 939 & $4.500,43$ & -26 \\
\hline 124 & $\begin{array}{l}\text { Eletrodo ECG infantil } \\
\text { descartável }\end{array}$ & 1.260 & 241,55 & 989 & 189,60 & -22 \\
\hline 163 & $\begin{array}{l}\text { Fio cirúrgico nylon } \\
\text { monof. } 4-0 \text { ag. } 3 / 8 \text { circ.tri. } \\
2,4 \mathrm{~cm}\end{array}$ & 1.232 & $2.069,76$ & 1.272 & $2.136,96$ & 3 \\
\hline 238 & $\begin{array}{l}\text { Saco } \mathrm{p} / \text { lixo } 30 \mathrm{~L} \text { branca } \\
59 \times 62 \mathrm{~cm}\end{array}$ & 1.200 & 312 & 800 & 208,00 & -33 \\
\hline 282 & Torneira 3 vias plástico & 1.102 & 731,24 & 1248 & 828,11 & 13 \\
\hline 37 & Bisturi descartável 15 & 1.000 & $3.297,35$ & 857 & $2.825,83$ & -14 \\
\hline 239 & $\begin{array}{l}\text { Saco p/ lixo 90L branca } \\
92 \times 90 \mathrm{~cm}\end{array}$ & 1.000 & 990 & 1300 & $1.287,00$ & 30 \\
\hline
\end{tabular}


Ao analisar alguns itens isolados desta tabela, foi detectado que o item equipo macrogotas apresentou um decréscimo de $32 \%$. Este material é utilizado em procedimento anestésico, e antes da implementação do SGM era armazenado na sala operatória, sem controle de uso. O item tubo aspirador cirúrgico (-26\%), como a compressa 30×30 de campo operatório ($26 \%$ ), conhecida como "compressinha", e o saco para lixo $30 \mathrm{~L}$ (-33\%) apresentaram diminuição, sendo atribuído ao controle de consumo de material e a mudança de comportamento da equipe multi profissional sobre o desperdício.

Outro item que se destaca é a compressa gaze 7,5 x 7,5 estéril que teve uma redução de $50 \%$ do custo anual. Nos hospitais, de um modo geral, onde não há um sistema de logística e controle de materiais, existe um excesso no consumo de gaze.

Aranha e Vieira (2004), ao analisarem as fontes de desperdício de um hospital público, detectaram que num total de $32,10 \%$ de desperdício de material hospitalar, os itens mais representativos foram: luva estéril, seringa, esparadrapo, gaze estéril, luva para procedimento, equipo, agulhas, cateter venoso e atadura de crepe.

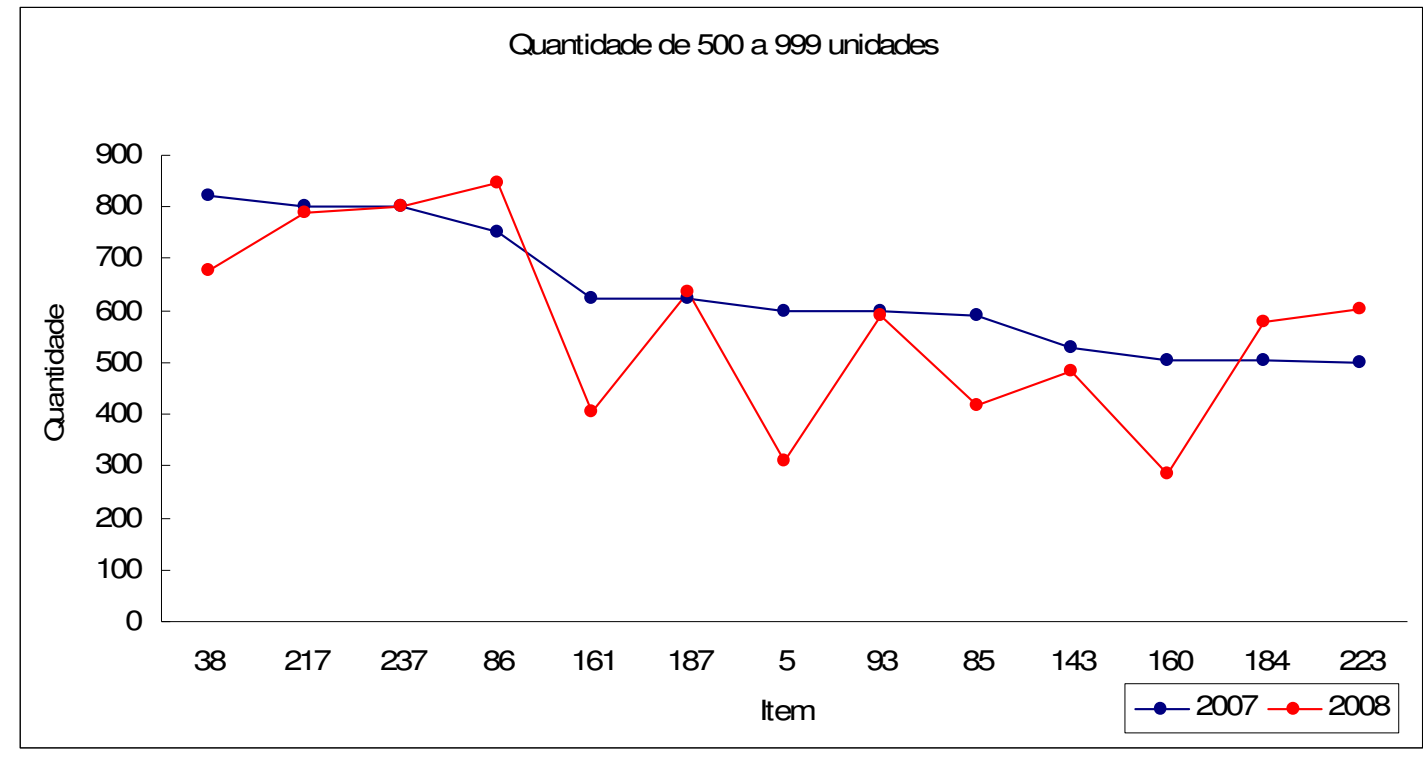

Figura 18. Quantidade de 500 a 999 unidades de materiais consumidos nos anos de 2007 e 2008, São Paulo - 2008 
Tabela 12 - Relação do consumo e do custo dos materiais que apresentaram de 500 a 999 unidades consumidas nos anos de 2007 e 2008, São Paulo $-2008$

\begin{tabular}{|c|c|c|c|c|c|c|}
\hline \multirow{2}{*}{ CÓDIGO } & \multirow{2}{*}{$\begin{array}{l}\text { DESCRIÇÃO DO } \\
\text { MATERIAL }\end{array}$} & \multicolumn{2}{|c|}{2007} & \multicolumn{2}{|c|}{2008} & \multirow{2}{*}{$\begin{array}{c}\% \text { da } \\
\text { diferença } \\
\text { dos anos }\end{array}$} \\
\hline & & $\begin{array}{c}\text { Consumo } \\
\text { Qt }\end{array}$ & Custo $\mathrm{R} \$$ & $\begin{array}{c}\text { Consumo } \\
\text { Qt }\end{array}$ & Custo $\mathrm{R} \$$ & \\
\hline 38 & Bisturi descartável 23 & 820 & $2.705,42$ & 679 & $2.240,22$ & -17 \\
\hline 217 & Luva cirúrgica 6,5 estéril & 800 & 352,00 & 788 & 346,72 & -2 \\
\hline 237 & $\begin{array}{l}\text { Saco } \mathrm{p} / \text { lixo } 15 \text { litros } \\
\text { branca } 39 \times 59 \mathrm{~cm}\end{array}$ & 800 & 136,00 & 800 & 136,00 & 0 \\
\hline 86 & $\begin{array}{l}\text { Cateter intravenoso } \\
\text { periférico } 20 \mathrm{~g}\end{array}$ & 750 & $1.316,92$ & 846 & $1.485,48$ & 13 \\
\hline 161 & $\begin{array}{l}\text { Fio cirúrgico nylon monof. } \\
3-0 \text { ag. } 3 / 8 \text { circ. cil. } 2,0 \mathrm{~cm}\end{array}$ & 624 & $1.560,00$ & 405 & $1.012,50$ & -35 \\
\hline 187 & $\begin{array}{l}\text { Fio cirúrgico sintético } \\
\text { absorv. } 3-0 \text { ag. } 1 / 2 \text { circ. } \\
\text { cil. } 2,5 \mathrm{~cm}\end{array}$ & 623 & $3.999,66$ & 637 & $4.089,54$ & 2 \\
\hline 5 & $\begin{array}{l}\text { Agulha hipodérmica } \\
13 \mathrm{~mm} \times 4,5 \mathrm{~mm} \\
\text { descartável }\end{array}$ & 600 & 36,00 & 309 & 18,54 & -49 \\
\hline 93 & $\begin{array}{l}\text { Coletor universal não } \\
\text { estéril desc, tampa branca }\end{array}$ & 600 & 90,00 & 591 & 88,65 & -2 \\
\hline 85 & $\begin{array}{l}\text { Cateter intravenoso } \\
\text { periférico } 18 \mathrm{~g}\end{array}$ & 590 & $1.020,70$ & 416 & 719,68 & -29 \\
\hline 143 & $\begin{array}{l}\text { Fio cirúrgico algodão } \\
\text { poliést. } 3-0 \text { ag } 1 / 2 \text { circ.cil } \\
2,5 \mathrm{~cm}\end{array}$ & 528 & $1.716,00$ & 482 & $1.566,50$ & -9 \\
\hline 160 & $\begin{array}{l}\text { Fio cirúrgico nylon monof. } \\
2-0 \text { ag. } 3 / 8 \text { circ. tri. } 2,0 \mathrm{~cm}\end{array}$ & 504 & $1.260,00$ & 285 & 712,50 & -43 \\
\hline 184 & $\begin{array}{l}\text { Fio cirúrgico sintético } \\
\text { absorv. } 1 \text { ag. } 1 / 2 \text { circ. cil. } \\
3,5 \mathrm{~cm}\end{array}$ & 504 & $3.563,28$ & 579 & $4.093,53$ & 15 \\
\hline 223 & $\begin{array}{l}\text { Luva procedimento médio } \\
\text { estéril }\end{array}$ & 500 & 200,00 & 601 & 240,40 & 20 \\
\hline
\end{tabular}

Para os itens com 500 a 999 unidades consumidas no período da coleta de dados, observa-se que em 13 itens (61,53\%), da Tabela 12, há diminuição de consumo entre 2007 e 2008. Dos materiais que apresentam maior redução de consumo, destaca-se a agulha hipodérmica $13 \mathrm{~mm} \times$ 4,5mm, os fios cirúrgicos nylon 2-0 e 3-0, seguido do cateter intravenoso periférico 18G. A agulha e os fios cirúrgicos eram acondicionados na sala operatória (SO) e disponibilizados à vontade sem controle de consumo. Quanto ao item cateter intravenoso, embora também ficasse na SO para ser 
disponibilizado, de acordo com a necessidade do momento, sua redução pode ser analisada de duas maneiras. A primeira pelo critério de uso do material, que envolve o tipo de cirurgia, o tipo de paciente e as condições de sua rede venosa. A segunda pode-se dizer que o SGM contribui para esta redução.

Quanto ao item fio cirúrgico sintético absorvível (código 184) que apresentou aumento do consumo (20\%), foi emprestado para a Unidade de Terapia Intensiva Pediátrica para ser utilizado em pacientes graves, sem condições de transporte para o Centro Cirúrgico.

Outro item que apresentou um aumento (20\%) foi a luva de procedimento estéril, utilizado em sondagem vesical de demora, sendo que foi observado também um aumento proporcional dos materiais bolsa coletora sistema fechado e sonda vesical, evidenciando um aumento desse procedimento.

Conforme demonstrado na Figura 19 e na Tabela 13, foi detectado que os materiais consumidos no Centro Cirúrgico do HU-USP em menor quantidade, ou seja, abaixo de 499 unidades no período estudado, apresentam uma curva com maior oscilação em 2008 do que em 2007. Quando se trabalha com o sistema tradicional de materiais, com cotas preestabelecidas e reposições mensais, é comum dar pouca importância para o controle do consumo de materiais, o que leva ao desconhecimento real da necessidade e quantidade de uso.

Uma das características do sistema tradicional é a manutenção de altos estoques, com materiais em abundancia,induzindo o consumo excessivo e desenfreado do material. O sistema Just in Time é voltado para a real necessidade de uso, para o controle de consumo, para evitar desperdícios e minimizar custos (Barbieri, Machline, 2006; Pozo, 2007).

Portanto, são compreensíveis os gráficos apresentados a seguir, pois só agora com o SGM (ano de 2008), baseado no JIT, é possível saber a real necessidade e quantidade de consumo.

$\mathrm{Na}$ Figura 19, mostra que, dos 22 itens, 12 (54,55\%) apresentaram diminuição, e 10 (45,45\%) aumentaram. 


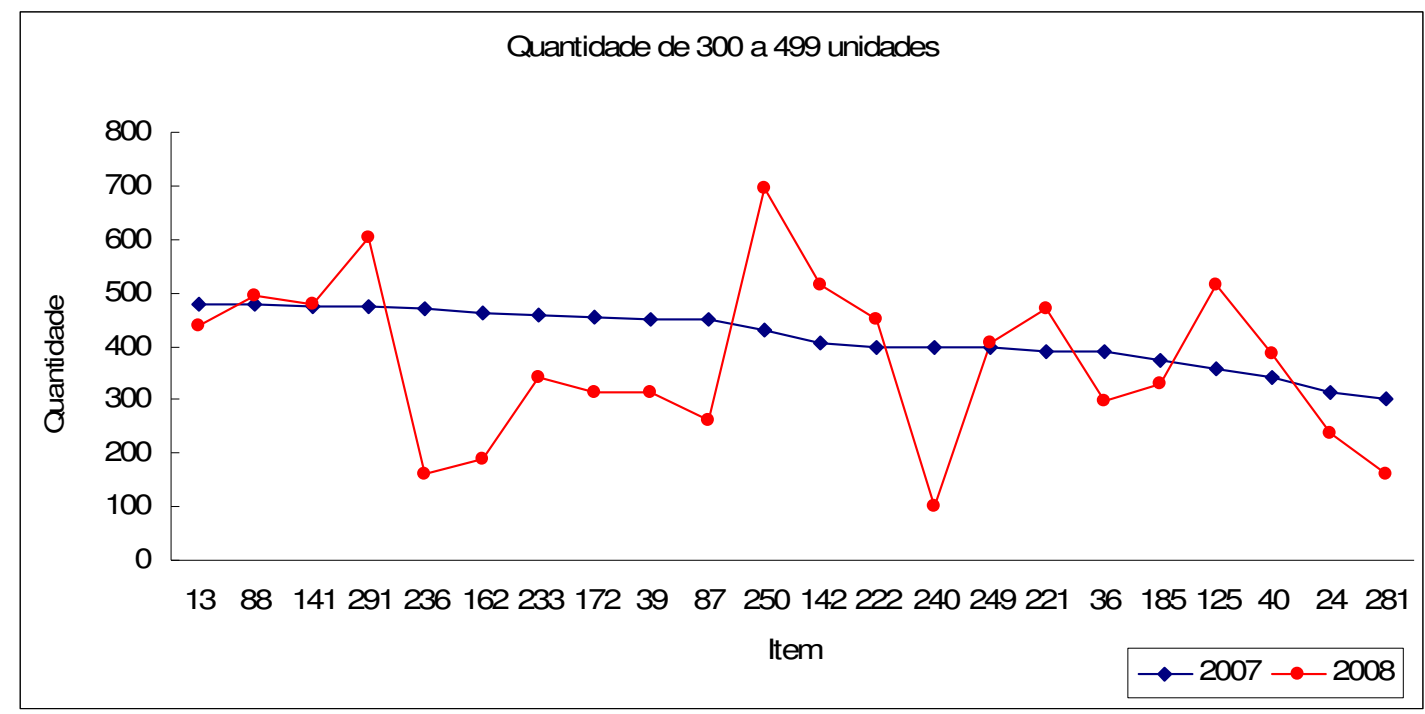

Figura 19. Quantidade de 300 a 499 unidades de materiais consumidos nos anos de $2007 \mathrm{e}$ 2008, São Paulo - 2008

Tabela 13 - Relação do consumo e do custo dos materiais que apresentaram de 300 a 499 unidades consumidas nos anos de 2007 e 2008, São Paulo $-2008$

\begin{tabular}{|c|c|c|c|c|c|c|}
\hline \multirow{2}{*}{ CÓDIGO } & \multirow{2}{*}{$\begin{array}{l}\text { DESCRIÇÃO DO } \\
\text { MATERIAL }\end{array}$} & \multicolumn{2}{|c|}{2007} & \multicolumn{2}{|c|}{2008} & \multirow{2}{*}{$\begin{array}{c}\% \text { da } \\
\text { diferença } \\
\text { dos anos }\end{array}$} \\
\hline & & $\begin{array}{c}\text { Consumo } \\
\text { Qt }\end{array}$ & Custo $\mathrm{R} \$$ & $\begin{array}{c}\text { Consumo } \\
\text { Qt }\end{array}$ & Custo $\mathrm{R} \$$ & \\
\hline 13 & $\begin{array}{l}\text { Agulha punção lombar } \\
27 g \text { x } 31 / 2 " \text { bisel ponta de } \\
\text { lápis }\end{array}$ & 480 & $7.195,00$ & 439 & $6.580,61$ & -9 \\
\hline 88 & $\begin{array}{l}\text { Cateter nasal oxigênio } \\
\text { adulto tipo óculos }\end{array}$ & 480 & 314,52 & 496 & 325,00 & 3 \\
\hline 141 & $\begin{array}{l}\text { Fio cirúrgico algodão } \\
\text { poliéster } 2-0 \text { ag. } 1 / 2 \text { circ. } \\
\text { cil. } 2,5 \mathrm{~cm}\end{array}$ & 475 & $1.225,50$ & 480 & $1.238,40$ & 1 \\
\hline 291 & $\begin{array}{l}\text { Tubo extensor } 60 \mathrm{~cm} \\
\text { conexão luer lock }\end{array}$ & 473 & 227,04 & 603 & 289,44 & 27 \\
\hline 236 & Sabonete glicerina $20 \mathrm{~g}$ & 470 & 108,10 & 159 & 36,57 & -66 \\
\hline 162 & $\begin{array}{l}\text { Fio cirúrgico nylon monof. } \\
4-0 \text { ag. } 3 / 8 \text { circ.tri. } 2,0 \mathrm{~cm}\end{array}$ & 464 & $1.160,00$ & 188 & 470,00 & -59 \\
\hline 233 & $\begin{array}{l}\text { Placa bisturi elétrico } \\
\text { adulto }\end{array}$ & 460 & $7.314,00$ & 342 & $5.437,80$ & -26 \\
\hline 172 & $\begin{array}{l}\text { Fio cirúrgico } \\
\text { poliglecaprone } 4-0 \text { ag. } 3 / 8 \\
\text { circ. tri. } 1,95 \mathrm{~cm}\end{array}$ & 456 & $4.199,76$ & 313 & $2.882,73$ & -31 \\
\hline 39 & $\begin{array}{l}\text { Bolsa coletora de urina } \\
2.000 \mathrm{ml} \mathrm{sacola}\end{array}$ & 450 & 81,11 & 312 & 56,24 & -31 \\
\hline
\end{tabular}

(continua) 
(continuação)

\begin{tabular}{|c|c|c|c|c|c|c|}
\hline \multirow{2}{*}{ CÓDIGO } & \multirow{2}{*}{$\begin{array}{l}\text { DESCRIÇÃO DO } \\
\text { MATERIAL }\end{array}$} & \multicolumn{2}{|c|}{2007} & \multicolumn{2}{|c|}{2008} & \multirow{2}{*}{$\begin{array}{c}\% \text { da } \\
\text { diferença } \\
\text { dos anos }\end{array}$} \\
\hline & & $\begin{array}{c}\text { Consumo } \\
\text { Qt }\end{array}$ & Custo $R \$$ & $\begin{array}{c}\text { Consumo } \\
\text { Qt }\end{array}$ & Custo $R \$$ & \\
\hline 87 & $\begin{array}{l}\text { Cateter intravenoso } \\
\text { periférico } 22 \mathrm{~g}\end{array}$ & 450 & $1.287,14$ & 262 & 749,40 & -42 \\
\hline 250 & $\begin{array}{l}\text { Sonda aspiração traqueal } \\
14 \mathrm{fr}\end{array}$ & 430 & 181,53 & 697 & 294,25 & 62 \\
\hline 142 & $\begin{array}{l}\text { Fio cirúrgico algodão } \\
\text { poliést.2-0 sem ag. } 15 \text { fios } \\
45 \mathrm{~cm}\end{array}$ & 408 & 285,60 & 513 & 359,10 & 26 \\
\hline 222 & Luva plástica estéril & 400 & 15,59 & 449 & 17,50 & 12 \\
\hline 240 & $\begin{array}{l}\text { Saco plástico branco } \\
\text { leitoso } 20 \mathrm{~cm} \times 40 \mathrm{~cm} \\
\text { placenta }\end{array}$ & 400 & 64,00 & 100 & 16,00 & -75 \\
\hline 249 & $\begin{array}{l}\text { Sonda aspiração traqueal } \\
12 \mathrm{fr}\end{array}$ & 400 & 180,40 & 405 & 182,66 & 1 \\
\hline 221 & Luva cirúrgica 8,5 estéril & 391 & 175,67 & 471 & 211,62 & 20 \\
\hline 36 & Bisturi descartável 11 & 390 & $1.294,99$ & 296 & 982,87 & -24 \\
\hline 185 & $\begin{array}{l}\text { Fio cirúrgico sintético } \\
\text { absorv. } 2-0 \mathrm{ag} .1 / 2 \\
\text { circ.cil. } 2,5 \mathrm{~cm}\end{array}$ & 372 & $2.287,24$ & 331 & $2.035,16$ & -11 \\
\hline 125 & $\begin{array}{l}\text { Equipo anestesia } \\
\text { endovenosa lifeshield } \\
\text { convencional }\end{array}$ & 357 & $32.665,50$ & 514 & $47.031,00$ & 44 \\
\hline 40 & $\begin{array}{l}\text { Bolsa coletora de urina } \\
2000 \mathrm{ml} \text { sistema fechado }\end{array}$ & 340 & $5.905,80$ & 387 & $6.722,19$ & 14 \\
\hline 24 & $\begin{array}{l}\text { Atadura crepon } 15 \mathrm{~cm} x \\
1,80 \mathrm{~m}\end{array}$ & 312 & 131,04 & 238 & 99,96 & -24 \\
\hline 281 & $\begin{array}{l}\text { Tira reagente para glicose } \\
\text { sangue }\end{array}$ & 300 & 248,00 & 159 & 131,97 & -47 \\
\hline
\end{tabular}

Alguns materiais representados na Tabela 13 merecem ser comentados.

O uso abusivo de materiais é um dos argumentos atribuídos aos desperdícios acometidos com impressos, material de higiene e limpeza, material hospitalar, entre outros (Aranha, Vieira, 2004).

No presente estudo, os dados encontrados foram favoráveis aos dados de Aranha e Vieira (2004). O item saco plástico branco leitoso para placenta teve uma redução de $75 \%$, assim como o item sabonete de glicerina $20 \mathrm{~g}(66 \%)$, utilizado para antissepsia das mãos de profissionais alérgicos a outros antissépticos e para a higienização das equipes, chamou 
a atenção porque não havia controle do uso criterioso do material antes da implantação do SGM. Os fios cirúrgicos nylon (código162) com 59\% e poliglecaprone (código 172) com 31\% tiveram redução no consumo que pode estar associada pelo fato de os fios cirúrgicos não estarem disponíveis na sala operatória. Após a implantação do SGM, o cirurgião solicita o fio desejado para o circulante de sala (técnico de enfermagem) antes de iniciar a cirurgia.

O item bolsa coletora urina $2.000 \mathrm{ml}$ sacola $(31 \%)$ passou a ser utilizado respeitando sua única finalidade, que é para coletas de líquidos ao realizar o procedimento de sondagem gástrica. A partir do momento que é necessário justificar o uso e sabendo que existe um controle desde o material mais simples, de menor custo até um material classificado como imprescindível para assistência ao paciente na cirurgia e de alto custo, o profissional faz uma reflexão da necessidade do uso: "É criar a cultura de pensar antes de consumir".

Outros dados que chamaram a atenção, foram o aumento dos itens tubo extensor de $60 \mathrm{~cm}$ para venoclise (27\%), tubo aspiração traqueal $14 \mathrm{fr}(62 \%)$ e equipo anestesia endovenosa lifeshield convencional (44\%), interpretado como um possível aumento de anestesia geral no período estudado, pois esses materiais são convencionalmente utilizados neste tipo de procedimento. Outra possibilidade é de conhecer o verdadeiro consumo e que talvez, para as características de cirurgias e pacientes que o HU-USP atende é necessário consumir essa quantidade de material.

Em relação aos materiais com 200 a 299 unidades consumidas, há também uma grande variação de consumo no ano de 2008, conforme demonstrado na Figura 20 e Tabela 14. 


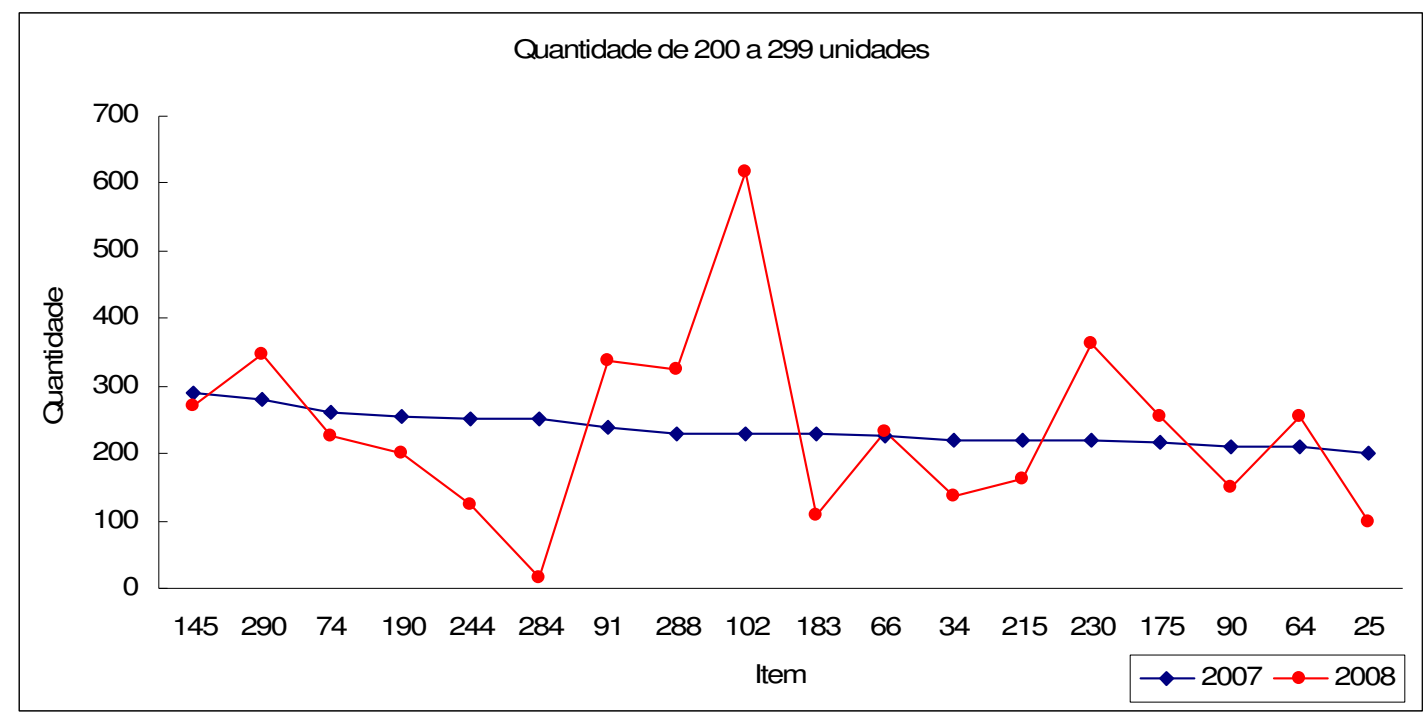

Figura 20. Quantidade de 200 a 299 unidades de materiais consumidos nos anos de 2007 e 2008, São Paulo - 2008

No gráfico acima (Figura 20), dos 18 itens estudados, observa-se que, no ano de 2008, 8(44,44\%) dos itens aumentaram e 10 (55,56\%) diminuíram o consumo. Esse fato pode ser entendido que, para os itens que aumentaram foi devido à necessidade da demanda cirúrgica, pois, com a implantação do SGM em 2008, todos os materiais são dispensados no nome do paciente, sabendo onde o material foi consumido. Para os itens que apresentam redução de consumo, foi atribuída como causa a diminuição do desperdício.

O Centro Cirúrgico é um dos setores do hospital que mais consome material, logo se pode pensar em um maior desperdício. Em um estudo sobre desperdício, o Centro Cirúrgico foi o principal consumidor de material hospitalar e foi responsável por $20 \%$ do desperdício (Aranha, Vieira, 2004).

Embora a literatura disponível, abordando as causas e motivos sobre o desperdício de material na área hospitalar, seja restrita, alguns autores relatam a presença do desperdício, a má utilização de insumos e equipamentos nas instituições e a necessidade de se obter informações específicas para colaborar com a formação de uma consciência técnicoadministrativa para a solução desses problemas (Castilho, Leite,1991; Queiroz, Spiri, Juliani, 2004; Noronha, Borges, 2005; Infante, Santos, 2007). 
Tabela 14 - Relação do consumo e do custo dos materiais que apresentaram de 200 a 299 unidades consumidas nos anos de 2007 e 2008, São Paulo $-2008$

\begin{tabular}{|c|c|c|c|c|c|c|}
\hline \multirow{2}{*}{ CÓDIGO } & \multirow{2}{*}{$\begin{array}{l}\text { DESCRIÇÃO DO } \\
\text { MATERIAL }\end{array}$} & \multicolumn{2}{|c|}{2007} & \multicolumn{2}{|c|}{2008} & \multirow{2}{*}{$\begin{array}{c}\% \text { da } \\
\text { diferença } \\
\text { dos anos }\end{array}$} \\
\hline & & $\begin{array}{c}\text { Consumo } \\
\text { Qt }\end{array}$ & Custo $\mathrm{R} \$$ & $\begin{array}{c}\text { Consumo } \\
\text { Qt }\end{array}$ & Custo $R \$$ & \\
\hline 145 & $\begin{array}{l}\text { Fio cirúrgico algodão } \\
\text { poliést. } 4-0 \text { ag. } 1 / 2 \text { circ. } \\
\text { cil. } 2,5 \mathrm{~cm}\end{array}$ & 288 & 936,00 & 271 & 880,75 & -6 \\
\hline 290 & $\begin{array}{l}\text { Tubo extensor } 20 \mathrm{~cm} \\
\text { conexão luer lock }\end{array}$ & 280 & 551,08 & 346 & 680,98 & 24 \\
\hline 74 & Capa laparoscópio estéril & 260 & 728,00 & 226 & 632,80 & -13 \\
\hline 190 & $\begin{array}{l}\text { Fita adesiva microporosa } \\
12 \mathrm{~mm} \times 100 \mathrm{~mm} \text { sutura de } \\
\text { pele }\end{array}$ & 255 & 606,41 & 200 & 475,62 & -22 \\
\hline 244 & Seringa 3ml descartável & 250 & 22,50 & 123 & 11,07 & -51 \\
\hline 284 & $\begin{array}{l}\text { Tubo coleta a vácuo com } \\
\text { gel, am ou vm de } 5 \text { a } 6 \mathrm{ml}\end{array}$ & 250 & 70,00 & 15 & 4,20 & -94 \\
\hline 91 & $\begin{array}{l}\text { Coletor artigo descartável } \\
31\end{array}$ & 240 & 324,00 & 336 & 453,60 & 40 \\
\hline 288 & $\begin{array}{l}\text { Tubo coleta de sangue a } \\
\text { vácuo,roxa } 3 \text { a } 4 \mathrm{ml} \text { edta }\end{array}$ & 230 & 45,30 & 323 & 63,61 & 40 \\
\hline 102 & $\begin{array}{l}\text { Condensador higroscópio } \\
\text { adulto }\end{array}$ & 228 & $1.896,96$ & 617 & $5.133,44$ & 171 \\
\hline 183 & $\begin{array}{l}\text { Fio cirúrgico sintético } \\
\text { absorv. } 0 \text { ag. } 3 / 8 \text { circ.cil. } \\
3,0 \mathrm{~cm}\end{array}$ & 228 & $1.114,92$ & 108 & 528,12 & -53 \\
\hline 66 & $\begin{array}{l}\text { Cânula endotraqueal } \\
8,0 \mathrm{~mm} \text { com cuff }\end{array}$ & 225 & 706,59 & 231 & 725,43 & 3 \\
\hline 34 & $\begin{array}{l}\text { Avental cirúrgico } \\
\text { extragrande ultra proteção }\end{array}$ & 220 & $3.960,00$ & 137 & $2.466,00$ & -38 \\
\hline 215 & $\begin{array}{l}\text { Lençol absorvente } 80 \mathrm{~cm} \mathrm{x} \\
150 \mathrm{~cm} \text { dry gel }\end{array}$ & 220 & 312,40 & 162 & 230,04 & -26 \\
\hline 230 & $\begin{array}{l}\text { Manta térmica superior } \\
60-80 \mathrm{~cm} \times 180-200 \mathrm{~cm}\end{array}$ & 220 & $9.897,80$ & 363 & $16.331,37$ & 65 \\
\hline 175 & $\begin{array}{l}\text { Fio cirúrgico polipropileno } \\
2-0 \text { ag. } 1 / 2 \text { circ.cil. } 2,5 \mathrm{~cm}\end{array}$ & 216 & 885,60 & 255 & 1045,50 & 18 \\
\hline 90 & $\begin{array}{l}\text { Clip laqueação mecânica } \\
\text { grande liga clip }\end{array}$ & 210 & $12.635,70$ & 150 & $9.025,50$ & -29 \\
\hline 64 & $\begin{array}{l}\text { Cânula endotraqueal } \\
7,5 \mathrm{~mm} \text { com cuff }\end{array}$ & 209 & 470,29 & 254 & 571,55 & 22 \\
\hline 25 & $\begin{array}{l}\text { Atadura crepon } 20 \mathrm{~cm} \mathrm{x} \\
1,80 \mathrm{~m}\end{array}$ & 200 & 114,00 & 98 & 55,86 & -51 \\
\hline
\end{tabular}


$\mathrm{Na}$ Tabela 14, demonstram-se, item a item, os materiais que diminuíram e aumentaram em termos de quantidade e quantia ( $R \$)$ apresentados na Figura 20.

O item tubo coleta a vácuo com gel apresentou $94 \%$ de redução, assim como a seringa de $3 \mathrm{ml}(-51 \%)$ e o fio cirúrgico sintético absorvível 0 ($53 \%$ ). Estes materiais são utilizados, com freqüência, em cirurgias e pode-se pensar em um consumo abusivo no ano de 2007.

Dois itens merecem destaque, pois apresentam um aumento muito elevado: a manta térmica superior com $65 \%$ e o condensador higroscópio adulto (171\%). O primeiro item é uma manta térmica que tem por finalidade aquecer o paciente e tem a indicação de uso em cirurgias em que leva a perda de líquidos e baixas temperaturas corporais. $O$ aumento de $65 \%$ de uso desse item pode estar associado ao tipo de cirurgia realizada. $O$ segundo item é um filtro para ser utilizado em todos os pacientes que são submetidos à anestesia geral. A sua utilização foi padronizada após a implantação do SGM. No Sistema Tradicional, não havia padronização do uso deste item e nem a garantia de tê-lo ininterruptamente no estoque do Centro Cirúrgico. No SGM, foi possível, além de padronizar o uso, garantir a presença do material para ser consumido em todos os procedimentos de anestesia geral, o que levou a um consumo maior, quando comparado ao ano de 2007.

O SGM permite ver, de fato, o que precisa ser consumido e auxilia a equipe de profissionais analisar a importância e a necessidade real de cada material para prestar assistência ao paciente.

No último grupo de materiais analisado com consumo entre $100 \mathrm{e}$ 199 unidades, foi observada a mesma situação do grupo anterior, conforme demonstra na Figura 21. 


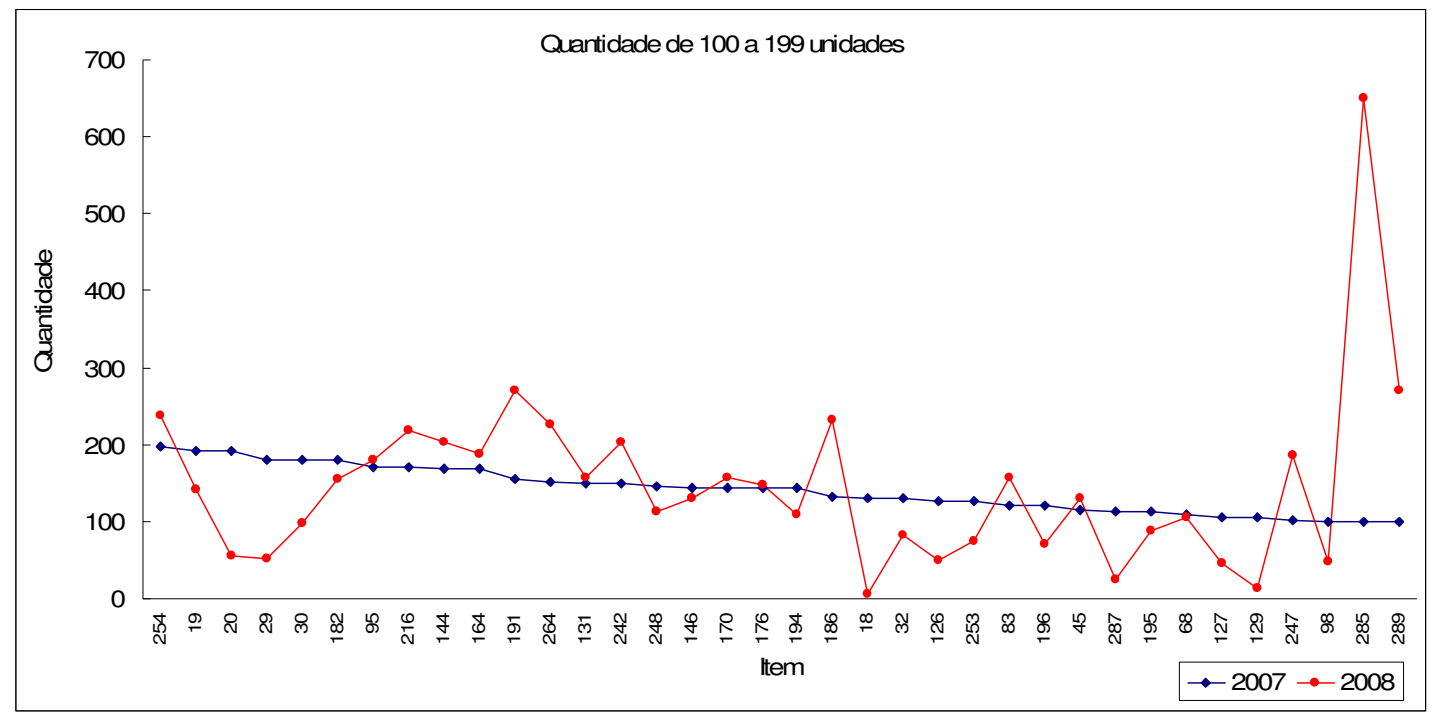

Figura 21. Quantidade de 100 a 199 unidades de materiais consumidos nos anos de 2007 e 2008, São Paulo - 2008

$\mathrm{Na}$ Tabela 15, 19 (52,78\%) materiais diminuíram e 17(47,22\%) aumentaram o consumo, atribuindo a necessidade das cirurgias e a contenção de desperdício.

Tabela 15 - Relação do consumo e do custo dos materiais que apresentaram de 100 a 199 unidades consumidas nos anos de 2007 e 2008, São Paulo $-2008$

\begin{tabular}{|c|c|c|c|c|c|c|}
\hline \multirow{2}{*}{ CÓDIGO } & \multirow{2}{*}{$\begin{array}{l}\text { DESCRIÇÃO DO } \\
\text { MATERIAL }\end{array}$} & \multicolumn{2}{|c|}{2007} & \multicolumn{2}{|c|}{2008} & \multirow{2}{*}{$\begin{array}{c}\% \text { da } \\
\text { diferença } \\
\text { dos anos }\end{array}$} \\
\hline & & $\begin{array}{c}\text { Consumo } \\
\text { Qt }\end{array}$ & Custo $R \$$ & $\begin{array}{c}\text { Consumo } \\
\text { Qt }\end{array}$ & Custo $\mathrm{R} \$$ & \\
\hline 254 & Sonda foley 142 vias & 197 & 139,87 & 238 & 168,98 & 21 \\
\hline 19 & $\begin{array}{l}\text { Atadura algodão } \\
\text { ortopédico } 15 \mathrm{~cm} \times 1,80 \mathrm{~m}\end{array}$ & 192 & 53,76 & 142 & 39,76 & -26 \\
\hline 20 & $\begin{array}{l}\text { Atadura algodão } \\
\text { ortopédico } 20 \mathrm{~cm} \times 1,80 \mathrm{~m}\end{array}$ & 192 & 57,60 & 55 & 16,50 & -71 \\
\hline 29 & $\begin{array}{l}\text { Atadura gessada } 10 \mathrm{~cm} x \\
3,0 \mathrm{~m}\end{array}$ & 180 & 97,20 & 52 & 28,08 & -71 \\
\hline 30 & $\begin{array}{l}\text { Atadura gessada } 15 \mathrm{~cm} x \\
3,0 \mathrm{~m}\end{array}$ & 180 & 185,40 & 98 & 100,94 & -46 \\
\hline 182 & $\begin{array}{l}\text { Fio cirúrgico sintético } \\
\text { absorv. } 0 \mathrm{ag} .1 / 2 \\
\text { circ.cil. } 5,0 \mathrm{~cm}\end{array}$ & 180 & $1.206,00$ & 156 & $1.045,20$ & -13 \\
\hline 95 & $\begin{array}{l}\text { Compressa gaze branco } \\
15 \mathrm{~cm} \times 10 \mathrm{~cm} \text { estéril }\end{array}$ & 170 & 130,90 & 180 & 138,60 & 6 \\
\hline 216 & Lixa bisturi elétrico & 170 & 504,90 & 219 & 650,43 & 29 \\
\hline
\end{tabular}


Tabela 15

(continuação)

\begin{tabular}{|c|c|c|c|c|c|c|}
\hline \multirow[b]{2}{*}{ CÓDIGO } & \multirow{2}{*}{$\begin{array}{l}\text { DESCRIÇÃO DO } \\
\text { MATERIAL }\end{array}$} & \multicolumn{2}{|c|}{2007} & \multicolumn{2}{|c|}{2008} & \multirow{2}{*}{$\begin{array}{c}\% \text { da } \\
\text { diferença } \\
\text { dos anos }\end{array}$} \\
\hline & & $\begin{array}{c}\text { Consumo } \\
\text { Qt }\end{array}$ & Custo $R \$$ & $\begin{array}{c}\text { Consumo } \\
\text { Qt }\end{array}$ & Custo $R \$$ & \\
\hline 144 & $\begin{array}{l}\text { flo cirúrgico algodão } \\
\text { poliést. } 3-0 \text { sem ag. } 15 \\
\text { fios } 45 \mathrm{~cm}\end{array}$ & 168 & 420,00 & 204 & 510,00 & 21 \\
\hline 164 & $\begin{array}{l}\text { Fio cirúrgico nylon monof. } \\
5-0 \text { ag. } 3 / 8 \text { circ. Tri. } 2,0 \mathrm{~cm}\end{array}$ & 168 & 420,00 & 187 & 467,50 & 11 \\
\hline 191 & $\begin{array}{l}\text { Fita adesiva microporosa } \\
6 \mathrm{~mm} \times 38 \mathrm{~mm} \text { sutura de } \\
\text { pele }\end{array}$ & 155 & 317,75 & 271 & 555,55 & 75 \\
\hline 264 & $\begin{array}{l}\text { Sonda gástrica } 18 \text { tipo } \\
\text { levine }\end{array}$ & 152 & 129,74 & 227 & 193,76 & 49 \\
\hline 131 & $\begin{array}{l}\text { Equipo transfusão de } \\
\text { sangue câmara dupla }\end{array}$ & 150 & 204,00 & 157 & 213,52 & 5 \\
\hline 242 & Seringa $1 \mathrm{ml}$ descartável & 150 & 27,00 & 203 & 36,54 & 35 \\
\hline 248 & $\begin{array}{l}\text { Sonda aspiração traqueal } \\
10 \mathrm{fr}\end{array}$ & 145 & 65,25 & 114 & 51,30 & -21 \\
\hline 146 & $\begin{array}{l}\text { Fio cirúrgico algodão } \\
\text { poliést. } 4-0 \text { sem ag. } 15 \text { fios } \\
45 \mathrm{~cm}\end{array}$ & 144 & 381,60 & 130 & 344,50 & -10 \\
\hline 170 & $\begin{array}{l}\text { Fio cirúrgico } \\
\text { poliglecaprone } 3-0 \text { ag1/2 } \\
\text { circ.cil } 2,5 \mathrm{~cm}\end{array}$ & 144 & $1.180,80$ & 158 & $1.295,60$ & 10 \\
\hline 176 & $\begin{array}{l}\text { Fio cirúrgico polipropileno } \\
3-02 \text { ag. } 1 / 2 \text { circ. Cil. } \\
3,0 \mathrm{~cm}\end{array}$ & 144 & $1.044,00$ & 147 & $1.065,75$ & 2 \\
\hline 194 & $\begin{array}{l}\text { Fita cirúrgica microporosa } \\
25 \mathrm{~mm} \times 10 \mathrm{mt} \text { hipoalérgica }\end{array}$ & 144 & 171,36 & 109 & 129,71 & -24 \\
\hline 186 & $\begin{array}{l}\text { Fio cirúrgico sintético } \\
\text { absorv. } 2-0 \text { ag. } 3 / 8 \text { circ. cil } \\
3,0 \mathrm{~cm}\end{array}$ & 132 & 646,80 & 232 & 1136,80 & 76 \\
\hline 18 & $\begin{array}{l}\text { Atadura algodão } \\
\text { ortopédico } 10 \mathrm{~cm} \times 1,80 \mathrm{~m}\end{array}$ & 130 & 23,40 & 5 & 0,90 & -96 \\
\hline 32 & $\begin{array}{l}\text { Atadura rayon } 7 \mathrm{~cm} \mathrm{x} \\
20 \mathrm{~cm}\end{array}$ & 130 & 84,50 & 83 & 53,95 & -36 \\
\hline 126 & Equipo cistoscopia & 127 & $1.140,46$ & 50 & 449,00 & -61 \\
\hline 253 & Sonda foley 122 vias & 127 & 102,87 & 75 & 60,75 & -41 \\
\hline 83 & $\begin{array}{l}\text { Cateter intravenoso } \\
\text { periférico } 14 \mathrm{~g}\end{array}$ & 120 & 350,34 & 158 & 461,28 & 32 \\
\hline 196 & $\begin{array}{l}\text { Fita crepe branco } 16 \mathrm{~mm} \mathrm{x} \\
50 \mathrm{mt} \text { hipoalérgica }\end{array}$ & 120 & 136,80 & 71 & 80,94 & -41 \\
\hline 45 & $\begin{array}{l}\text { Caneta marcação de } \\
\text { varizes preta }\end{array}$ & 116 & $1.984,89$ & 130 & $2.224,44$ & 12 \\
\hline 287 & $\begin{array}{l}\text { Tubo coleta sangue a } \\
\text { vácuo azul } 1,8 \mathrm{ml} \text { citrato }\end{array}$ & 114 & 36,48 & 25 & 8,00 & -78 \\
\hline 195 & $\begin{array}{l}\text { Fita cirúrgica microporosa } \\
50 \mathrm{~mm} \times 10 \mathrm{mt} \text { hipoalérgica }\end{array}$ & 113 & 334,84 & 88 & 260,76 & -22 \\
\hline
\end{tabular}




\begin{tabular}{|c|c|c|c|c|c|c|}
\hline \multirow[b]{2}{*}{ CÓDIGO } & \multirow{2}{*}{$\begin{array}{l}\text { DESCRIÇÃO DO } \\
\text { MATERIAL }\end{array}$} & \multicolumn{2}{|c|}{2007} & \multicolumn{2}{|c|}{2008} & \multirow{2}{*}{$\begin{array}{c}\% \text { da } \\
\text { diferença } \\
\text { dos anos }\end{array}$} \\
\hline & & $\begin{array}{c}\text { Consumo } \\
\text { Qt }\end{array}$ & Custo $R \$$ & $\begin{array}{c}\text { Consumo } \\
\text { Qt }\end{array}$ & Custo $R \$$ & \\
\hline 127 & $\begin{array}{l}\text { Equipo irrigação vesical } \\
2 \mathrm{v}\end{array}$ & 106 & 907,36 & 46 & 393,76 & -57 \\
\hline 129 & Equipo microgotas & 105 & 225,75 & 14 & 30,10 & -87 \\
\hline 247 & Seringa gasometria $2 \mathrm{ml}$ & 102 & 156,06 & 186 & 284,58 & 82 \\
\hline 98 & $\begin{array}{l}\text { Compressa gaze branco } \\
7,5 \mathrm{~cm} \times 6 \mathrm{~cm} \text { ocular }\end{array}$ & 100 & 70,00 & 47 & 32,90 & -53 \\
\hline 285 & $\begin{array}{l}\text { Tubo coleta vácuo fluoreto } \\
\text { de sódio, edta cinza } \\
2 \mathrm{ml} / 3 \mathrm{ml}\end{array}$ & 100 & 35,00 & 10 & 3,50 & -90 \\
\hline 289 & $\begin{array}{l}\text { Tubo coleta sangue a } \\
\text { vácuo verm } 9 \text { a } 10 \mathrm{ml} \text { sem } \\
\text { gel }\end{array}$ & 100 & 29,72 & 271 & 80,54 & 171 \\
\hline
\end{tabular}

Os materiais utilizados em procedimentos ortopédicos, atadura de algodão ortopédico (códigos 19, 20 e 18) e atadura gessada (códigos 29 e 30), tiveram uma redução de 26 a $96 \%$ de consumo. Antes da implantação do SGM, esses materiais eram armazenados em um carro de inox de 3 andares onde ficavam todos os materiais para confecção de gesso. Ao precisar dos materiais para o procedimento, o carro era levado até a sala operatória e o cirurgião consumia o material que julgasse necessário. Hoje, esses materiais ficam na área de suprimentos e são levados para à sala operatória somente a quantidade necessária para um procedimento.

O equipo de cistoscopia é utilizado em procedimentos de cirurgia de próstata, cistoscopia e artroscopia. No período da coleta de dados, em 2008, houve uma diminuição dos procedimentos justificados por quebra de óptica de urologia e diminuição da demanda de artroscopia, o que levou a uma redução de consumo em $61 \%$ desse item.

Para o equipo microgotas (-87\%), foi entendido como uma diminuição do desperdício, e, no equipo irrigação vesical 2 vias (- 57\%, foi detectada a sua subutilização atribuída à diminuição dos procedimentos de Ressecção Trans Uretral de próstata.

O fio cirúrgico sintético absorvível 2.0 ag. $3 / 8$ circ. cil. 3,0cm (76\%) e o tubo coleta sangue a vácuo verm. 9 a $10 \mathrm{ml}$ sem gel (171\%) apresentaram aumento no consumo, o que possibilitou conhecer o gasto real. A seringa de $1 \mathrm{ml}$ também teve aumento representativo de $35 \%$. Para 
este material foi verificada a mudança de conduta do procedimento anestésico com analgesia pós-operatória. Assim como o cateter intravenoso periférico $14 \mathrm{G}$ com $35 \%$ de aumento de consumo utilizado no intraoperatório de colecistectomia e cirurgia endonasal da especialidade da otorrinolaringologia. O desenvolvimento dos procedimentos cirúrgicos leva a algumas adaptações, influenciando diretamente no consumo de materiais. Quanto ao aumento de $82 \%$ do consumo de seringa de gasometria, não foi encontrada a causa que justificasse o resultado.

$\mathrm{Na}$ fita adesiva microporosa para sutura de pele (código 191), foi observado um aumento de consumo de $75 \%$ por falta de uma política de padronização dos materiais para critérios de uso. No hospital, existe somente a padronização do material para aquisição que passa a fazer parte do estoque, necessitando ser instituída a política de critérios de uso do material. A fita adesiva microporosa deve ser utilizada em procedimentos em que a fita deve ser estéril e aplicada diretamente na pele, ao final da cirurgia, entretanto a utilização desse material no hospital varia muito da preferência do cirurgião e não do critério de uso. Esse material deve ter sua utilização padronizada, pois por um lado, evita o uso indiscriminado do material e, por outro lado, facilita a previsão e provisão do estoque.

Os profissionais não conscientizados e mal orientados utilizam os materiais de forma inadequada, sem a preocupação do custo, gerando desperdício (Queiroz, Spiri, Juliani, 2004).

$\mathrm{Na}$ implementação do SGM, houve a participação, orientação e sensibilização de todos os profissionais envolvidos.

Finalizando o estudo do consumo de materiais, dos 115 itens que apresentaram acima de 100 a 45.000 unidades consumidas, no período da coleta de dados, 70 (60,87\%) itens apresentaram redução, e 45 (39,13\%) itens apresentaram aumento do consumo de material.

Em seguida, dentre os 293 itens de materiais, foi estudado o consumo de todos os fios cirúrgicos. Na Figura 22 e na Tabela 16, mostra o consumo de 52 itens de fios cirúrgicos, podendo ser observado que, em 2007 e 2008, apresentou um consumo, com algumas diferenças, como se pode observar na Figura 22, a seguir. 


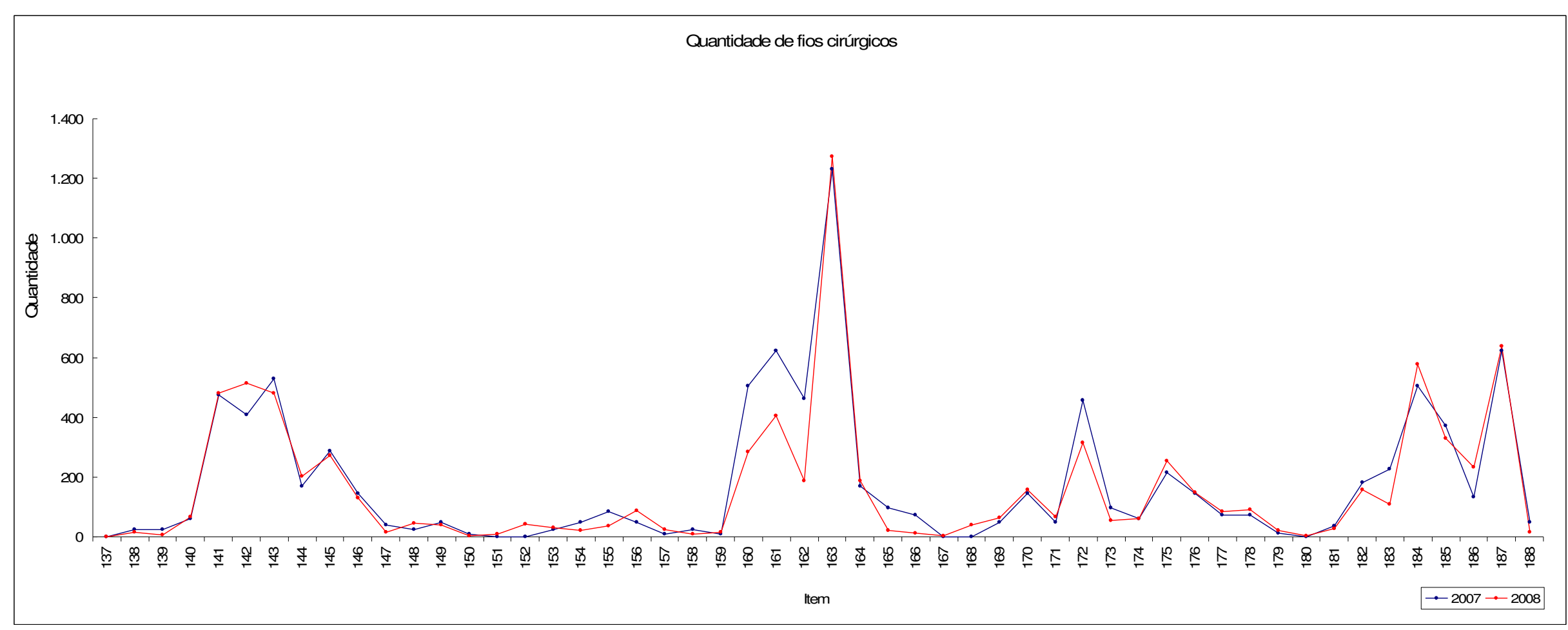

Figura 22. Quantidade dos fios cirúrgicos consumidos nos anos de 2007 e 2008, São Paulo - 2008 
Na Figura 22, dos 52 tipos de fios, 1 (1,92\%) manteve a mesma quantidade consumida, 23 (44,24\%) diminuíram e 28 (53,84\%) aumentaram. A diminuição encontrada pode ser atribuída a sensibilização da equipe cirúrgica em relação ao desperdício. Nos hospitais de ensino, é comum em sala operatória o aluno ou residente solicitarem a abertura do material antes de terem certeza que será utilizado. No HU, o SGM serviu como uma ferramenta para despertar uma nova consciência entre os cirurgiões que passaram a pedir a abertura do fio cirúrgico somente no momento do uso, sendo uma medida educativa para alunos e residentes.

$\mathrm{Na}$ verdade, o Centro Cirúrgico não conhecia o consumo real de fios, tendo como mito ser este um material muito caro para a instituição, com muitos tipos de fios cirúrgicos e com consumo em demasia. Em 2007, os fios cirúrgicos eram armazenados em carros próximos às salas operatórias, e o cirurgião escolhia o fio que iria precisar. Em 2008, todos os fios cirúrgicos passaram a serem armazenados na Área de Suprimentos do Centro Cirúrgico, e o cirurgião somente solicita o fio ao circulante de sala antes de iniciar a cirurgia. Desta forma, a intenção era diminuir o consumo, mas, analisando a Figura 22, foi observado que, dos 52 tipos, de fios houve um aumento de $53,84 \%$ do consumo, o que nos leva a pensar ser esta quantidade realmente necessária.

Outro ponto relevante é a representação gráfica de 2007 e 2008 da Figura 22 que mostrou o perfil do tipo e as quantidades de fios necessárias para serem consumidas no HU-USP.

Quando os dados mostram o consumo real, é possível perceber quais os fios cirúrgicos são imprescindíveis, apesar de alguns tipos apresentarem um consumo baixo. Normalmente, os fios cirúrgicos não são substituíveis, tamanha é a sua importância e a necessidade de se ter esse material em Centro Cirúrgico em quantidade certa, no tipo certo e na hora certa para ser utilizado. Por isso, são atribuídos como Z na classificação de criticidade preconizado por Lourenço, 2006.

Em uma pesquisa realizada em 74 hospitais do município de São Paulo, foi possível conhecer que a maioria das instituições estudadas possui a maioria de fios cirúrgicos disponíveis no mercado em variedade de 
composição, tanto na categoria de absorvíveis como inabsorviveis (Ribeiro, 2001).

O mito de grandes consumos, de muitos tipos de fios e de alto custo no Hospital Universitário pode ser conseqüência de um estoque inadequado, com grandes quantidades por desconhecimento real do consumo e dos tipos de fios que são necessários em determinadas demandas cirúrgicas.

Tabela 16 - Relação do consumo e do custo dos fios cirúrgicos nos anos de 2007 e 2008, São Paulo - 2008

\begin{tabular}{|c|c|c|c|c|c|c|}
\hline \multirow{2}{*}{ CÓDIGO } & \multirow{2}{*}{$\begin{array}{l}\text { DESCRIÇÃO DO } \\
\text { MATERIAL }\end{array}$} & \multicolumn{2}{|c|}{2007} & \multicolumn{2}{|c|}{2008} & \multirow{2}{*}{$\begin{array}{c}\% \text { da } \\
\text { diferença } \\
\text { dos anos }\end{array}$} \\
\hline & & $\begin{array}{c}\text { Consumo } \\
\text { Qt }\end{array}$ & Custo $R \$$ & $\begin{array}{c}\text { Consumo } \\
\text { Qt }\end{array}$ & Custo $R \$$ & \\
\hline 137 & $\begin{array}{l}\text { Fio cirúrgico aço } 0 \text { sem } \\
\text { ag. } 3 \text { fios } 60 \mathrm{~cm}\end{array}$ & 0 & 0,00 & 1 & 3,79 & 1 \\
\hline 138 & $\begin{array}{l}\text { Fio cirúrgico aço } 1 \mathrm{sem} \\
\text { ag. } 3 \text { fios } 60 \mathrm{~cm}\end{array}$ & 24 & 105,60 & 14 & 61,60 & -42 \\
\hline 139 & $\begin{array}{l}\text { Fio cirúrgico aço } 2-0 \text { sem } \\
\text { ag. } 3 \text { fios } 60 \mathrm{~cm}\end{array}$ & 24 & 106,08 & 6 & 26,52 & -75 \\
\hline 140 & $\begin{array}{l}\text { Fio cirúrgico algodão } \\
\text { poliést.0 sem ag. } 15 \text { fios } \\
45 \mathrm{~cm}\end{array}$ & 60 & 193,80 & 68 & 219,64 & 13 \\
\hline 141 & $\begin{array}{l}\text { Fio cirúrgico algodão } \\
\text { poliést.2-0 ag. } 1 / 2 \text { circ. } \\
\text { cil.2,5cm }\end{array}$ & 475 & $1.225,50$ & 480 & $1.238,40$ & 1 \\
\hline 142 & $\begin{array}{l}\text { Fio cirúrgico algodão } \\
\text { poliést.2-0 sem ag. } 15 \text { fios } \\
45 \mathrm{~cm}\end{array}$ & 408 & 285,60 & 513 & 359,10 & 26 \\
\hline 143 & $\begin{array}{l}\text { Fio cirúrgico algodão } \\
\text { poliést.3-0 ag. } 1 / 2 \text { circ. } \\
\text { cil.2,5cm }\end{array}$ & 528 & $1.716,00$ & 482 & $1.566,50$ & -9 \\
\hline 144 & $\begin{array}{l}\text { Fio cirúrgico algodão } \\
\text { poliést.3-0 sem ag. } 15 \text { fios } \\
45 \mathrm{~cm}\end{array}$ & 168 & 420,00 & 204 & 510,00 & 21 \\
\hline 145 & $\begin{array}{l}\text { Fio cirúrgico algodão } \\
\text { poliést. } 4-0 \text { ag. } 1 / 2 \text { circ. cil. } \\
2,5 \mathrm{~cm}\end{array}$ & 288 & 936,00 & 271 & 880,75 & -6 \\
\hline 146 & $\begin{array}{l}\text { Fio cirúrgico algodão } \\
\text { poliést. } 4-0 \text { sem ag. } 15 \text { fios } \\
45 \mathrm{~cm}\end{array}$ & 144 & 381,60 & 130 & 344,50 & -10 \\
\hline 147 & $\begin{array}{l}\text { Fio cirúrgico catigut crom. } \\
1 \text { ag. } 1 / 2 \text { circ. cil. } 5,0 \mathrm{~cm}\end{array}$ & 40 & 100,00 & 15 & 37,50 & -63 \\
\hline 148 & $\begin{array}{l}\text { Fio cirúrgico catigut crom. } \\
2-0 \text { ag. } 1 / 2 \text { circ. cil. } 2,5 \mathrm{~cm}\end{array}$ & 24 & 63,84 & 45 & 119,70 & 88 \\
\hline 149 & $\begin{array}{l}\text { Fio cirúrgico catigut crom. } \\
3-0 \text { ag. } 1 / 2 \text { circ. cil. } 2,5 \mathrm{~cm}\end{array}$ & 48 & 192,00 & 39 & 156,00 & -19 \\
\hline
\end{tabular}




\begin{tabular}{|c|c|c|c|c|c|c|}
\hline \multirow{2}{*}{ CÓDIGO } & \multirow{2}{*}{$\begin{array}{l}\text { DESCRIÇÃO DO } \\
\text { MATERIAL }\end{array}$} & \multicolumn{2}{|c|}{2007} & \multicolumn{2}{|c|}{2008} & \multirow{2}{*}{$\begin{array}{c}\% \text { da } \\
\text { diferença } \\
\text { dos anos }\end{array}$} \\
\hline & & $\begin{array}{l}\text { Consumo } \\
\text { Qt }\end{array}$ & Custo $R \$$ & $\begin{array}{c}\text { Consumo } \\
\text { Qt }\end{array}$ & Custo $R \$$ & \\
\hline 150 & $\begin{array}{l}\text { Fio cirúrgico catigut } \\
\text { crom.5-0 ag. } 1 / 2 \text { circ. cil. } \\
1,5 \mathrm{~cm}\end{array}$ & 8 & 27,04 & 3 & 10,14 & -63 \\
\hline 151 & $\begin{array}{l}\text { Fio cirúrgico catigut } \\
\text { simples } 0 \text { ag. } 1 / 2 \text { circ. cil.. } \\
2,5 \mathrm{~cm}\end{array}$ & 0 & 0,00 & 9 & 27,90 & 9 \\
\hline 152 & $\begin{array}{l}\text { Fio cirúrgico catigut } \\
\text { simples } 2-0 \text { ag. } 1 / 2 \text { circ. } \\
\text { cil. } 2,5 \mathrm{~cm}\end{array}$ & 0 & 0,00 & 42 & 65,10 & 42 \\
\hline 153 & $\begin{array}{l}\text { Fio cirúrgico catigut } \\
\text { simples } 2-0 \text { ag. } 1 / 2 \text { circ. } \\
\text { cil. } 3,5 \mathrm{~cm}\end{array}$ & 24 & 37,20 & 29 & 44,95 & 21 \\
\hline 154 & $\begin{array}{l}\text { Fio cirúrgico catigut } \\
\text { simples } 2-0 \mathrm{sem} \\
\text { ag. } 150 \mathrm{~cm}\end{array}$ & 48 & 110,40 & 20 & 46,00 & -58 \\
\hline 155 & $\begin{array}{l}\text { Fio cirúrgico catigut } \\
\text { simples } 3-0 \text { ag. } 1 / 2 \text { circ. cil. } \\
2,0 \mathrm{~cm}\end{array}$ & 84 & 202,53 & 37 & 89,21 & -56 \\
\hline 156 & $\begin{array}{l}\text { Fio cirúrgico catigut } \\
\text { simples } 3-0 \text { ag. } 1 / 2 \text { circ. } \\
\text { cil. } 3,5 \mathrm{~cm}\end{array}$ & 48 & 129,12 & 88 & 236,72 & 83 \\
\hline 157 & $\begin{array}{l}\text { Fio cirúrgico catigut } \\
\text { simples } 3-0 \text { sem ag. } \\
150 \mathrm{~cm}\end{array}$ & 9 & 20,70 & 23 & 52,90 & 156 \\
\hline 158 & $\begin{array}{l}\text { Fio cirúrgico catigut } \\
\text { simples } 4-0 \text { sem ag. } \\
150 \mathrm{~cm}\end{array}$ & 24 & 100,56 & 9 & 37,71 & -63 \\
\hline 159 & $\begin{array}{l}\text { Fio cirúrgico catigut } \\
\text { simples } 5-0 \text { ag. } 1 / 2 \text { circ. } \\
\text { cil. } 2,0 \mathrm{~cm}\end{array}$ & 10 & 24,00 & 16 & 38,40 & 60 \\
\hline 160 & $\begin{array}{l}\text { Fio cirúrgico nylon monof. } \\
2-0 \text { ag. } 3 / 8 \text { circ. tri. } 2,0 \mathrm{~cm}\end{array}$ & 504 & $1.260,00$ & 285 & 712,50 & -43 \\
\hline 161 & $\begin{array}{l}\text { Fio cirúrgico nylon monof. } \\
3-0 \text { ag. } 3 / 8 \text { circ. cil. } 2,0 \mathrm{~cm}\end{array}$ & 624 & $1.560,00$ & 405 & $1.012,50$ & -35 \\
\hline 162 & $\begin{array}{l}\text { Fio cirúrgico nylon monof. } \\
4-0 \text { ag. } 3 / 8 \text { circ. tri. } 2,0 \mathrm{~cm}\end{array}$ & 464 & $1.160,00$ & 188 & 470,00 & -59 \\
\hline 163 & $\begin{array}{l}\text { Fio cirúrgico nylon monof. } \\
4-0 \text { ag. } 3 / 8 \text { circ. tri. } 2,4 \mathrm{~cm}\end{array}$ & 1.232 & $2.069,76$ & 1272 & $2.136,96$ & 3 \\
\hline 164 & $\begin{array}{l}\text { Fio cirúrgico nylon monof. } \\
5-0 \text { ag. } 3 / 8 \text { circ.tri. } 2,0 \mathrm{~cm}\end{array}$ & 168 & 420,00 & 187 & 467,50 & 11 \\
\hline 165 & $\begin{array}{l}\text { Fio cirúrgico poliéster } 2 \\
\text { ag. } 1 / 2 \text { circ. tri. } 4,0 \mathrm{~cm}\end{array}$ & 96 & $1.022,40$ & 21 & 223,65 & -78 \\
\hline 166 & $\begin{array}{l}\text { Fio cirúrgico poliéster } 2-0 \\
2 \text { ag. } 1 / 2 \text { circ. cil. } 2,0 \mathrm{~cm}\end{array}$ & 72 & 307,44 & 11 & 46,97 & -85 \\
\hline 167 & $\begin{array}{l}\text { Fio cirúrgico poliéster } 5 \\
\text { ag. } 1 / 2 \text { circ. tri. } 4,7 \mathrm{~cm}\end{array}$ & 0 & 0,00 & 4 & 95,64 & 4 \\
\hline 168 & $\begin{array}{l}\text { Fio cirúrgico } \\
\text { poliglecaprone } 0 \text { ag. } 1 / 2 \\
\text { circ. cil. } 4,0 \mathrm{~cm}\end{array}$ & 0 & 0,00 & 39 & 210,99 & 39 \\
\hline 169 & $\begin{array}{l}\text { Fio cirúrgico } \\
\text { poliglecaprone } 1 \text { ag. } 1 / 2 \\
\text { circ. cil. } 4,0 \mathrm{~cm}\end{array}$ & 48 & 331,20 & 63 & 434,70 & 31 \\
\hline
\end{tabular}




\begin{tabular}{|c|c|c|c|c|c|c|}
\hline \multirow{2}{*}{ CÓDIGO } & \multirow{2}{*}{$\begin{array}{l}\text { DESCRIÇÃO DO } \\
\text { MATERIAL }\end{array}$} & \multicolumn{2}{|c|}{2007} & \multicolumn{2}{|c|}{2008} & \multirow{2}{*}{$\begin{array}{c}\% \text { da } \\
\text { diferença } \\
\text { dos anos }\end{array}$} \\
\hline & & $\begin{array}{c}\text { Consumo } \\
\text { Qt }\end{array}$ & Custo $\mathrm{R} \$$ & $\begin{array}{c}\text { Consumo } \\
\text { Qt }\end{array}$ & Custo $R \$$ & \\
\hline 170 & $\begin{array}{l}\text { Fio cirúrgico } \\
\text { poliglecaprone } 3-0 \text { ag. } 1 / 2 \\
\text { circ. cil. } 2,5 \mathrm{~cm}\end{array}$ & 144 & $1.180,80$ & 158 & $1.295,60$ & 10 \\
\hline 171 & $\begin{array}{l}\text { Fio cirúrgico } \\
\text { poliglecaprone } 4-0 \text { ag. } 1 / 2 \\
\text { circ. cil. } 2,5 \mathrm{~cm}\end{array}$ & 48 & 271,20 & 67 & 378,55 & 40 \\
\hline 172 & $\begin{array}{l}\text { Fio cirúrgico } \\
\text { poliglecaprone } 4-0 \text { ag. } 3 / 8 \\
\text { circ. tri. } 1,95 \mathrm{~cm}\end{array}$ & 456 & $4.199,76$ & 313 & $2.882,73$ & -31 \\
\hline 173 & $\begin{array}{l}\text { Fio cirúrgico } \\
\text { poliglecaprone } 5-0 \text { ag. } 3 / 8 \\
\text { circ. tri. } 1,65 \mathrm{~cm}\end{array}$ & 96 & $1.161,60$ & 54 & 653,40 & -44 \\
\hline 174 & $\begin{array}{l}\text { Fio cirúrgico polipropileno } \\
2 \text { ag. } 3 / 8 \text { circ. cil. } 7,5 \mathrm{~cm}\end{array}$ & 60 & $1.231,80$ & 60 & $1.231,80$ & 0 \\
\hline 175 & $\begin{array}{l}\text { Fio cirúrgico polipropileno } \\
2-0 \text { ag. } 1 / 2 \text { circ. cil. } 2,5 \mathrm{~cm}\end{array}$ & 216 & 885,60 & 255 & $1.045,50$ & 18 \\
\hline 176 & $\begin{array}{l}\text { Fio cirúrgico polipropileno } \\
3-02 \text { ag. } 1 / 2 \text { circ. cil. } \\
3,0 \mathrm{~cm}\end{array}$ & 144 & $1.044,00$ & 147 & $1.065,75$ & 2 \\
\hline 177 & $\begin{array}{l}\text { Fio cirúrgico polipropileno } \\
4-02 \text { ag. } 1 / 2 \text { circ. cil. } 2,0 \mathrm{~cm}\end{array}$ & 72 & 590,20 & 84 & 688,57 & 17 \\
\hline 178 & $\begin{array}{l}\text { Fio cirúrgico polipropileno } \\
4-02 \text { ag. } 1 / 2 \text { circ. cil. } \\
1,5 \mathrm{~cm}\end{array}$ & 72 & 536,40 & 90 & 670,50 & 25 \\
\hline 179 & $\begin{array}{l}\text { Fio cirúrgico polipropileno } \\
6-02 \text { ag. } 3 / 8 \text { circ. cil. } \\
1,3 \mathrm{~cm}\end{array}$ & 12 & 132,00 & 20 & 220,00 & 67 \\
\hline 180 & $\begin{array}{l}\text { Fio cirúrgico polipropileno } \\
7-02 \mathrm{ag} .3 / 8 \text { circ. cil. } \\
1,0 \mathrm{~cm}\end{array}$ & 0 & 0,00 & 2 & 23,50 & 2 \\
\hline 181 & $\begin{array}{l}\text { Fio cirúrgico seda } 4-0 \text { ag. } \\
3 / 8 \text { circ. tri. } 1,3 \mathrm{~cm}\end{array}$ & 36 & 216,00 & 28 & 168,00 & -22 \\
\hline 182 & $\begin{array}{l}\text { Fio cirúrgico sintético } \\
\text { absorv. } 0 \text { ag. } 1 / 2 \text { circ. cil. } \\
5,0 \mathrm{~cm}\end{array}$ & 180 & $1.206,00$ & 156 & $1.045,20$ & -13 \\
\hline 183 & $\begin{array}{l}\text { Fio cirúrgico sintético } \\
\text { absorv. } 0 \text { ag. } 3 / 8 \text { circ. cil. } \\
3,0 \mathrm{~cm}\end{array}$ & 228 & $1.114,92$ & 108 & 528,12 & -53 \\
\hline 184 & $\begin{array}{l}\text { Fio cirúrgico sintético } \\
\text { absorv. } 1 \text { ag. } 1 / 2 \text { circ. cil. } \\
3,5 \mathrm{~cm}\end{array}$ & 504 & $3.563,28$ & 579 & $4.093,53$ & 15 \\
\hline 185 & $\begin{array}{l}\text { Fio cirúrgico sintético } \\
\text { absorv. } 2-0 \text { ag. } 1 / 2 \text { circ. cil. } \\
2,5 \mathrm{~cm}\end{array}$ & 372 & $2.287,24$ & 331 & $2.035,16$ & -11 \\
\hline 186 & $\begin{array}{l}\text { Fio cirúrgico sintético } \\
\text { absorv. } 2-0 \text { ag. } 3 / 8 \text { circ.cil. } \\
3,0 \mathrm{~cm}\end{array}$ & 132 & 646,80 & 232 & $1.136,80$ & 76 \\
\hline 187 & $\begin{array}{l}\text { Fio cirúrgico sintético } \\
\text { absorv. } 3-0 \text { ag. } 1 / 2 \text { circ.cil. } \\
2,5 \mathrm{~cm}\end{array}$ & 623 & $3.999,66$ & 637 & $4.089,54$ & 2 \\
\hline 188 & $\begin{array}{l}\text { Fio cirúrgico sintético } \\
\text { absorv. } 6-02 \text { ag. } 3 / 8 \text { cil. } \\
0,65 \mathrm{~cm}\end{array}$ & 48 & $2.448,00$ & 15 & 765,00 & -69 \\
\hline
\end{tabular}


$\mathrm{Na}$ Tabela 16, alguns fios apresentaram aumento e diminuição de consumo. Entretanto, ao compará-los com a representação gráfica da Figura 10, foi possível observar que 24 tipos de fios apresentaram abaixo de 88 unidades consumidas no período de 4 meses, o que sugere uma reavaliação do estoque. Esses fios são da categoria de fio de aço (código 137 a 139), catgut cromado e simples (código 147 a 159), os fios poliéster e poliglecaprone (código 165 a 169) e os fios polipropileno e seda (código 179 a 181).

\subsection{AVALIAÇÃO DO CONSUMO DOS KITS CIRÚRGICOS E ANESTÉSICOS EM 2008}

Com a implantação do SGM, houve a possibilidade de reavaliar todos os kit já existentes no Centro Cirúrgico, uma vez que sua utilização facilita o controle do consumo, conforme já explicado nesse estudo. Assim, para a realização dos procedimentos cirúrgicos, foram padronizados 90 kits. Para toda a cirurgia realizada no Centro Cirúrgico do HU-USP, existe no mínimo a reserva de um kit cirúrgico, um kit anestésico e um conjunto de materiais avulsos dispensados durante a cirurgia.

A padronização desses kits foi baseada na experiência de consumo referido pela equipe de enfermagem e médica.

No período de fevereiro a maio de 2008, foram utilizados $81 \mathrm{kit}$.

O estudo do consumo desses kits nos 4 meses de 2008, envolvendo na sua confecção 400 itens de materiais, demonstrou a necessidade de maiores ajustes na quantidade de materiais que os compõem. Isto pode ser observado na Tabela 17. 
Tabela 17 - Distribuição de itens consumidos em 2008, São Paulo - 2008

\begin{tabular}{lccccc}
\hline MÊS/2008 & $\begin{array}{c}\text { TOTAL DE } \\
\text { ITENS } \\
\text { CONSUMIDOS }\end{array}$ & $\begin{array}{c}\text { TOTAL DE } \\
\text { ITENS } \\
\begin{array}{c}\text { cONSUMIDOS } \\
\text { DOS KIT }\end{array}\end{array}$ & \% DE KIT & $\begin{array}{c}\text { TOTAL DE } \\
\text { ITENS } \\
\text { AVULSOS } \\
\text { CONSUMIDOS }\end{array}$ & $\begin{array}{c}\text { \% DE } \\
\text { AVULSOS EM } \\
\text { RELAÇO AO } \\
\text { TOTAL }\end{array}$ \\
\hline Fevereiro & 17.229 & 11.918 & 69,2 & 5.311 & 30,8 \\
Março & 20.465 & 12.791 & 62,5 & 7.674 & 37,5 \\
Abril & 20.516 & 13.471 & 65,7 & 7.045 & 34,3 \\
Maio & 19.206 & 11.922 & 62,1 & 7.284 & 37,9 \\
\hline $\begin{array}{l}\text { Total em } \\
\mathbf{2 0 0 8}\end{array}$ & $\mathbf{7 7 . 4 1 6}$ & $\mathbf{5 0 . 1 0 2}$ & $\mathbf{6 4 , 7}$ & $\mathbf{2 7 . 3 1 4}$ & $\mathbf{3 5 , 3}$ \\
\hline
\end{tabular}

Para este período, foi detectado que $64,7 \%$ do consumo de materiais fazem parte de kits de procedimentos cirúrgicos e anestésicos, e $35,3 \%$ são materiais avulsos durante a cirurgia. Acreditamos que esses valores de consumo de materiais avulsos são consequências do período de adaptação ao SGM, pois envolve a confiança do usuário ao acreditar que o material que compõe o kit é suficiente para a cirurgia, não havendo necessidade de materiais avulsos em demasia.

Não foram encontrados, na literatura, dados sobre o consumo de materiais e nem nos hospitais privados, que tem um sistema de gestão de materiais informatizado, não apresentaram dados sobre os kits ou materiais avulsos.

Diante dessa colocação, não é possível fazer uma análise sobre esses valores. Mas sabemos que o importante é estabelecer como meta uma proporção considerada aceitável pela instituição entre o kit e os materiais dispensados de maneira avulsa. Portanto, cada instituição deve estabelecer medidas para reduzir cada vez mais os materiais avulsos e utilizar o máximo de materiais dos kit baseado nas metas que pretende atingir.

O kit é produzido para atender melhor o paciente, minimizar o estresse, controlar os materiais, evitar desperdícios, manter a quantidade e $o$ tipo de material suficiente para cada procedimento, de maneira estruturada e planejada, para melhor aproveitamento da estrutura de recursos humanos, 
facilitando as atividades do profissional, diminuindo o trabalho redobrado da equipe, e por fim, minimizando os custos.

No Hospital Universitário, estima-se, como meta, aumentar em até $80 \%$ para o consumo de materiais em kit e diminuir cada vez mais os materiais consumidos de maneira avulsa.

Desse modo, é importante realizar avaliação periódica dos kits com um olhar crítico para a quantidade, e os tipos de materiais que devem fazer parte desse conjunto, com o objetivo de um melhor aproveitamento e, consequentemente, diminuição do estorno (devolução) do material.

$\mathrm{Na}$ Tabela 18, observam-se todos os kits consumidos no período estudado do ano de 2008. Os kits apresentam um estorno (devolução) de material que deve ser considerado. Ao analisar todos os kits percebe-se que, dos 81 kits utilizados, 54(66,6\%) apresentam um consumo de material abaixo de $51,9 \%$.

Tabela 18 - Relação do consumo de materiais (\%) dos kits cirúrgicos e anestésicos em 2008, São Paulo - 2008

\begin{tabular}{|c|c|c|c|c|}
\hline KIT & SAÍDA & ESTORNO & CONSUMO & CONSUMIDA \\
\hline Timpanoplastia & 312 & 99 & 213 & 68,3 \\
\hline $\begin{array}{l}\text { Artroscopia e reconstrução } \\
\text { ligamentar de joelho }\end{array}$ & 669 & 216 & 453 & 67,7 \\
\hline Nefrectomia & 188 & 65 & 123 & 65,4 \\
\hline Facectomia extracapsular & 871 & 311 & 560 & 64,3 \\
\hline Esofagogastrofundoplicatura & 130 & 49 & 81 & 62,3 \\
\hline Buco maxilo pequeno & 574 & 237 & 337 & 58,7 \\
\hline $\begin{array}{l}\text { Laringoscopia direta com vídeo ou } \\
\text { traqueoplastia }\end{array}$ & 193 & 80 & 113 & 58,5 \\
\hline Retossigmoidectomia & 580 & 245 & 335 & 57,8 \\
\hline $\begin{array}{l}\text { Correção de incontinência urinária } \\
\text { com TVTO }\end{array}$ & 340 & 145 & 195 & 57,4 \\
\hline Mastoidectomia & 58 & 25 & 33 & 56,9 \\
\hline Postectomia & 1.634 & 708 & 926 & 56,7 \\
\hline Pielolitotomia & 113 & 50 & 63 & 55,8 \\
\hline RTU & 1.169 & 525 & 644 & 55,1 \\
\hline Laparoscopia ginecológica & 1.217 & 548 & 669 & 55,0 \\
\hline Enxerto de pele & 226 & 102 & 124 & 54,9 \\
\hline Endoscopia & 371 & 168 & 203 & 54,7 \\
\hline Fístula artério venosa & 175 & 80 & 95 & 54,3 \\
\hline Mastectomia & 148 & 68 & 80 & 54,1 \\
\hline Cateter central & 253 & 117 & 136 & 53,8 \\
\hline
\end{tabular}


(continuação)

\begin{tabular}{|c|c|c|c|c|}
\hline KIT & SAÍDA & ESTORNO & CONSUMO & $\begin{array}{c}\% \\
\text { CONSUMIDA }\end{array}$ \\
\hline $\begin{array}{l}\text { Passagem e retirada de cateter } \\
\text { duplo } \mathrm{J}\end{array}$ & 200 & 93 & 107 & 53,5 \\
\hline Conização & 58 & 27 & 31 & 53,4 \\
\hline Gastrectomia & 763 & 359 & 404 & 52,9 \\
\hline Orquipexia & 318 & 150 & 168 & 52,8 \\
\hline Pancreatectomia & 312 & 149 & 163 & 52,2 \\
\hline Derivação bileodigestiva & 69 & 33 & 36 & 52,2 \\
\hline Pequena cirurgia ginecológica & 192 & 92 & 100 & 52,1 \\
\hline Histerectomia abdominal & 2.094 & 1.006 & 1.088 & 52,0 \\
\hline Herniorrafia & 6.971 & 3.350 & 3621 & 51,9 \\
\hline Cirurgia de calázio & 176 & 87 & 89 & 50,6 \\
\hline Hemorroidectomia & 1.884 & 953 & 931 & 49,4 \\
\hline Erradicação de varizes & 1.135 & 586 & 549 & 48,4 \\
\hline Cirurgia ortopédica & 4.009 & 2.070 & 1.939 & 48,4 \\
\hline Buco maxilo grande & 2.671 & 1.397 & 1.274 & 47,7 \\
\hline Microcirurgia de laringe & 32 & 17 & 15 & 46,9 \\
\hline $\begin{array}{l}\text { Correção de hérnia hiatal } \\
\text { laparoscópica }\end{array}$ & 141 & 75 & 66 & 46,8 \\
\hline Drenagem tórax infantil & 106 & 57 & 49 & 46,2 \\
\hline Tireoidectomia & 937 & 506 & 431 & 46,0 \\
\hline Cirurgia oftalmológica & 242 & 131 & 111 & 45,9 \\
\hline Ureterolitotomia endoscopica & 240 & 131 & 109 & 45,4 \\
\hline Prostatectomia & 1.131 & 618 & 513 & 45,4 \\
\hline Facectomia com facoemulsificador & 1.367 & 747 & 620 & 45,4 \\
\hline Anestesia complementar & 270 & 148 & 122 & 45,2 \\
\hline Cirurgia ginecológica vaginal & 1.292 & 713 & 579 & 44,8 \\
\hline Endonasal & 1.686 & 944 & 742 & 44,0 \\
\hline Traqueostomia & 280 & 157 & 123 & 43,9 \\
\hline Histerectomia laparoscopica & 130 & 73 & 57 & 43,8 \\
\hline Artroplastia total de quadril & 727 & 409 & 318 & 43,7 \\
\hline Laparotomia exploradora & 11.112 & 6.266 & 4.846 & 43,6 \\
\hline Artroscopia de ombro & 218 & 123 & 95 & 43,6 \\
\hline Plástica pequeno & 1.153 & 660 & 493 & 42,8 \\
\hline Cirurgia laparoscópica & 7.400 & 4.241 & 3.159 & 42,7 \\
\hline Colocação de porto cath ( para Qt) & 54 & 31 & 23 & 42,6 \\
\hline Setorectomia & 546 & 314 & 232 & 42,5 \\
\hline Artroscopia & 92 & 53 & 39 & 42,4 \\
\hline $\begin{array}{l}\text { Colecistectomia convencional } \\
\text { ERVB }\end{array}$ & 2.312 & 1.350 & 962 & 41,6 \\
\hline Histeroscopia & 808 & 473 & 335 & 41,5 \\
\hline Toracotomia adulto & 1.080 & 633 & 447 & 41,4 \\
\hline Aneurisma de aorta & 92 & 54 & 38 & 41,3 \\
\hline Ureterolitotomia & 212 & 125 & 87 & 41,0 \\
\hline Cistoscopia & 126 & 75 & 51 & 40,5 \\
\hline Adenoamigdalectomia & 1.443 & 862 & 581 & 40,3 \\
\hline Osteossíntese membro inferior & 3.682 & 2.205 & 1.477 & 40,1 \\
\hline Esofagogastrofundoplicatura RN & 65 & 39 & 26 & 40,0 \\
\hline
\end{tabular}

(continua) 


\begin{tabular}{lrrrr}
\hline \multicolumn{1}{c}{ KIT } & SAÍDA & ESTORNO & CONSUMO & $\begin{array}{c}\% \\
\text { CONSUMIDA }\end{array}$ \\
\hline Drenagem de abscesso MMII & 80 & 48 & 32 & 40,0 \\
Osteossíntese de membro superior & 1.854 & 1.149 & 705 & 38,0 \\
Amputação de membros & 687 & 426 & 261 & 38,0 \\
Urologia adulto pequeno & 676 & 423 & 253 & 37,4 \\
Toracoscopia adulto & 346 & 220 & 126 & 36,4 \\
Pequena cirurgia & 1880 & 1.202 & 678 & 36,1 \\
Anestesia infantil & 10.977 & 7.200 & 3.777 & 34,4 \\
Alongamento de partes moles & 32 & 21 & 11 & 34,4 \\
Plástica grande & 1.571 & 1.034 & 537 & 34,2 \\
Curetagem uterina & 209 & 138 & 71 & 34,0 \\
Anestesia adulto & 73.541 & 48.672 & 24.869 & 33,8 \\
Enxerto femuro popliteo & 278 & 185 & 93 & 33,5 \\
Cirurgia vascular & 80 & 54 & 26 & 32,5 \\
Drenagem de tórax adulto & 36 & 25 & 11 & 30,6 \\
Cirurgia de dácrio & 21 & 15 & 6 & 28,6 \\
Correção de hipospadia & 119 & 86 & 33 & 27,7 \\
Urologia Infantil pequeno & 107 & 81 & 26 & 24,3 \\
Toracotomia infantil & 245 & 198 & 47 & 19,2 \\
\hline
\end{tabular}

Analisando a Tabela 18, o kit de toracotomia infantil é o kit que apresenta a menor porcentagem de itens consumidos com $19,2 \%$. O que significa que $80,8 \%$ do material não são consumidos e são devolvidos para Área de Suprimentos, ocorrendo o trabalho dobrado do profissional. Entretanto, é um kit pouco utilizado, devido ao baixo movimento cirúrgico apresentado.

O mesmo não se pode dizer sobre o kit anestésico adulto. Este kit é dispensado para todas as cirurgias de pacientes adultos, e o consumo de materiais que ele é composto é somente de $33,8 \%$. Em seguida, encontra-se o kit de cirurgia laparoscópica com $42,7 \%$ dos materiais utilizados; o kit de laparotomia exploradora com 43,6\%; e o kit de herniorrafia com 51,9\%. Todos esses kits citados são bastante utilizados, pois eles são considerados básicos que atendem a maioria das cirurgias de pequeno, médio e grande porte.

Apesar de 54 kits $(66,6 \%)$ atingirem o consumo de material abaixo de $51,9 \%$ e, dentre eles, o kit de toracotomia infantil consumir apenas $19,2 \%$ 
de material, como mostra a Tabela 18, vale ressaltar a importância de iniciar uma reestruturação pelos kits mais utilizados.

A equipe de enfermagem tem um trabalho redobrado grande na Área de Suprimentos I do Centro Cirúrgico, com o estorno (devolução) de materiais no final da cirurgia, impactando o estoque do setor. Desse modo, há necessidade de estudos futuros que possibilitem a avaliação do conteúdo e quantidades dos materiais dos kits cirúrgicos mais utilizados e que apresentem menor consumo e, consequentemente, maior estorno.

$\mathrm{Na}$ literatura consultada, não foram encontradas referências sobre a composição de kits de procedimentos de cirurgia e anestesia e sobre a metodologia aplicada para a sua elaboração. Nos hospitais que trabalham com padronização de kits de procedimentos, costuma-se fazer um levantamento dos que têm sido utilizados em cada procedimento e analisados esses dados com a equipe cirúrgica e anestésica, de acordo com as necessidades e desejos de cada um. A escolha dos itens e a quantidade dependem da conscientização de cada equipe. Como resultado, encontra-se kit com excesso de materiais.

Todavia é impossível elaborar um kit com quantidade e tipos de materiais exatos a serem consumidos, mas é fundamental elaborar kit que não tenha nem falta de material e nem excesso.

Para a reestruturação dos kits cirúrgicos, é fundamental estabelecer critérios para a seleção e quantidade dos materiais e não apenas um levantamento dos itens mais utilizados.

Portanto é importante que, além de realizar periodicamente a avaliação dos kits cirúrgicos, cada instituição deve estabelecer um método de avaliação.

No HU-USP, com a implantação do SGM, tornou-se possível elaborar um método para avaliação dos kits utilizando a Classificação $X Y Z$ (grau de criticidade do material) e a análise dos dados do consumo de material de um determinado período, para estabelecer o tipo e a quantidade de cada item. 


\subsection{AVALIAÇÃO DO ESTOQUE DE MATERIAIS DO CENTRO CIRÚRGICO NO PERÍODO ESTUDADO}

Antes da implantação do SGM,o Hospital Universitário utilizava o sistema tradicional de gestão de materiais, com a manutenção de estoque baseada $\mathrm{m}$ cotas preestabelecidas,e reposição mensal para completar a cota, ocasionando grandes estoques com um custo elevado. A complementação da cota era feita pela contagem dos itens consumidos no período.

Ao implantar o sistema SGM em 2008, baseado no JIT, foi estabelecido, aleatoriamente, um ponto de pedido inicial para os materiais. Ou seja, um ponto mínimo (estoque de segurança) e uma quantidade de abastecimento com reposição contínua de material, de acordo com a experiência da equipe de enfermagem do Centro Cirúrgico e do almoxarifado.

Para obter a quantidade do estoque nos dois anos estudados, foi utilizado, para calcular o estoque de 2007, 2 parâmetros: a quantidade de material que já havia em estoque e o material solicitado para completar a cota preestabelecida ou a cota integral ao setor de Almoxarifado. Esta prática, de manter o estoque do sistema tradicional, levava a um acúmulo de materiais excessivos no Centro Cirúrgico. Em 2008, para o cálculo do estoque, foi utilizado o ponto mínimo (estoque de segurança) e a quantidade de abastecimento de cada material.

Assim, considerando os 293 itens, foi possível estudar a quantidade existente de materiais no estoque do ano de 2007 e 2008, conforme demonstra a Tabela 19 a seguir. 
Tabela 19 - Distribuição mensal de itens estocados no Centro Cirúrgico nos anos de 2007 e 2008, São Paulo - 2008

\begin{tabular}{lcccccccc}
\hline \multirow{2}{*}{ MÊS } & \multicolumn{2}{c}{2007} & \multicolumn{2}{c}{2008} & \multicolumn{3}{c}{ DIFERENÇA DOS ANOS } \\
\cline { 2 - 9 } & QTDE & $\begin{array}{c}\text { CUSTO } \\
(\mathrm{R} \$)\end{array}$ & QTDE & $\begin{array}{c}\text { CUSTO } \\
(\mathrm{R} \$)\end{array}$ & QTDE & $\begin{array}{c}\text { \% } \\
\text { QTDE }\end{array}$ & CUSTO & $\begin{array}{c}\text { \% } \\
\text { CUSTO }\end{array}$ \\
\hline Fevereiro & 56.974 & $196.722,60$ & 43.576 & $178.574,30$ & 13.398 & $-23,51$ & $18.148,29$ & $-9,22$ \\
Março & 69.892 & $233.316,00$ & 43.575 & $177.423,40$ & 26.317 & $-37,65$ & $55.892,61$ & $-23,95$ \\
Abril & 60.547 & $192.523,20$ & 45.097 & $172.570,20$ & 15.450 & $-25,51$ & $19.953,00$ & $-10,36$ \\
Maio & 55.389 & $177.343,10$ & 46.892 & $171.612,10$ & 8.497 & $-15,34$ & $5.730,95$ & $-3,23$ \\
\hline TOTAL & $\mathbf{2 4 2 . 8 0 2}$ & $\mathbf{7 9 9 . 9 0 4 , 8 0}$ & $\mathbf{1 7 9 . 1 4 0}$ & $\mathbf{7 0 0 . 1 8 0 , 0 0}$ & $\mathbf{6 3 . 6 6 2}$ & $\mathbf{- 2 6 , 2 2}$ & $\mathbf{9 9 . 7 2 4 , 8 5}$ & $\mathbf{- 1 2 , 4 6}$ \\
\hline
\end{tabular}

Ao analisar o estoque de materiais no período estudado, foi possível detectar uma diminuição dos itens de materiais estocados $(26,22 \%)$ e uma redução em seus custos (12,46\%). Pode-se dizer que há uma tendência em diminuir o estoque e o seu custo ao implantar um sistema informatizado de gestão de materiais.

Embora na Tabela 19 apresente uma diminuição dos materiais e seus custos, observa-se um estoque ainda com valores altos. O SGM, avaliado após 44 dias de implantação e seguido apenas por 4 meses, pode justificar esses números elevados. O SGM necessita de um período maior com um acompanhamento contínuo, pois o consumo está sendo ajustado mês a mês. Entretanto, a manutenção de altos estoques no Centro Cirúrgico ainda se explica pelo número de materiais não necessários nos kits, porém isso faz parte da estratégia de não faltar o material. Na implantação do sistema, optou-se manter altos estoques, para garantir o material, proporcionando segurança ao usuário.

Pode-se dizer que o nível de estoque ainda é alto, mas, com acompanhamento contínuo dos dados históricos de consumo de materiais fornecidos pelo SGM, é possível e necessário ajustar os kits e consequentemente o estoque, com probabilidade de uma redução maior da quantidade de itens estocados e de seus custos do que foi encontrado neste estudo. 
Uma administração de materiais bem estruturada pode proporcionar a obtenção de vantagens por meio de redução de custos e redução dos investimentos em estoques (Gonçalves, 2007). Mas, para obter todos os dados necessários para análise e a gestão de materiais, é fundamental ter um sistema informatizado, permitindo e auxiliando nos dados e informações para o melhor ajuste do estoque.

O volume ou nível dos estoques de qualquer tipo de material é afetado pela qualidade e quantidade de informações sobre eles. Quanto mais precisas forem as informações disponíveis, maiores serão as possibilidades de determinar o estoque (Barbieri, Machline,2006).

O estoque é um investimento envolvendo comprometimento de recursos que poderiam estar sendo aplicados em outras atividades. Porém, sua existência é indispensável ao funcionamento de um hospital. Para o bom funcionamento do estoque, é importante ter dados históricos de consumo de cada item, para projeções de demanda dentro de níveis adequados, que permitam suprir as necessidades de consumo com estoques menores.

O que nos leva a refletir muito é: como será possível estocar itens sem conhecer o consumo real dos materiais?

Novamente, salienta-se a necessidade de estudar o consumo dos materiais para um novo sistema de gestão de estoques, incluindo o ponto de pedido ou o ponto de estoque considerados de extrema importância na gestão de suprimentos (Lourenço, 2006).

O estoque de materiais do Centro Cirúrgico foi reestruturado em 2008 com a finalidade de eliminar o desperdício, diminuindo os itens estocados desnecessários, otimizando espaço e, consequentemente, minimizando os custos. Para isso, foi preciso adotar a reposição contínua, utilizando o ponto de pedido de materiais.

O ponto de pedido é a quantidade de itens que existe no estoque e que garante o processo produtivo para que não tenha problemas de continuidade, enquanto aguarda a reposição. Isso quer dizer que, quando um determinado item de material atinge uma determinada quantidade preestabelecida, deve ocorrer o ressuprimento do seu estoque (Pozo, 2007; Franscischini, Gurgel, 2004). 
A reposição contínua leva ao aumento da frequência das entregas dos materiais, sincronizando-as com a demanda, reduzindo drasticamente os estoques (Barbieri, Machline,2006).

Desse modo, ao implantar o SGM em 2008, utilizando o ponto mínimo e o abastecimento com reposição contínua do material, possibilitou avaliar e obter um nível de estoque menor e, consequentemente, a diminuição do custo.

Portanto, o SGM é uma ferramenta indispensável para obter dados do consumo real do estoque e auxiliar na gestão de materiais para reduzir o desperdício e o capital empatado desnecessariamente.

Diante disso, vale ressaltar que é possível reduzir o custo do estoque do Centro Cirúrgico, diminuir o desperdício e otimizar espaço, quando utiliza a reposição contínua, ressaltando a importância do ponto de pedido como um dos métodos de trabalho mais adequados.

Sem dúvida, um dos papeis mais importantes da administração de materiais está relacionado com o controle de níveis de estoque, visto que esta área desempenha e afeta diretamente no resultado da organização. 
8 CONCLUSÕES 
Esta pesquisa permitiu realizar um estudo comparativo entre dois sistemas de gestão de materiais: o Sistema Tradicional e o Sistema de Gestão de Materiais informatizado (SGM) e que permitiu chegar às seguintes conclusões:

- o Sistema Tradicional, utilizado no HU-USP desde 1981, baseado em cotas preestabelecidas com controle manual e reposição mensal, ocasionou grandes estoques, desperdício, desconhecimento do consumo de material e um custo elevado para a instituição;

- o Sistema de Gestão de Material informatizado (SGM), implementado em 2008 no HU-USP, baseado no Just in Time, com um estoque mínimo e uma reposição contínua de materiais a partir do consumo, possibilitou conhecer o consumo real dos materiais, reduzir os materiais consumidos e diminuir o custo do estoque no Centro Cirúrgico;

- no período da coleta de dados, foi realizado um total de 3.036 cirurgias, sendo que 1.581 procedimentos foram realizados em 2007, e 1.455 cirurgias foram realizadas em 2008. Entretanto, ao comparar os valores da média, mediana, desvio padrão e aplicado o teste nãoparamétrico de Mann-Whitney $(p=0,343)$, não foi encontrada diferença estatística entre o número de cirurgias dos anos de 2007 e 2008;

- quanto à caracterização dos pacientes, houve um predomínio do sexo masculino, correspondendo a $52 \%$ em 2007 e $54 \%$ em 2008. A idade média foi de $41,83(52 \%)$ e $41,70(55,6 \%)$. A classificação física do paciente correspondeu $52 \%$ e $55,6 \%$ na classe 1 , considerado saudável normal, sem distúrbio fisiológico, psicológico, bioquímico ou orgânico. As cirurgias realizadas foram de pequeno porte com 52,0\% em 2007 e 52,4\% em 2008, e a intercorrência durante a cirurgia do 
ano de 2008 apresentou uma porcentagem significativamente maior de casos $(8,4 \%)$ do que 2007 (3,5\%);

- o consumo dos 293 itens de materiais do Centro Cirúrgico no ano de 2008 foi significativamente menor do que o ano de 2007 (redução de $8,13 \%)$

- o custo total dos 293 itens de materiais consumidos do Centro Cirúrgico no ano de 2007 foi de $R \$ 457.153,99$, e o custo dos materiais consumidos em 2008 foi de $R \$ 467.234,06$, mostrando um aumento de $R \$ 10.080,07$, o que representou $2,20 \%$ de acréscimo;

- dos 293 itens de materiais estudados, em 2008, houve uma redução do consumo de materiais de 177 itens (60,41\%); 13 itens (4,44\%) mantiveram; e 103 (35,15\%) aumentaram o consumo em relação ao ano de 2007;

- quanto ao grupo de materiais consumidos; foram estudados todos os itens que apresentaram acima de 100 a 45.000 unidades consumidas; representados por 115 itens; e que corresponderam a um custo de $77,9 \%$ em 2007 e 80,5\% em 2008 do custo total de 293 itens;

- dos 52 tipos de fios cirúrgicos estudados no ano de 2008, 23 itens $(44,24 \%)$ diminuíram o consumo, 1(1,92\%)manteve e $28(53,84 \%)$ aumentaram em relação ao ano de 2007. A representação gráfica dos fios cirúrgicos nos dois anos mostrou um comportamento semelhante do tipo e quantidades de fios consumidos no HU-USP;

- nos quatro meses estudados do ano de 2008, foi detectado que $64,7 \%$ do consumo foram de materiais que fizeram parte de kits de procedimentos cirúrgicos e anestésicos e 35,3\% foram materiais avulsos utilizados durante a cirurgia; 
- dos 81 tipos de kits utilizados, 54 (66,6\%) apresentaram um consumo de material abaixo de 51,9\%, demonstrando a necessidade de diminuição de materiais dos kits;

- houve uma redução de 63.662 unidades $(26,22 \%)$ de materiais do estoque do Centro Cirúrgico no ano de 2008 em relação ao ano de 2007;

- o custo dos materiais estocados no ano de 2007 foi de $R \$ 799.904,82$ e no ano de 2008 foi de $R \$ 700.179,97$. Portanto houve uma diferença de $R \$ 99.724,85$, resultando em uma redução de $12,46 \%$. 
A realização deste estudo teve como finalidade comparar o consumo e o estoque de materiais médico-hospitalares do Sistema de Gestão de Materiais informatizado (SGM) em relação ao Sistema Tradicional.

O Sistema Tradicional utilizado desde 1981, com controle manual, apresentava alguns problemas entre outros como: previsão mensal com cotas mal-dimensionadas, perda de controle do estoque, desconhecimento total do consumo, desperdício e extravio de material, ocorrendo um custo elevado para a instituição.

O Sistema de Gestão de Materiais informatizado (SGM) implementado em 2008, baseado no JIT, possibilitou conhecer, de fato, o consumo real dos materiais, levando à redução do desperdício, a redução dos materiais consumidos e, consequentemente, a diminuição da quantidade e do custo de materiais do estoque do Centro Cirúrgico.

O SGM informatizado pode contribuir e auxiliar na administração hospitalar, com dados e informações para subsidiar na tomada de decisões, desde o processo de aquisição até a distribuição para o usuário. O sistema auxilia nos dados e informações para que os gestores de materiais possam tomar medidas assertivas, corretivas e preventivas para o alcance de metas estabelecidas pela administração do hospital.

Este trabalho evidenciou que o sistema informatizado, como ferramenta de integração das informações sobre os materiais, possibilita um melhor levantamento das necessidades de consumo, controle de estoques, além de permitir o uso de indicadores da gestão organizacional, promovendo maior qualidade e eficiência no serviço de gestão de materiais e recursos financeiros do hospital.

Alem disso, foi possível aplicar os princípios dos "4Rs", ou seja, atender com agilidade as demandas do usuário, a responsividade (responsiveness); proporcionar a segurança e a confiabilidade (reliability) do sistema treinando todos os profissionais do Centro Cirúrgico para utilizar o SGM; a resiliência (resilience) a situações inesperadas para não faltar o material; e, por fim, desenvolver os relacionamentos (relationships) de 
interação e reciprocidade entre os setores de Almoxarifado, Compras e Centro Cirúrgico.

Entretanto, não foi possível comparar os dados observados nesta pesquisa com outros estudos, pois não foram encontrados na literatura esses dados e nem nos hospitais, que possuem um sistema de gerenciamento de materiais informatizado e, assim, poder estabelecer indicadores para análise e tomadas de decisão para a gestão de materiais.

Cabe enfatizar que, pouco se sabe sobre os dados e informações que um setor de gestão de materiais pode gerar. Como exemplo, o quanto um hospital gasta de luva cirúrgica, quantos e quais os materiais que são consumidos de um kit para cirurgia e qual é o custo do estoque. Esta área de materiais é um dos setores mais vitais de uma organização que absorve parcela substancial de seu orçamento. Por isso, é imprescindível fornecer aos gestores a visão real de seus gastos e como controlá-los.

No Brasil, as pesquisas sobre gestão de materiais informatizada com código de barras descritas neste estudo não foram encontradas, o que torna difícil estabelecer parâmetros necessários que possam contribuir para a administração das organizações hospitalares.

Em virtude da limitação do trabalho, atribuído ao pouco tempo de implantação do SGM no Centro Cirúrgico, só foram analisados 4 meses do sistema de gestão, contudo é importante a continuação do acompanhamento do SGM para aprofundar o conhecimento e obter mais informações e dados sobre gestão de materiais.

No entanto, verificou-se que este estudo alcançou plenamente seus objetivos, proporcionando subsídios para o gerenciamento de materiais do Hospital Universitário da USP.

Este estudo permitiu, além da obtenção dos dados já expostos, criar um referencial para pesquisas futuras na área de gestão de materiais hospitalares. A partir de seus resultados, ficou evidente a importância e necessidade de se ter um sistema de gerenciamento de materiais que permita o controle e informações para tomadas de decisões. Sendo que somente é possível por meio de um sistema informacional. Os hospitais apresentam números elevados em seus almoxarifados, na ordem de 
grandeza de 3.000 a 6.000 itens de materiais, o que inviabiliza qualquer controle e gerenciamento desses dados, se não houver um sistema rápido, ágil e seguro da informação.

Sabemos que o assunto é complexo e amplo, por isso não tivemos a pretensão de esgotá-lo.

Assim, o desenvolvimento deste estudo, apesar de suas limitações, demonstrou a necessidade e a possibilidade de se obter, cada vez mais, informações e dados sobre os materiais e insumos para aplicar novas ferramentas de gestão dentro das organizações hospitalares.

Desse modo, espera-se que este trabalho venha a contribuir a quem de interesse sobre o tema, sobretudo sobre as dificuldades que permeiam a tarefa do gerenciamento adequado de materiais hospitalares, cujos objetivos fundamentais são: afastar aquisições mais caras mediante produtos de eficácias semelhantes; evitar estoque excessivo e a falta de material. 


\section{REFERÊNCIAS}


Aptel O, Pourjalali $\mathrm{H}$. Improving activities and decreasing costs of logistics in hospitals: a comparison of U.S. and french hospitals. Int J Accounting. $2001 ; 36(1): 65-90$.

Aranha GTC, Vieira RW. Estudo de um dos indicadores do custo da qualidade: o desperdício. Rev Adm Saúde. 2004;6(23):43-55.

Barbieri JC, Machline C. Logística hospitalar: teoria e prática. São Paulo: Saraiva; 2006.

Bittar E, Castilho V. Análise do preenchimento da ficha de controle de gastos de material de consumo em cirurgia de revascularização do miocárdio: dificuldades e sugestões. In: Cad Centro Universit S Camilo. 2003;9(3):6877.

Bittar OJN. Números do planejamento de saúde. Rev Adm Saúde. 2005; $7(28): 79-94$.

Brasil. Decreto n. 47.297, de 6 de novembro de 2002. Dispõe sobre pregão, a que se refere à Lei Federal n. 10.520, de 17 de julho de 2002 e dá providências correlatas [online]. São Paulo: Secretaria de Gestão Pública; 2002a [citado 20 nov. 2007]. Disponível em:

http://www.pregao.sp.gov.br/legislacao/decretos/decreto47297.htm

Brasil. Lei n. 10.520, de 17 de julho de 2002. Institui, no âmbito da União, Estados, Distrito Federal e Municípios, nos termos do art. 37, inciso XXI da Constituição Federal, a modalidade de licitação denominada pregão, para aquisição de bens e serviços comuns, e dá outras providências [online]. Diário Oficial da União, Brasília; 18 jul. 2002b [citado 13 nov 2007]. Disponível em: http://www.planalto.gov.br/ccivil/LEIS/2002/L10520.htm 
Brasil. Lei n.8.666, de21 de junho de 1993. Regulamenta o art.37, inciso XXI, da Constituição Federal, institui normas para licitações e contratos da administração pública e dá outras providências [online]. Diário Oficial da União, Brasília; 22 jun 1993 [citado 15 mar 2008]. Disponível em: http://www.planalto.gov.br/ccivil/LEIS/L8666cons.htm

Castilho V, Gonçalves VLM. Gerenciamento de recursos materiais. In: Kurcgant P. Gerenciamento em enfermagem. São Paulo: Guanabara Koogan; 2005. p. 157-70.

Castilho V, Leite MMJ. A administração de recursos materiais na enfermagem. In: Kurcgant $P$, editor. Administração em enfermagem. São Paulo: EPU;1991. cap. 6, p. 73-88.

Chiavenato I. Iniciação à administração de materiais. São Paulo: Makson Books; 1991.

Ching HY. Manual de custos de instituições de saúde. São Paulo: Atlas; 2001. p. 13-38: Fundamentos de custos e método de custeio.

Christopher M. Logística e gerenciamento da cadeia de suprimentos: criando redes que agregam valor. São Paulo: Pioneira Thomson Learning; 2007.

Christopher M. Logística e gerenciamento da cadeia de suprimentos. estratégias para a redução de custos e melhoria dos serviços. São Paulo: Pioneira; 2001.

Conallen J. Building web applications with UML. 2nd ed. Boston: AddisonWesley; 2002.

Darnell T. Materials management systems: all about controlling costs. Health Manag Technol. 1996;17(13):14-8. 
Dutra, DMPS, Neves AP. Administração de materiais no setor público [online]. Belo Horizonte: Prefeitura, 2000 [citado 2 maio 2000]. Disponível em: http://www.belohorizonte.mg.gov.br/smad/materiais.html

Egbelu PJ, Harmonosky CM, Ventura JA, O'Brien WE, Sommer III HJ. Cost analysis of hospital material management systems. J Soc health Syst. 1998;5(4):1-10.

Francischini PG, Gurgel FA. Administração de materiais e do patrimônio. São Paulo: Pioneira Thomson Learning; 2004.

Francisco IMF, Castilho V. A enfermagem e o gerenciamento de custos. Rev Esc Enferm USP. 2002; 36(3):240-4.

Gomes CFS, Ribeiro PCC. Gestão da cadeia de suprimentos: integrada à tecnologia da informação. São Paulo: Pioneira Thomson Learning; 2004.

Gonçalves OS. Administração de materiais. Rio de Janeiro: Elsevier; 2007.

Gualda DMR. A organização do Departamento de Enfermagem do Hospital Universitário da Universidade de São Paulo: filosofia e pressupostos acadêmico-assistenciais. In: Ciarullo TI, Gualda DMR, Melleiro MM, Anabuki $\mathrm{MH}$, editores. Sistema de Assistência de Enfermagem: evolução e tendências. São Paulo: Ícone; 2001. p. 93-107.

Haddad SC, Ribeiro CA, Silva, EMS, Ferreira JM, Queiroz NR, Campos RT, et al. Informatização das Unidades Básicas de Saúde em Belo Horizonte: mudanças e aperfeiçoamento dos processos de trabalho e de gestão. Anais do IX Congresso Brasileiro de Informática em Saúde; 2004; Ribeirão Preto. Ribeirão Preto: Sociedade Brasileira de Informática em Saúde; 2004. 
Horr L, Cipriano ZM, Rabello ES. Proposta de controle de material de consumo. Rev Gaúch Enferm. 1989;10(1):24-7.

Infante M, Santos MAB. A organização do abastecimento do hospital público a partir da cadeia produtiva: uma abordagem logística para a área da saúde. Ciênc Saúde Coletiva. 2007;12(4):945-54.

Kenneth AF. Can a hospital be like a supermarket? Better data will provide cost controls, efficiencies, and income streams. J Health Care Financ. $1997 ; 23(3): 44-9$.

King J, McLaughlin J, Zellermeyer V, Asani M, Abarca R. Can supply chain software really deliver more nurses? Healthc Q. 2005;8(3):125-7.

Long G. Pursuing supply chain gains. Healthc Financ Manage. 2005; 59(9):118-22.

Lourenço KG, Castilho V. Classificação ABC dos materiais: uma ferramenta gerencial de custos em enfermagem. Rev Bras Enferm. 2006; 59(1):52-5.

Lourenço KG. Nível de atendimento dos materiais classificados como críticos no Hospital Universitário da USP [dissertação]. São Paulo: Escola de Enfermagem da Universidade de São Paulo; 2006.

Machado RF, Yamaguchi RY, Paschoal MLH. Reestruturação e preparo dos kits cirúrgicos para a implantação de um programa informatizado. Rev SOBECC. 2007; 12(2):32-8.

Machado TDO, Teixeira TB, Moraes WG, Santos RV. Aplicação do Sistema de Custeio $A B C$ no Departamento de Tecnologia de Informação do Hospital das Clínicas de Faculdade de Medicina de Ribeirão Preto. Anais do IX 
Congresso Brasileiro de Informática em Saúde; 2004; Ribeirão Preto.

Ribeirão Preto: Sociedade Brasileira de Informática em Saúde; 2004.

Martins PG, Laugeni FP. Administração da produção. São Paulo: Saraiva; 2000.

Médici AC. Financiamento e contenção de custos nas políticas de saúde: tendências atuais e perspectivas futuras. Planej Polít Públicas. 1990;(4):8393.

Noronha AGGM, Borges DF. Qualidade da gestão de medicamentos em hospitais públicos. Rev Adm Pública. 2005;39(4):895-912.

Ortiz DCF, Gaidzinski RR. O custo do material de consumo na visão dos profissionais de enfermagem. Rev Nursing. 1999;2(18):28-34.

Paterno D. A qualidade da administração de materiais no processo da qualidade total aplicada aos hospitais. Hosp Adm Saúde. 1992;16(5):196200.

Pozo H. Administração de recursos materiais e patrimoniais: uma abordagem logística. São Paulo: Atlas; 2007.

Queiroz FC, Spiri WC, Juliani CMCM. Classificação na curva ABC do custo dos suprimentos médico hospitalares da UTI neonatal de um hospital-escola no interior paulista. Mundo Saúde. 2004;28(2): 225-9.

Quinto Neto A, Bittar OJNV, editores. Hospitais: administração da qualidade e acreditação de organizações complexas. Porto Alegre: Dacasa; 2004. 
Rezende DA. Tecnologia da informação aplicada a sistema de informações empresariais: o papel estratégico da informação e dos sistemas de informação nas empresas. São Paulo: Atlas; 2000.

Ribeiro AR. Os fios de sutura cirúrgica e a enfermeira de centro cirúrgico: critérios de previsão e provisão segundo a natureza pública ou privada das instituições hospitalares [dissertação]. São Paulo: Escola de Enfermagem da Universidade de São Paulo; 2001.

Tamaki PAO. Uma extensão do RUP com ênfase no gerenciamento de projeto do PMBOK baseada em process patterns [dissertação]. São Paulo: Escola Politécnica da Universidade de São Paulo; 2007.

Toscan PR. A administração e a informatização do serviço de materiais nos hospitais. Rev Hosp Adm Saúde. 1990;14(1):9-19.

Universidade de São Paulo. Hospital Universitário. Regimento: Resolução n. 4886, de 20 de dezembro de 2001 [online]. Diário Oficial do Estado, São Paulo, 21 dez 2001 [citado 25 jul 2008]. Disponível em:

http://www.hu.usp.br/default.htm

Universidade de São Paulo. Hospital Universitário. Relatório de cirurgia mensal realizada de 2007, disponível no módulo GCC. São Paulo: HU USP; 2007.

Universidade de São Paulo. Hospital Universitário. Relatório de cirurgia mensal realizada de 2008, disponível no módulo GCC. São Paulo: HU USP; 2008.

Vecina Neto G, Ferreira Júnior WC. Administração de materiais para sistemas locais de saúde. In: Escola Politécnica de Saúde Joaquim Venâncio. Administração. Rio de Janeiro: Fiocruz; 2001. p. 117-58. 
Vecina Neto G, Reinhardt Filho W. Gestão de recursos materiais e de medicamentos. São Paulo: Faculdade de Saúde Pública da USP; 1998. 


\section{APÊNDICES}




\section{Apêndice 1 - Relação das unidades consumidas dos itens avaliados nos anos de 2007 e 2008}

\begin{tabular}{|c|c|c|c|c|c|c|c|c|}
\hline \multirow{2}{*}{ NOME DO PRODUTO } & \multicolumn{4}{|c|}{2007} & \multicolumn{4}{|c|}{2008} \\
\hline & FEV. & MAR. & ABR. & MAIO & FEV. & MAR. & ABR. & MAIO \\
\hline ABSORVENTE HIGIÊNICO 10CM X 37CM TIPO HOSPITALAR & 20 & 0 & 0 & 20 & 0 & 3 & 0 & 1 \\
\hline ADESIVO TISSULAR 0,5ML & 7 & 5 & 10 & 10 & 1 & 3 & 3 & 1 \\
\hline AGULHA BIÓPSIA HEPÁTICA 18G X 16CM & 0 & 1 & 0 & 0 & 1 & 0 & 1 & 0 \\
\hline AGULHA BIÓPSIA HEPÁTICA 20G X 16CM & 0 & 2 & 0 & 0 & 1 & 0 & 0 & 0 \\
\hline AGULHA HIPODÉRMICA 20MM X 5MM DESCARTÁVEL & 5 & 25 & 0 & 0 & 0 & 0 & 0 & 0 \\
\hline AGULHA HIPODÉRMICA 25MM X 6MM DESCARTÁVEL & 10 & 60 & 0 & 5 & 7 & 7 & 8 & 4 \\
\hline AGULHA HIPODÉRMICA 30MM X 8MM DESCARTÁVEL & 2.200 & 1.500 & 1.000 & 2.000 & 627 & 646 & 607 & 505 \\
\hline AGULHA HIPODÉRMICA 30MMX 7,0MM DESCARTÁVEL & 300 & 1.300 & 150 & 1.000 & 1.330 & 1.441 & 1.605 & 1.230 \\
\hline AGULHA HIPODÉRMICA 13MMX4,5MM DESCARTÁVEL & 280 & 70 & 150 & 100 & 81 & 84 & 81 & 63 \\
\hline AGULHA ODONTOLÓGICA 27G & 20 & 10 & 0 & 10 & 0 & 2 & 3 & 2 \\
\hline AGULHA ODONTOLÓGICA 30G. & 10 & 30 & 0 & 10 & 5 & 0 & 3 & 5 \\
\hline AGULHA PUNÇÃO LOMBAR 25G X 3 1/2"/0,5MM X 89MM BISEL TIPO PONTA DE LÁPIS & 13 & 0 & 0 & 0 & 5 & 2 & 2 & 4 \\
\hline AGULHA PUNÇÃO LOMBAR $27 G$ X 3 1/2"/0,4MM X 89MM BISEL TIPO PONTA DE LÁPIS & 180 & 125 & 55 & 120 & 94 & 152 & 95 & 98 \\
\hline AGULHA PUNÇÃO LOMBAR 27G X 411/16"/0,4MM X 11,9MM BISEL TIPO PONTA DE LÁPIS & 1 & 0 & 0 & 2 & 9 & 3 & 1 & 0 \\
\hline AGULHA VERESS 14G X 120MM PNEUMOPERITÔNIO & 17 & 23 & 20 & 20 & 17 & 10 & 12 & 12 \\
\hline ALGODÃO HIDRÓFILO C/ 500 G. & 0 & 0 & 0 & 1 & 0 & 0 & 0 & 0 \\
\hline ALGODÃO HIDROFILO BRANCO 5CM X 6CM FORMATO QUADRADO & 18 & 27 & 20 & 20 & 14 & 12 & 13 & 23 \\
\hline ATADURA ALGODÃO ORTOPÉDICO 10CM X 1,80M & 34 & 24 & 24 & 48 & 3 & 0 & 2 & 0 \\
\hline ATADURA ALGODÃO ORTOPÉDICO 15CM X 1,80M & 36 & 60 & 48 & 48 & 47 & 40 & 24 & 31 \\
\hline ATADURA ALGODÃO ORTOPÉDICO 20CM X 1,80M & 24 & 48 & 48 & 72 & 17 & 14 & 3 & 21 \\
\hline ATADURA ALGODÃO ORTOPÉDICO 6CM X 1,80M & 10 & 12 & 12 & 12 & 0 & 0 & 0 & 0 \\
\hline ATADURA BORRACHA 10CM FAIXA DE SMARCH & 12 & 10 & 0 & 0 & 2 & 1 & 3 & 4 \\
\hline ATADURA BORRACHA 15CM FAIXA DE SMARCH & 5 & 10 & 0 & 0 & 0 & 3 & 5 & 1 \\
\hline ATADURA CREPON 15CM X 1,80M & 72 & 70 & 86 & 84 & 80 & 60 & 40 & 58 \\
\hline ATADURA CREPON 20CM X 1,80M & 60 & 30 & 50 & 60 & 28 & 27 & 19 & 24 \\
\hline ATADURA CREPON 25CM X 1,80M & 0 & 0 & 10 & 4 & 2 & 2 & 0 & 0 \\
\hline ATADURA CREPON 6CM X 1,80M & 12 & 2 & 10 & 12 & 2 & 2 & 1 & 0 \\
\hline ATADURA ELÁSTICA 5CM X 4,50M ADESIVA & 2 & 6 & 2 & 12 & 3 & 5 & 4 & 8 \\
\hline ATADURA GESSADA 10CM X 3,0M & 10 & 90 & 40 & 40 & 10 & 17 & 16 & 9 \\
\hline ATADURA GESSADA $15 \mathrm{CM} \times 3,0 \mathrm{M}$ & 50 & 70 & 40 & 20 & 42 & 28 & 12 & 16 \\
\hline ATADURA GESSADA 6CM X 3,0M & 10 & 8 & 28 & 20 & 3 & 0 & 0 & 4 \\
\hline ATADURA RAYON 7CM X 20CM & 60 & 50 & 0 & 20 & 29 & 13 & 20 & 21 \\
\hline ATADURA RAYON 7CM X 50CM & 30 & 0 & 0 & 0 & 1 & 13 & 5 & 7 \\
\hline AVENTAL CIRÚRGICO EXTRAGRANDE ULTRAPROTEÇÃO & 40 & 60 & 40 & 80 & 25 & 38 & 20 & 54 \\
\hline BASKET 2,4FR X 115CM RETIRADA DE CÁLCULO BILIAR & 0 & 0 & 4 & 0 & 0 & 2 & 0 & 1 \\
\hline
\end{tabular}


Apêndices 156

\begin{tabular}{|c|c|c|c|c|c|c|c|c|}
\hline \multirow{2}{*}{ NOME DO PRODUTO } & \multicolumn{4}{|c|}{2007} & \multicolumn{4}{|c|}{2008} \\
\hline & FEV. & MAR. & ABR. & MAIO & FEV. & MAR. & ABR. & MAIO \\
\hline BISTURI DESCARTÁVEL 11 & 130 & 150 & 10 & 100 & 63 & 81 & 71 & 81 \\
\hline BISTURI DESCARTÁVEL 15 & 200 & 300 & 240 & 260 & 188 & 258 & 222 & 189 \\
\hline BISTURI DESCARTÁVEL 23 & 200 & 220 & 220 & 180 & 169 & 199 & 141 & 170 \\
\hline BOLSA COLETORA DE URINA 2.000ML SACOLA & 100 & 150 & 100 & 100 & 58 & 81 & 90 & 83 \\
\hline BOLSA COLETORA DE URINA 2.000ML SISTEMA FECHADO & 20 & 160 & 80 & 80 & 87 & 111 & 89 & 100 \\
\hline 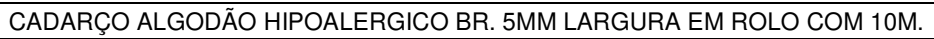 & 2 & 4 & 2 & 2 & 1 & 2 & 2 & 3 \\
\hline CAMPO CIRÚRGICO 60CM X 36CM IODOFORADO & 0 & 5 & 0 & 0 & 4 & 2 & 4 & 2 \\
\hline CAMPO CIRÚRGICO 90CM X 45CM IODOFORADO & 0 & 5 & 0 & 0 & 3 & 8 & 3 & 12 \\
\hline CAMPO IMPERMEÁVEL 110-150CM X 200-230CM MESA & 500 & 600 & 550 & 550 & 449 & 574 & 480 & 486 \\
\hline CANETA MARCAÇÃO DE VARIZES PRETA & 16 & 40 & 40 & 20 & 30 & 36 & 37 & 27 \\
\hline CÂNULA ENDOTRAQUEAL 3,5MM COM CUFF & 5 & 2 & 2 & 0 & 4 & 2 & 1 & 2 \\
\hline CÂNULA ENDOTRAQUEAL 3,5MM SEM CUFF & 0 & 7 & 10 & 2 & 4 & 1 & 2 & 3 \\
\hline CÂNULA ENDOTRAQUEAL 4,0MM COM CUFF & 5 & 2 & 7 & 4 & 8 & 13 & 5 & 3 \\
\hline CÂNULA ENDOTRAQUEAL 4,0MM SEM CUFF & 9 & 3 & 5 & 1 & 5 & 3 & 2 & 5 \\
\hline CÂNULA ENDOTRAQUEAL 4,5MM COM CUFF & 9 & 8 & 5 & 8 & 7 & 11 & 3 & 5 \\
\hline CÂNULA ENDOTRAQUEAL 4,5MM SEM CUFF & 12 & 9 & 3 & 5 & 6 & 2 & 2 & 2 \\
\hline $\begin{array}{l}\text { CÂNULA ENDOTRAQUEAL 5,0MM COM CUFF } \\
\end{array}$ & 8 & 9 & 0 & 1 & 6 & 9 & 8 & 10 \\
\hline CÂNULA ENDOTRAQUEAL 5,OMM SEM CUFF & 10 & 0 & 6 & 0 & 1 & 1 & 5 & 2 \\
\hline CÂNULA ENDOTRAQUEAL 5,5MM COM CUFF & 12 & 0 & 11 & 6 & 5 & 10 & 8 & 6 \\
\hline CÂNULA ENDOTRAQUEAL 5,5MM SEM CUFF & 2 & 1 & 0 & 2 & 3 & 2 & 2 & 1 \\
\hline CÂNULA ENDOTRAQUEAL 6,0MM COM CUFF & 15 & 0 & 19 & 6 & 7 & 13 & 8 & 9 \\
\hline CÂNULA ENDOTRAQUEAL 6,0MM SEM CUFF & 0 & 2 & 0 & 5 & 1 & 0 & 0 & 0 \\
\hline CÂNULA ENDOTRAQUEAL 6,5 COM CUFF & 9 & 8 & 5 & 7 & 6 & 3 & 6 & 6 \\
\hline CÂNULA ENDOTRAQUEAL 6,5MM SEM CUFF & 2 & 0 & 0 & 1 & 3 & 1 & 0 & 0 \\
\hline CÂNULA ENDOTRAQUEAL 7,0MM ARAMADA COM CUFF & 0 & 6 & 2 & 2 & 1 & 1 & 2 & 2 \\
\hline CÂNULA ENDOTRAQUEAL 7,0MM COM CUFF & 18 & 10 & 10 & 20 & 19 & 16 & 26 & 25 \\
\hline CÂNULA ENDOTRAQUEAL 7,0MM SEM CUFF & 0 & 5 & 0 & 6 & 0 & 1 & 0 & 0 \\
\hline CÂNULA ENDOTRAQUEAL 7,5MM ARAMADA COM CUFF & 2 & 0 & 7 & 9 & 8 & 9 & 8 & 7 \\
\hline CÂNULA ENDOTRAQUEAL 7,5MM COM CUFF & 80 & 38 & 42 & 49 & 60 & 71 & 68 & 55 \\
\hline CÂNULA ENDOTRAQUEAL 8,0MM ARAMADA COM CUFF & 0 & 6 & 12 & 4 & 5 & 3 & 7 & 5 \\
\hline CÂNULA ENDOTRAQUEAL 8,0MM COM CUFF & 70 & 35 & 65 & 55 & 65 & 60 & 55 & 51 \\
\hline CÂNULA ENDOTRAQUEAL 8,5MM ARAMADA COM CUFF & 0 & 0 & 1 & 0 & 1 & 0 & 1 & 0 \\
\hline CÂNULA ENDOTRAQUEAL 8,5MM COM CUFF & 40 & 17 & 33 & 20 & 19 & 27 & 27 & 32 \\
\hline CÂNULA ENDOTRAQUEAL ARAMADA 5,5MM COM CUFF & 0 & 3 & 0 & 0 & 1 & 0 & 0 & 0 \\
\hline CÂNULA ENDOTRAQUEAL ARAMADA 6,5MM COM CUFF & 2 & 0 & 3 & 4 & 4 & 1 & 0 & 0 \\
\hline CÂNULA TRAQUEOSTOMIA 7,0MM DESCARTÁVEL COM CUFF & 7 & 1 & 0 & 0 & 0 & 2 & 0 & 1 \\
\hline CÂNULA TRAQUEOSTOMIA 8,0 DESCARTÁVEL COM CUFF & 6 & 2 & 0 & 3 & 1 & 4 & 2 & 2 \\
\hline $\begin{array}{l}\text { CÂNULA TRAQUEOSTOMIA 9,OMM DESCARTÁVEL COM CUFF } \\
\end{array}$ & 2 & 1 & 0 & 2 & 0 & 0 & 2 & 2 \\
\hline CAPA LAPAROSCOPIO ESTÉRIL & 55 & 75 & 50 & 80 & 57 & 63 & 49 & 57 \\
\hline
\end{tabular}




\begin{tabular}{|c|c|c|c|c|c|c|c|c|}
\hline \multirow{2}{*}{ NOME DO PRODUTO } & \multicolumn{4}{|c|}{2007} & \multicolumn{4}{|c|}{2008} \\
\hline & FEV. & MAR. & ABR. & MAIO & FEV. & MAR. & ABR. & MAIO \\
\hline CARGA GRAMPO GRAMPEADOR LINEAR 45MM TECIDO VASCULAR & 0 & 1 & 0 & 1 & 0 & 3 & 0 & 0 \\
\hline $\begin{array}{l}\text { CARGA GRAMPO GRAMPEADOR LINEAR RECARREGAVEL 55MM } \\
\end{array}$ & 0 & 1 & 4 & 0 & 0 & 12 & 6 & 7 \\
\hline CARGA GRAMPO GRAMPEADOR LINEAR RECARREGAVEL 75MM & 15 & 13 & 13 & 13 & 16 & 22 & 32 & 8 \\
\hline CATETER EMBOLECTOMIA ARTERIAL 4FR X 80CM TIPO FOGARTY & 4 & 0 & 0 & 0 & 0 & 0 & 0 & 0 \\
\hline $\begin{array}{l}\text { CATETER INTRAVENOSO CENTRAL 19GX30,5 CM MONOLÚMEN } \\
\end{array}$ & 3 & 3 & 0 & 0 & 2 & 5 & 5 & 5 \\
\hline CATETER INTRAVENOSO CENTRAL 16G X 30,5CM MONOLÚMEN & 0 & 12 & 0 & 4 & 2 & 0 & 0 & 1 \\
\hline $\begin{array}{l}\text { CATETER INTRAVENOSO CENTRAL 7FR X 20CM DUPLOLÚMEN } \\
\end{array}$ & 3 & 3 & 3 & 3 & 1 & 5 & 3 & 3 \\
\hline CATETER INTRAVENOSO CENTRAL 7FR X 20CM TRIPLOLUMEN & 5 & 13 & 0 & 5 & 2 & 5 & 3 & 5 \\
\hline CATETER INTRAVENOSO PERIFÉRICO 14G & 30 & 20 & 70 & 0 & 33 & 33 & 51 & 41 \\
\hline CATETER INTRAVENOSO PERIFÉRICO 16G & 25 & 15 & 5 & 30 & 8 & 11 & 10 & 11 \\
\hline CATETER INTRAVENOSO PERIFÉRICO 18G & 100 & 150 & 250 & 90 & 99 & 98 & 112 & 107 \\
\hline CATETER INTRAVENOSO PERIFÉRICO 20G & 150 & 200 & 200 & 200 & 185 & 217 & 225 & 219 \\
\hline CATETER INTRAVENOSO PERIFÉRICO 22G & 100 & 150 & 100 & 100 & 58 & 76 & 65 & 63 \\
\hline CATETER NASAL OXIGÊNIO ADULTO TIPO ÓCULOS & 70 & 40 & 210 & 160 & 123 & 127 & 122 & 124 \\
\hline CERA PARA OSSO 2,5 GRAMAS & 6 & 6 & 5 & 12 & 1 & 2 & 0 & 3 \\
\hline CLIP LAQUEAÇAO MECÂNICA GRANDE LIGA CLIP & 72 & 83 & 31 & 24 & 20 & 34 & 38 & 58 \\
\hline COLETOR ARTIGO DESCARTÁVEL 3 LITROS & 20 & 120 & 30 & 70 & 51 & 145 & 70 & 70 \\
\hline COLETOR ARTIGO DESCARTÁVEL 7 LITROS & 20 & 10 & 10 & 10 & 10 & 12 & 1 & 9 \\
\hline 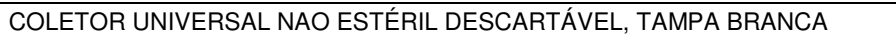 & 150 & 150 & 150 & 150 & 140 & 253 & 101 & 97 \\
\hline COLETOR URINA INFANTIL UNISSEX & 6 & 11 & 0 & 0 & 0 & 5 & 2 & 1 \\
\hline COMPRESSA GAZE BRANCO 15CM X 10CM ESTÉRIL & 50 & 70 & 0 & 50 & 50 & 79 & 34 & 17 \\
\hline COMPRESSA GAZE BRANCO 30CM X 30CM CAMPO OPERATÓRIO & 570 & 210 & 184 & 300 & 242 & 280 & 195 & 222 \\
\hline COMPRESSA GAZE BRANCO 45CM X 45CM CAMPO OPERATÓRIO ESTÉRIL & 1.240 & 1.000 & 1.120 & 1.640 & 792 & 1.089 & 972 & 979 \\
\hline COMPRESSA GAZE BRANCO 7,5CM X 6CM OCULAR & 20 & 20 & 23 & 37 & 12 & 14 & 12 & 9 \\
\hline COMPRESSA GAZE BRANCO 7,5CM X 7,5CM ESTÉRIL & 360 & 300 & 360 & 360 & 151 & 227 & 179 & 131 \\
\hline COMPRESSA GAZE BRANCO 7,5CM X 7,5CM FILAMENTO RADIOPACO & 400 & 890 & 600 & 800 & 633 & 758 & 691 & 650 \\
\hline COMPRESSA GAZE BRANCO 90CM X 100CM ESTÉRIL & 0 & 0 & 0 & 20 & 5 & 10 & 2 & 6 \\
\hline CONDENSADOR HIGROSCÓPIO ADULTO & 60 & 85 & 23 & 60 & 129 & 127 & 191 & 170 \\
\hline CONJUNTO ANESTESIA EPIDURAL AGULHA 16G PU 17G & 20 & 7 & 8 & 17 & 9 & 9 & 10 & 13 \\
\hline CONJUNTO ANESTESIA RAQUIDIANA/EPIDURAL DUPLO BLOQUEIO & 9 & 4 & 5 & 1 & 1 & 2 & 2 & 0 \\
\hline CONJUNTO DRENAGEM VESICAL 10 AGULHA 12CM & 0 & 1 & 0 & 0 & 0 & 0 & 0 & 0 \\
\hline CONJUNTO DRENAGEM VESICAL 10 AGULHA 8CM & 1 & 1 & 0 & 0 & 0 & 1 & 0 & 0 \\
\hline CONJUNTO DRENAGEM VESICAL 12 COM BALÃO & 1 & 0 & 0 & 1 & 0 & 1 & 0 & 0 \\
\hline CONJUNTO TROCARTE 10/12MM LAPAROSCOPIA & 10 & 48 & 30 & 0 & 43 & 34 & 24 & 29 \\
\hline CONJUNTO TROCARTE 5MM LAPAROSCOPIA & 15 & 24 & 60 & 0 & 50 & 31 & 26 & 28 \\
\hline CURATIVO HIDROATIVO 10CM X 10CM & 2 & 0 & 4 & 2 & 0 & 3 & 0 & 1 \\
\hline CURATIVO HIDROATIVO 10CM X 10CM EXTRAFINO & 5 & 5 & 5 & 5 & 1 & 7 & 3 & 3 \\
\hline CURATIVO TRAQUEOSTOMIA 9CM X 9CM & 4 & 2 & 0 & 0 & 0 & 0 & 0 & 0 \\
\hline DISPOSITIVO INFUSÃO VENOSA 19G & 14 & 15 & 0 & 24 & 3 & 4 & 4 & 1 \\
\hline
\end{tabular}




\begin{tabular}{|c|c|c|c|c|c|c|c|c|}
\hline \multirow{2}{*}{ NOME DO PRODUTO } & \multicolumn{4}{|c|}{2007} & \multicolumn{4}{|c|}{2008} \\
\hline & FEV. & MAR. & ABR. & MAIO & FEV. & MAR. & ABR. & MAIO \\
\hline DISPOSITIVO INFUSÃO VENOSA 21G & 5 & 5 & 0 & 10 & 7 & 7 & 5 & 4 \\
\hline DISPOSITIVO INFUSÃO VENOSA $23 \mathrm{G}$ & 5 & 5 & 0 & 10 & 2 & 6 & 9 & 1 \\
\hline DISPOSITIVO INFUSÃO VENOSA 25G & 3 & 3 & 0 & 3 & 2 & 1 & 0 & 3 \\
\hline DISPOSITIVO INFUSÃO VENOSA 27G & 2 & 2 & 0 & 2 & 0 & 0 & 1 & 0 \\
\hline DRENO OTOLÓGICO 1ML X 2,4ML & 0 & 0 & 0 & 0 & 3 & 4 & 5 & 4 \\
\hline DRENO PENROSE 1 & 12 & 36 & 0 & 20 & 8 & 14 & 21 & 7 \\
\hline DRENO SUCÇÃO DE FERIDA FECHADA AGULHA 3,2MM & 2 & 52 & 0 & 0 & 22 & 15 & 9 & 13 \\
\hline DRENO SUCÇÃO DE FERIDA FECHADA AGULHA 4,8MM & 4 & 12 & 7 & -3 & 4 & 10 & 4 & 11 \\
\hline DRENO TÓRAX TUBULAR 28FR PVC & 3 & 3 & 7 & 4 & 4 & 9 & 2 & 6 \\
\hline DRENO TÓRAX TUBULAR 36FR PVC & 11 & 14 & 0 & -10 & 3 & 6 & 5 & 4 \\
\hline ELETRODO ECG INFANTIL DESCARTÁVEL & 420 & 420 & 420 & 0 & 207 & 278 & 281 & 223 \\
\hline EQUIPO ANESTESIA ENDOVENOSA LIFESHIELD CONVENCIONAL & 25 & 131 & 84 & 117 & 87 & 150 & 158 & 119 \\
\hline EQUIPO CISTOSCOPIA & 27 & 25 & 60 & 15 & 11 & 15 & 16 & 8 \\
\hline EQUIPO IRRIGAÇÃO VESICAL 2 VIAS & 21 & 50 & 5 & 30 & 14 & 13 & 10 & 9 \\
\hline EQUIPO MACROGOTAS & 400 & 980 & 300 & 800 & 391 & 434 & 456 & 414 \\
\hline EQUIPO MICROGOTAS & 35 & 35 & 15 & 20 & 2 & 5 & 3 & 4 \\
\hline EQUIPO MICROGOTAS RESERVATÓRIO GRADUADO & 35 & 20 & 10 & 30 & 19 & 26 & 31 & 30 \\
\hline EQUIPO TRANSFUSÃO DE SANGUE CÂMARA DUPLA & 50 & 50 & 0 & 50 & 20 & 34 & 41 & 62 \\
\hline ESCOVA ASSEPSIA SECA & 720 & 1504 & 960 & 1.032 & 724 & 1.023 & 1.052 & 1.068 \\
\hline ESPARADRAPO IMPERMEÁVEL BRANCO 10CM X 4,5M & 31 & 22 & 18 & 18 & 15 & 17 & 15 & 13 \\
\hline ESPARADRAPO RAYON BRANCO 5CM X 4,5M & 0 & 0 & 2 & 1 & 1 & 0 & 1 & 0 \\
\hline ESPONJA HEMOSTÁTICA 7CM X 5CM & 17 & 16 & 9 & 15 & 18 & 14 & 18 & 30 \\
\hline FILTRO ANTIMICROBIANO APARELHO ANESTESIA DRAGER & 0 & 25 & 0 & 15 & 9 & 6 & 8 & 12 \\
\hline FIO CIRÚRGICO AÇO 0 SEM AGULHA 3 FIOS DE 60CM & 0 & 0 & 0 & 0 & 1 & 0 & 0 & 0 \\
\hline FIO CIRÚRGICO AÇO 1 SEM AGULHA 3 FIOS DE 60CM & 0 & 16 & 8 & 0 & 1 & 3 & 7 & 3 \\
\hline FIO CIRÚRGICO AÇO 2-0 SEM AGULHA 3 FIOS DE 60CM & 16 & 8 & 0 & 0 & 2 & 1 & 0 & 3 \\
\hline FIO CIRÚRGICO ALGODÃO POLIÉSTER O SEM AGULHA 15 FIOS DE 45 CM & 0 & 60 & 0 & 0 & 17 & 23 & 17 & 11 \\
\hline FIO CIRÚRGICO ALGODÃO POLIÉSTER 2-0 AGULHA 1/2 CÍRCULO CILÍNDRICA 2,5CM & 120 & 216 & 67 & 72 & 108 & 134 & 126 & 112 \\
\hline FIO CIRÚRGICO ALGODÃO POLIÉSTER 2-0 SEM AGULHA 15 FIOS DE 45CM & 96 & 120 & 96 & 96 & 99 & 138 & 154 & 122 \\
\hline FIO CIRÚRGICO ALGODÃO POLIÉSTER 3-0 AGULHA 1/2 CÍRCULO CILÍNDRICA 2,5CM & 144 & 192 & 72 & 120 & 92 & 150 & 56 & 184 \\
\hline FIO CIRÚRGICO ALGODÃO POLIÉSTER 3-0 SEM AGULHA 15 FIOS DE 45CM & 0 & 96 & 24 & 48 & 65 & 61 & 34 & 44 \\
\hline FIO CIRÚRGICO ALGODÃO POLIÉSTER 4-0 AGULHA 1/2 CÍRCULO CILÍNDRICA 2,5CM & 68 & 76 & 72 & 72 & 73 & 40 & 105 & 53 \\
\hline FIO CIRÚRGICO ALGODÃO POLIÉSTER 4-0 SEM AGULHA 15 FIOS DE 45CM & 24 & 72 & 0 & 48 & 32 & 39 & 31 & 28 \\
\hline FIO CIRÚRGICO CATIGUTE CROMADO 1 AGULHA 1/2 CÍRCULO CILÍNDRICA 5,0CM & 24 & 8 & 0 & 8 & 0 & 5 & 8 & 2 \\
\hline FIO CIRÚRGICO CATIGUTE CROMADO 2-0 AGULHA 1/2 CÍRCULO CILÍNDRICA 2,5CM & 0 & 24 & 0 & 0 & 8 & 14 & 20 & 3 \\
\hline FIO CIRÚRGICO CATIGUTE CROMADO 3-0 AGULHA 1/2 CÍRCULO CILÍNDRICA 2,5CM & 0 & 0 & 48 & 0 & 3 & 15 & 20 & 1 \\
\hline FIO CIRÚRGICO CATIGUTE CROMADO 5-0 AGULHA 1/2 CÍRCULO CILÍNDRICA 1,5CM & 8 & 0 & 0 & 0 & 0 & 3 & 0 & 0 \\
\hline FIO CIRÚRGICO CATIGUTE SIMPLES o AGULHA 1/2 CÍRCULO CILÍNDRICA 2,5CM & 0 & 0 & 0 & 0 & 2 & 1 & 3 & 3 \\
\hline FIO CIRÚRGICO CATIGUTE SIMPLES 2-0 AGULHA 1/2 CÍRCULO CILÍNDRICA 2,5CM & 0 & 0 & 0 & 0 & 6 & 4 & 19 & 13 \\
\hline
\end{tabular}




\begin{tabular}{|c|c|c|c|c|c|c|c|c|}
\hline \multirow{2}{*}{ NOME DO PRODUTO } & \multicolumn{4}{|c|}{2007} & \multicolumn{4}{|c|}{2008} \\
\hline & FEV. & MAR. & ABR. & MAIO & FEV. & MAR. & ABR. & MAIO \\
\hline FIO CIRÚRGICO CATIGUTE SIMPLES 2-0 AGULHA 1/2 CÍRCULO CILÍNDRICA 3,5CM & 0 & 24 & 0 & 0 & 16 & 4 & 3 & 6 \\
\hline FIO CIRÚRGICO CATIGUTE SIMPLES 2-0 SEM AGULHA 150CM & 24 & 24 & 0 & 0 & 0 & 4 & 12 & 4 \\
\hline FIO CIRÚRGICO CATIGUTE SIMPLES 3-0 AGULHA 1/2 CÍRCULO CILÍNDRICA 2,0CM & 0 & 48 & 0 & 36 & 10 & 9 & 9 & 9 \\
\hline FIO CIRÚRGICO CATIGUTE SIMPLES 3-0 AGULHA 1/2 CÍRCULO CILÍNDRICA 3,5CM & 0 & 0 & 0 & 48 & 23 & 15 & 32 & 18 \\
\hline FIO CIRÚRGICO CATIGUTE SIMPLES 3-0 SEM AGULHA 150CM & 3 & 0 & 3 & 3 & 2 & 3 & 14 & 4 \\
\hline FIO CIRÚRGICO CATIGUTE SIMPLES 4-0 SEM AGULHA 150CM & 0 & 24 & 0 & 0 & 1 & 1 & 5 & 2 \\
\hline FIO CIRÚRGICO CATIGUTE SIMPLES 5-0 AGULHA 1/2 CÍRCULO CILÍNDRICA 2,0CM & 2 & 2 & 4 & 2 & 4 & 1 & 11 & 0 \\
\hline FIO CIRÚRGICO NYLON MONOFILAMENTADO 2-0 AGULHA 3/8 CÍRCULO TRIANGULAR 2,0CM & 120 & 144 & 96 & 144 & 99 & 76 & 46 & 64 \\
\hline FIO CIRÚRGICO NYLON MONOFILAMENTADO 3-0 AGULHA 3/8 CÍRCULO CILÍNDRICA 2,0CM & 72 & 240 & 168 & 144 & 27 & 153 & 108 & 117 \\
\hline FIO CIRÚRGICO NYLON MONOFILAMENTADO 4-0 AGULHA 3/8 CÍRCULO TRIANGULAR 2,0CM & 112 & 208 & 0 & 144 & 69 & 39 & 43 & 37 \\
\hline FIO CIRÚRGICO NYLON MONOFILAMENTADO 4-0 AGULHA 3/8 CÍRCULO TRIANGULAR 2,4CM & 272 & 312 & 384 & 264 & 248 & 370 & 338 & 316 \\
\hline FIO CIRÚRGICO NYLON MONOFILAMENTADO 5-0 AGULHA 3/8 CÍRCULO TRIANGULAR 2,0CM & 72 & 0 & 24 & 72 & 27 & 69 & 43 & 48 \\
\hline FIO CIRÚRGICO POLIÉSTER 2 AGULHA 1/2 CÍRCULO TRIANGULAR 4,0CM & 24 & 8 & 40 & 24 & 9 & 5 & 7 & 0 \\
\hline FIO CIRÚRGICO POLIÉSTER 2-0 2 AGULHAS 1/2 CÍRCULO CILÍNDRICAS 2,0CM & 24 & 0 & 24 & 24 & 1 & 7 & 3 & 0 \\
\hline FIO CIRÚRGICO POLIÉSTER 5 AGULHA 1/2 CÍRCULO TRIANGULAR 4,7CM & 0 & 0 & 0 & 0 & 2 & 2 & 0 & 0 \\
\hline FIO CIRÚRGICO POLIGLECAPRONE 0 AGULHA 1/2 CÍRCULO CILÍNDRICA 4,0CM & 0 & 0 & 0 & 0 & 7 & 12 & 7 & 13 \\
\hline FIO CIRÚRGICO POLIGLECAPRONE 1 AGULHA 1/2 CÍRCULO CILÍNDRICA 4,0CM & 24 & 0 & 0 & 24 & 16 & 32 & 3 & 12 \\
\hline FIO CIRÚRGICO POLIGLECAPRONE 3-0 AGULHA 1/2 CÍRCULO CILÍNDRICA 2,5CM & 72 & 48 & 0 & 24 & 17 & 54 & 13 & 74 \\
\hline FIO CIRÚRGICO POLIGLECAPRONE 4-0 AGULHA 1/2 CÍRCULO CILÍNDRICA 2,5CM & 0 & 24 & 24 & 0 & 23 & 10 & 23 & 11 \\
\hline FIO CIRÚRGICO POLIGLECAPRONE 4-0 AGULHA 3/8 CÍRCULO TRIANGULAR 1,95CM & 228 & 84 & 72 & 72 & 71 & 98 & 84 & 60 \\
\hline FIO CIRÚRGICO POLIGLECAPRONE 5-0 AGULHA 3/8 CÍRCULO TRIANGULAR 1,65CM & 60 & 24 & 12 & 0 & 17 & 11 & 11 & 15 \\
\hline FIO CIRÚRGICO POLIPROPILENO 2 AGULHA 3/8 CÍRCULO CILÍNDRICA 7,5CM & 0 & 2 & 58 & 0 & 13 & 15 & 9 & 23 \\
\hline FIO CIRÚRGICO POLIPROPILENO 2-0 AGULHA 1/2 CÍRCULO CILÍNDRICA 2,5CM & 96 & 0 & 24 & 96 & 75 & 40 & 78 & 62 \\
\hline FIO CIRÚRGICO POLIPROPILENO 3-0 2 AGULHAS 1/2 CÍRCULO CILÍNDRICAS 3,0CM & 48 & 24 & 48 & 24 & 28 & 58 & 31 & 30 \\
\hline FIO CIRÚRGICO POLIPROPILENO 4-0 2 AGULHAS 1/2 CÍRCULO CILÍNDRICAS 1,5CM & 24 & 24 & 0 & 24 & 14 & 21 & 23 & 32 \\
\hline FIO CIRÚRGICO POLIPROPILENO 4-0 2 AGULHAS 1/2 CÍRCULO CILÍNDRICAS 2,0CM & 24 & 24 & 0 & 24 & 14 & 35 & 17 & 18 \\
\hline FIO CIRÚRGICO POLIPROPILENO 6-0 2 AGULHAS 3/8 CÍRCULO CILÍNDRICAS 1,3CM & 4 & 4 & -6 & 10 & 9 & 6 & 2 & 3 \\
\hline FIO CIRÚRGICO POLIPROPILENO 7-0 2 AGULHAS 3/8 CÍRCULO CILÍNDRICAS 1,0CM & 0 & 0 & 0 & 0 & 0 & 0 & 0 & 2 \\
\hline FIO CIRÚRGICO SEDA 4-0 AGULHA 3/8 CÍRCULO TRIANGULAR 1,3CM & 24 & 4 & 8 & 0 & 6 & 5 & 9 & 8 \\
\hline FIO CIRÚRGICO SINTÉTICO ABSORVÍVEL O AGULHA 1/2 CÍRCULO CILÍNDRICA 5,0CM & 72 & 0 & 84 & 24 & 11 & 57 & 20 & 68 \\
\hline FIO CIRÚRGICO SINTÉTICO ABSORVÍVEL O AGULHA 3/8 CÍRCULO CILÍNDRICA 3,0CM & 48 & 0 & 120 & 60 & 21 & 50 & 24 & 13 \\
\hline FIO CIRÚRGICO SINTÉTICO ABSORVÍVEL 1 AGULHA 1/2 CÍRCULO CILÍNDRICA 3,5CM & 72 & 180 & 180 & 72 & 142 & 169 & 108 & 160 \\
\hline FIO CIRÚRGICO SINTÉTICO ABSORVÍVEL 2-0 AGULHA 1/2 CíRCULO CILÍNDRICA 2,5CM & 84 & 96 & 108 & 84 & 48 & 85 & 131 & 67 \\
\hline FIO CIRÚRGICO SINTÉTICO ABSORVÍVEL 2-0 AGULHA 3/8 CÍRCULO CILÍNDRICA 3,0CM & 0 & 72 & 36 & 24 & 34 & 48 & 51 & 99 \\
\hline FIO CIRÚRGICO SINTÉTICO ABSORVÍVEL 3-0 AGULHA 1/2 CÍRCULO CILÍNDRICA 2,5CM & 108 & 175 & 160 & 180 & 115 & 186 & 148 & 188 \\
\hline FIO CIRÚRGICO SINTÉTICO ABSORVÍVEL 6-0 2 AGULHAS 3/8 CILÍNDRICA 0,65CM & 30 & 6 & 0 & 12 & 5 & 2 & 3 & 5 \\
\hline FIO GUIA 0,035" X 150CM HIDROFÍLICO & 0 & 5 & 10 & 5 & 7 & 1 & 1 & 3 \\
\hline FITA ADESIVA MICROPOROSA BRANCO 12MM X 100MM SUTURA DE PELE & 25 & 110 & 60 & 60 & 48 & 70 & 35 & 47 \\
\hline FITA ADESIVA MICROPOROSA BRANCO 6MM X 38MM SUTURA DE PELE & 15 & 50 & 53 & 37 & 67 & 77 & 82 & 45 \\
\hline
\end{tabular}




\begin{tabular}{|c|c|c|c|c|c|c|c|c|}
\hline \multirow{2}{*}{ NOME DO PRODUTO } & \multicolumn{4}{|c|}{2007} & \multicolumn{4}{|c|}{2008} \\
\hline & FEV. & MAR. & ABR. & MAIO & FEV. & MAR. & ABR. & MAIO \\
\hline FITA CIRÚRGICA MICROPOROSA BRANCO 100MM X 10MT HIPOALÉRGICA & 9 & 12 & 30 & 0 & 8 & 7 & 9 & 14 \\
\hline FITA CIRÚRGICA MICROPOROSA BRANCO 12MM X 10MT HIPOALÉRGICA & 36 & 1 & 0 & 35 & 12 & 10 & 10 & 21 \\
\hline FITA CIRÚRGICA MICROPOROSA BRANCO 25MM X 10MT HIPOALÉRGICA & 34 & 40 & 35 & 35 & 21 & 33 & 32 & 23 \\
\hline FITA CIRÚRGICA MICROPOROSA BRANCO 50MM X 10MT HIPOALÉRGICA & 21 & 17 & 60 & 15 & 22 & 20 & 24 & 22 \\
\hline FITA CREPE BRANCO 16MM X 50MT HIPOALÉRGICA & 27 & 23 & 30 & 40 & 16 & 14 & 28 & 13 \\
\hline FITA PROLENE 1,1CM X 45CM INABSORVÍVEL POLIPROPILENO & 3 & 2 & 5 & 2 & 1 & 1 & 4 & 2 \\
\hline FRAGMENTADOR DE TECIDOS 15MM LAPAROSCÓPICO & 4 & 0 & 0 & 0 & 0 & 2 & 1 & 0 \\
\hline FRALDA DESCARTÁVEL ATÉ 5KG & 0 & 13 & 0 & 1 & 0 & 3 & 0 & 0 \\
\hline FRASCO BRANCO 67ML COM TAMPA & 0 & 4 & 0 & 4 & 0 & 0 & 22 & 0 \\
\hline FRASCO DE VIDRO BRANCO CAPACIDADE 250 ML DIÂMETRO DE 3 CM - COM TAMPA & 0 & 1 & 0 & 1 & 1 & 0 & 0 & 0 \\
\hline FRASCO DRENAGEM DE TÓRAX 2000MIL & 24 & 6 & 20 & 20 & 7 & 7 & 4 & 10 \\
\hline FRASCO DRENAGEM DE TÓRAX 500MIL & 0 & 2 & 0 & 3 & 0 & 2 & 1 & 1 \\
\hline GRAMPEADOR CIRÚRGICO CURVO 21MM INTRALUMINAL DESCARTÁVEL & 0 & 1 & 0 & 1 & 1 & 0 & 2 & 1 \\
\hline GRAMPEADOR CIRÚRGICO CURVO 25MM INTRALUMINAL DESCARTÁVEL & 0 & 1 & 0 & 1 & 1 & 1 & 0 & 0 \\
\hline GRAMPEADOR CIRÚRGICO CURVO 28/29MM INTRALUMINAL DESCARTÁVEL & 1 & 1 & 0 & 0 & 1 & 2 & 0 & 0 \\
\hline GRAMPEADOR CIRÚRGICO CURVO 33/34MM INTRALUMINAL DESCARTÁVEL & 2 & 2 & 0 & 0 & 0 & 1 & 3 & 0 \\
\hline GRAMPEADOR CIRÚRGICO LINEAR 45MM ARTICULADO INTRALUMINAL DESCARTÁVEL & 1 & 1 & 0 & 0 & 1 & 0 & 0 & 0 \\
\hline GRAMPEADOR CIRÚRGICO LINEAR 55MM RECARREGAVEL DESCARTÁVEL & 0 & 1 & 0 & 0 & 1 & 2 & 4 & 1 \\
\hline GRAMPEADOR CIRÚRGICO LINEAR 75MM RECARREGAVEL DESCARTÁVEL & 1 & 2 & 2 & 1 & 2 & 3 & 0 & 4 \\
\hline GUIA ENTUBAÇÃO 2,5MM X 4,5MM & 7 & 3 & 4 & 1 & 2 & 0 & 3 & 2 \\
\hline GUIA ENTUBAÇÃO 4,0MM 10FR & 9 & 12 & 8 & 18 & 2 & 4 & 12 & 0 \\
\hline GUIA ENTUBAÇÃO 5,0MM 14FR & 5 & 15 & 10 & 20 & 45 & 27 & 39 & 39 \\
\hline LÂMINA BARBEAR & 2 & 20 & 15 & 15 & 1 & 0 & 0 & 2 \\
\hline LENÇOL ABSORVENTE 80CM X 150CM DRY GEL & 54 & 58 & 54 & 54 & 30 & 46 & 50 & 36 \\
\hline LIXA BISTURI ELÉTRICO & 50 & 40 & 80 & 0 & 51 & 57 & 58 & 53 \\
\hline LUVA CIRÚRGICA 6,5 ESTÉRIL & 200 & 200 & 200 & 200 & 200 & 145 & 218 & 225 \\
\hline LUVA CIRÚRGICA 7,0 ESTÉRIL & 200 & 700 & 0 & 400 & 279 & 394 & 286 & 301 \\
\hline LUVA CIRÚRGICA 7,5 ESTÉRIL & 650 & 800 & 400 & 400 & 561 & 632 & 516 & 489 \\
\hline LUVA CIRÚRGICA 8,0 ESTÉRIL & 350 & 800 & 200 & 200 & 447 & 575 & 491 & 468 \\
\hline LUVA CIRÚRGICA 8,5 ESTÉRIL & 161 & 130 & 0 & 100 & 97 & 127 & 105 & 142 \\
\hline LUVA PLÁSTICA ESTÉRIL & 100 & 0 & 0 & 300 & 185 & 4 & 202 & 58 \\
\hline LUVA PROCEDIMENTO MÉDIO ESTÉRIL & 100 & 0 & 0 & 400 & 36 & 24 & 221 & 320 \\
\hline LUVA PROCEDIMENTO MÉDIO NÃO ESTÉRIL & 9.000 & 5.000 & 15.000 & 12.000 & 7.924 & 10.508 & 10.301 & 13.892 \\
\hline MALHA TUBULAR 10CM X 25M & 0 & 2 & 1 & 1 & 0 & 1 & 1 & 0 \\
\hline MALHA TUBULAR 20CM X 25M & 3 & 2 & 1 & 1 & 1 & 0 & 0 & 0 \\
\hline MANTA TÉRMICA ADULTO 90-130CM X 200-240CM & 0 & 10 & 5 & 5 & 7 & 9 & 5 & 8 \\
\hline MANTA TÉRMICA INFERIOR 90-110CM X 140-160CM & 20 & 30 & 0 & 40 & 15 & 22 & 21 & 16 \\
\hline MANTA TÉRMICA PEDIÁTRICA 60-105CM X 100-155CM & 5 & 20 & 0 & 20 & 7 & 12 & 6 & 8 \\
\hline MANTA TÉRMICA SUPERIOR 60-80CM X 180-200CM & 40 & 110 & 30 & 40 & 79 & 102 & 85 & 97 \\
\hline
\end{tabular}


Apêndices 161

\begin{tabular}{|c|c|c|c|c|c|c|c|c|}
\hline \multirow{2}{*}{ NOME DO PRODUTO } & \multicolumn{4}{|c|}{2007} & \multicolumn{4}{|c|}{2008} \\
\hline & FEV. & MAR. & ABR. & MAIO & FEV. & MAR. & ABR. & MAIO \\
\hline MASCARA CIRÚRGICA DESCARTÁVEL & 2.150 & 3.350 & 1.300 & 2.200 & 1.600 & 2.400 & 2.150 & 2.200 \\
\hline PASTA CONDUTORA ELETRODO & 1 & 4 & 4 & 4 & 4 & 2 & 7 & 4 \\
\hline PLACA BISTURI ELÉTRICO ADULTO & 110 & 120 & 130 & 100 & 73 & 87 & 103 & 79 \\
\hline PLACA BISTURI ELÉTRICO INFANTIL & 17 & 21 & 15 & 12 & 2 & 9 & 5 & 5 \\
\hline PROPE DESCARTÁVEL & 2.800 & 14.100 & 9.000 & 9.000 & 3.950 & 6.250 & 9.850 & 9.100 \\
\hline SABONETE GLICERINA 20 GRAMAS & 100 & 170 & 100 & 100 & 24 & 25 & 16 & 94 \\
\hline 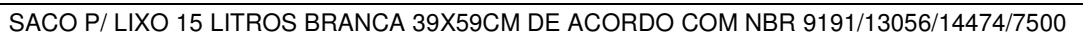 & 200 & 200 & 200 & 200 & 200 & 100 & 0 & 500 \\
\hline 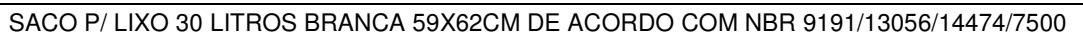 & 300 & 400 & 300 & 200 & 100 & 300 & 300 & 100 \\
\hline SACO P/ LIXO 90 LITROS BRANCA 92X90CM DE ACORDO COM NBR 9191/13056/14474/7500 & 200 & 0 & 800 & 0 & 200 & 300 & 300 & 500 \\
\hline SACO PLÁSTICO BRANCO LEITOSO 20CM X 40CM PLACENTA & 100 & 100 & 100 & 100 & 0 & 100 & 0 & 0 \\
\hline SERINGA 10ML DESCARTÁVEL & 1.600 & 1.100 & 400 & 800 & 737 & 951 & 776 & 740 \\
\hline SERINGA 1ML DESCARTÁVEL & 70 & 30 & 20 & 30 & 53 & 53 & 54 & 43 \\
\hline SERINGA 20ML DESCARTÁVEL & 950 & 750 & 1.066 & 800 & 738 & 922 & 893 & 722 \\
\hline SERINGA 3ML DESCARTÁVEL & 70 & 50 & 80 & 50 & 42 & 29 & 38 & 14 \\
\hline SERINGA 5ML DESCARTÁVEL & 700 & 1.106 & 400 & 1.000 & 715 & 914 & 709 & 727 \\
\hline SERINGA 60ML DESCARTÁVEL & 10 & 8 & 18 & 18 & 6 & 11 & 19 & 13 \\
\hline SERINGA GASOMETRIA 2ML & 17 & 33 & 25 & 27 & 39 & 39 & 61 & 47 \\
\hline SONDA ASPIRAÇÃO TRAQUEAL 10FR & 30 & 40 & 35 & 40 & 23 & 35 & 32 & 24 \\
\hline SONDA ASPIRAÇÃO TRAQUEAL 12FR & 70 & 180 & 50 & 100 & 104 & 102 & 109 & 90 \\
\hline SONDA ASPIRAÇÃO TRAQUEAL 14FR & 130 & 100 & 100 & 100 & 146 & 169 & 188 & 194 \\
\hline SONDA ASPIRAÇÃO TRAQUEAL 6FR & 30 & 6 & 6 & 6 & 8 & 8 & 14 & 12 \\
\hline SONDA ASPIRAÇÃO TRAQUEAL 8FR & 20 & 15 & 15 & 15 & 19 & 14 & 21 & 11 \\
\hline SONDA FOLEY 122 VIAS & 25 & 35 & 25 & 42 & 13 & 31 & 16 & 15 \\
\hline SONDA FOLEY 142 VIAS & 40 & 100 & 27 & 30 & 53 & 67 & 53 & 65 \\
\hline SONDA FOLEY 162 VIAS & 0 & 20 & 10 & 20 & 15 & 15 & 10 & 25 \\
\hline SONDA FOLEY 182 VIAS & 2 & 18 & 0 & 5 & 4 & 9 & 4 & 8 \\
\hline SONDA FOLEY 183 VIAS & 1 & 1 & 2 & 0 & 3 & 1 & 0 & 0 \\
\hline SONDA FOLEY 202 VIAS & 2 & 3 & 4 & 0 & 0 & 1 & 2 & 0 \\
\hline SONDA FOLEY 203 VIAS & 7 & 13 & 0 & 10 & 6 & 3 & 2 & 4 \\
\hline SONDA FOLEY 222 VIAS & 3 & 2 & 4 & 0 & 0 & 1 & 2 & 0 \\
\hline SONDA FOLEY 223 VIAS & 1 & 9 & 0 & 5 & 5 & 4 & 6 & 4 \\
\hline SONDA FOLEY 8 SILICONE 2 VIAS & 2 & 2 & 1 & 0 & 1 & 0 & 1 & 0 \\
\hline SONDA GÁSTRICA 16 TIPO LEVINE & 28 & 40 & 10 & 10 & 36 & 34 & 43 & 40 \\
\hline SONDA GÁSTRICA 18 TIPO LEVINE & 35 & 35 & 52 & 30 & 49 & 55 & 61 & 62 \\
\hline SONDA GÁSTRICA 8 TIPO LEVINE & 0 & 8 & 5 & 5 & 6 & 10 & 8 & 6 \\
\hline SONDA GASTROSTOMIA 14FR COM BALÃO 3 VIAS & 2 & 0 & 1 & 0 & 0 & 2 & 1 & 0 \\
\hline SONDA GASTROSTOMIA 16FR COM BALÃO 3 VIAS & 0 & 3 & 1 & 0 & 0 & 0 & 0 & 1 \\
\hline SONDA RETAL 26 & 1 & 2 & 0 & 1 & 0 & 1 & 1 & 0 \\
\hline SONDA RETAL 28 & 0 & 2 & 0 & 2 & 1 & 2 & 2 & 3 \\
\hline
\end{tabular}


Apêndices 162

\begin{tabular}{|c|c|c|c|c|c|c|c|c|}
\hline \multirow{2}{*}{ NOME DO PRODUTO } & \multicolumn{4}{|c|}{2007} & \multicolumn{4}{|c|}{2008} \\
\hline & FEV. & MAR. & ABR. & MAIO & FEV. & MAR. & ABR. & MAIO \\
\hline SONDA URETRAL 6 & 3 & 22 & 0 & 18 & 11 & 17 & 9 & 12 \\
\hline SONDA URETRAL DESC. CAL. 04. URETRAL 4 & 8 & 12 & 0 & 15 & 3 & 7 & 5 & 5 \\
\hline SONDA URETRAL DESC. CAL. 10. URETRAL 10 & 10 & 10 & 0 & 0 & 3 & 9 & 5 & 1 \\
\hline SONDA URETRAL DESC. CAL. 12. URETRAL 12 & 20 & 5 & 40 & 15 & 4 & 6 & 6 & 2 \\
\hline SONDA URETRAL DESC. CAL. 14. URETRAL 14 & 20 & 20 & 10 & 20 & 6 & 19 & 19 & 9 \\
\hline TALA IMOBILIZAÇÃO PROVISÓRIA 10CM X 2CM DEDO & 1 & 1 & 0 & 1 & 0 & 0 & 0 & 0 \\
\hline TALA IMOBILIZAÇÃO PROVISÓRIA 30CM X 8CM X 2CM & 1 & 1 & 0 & 1 & 1 & 2 & 0 & 0 \\
\hline TALA IMOBILIZAÇÃO PROVISÓRIA 63CM X 8CM X 2CM & 1 & 3 & 0 & 0 & 0 & 2 & 1 & 0 \\
\hline TALA IMOBILIZAÇÃO PROVISÓRIA 86CM X 9CM X 2CM & 2 & 3 & 0 & 0 & 1 & 3 & 1 & 1 \\
\hline TELA CIRÚRGICA 15CM X 15CM PARCIALMENTE ABSORVIIVEL POLIPROPILENO & 0 & 14 & 0 & 0 & 2 & 5 & 6 & 10 \\
\hline TELA CIRÚRGICA 30,5CM X 30,5CM INBSORVÍVEL POLIPROPILENO & 7 & 11 & 4 & 12 & 2 & 6 & 10 & 10 \\
\hline TIRA REAGENTE PARA DETERMINAÇÃO DE GLICOSE SANGUE & 100 & 0 & 150 & 50 & 55 & 2 & 52 & 50 \\
\hline TORNEIRA 3 VIAS PLÁSTICO & 300 & 400 & 100 & 302 & 267 & 328 & 349 & 304 \\
\hline TOUCA DESCARTÁVEL & 2.009 & 3.003 & 2.000 & 2.000 & 1.800 & 1.400 & 3.100 & 2.600 \\
\hline TUBO ASPIRADOR CIRÚRGICO 200CM ESTÉRIL & 400 & 615 & 560 & 660 & 511 & 0 & 587 & 554 \\
\hline TUBO COLETA A VÁCUO COM GEL TAMPA DE COR AM OU VM 13 MM X 100 MM, DE 5 A 6 ML & 100 & 0 & 100 & 50 & 5 & 7 & 1 & 2 \\
\hline TUBO COLETA A VÁCUO FLUORETO DE SÓDIO E EDTA T. DE COR CZ 13MMX75MM DE 2 A 3 ML & 10 & 15 & 45 & 30 & 0 & 647 & 3 & 0 \\
\hline TUBO COLETA DE SANGUE A VÁCUO TAMPA AZUL 1,8 ML CITRATO & 24 & 15 & 45 & 30 & 3 & 5 & 7 & 10 \\
\hline TUBO COLETA DE SANGUE A VÁCUO TAMPA ROXA 3 A 4 ML EDTA & 30 & 100 & 0 & 100 & 61 & 76 & 101 & 85 \\
\hline TUBO COLETA DE SANGUE A VÁCUO TAMPA VERMELHA 9 A 10 ML SEM GEL & 0 & 40 & 60 & 0 & 62 & 54 & 91 & 64 \\
\hline TUBO EXTENSOR 20CM CONEXÃO LUER LOCK & 50 & 160 & 30 & 40 & 85 & 91 & 84 & 86 \\
\hline TUBO EXTENSOR 60CM CONEXÃO LUER LOCK & 140 & 127 & 6 & 200 & 140 & 152 & 170 & 141 \\
\hline TUBO LÁTEX DIÂMETRO INTERNO 3MM GARROTE & 1 & 0 & 1 & 2 & 1 & 0 & 0 & 1 \\
\hline TUBO VACUTAINER FLUORETO DE SÓDIO $3 \mathrm{ML}$ & 0 & 0 & 0 & 15 & 0 & 0 & 6 & 3 \\
\hline
\end{tabular}




\section{Apêndice 2 - Instrumentos de coleta dos dados}

\begin{tabular}{|c|c|c|c|c|c|c|c|}
\hline Data & Nome cirurgia & Qtde cirurgia & Porte & Idade & Sexo & $\mathbf{P}^{*}$ & Intercorrências \\
\hline & & & & & & & \\
\hline & & & & & & & \\
\hline & & & & & & & \\
\hline & & & & & & & \\
\hline & & & & & & & \\
\hline & & & & & & & \\
\hline & & & & & & & \\
\hline
\end{tabular}

* P - Classificação do estado físico do paciente.

Segunda Planilha:

\begin{tabular}{|c|c|c|c|c|}
\hline Data & Código material & Nome material & Qtde material consumido & Custo unitário material \\
\hline & & & & \\
\hline & & & & \\
\hline & & & & \\
\hline & & & & \\
\hline & & & & \\
\hline
\end{tabular}




\section{Terceira Planilha:}

\begin{tabular}{|c|c|c|c|c|c|c|c|}
\hline Data & Nome kit cirúrgico/anestésico & $\begin{array}{c}\text { Qtde kit } \\
\text { dispensado }\end{array}$ & $\begin{array}{l}\text { Qtde kit } \\
\text { estornado }\end{array}$ & $\begin{array}{l}\text { Qtde kit } \\
\text { consumido }\end{array}$ & Nome material que compõe o kit & $\begin{array}{l}\text { Qtde material } \\
\text { consumido kit }\end{array}$ & $\begin{array}{l}\text { Custo unitário } \\
\text { material do kit }\end{array}$ \\
\hline & & & & & & & \\
\hline & & & & & & & \\
\hline & & & & & & & \\
\hline & & & & & & & \\
\hline & & & & & & & \\
\hline & & & & & & & \\
\hline & & & & & & & \\
\hline & & & & & & & \\
\hline
\end{tabular}

\section{Quarta Planilha:}

\begin{tabular}{|c|c|c|c|c|}
\hline Data & Nome do material estocado & Qtde mínima material estocado & Qtde abastecimento material no estoque & Custo unitário material \\
\hline & & & & \\
\hline & & & & \\
\hline & & & & \\
\hline & & & & \\
\hline & & & & \\
\hline & & & & \\
\hline & & & & \\
\hline & & & & \\
\hline
\end{tabular}




\section{Apêndice 3 - Relação de cirurgias realizadas no período de coleta de dados}

\begin{tabular}{|c|c|c|c|c|c|}
\hline PROCEDIMENTO - 2007 & $\mathbf{N}$ & $\%$ & PROCEDIMENTO - 2008 & $\mathbf{N}$ & $\%$ \\
\hline COLECISTECTOMIA VIDEOLAPAROSCÓPICA & 81 & 5,1 & APENDICECTOMIA & 94 & 6,5 \\
\hline APENDICECTOMIA & 76 & 4,8 & LAPAROTOMIA EXPLORADORA & 90 & 6,2 \\
\hline LAPAROTOMIA EXPLORADORA & 63 & 4,0 & COLECISTECTOMIA VIDEOLAPAROSCÓPICA & 70 & 4,8 \\
\hline HERNIORRAFIA INGUINAL (UNILATERAL) & 55 & 3,5 & HERNIORRAFIA INGUINAL (UNILATERAL) & 56 & 3,8 \\
\hline $\begin{array}{l}\text { FACECTOMIA PARA IMPLANTE DE LENTE } \\
\text { INTRAOCULAR }\end{array}$ & 50 & 3,2 & $\begin{array}{l}\text { FACOEMULSIFICAÇÃO COM IMPLANTE DE } \\
\text { LENTE INTRAOCULAR }\end{array}$ & 31 & 2,1 \\
\hline $\begin{array}{l}\text { RETIRADA DE MATERIAL DE SÍNTESE - FIO DE } \\
\text { KIRSCHNER }\end{array}$ & 42 & 2,7 & ENDOSCOPIA DIGESTIVA ALTA & 29 & 2,0 \\
\hline HERNIORRAFIA UMBILICAL & 30 & 1,9 & COLECISTECTOMIA & 27 & 1,9 \\
\hline ENDOSCOPIA DIGESTIVA ALTA & 29 & 1,8 & HEMORROIDECTOMIA & 24 & 1,6 \\
\hline COLECISTECTOMIA & 21 & 1,3 & POSTECTOMIA (CIRCUNCISÃO) & 24 & 1,6 \\
\hline $\begin{array}{l}\text { AMIGDALECTOMIA COM OU SEM } \\
\text { ADENOIDECTOMIA }\end{array}$ & 20 & 1,3 & HERNIORRAFIA UMBILICAL & 23 & 1,6 \\
\hline HERNIORRAFIA INCISIONAL GRANDE & 20 & 1,3 & RESSECÇÃO ENDOSCÓPICA DE PRÓSTATA & 22 & 1,5 \\
\hline $\begin{array}{l}\text { FACOEMULSIFICAÇÃO COM IMPLANTE DE } \\
\text { LENTE INTRAOCULAR }\end{array}$ & 19 & 1,2 & $\begin{array}{l}\text { FACECTOMIA PARA IMPLANTE DE LENTE } \\
\text { INTRA-OCULAR }\end{array}$ & 21 & 1,4 \\
\hline RESSECÇÃO ENDOSCÓPICA DE PRÓSTATA & 19 & 1,2 & $\begin{array}{l}\text { AMIGDALECTOMIA COM OU SEM } \\
\text { ADENOIDECTOMIA }\end{array}$ & 19 & 1,3 \\
\hline AMIDALECTOMIA COM ADENOIDECTOMIA & 17 & 1,1 & CIRURGIA DE VARIZES BILATERAL & 15 & 1,0 \\
\hline HERNIORRAFIA INGUINAL (BILATERAL) & 17 & 1,1 & FISTULECTOMIA & 15 & 1,0 \\
\hline HEMORROIDECTOMIA & 15 & 0,9 & SEPTOPLASTIA (DESVIO DO SEPTO) & 14 & 1,0 \\
\hline $\begin{array}{l}\text { DEBRIDAMENTO DE ÚLCERA OU DE TECIDOS } \\
\text { DESVITALIZADOS }\end{array}$ & 14 & 0,9 & COLECTOMIA PARCIAL (HEMICOLECTOMIA) & 13 & 0,9 \\
\hline EXERESE DE LIPOMA & 14 & 0,9 & $\begin{array}{l}\text { DEBRIDAMENTO DE ÚLCERA OU DE TECIDOS } \\
\text { DESVITALIZADOS }\end{array}$ & 13 & 0,9 \\
\hline HISTERECTOMIA TOTAL ABDOMINAL & 14 & 0,9 & AMIDALECTOMIA COM ADENOIDECTOMIA & 12 & 0,8 \\
\hline HISTEROSCOPIA DIAGNÓSTICA E CIRÚRGICA & 14 & 0,9 & HERNIORRAFIA INCISIONAL GRANDE & 12 & 0,8 \\
\hline POSTECTOMIA (CIRCUNCISÃO) & 14 & 0,9 & EXERESE DE LIPOMA & 11 & 0,8 \\
\hline $\begin{array}{l}\text { TRATAMENTO CIRÚRGICO DA FRATURA DA } \\
\text { DIÁFISE DO FÊMUR }\end{array}$ & 14 & 0,9 & HERNIORRAFIA EPIGÁSTRICA & 11 & 0,8 \\
\hline CIRURGIA DE VARIZES BILATERAL & 13 & 0,8 & HERNIORRAFIA INGUINAL (BILATERAL) & 11 & 0,8 \\
\hline COLECTOMIA PARCIAL (HEMICOLECTOMIA) & 12 & 0,8 & HISTERECTOMIA TOTAL ABDOMINAL & 11 & 0,8 \\
\hline $\begin{array}{l}\text { FECHAMENTO DE ENTEROSTOMIA } \\
\text { (QUALQUER SEGMENTO) }\end{array}$ & 12 & 0,8 & $\begin{array}{l}\text { TRATAMENTO CONSERVADOR DA FRAT.DOS } \\
\text { OSSOS DA FACE }\end{array}$ & 11 & 0,8 \\
\hline VASECTOMIA PARCIAL OU COMPLETA & 12 & 0,8 & ADENOIDECTOMIA & 10 & 0,7 \\
\hline EXERESE DE CALÁZIO & 11 & 0,7 & $\begin{array}{l}\text { CURETAGEM SEMIOTICA COM OU SEM } \\
\text { DILAT.DO COLO UTERINO }\end{array}$ & 10 & 0,7 \\
\hline HERNIORRAFIA EPIGÁSTRICA & 11 & 0,7 & $\begin{array}{l}\text { LAPAROTOMIA VIDEOLAPAROSCÓPICA } \\
\text { P/DRENAGEM E/OU BIÓPSIA }\end{array}$ & 10 & 0,7 \\
\hline $\begin{array}{l}\text { TRATAMENTO CIRÚRGICO DE FRATURA DA } \\
\text { DIÁFISE DA TÍBIA }\end{array}$ & 11 & 0,7 & TURBINECTOMIA & 10 & 0,7 \\
\hline AMIGDALECTOMIA & 10 & 0,6 & COLOCAÇÃO DE CATETER DUPLO J & 9 & 0,6 \\
\hline CISTOSCOPIA COM BIÓPSIA DE BEXIGA & 10 & 0,6 & MIOMECTOMIA & 9 & 0,6 \\
\hline $\begin{array}{l}\text { CURETAGEM SEMIÓTICA COM OU SEM } \\
\text { DILATACAO DO COLO UTERINO }\end{array}$ & 10 & 0,6 & RECONSTRUÇÃO DE MANDÍBULA & 9 & 0,6 \\
\hline $\begin{array}{l}\text { TRATAMENTO CIRÚRGICO DA FRATURA DO } \\
\text { TORNOZELO UNIMALEOLAR }\end{array}$ & 10 & 0,6 & $\begin{array}{l}\text { REDUÇÃO INCRUENTA DA FRATURA DO } \\
\text { FÊMUR }\end{array}$ & 9 & 0,6 \\
\hline $\begin{array}{l}\text { VIDEOSCOPIA PARA SÍNTESE, RECONST.OU } \\
\text { TRANSPL.DE ESTRUT.INTRA }\end{array}$ & 10 & 0,6 & TIREOIDECTOMIA TOTAL & 9 & 0,6 \\
\hline $\begin{array}{l}\text { GASTRECTOMIA SUBTOTAL COM OU SEM } \\
\text { VAGOTOMIA }\end{array}$ & 9 & 0,6 & $\begin{array}{l}\text { TRATAMENTO CIRÚRGICO DA FRATURA DA } \\
\text { DIÁFISE DO FÊMUR }\end{array}$ & 9 & 0,6 \\
\hline PROSTATOVESICULECTOMIA & 9 & 0,6 & VASECTOMIA PARCIAL OU COMPLETA & 9 & 0,6 \\
\hline TIMPANOTOMIA PARA TUBO DE VENTILAÇÃO & 9 & 0,6 & AMPUTAÇÃO DE DEDO - POR DEDO & 8 & 0,5 \\
\hline $\begin{array}{l}\text { TRATAMENTO CIRÚRGICO DA FRATURA } \\
\text { TRANSTROCANTERIANA }\end{array}$ & 9 & 0,6 & $\begin{array}{l}\text { FECHAMENTO DE ENTEROSTOMIA } \\
\text { (QUALQUER SEGMENTO) }\end{array}$ & 8 & 0,5 \\
\hline $\begin{array}{l}\text { TRATAMENTO CIRÚRGICO DE FRATURA } \\
\text { DIAFISÁRIA DO RÁDIO }\end{array}$ & 9 & 0,6 & GASTRECTOMIA COM LINFADENECTOMIA & 8 & 0,5 \\
\hline EXERESE DE TUMOR DE PELE & 8 & 0,5 & HISTEROSCOPIA DIGNÓSTICA E CIRÚRGICA & 8 & 0,5 \\
\hline EXODONTIA DENTES INCLUSOS & 8 & 0,5 & URETEROLITOTOMIA & 8 & 0,5 \\
\hline $\begin{array}{l}\text { LAPAROTOMIA VIDEOLAPAROSCÓPICA PARA } \\
\text { DRENAGEM E/OU BIÓPSIA }\end{array}$ & 8 & 0,5 & $\begin{array}{l}\text { BRONCOSCOPIA COM OU SEM ASPIRADO } \\
\text { LAVADO BROONQUICO }\end{array}$ & 7 & 0,5 \\
\hline TENORRAFIA & 8 & 0,5 & COLPOPLASTIA ANTERIOR & 7 & 0,5 \\
\hline $\begin{array}{l}\text { TRATAMENTO CIRÚRGICO DE FRATURA DAS } \\
\text { FALANGES, COM FIXAÇÃO }\end{array}$ & 8 & 0,5 & DEBRIDAMENTO DA FASCEITE NECROTIZANTE & 7 & 0,5 \\
\hline BIÓPSIA DA BOCA & 7 & 0,4 & ENXERTO DERMO EPIDÉRMICO & 7 & 0,5 \\
\hline COLOCAÇÃO DE CATETER DUPLO J & 7 & 0,4 & $\begin{array}{l}\text { TRATAMENTO CIRÚRGICO DE FRATURA DA } \\
\text { DIÁFISE DA TÍBIA }\end{array}$ & 7 & 0,5 \\
\hline FISTULECTOMIA & 7 & 0,4 & $\begin{array}{l}\text { BIÓPSIA DA PELE, TECIDO CELULAR OU } \\
\text { GÂNGLIO SUBCUTÂNEO } \\
\end{array}$ & 6 & 0,4 \\
\hline $\begin{array}{l}\text { HERNIOPLASTIA HIATAL (CARDIOPLASTIA) } \\
\text { VIDEOLAPAROSCÓPICA }\end{array}$ & 7 & 0,4 & EXERESE DE CALÁZIO & 6 & 0,4 \\
\hline $\begin{array}{l}\text { TRATAMENTO CONSERVADOR DA FRATURA } \\
\text { DOS OSSOS DA FACE }\end{array}$ & 7 & 0,4 & $\begin{array}{l}\text { INCISÃO E DRENAGEM DE ABSCESSO DA } \\
\text { BOCA E ANEXOS }\end{array}$ & 6 & 0,4 \\
\hline ARTROSCOPIA & 6 & 0,4 & $\begin{array}{l}\text { LARINGOSCOPIA/ TRAQUEOSCOPIA } \\
\text { C/DILATAÇÃO E ESTENOSE }\end{array}$ & 6 & 0,4 \\
\hline BIÓPSIA DE GÂNGLIO LINFÁTICO & 6 & 0,4 & PROSTATECTOMIA SUPRAPÚBICA & 6 & 0,4 \\
\hline
\end{tabular}




\begin{tabular}{|c|c|c|c|c|c|}
\hline PROCEDIMENTO - 2007 & $\mathbf{N}$ & $\%$ & PROCEDIMENTO - 2008 & $\mathbf{N}$ & $\%$ \\
\hline ENXERTO COMPOSTO & 6 & 0,4 & PROSTATOVESICULECTOMIA & 6 & 0,4 \\
\hline $\begin{array}{l}\text { ESFINCTEROTOMIA INTERNA E TRATAMENTO } \\
\text { DE FISSURA ANAL }\end{array}$ & 6 & 0,4 & $\begin{array}{l}\text { TRATAMENTO CIRÚRGICO DA FRAT.DIAF.DOS } \\
\text { OSSOS DO ANTEB. }\end{array}$ & 6 & 0,4 \\
\hline PLÁSTICA MAMÁRIA FEMININA NÃO ESTÉTICA & 6 & 0,4 & $\begin{array}{l}\text { TRATAMENTO CIRÚRGICO DA INCONTINÊNCIA } \\
\text { URIN.POR VIA VAG. }\end{array}$ & 6 & 0,4 \\
\hline $\begin{array}{l}\text { RESSECÇÃO ENDOSCÓPICA DE PÓLIPOS } \\
\text { VESICAIS }\end{array}$ & 6 & 0,4 & $\begin{array}{l}\text { TRATAMENTO CIRÚRGICO DE PATOLOGIA DE } \\
\text { OMBRO }\end{array}$ & 6 & 0,4 \\
\hline $\begin{array}{l}\text { RESSUTURA DE PAREDE ABDOMINAL (POR } \\
\text { DEISCÊNCIA TOT.OU EVISC.) }\end{array}$ & 6 & 0,4 & COLECTOMIA TOTAL & 5 & 0,3 \\
\hline $\begin{array}{l}\text { RETIRADA DE MATERIAL DE } \\
\text { SÍNTESE(FIOS,PINOS, ARCOS E PLACAS A) }\end{array}$ & 6 & 0,4 & $\begin{array}{l}\text { COLPOPERINEOPLASTIA ANTERIOR E } \\
\text { POSTERIOR }\end{array}$ & 5 & 0,3 \\
\hline RETOSSIGMOIDECTOMIA ABDOMINAL & 6 & 0,4 & DRENAGEM DE ABSCESSO ANAL & 5 & 0,3 \\
\hline $\begin{array}{l}\text { TRATAMENTO CIRÚRGICO DA FRATURA } \\
\text { DIAFISÁRIA DOS OSSOS DO ANTEB. }\end{array}$ & 6 & 0,4 & \begin{tabular}{|l|} 
EXCISÃO E SUTURA DE LESÃO \\
CIRC.C/ROTA.DE RETALHO \\
\end{tabular} & 5 & 0,3 \\
\hline $\begin{array}{l}\text { TRATAMENTO CIRÚRGICO DA FRATURA DO } \\
\text { COLO DO FÊMUR }\end{array}$ & 6 & 0,4 & EXERESE DE PTERÍGIO & 5 & 0,3 \\
\hline $\begin{array}{l}\text { TRATAMENTO CIRÚRGICO DE PATOLOGIA DE } \\
\text { OMBRO }\end{array}$ & 6 & 0,4 & $\begin{array}{l}\text { HISTERECTOMIA VAGINAL COM OU SEM } \\
\text { PROLAPSO DO ÚTERO }\end{array}$ & 5 & 0,3 \\
\hline AMPUTAÇÃO DA COXA & 5 & 0,3 & OOFORECTOMIA UNI OU BILATERAL & 5 & 0,3 \\
\hline $\begin{array}{l}\text { CIRURGIA ORTOGNÁTICA PARA MAXILAR OU } \\
\text { MAXILO/MANDIBULAR }\end{array}$ & 5 & 0,3 & ORQUIECTOMIA BILATERAL & 5 & 0,3 \\
\hline $\begin{array}{l}\text { COLOCAÇÃO DE CATETER TOTALMENTE OU } \\
\text { SEMI IMPLANTÁVEL } \\
\end{array}$ & 5 & 0,3 & ORQUIECTOMIA UNILATERAL & 5 & 0,3 \\
\hline EXERESE DE CISTO DERMÓIDE & 5 & 0,3 & $\begin{array}{l}\text { REDUÇÃO INCRUENTA DA FRAT.DOS OSSOS } \\
\text { DO ANTEBRAÇO }\end{array}$ & 5 & 0,3 \\
\hline EXERESE DE PTERÍGIO & 5 & 0,3 & $\begin{array}{l}\text { REDUÇÃO INCRUENTA DA FRAT. } \\
\text { SUPRACONDILIANA DO ÚMERO }\end{array}$ & 5 & 0,3 \\
\hline HERNIORRAFIA RECIDIVANTE & 5 & 0,3 & $\begin{array}{l}\text { REDUÇÃO INCRUENTA DA FRAT., LUX. OU } \\
\text { FRAT.-LUX.DO TORNOZ. }\end{array}$ & 5 & 0,3 \\
\hline ORQUIDOPEXIA UNILATERAL & 5 & 0,3 & $\begin{array}{l}\text { RESSUTURA DE PAREDE ABDOMINAL (POR } \\
\text { DEISC.TOT. OU EVISCER.) }\end{array}$ & 5 & 0,3 \\
\hline RECONSTRUÇÃO DE MANDÍBULA & 5 & 0,3 & $\begin{array}{l}\text { RETIRADA DE MATERIAL DE SÍNTESE - FIO DE } \\
\text { KIRSCHNER }\end{array}$ & 5 & 0,3 \\
\hline $\begin{array}{l}\text { REDUÇÃO INCRUENTA DA FRATURA DO } \\
\text { FÊMUR }\end{array}$ & 5 & 0,3 & RETOSSIGMOIDECTOMIA ABDOMINAL & 5 & 0,3 \\
\hline TIMPANOPLASTIA (TIPO I - UNILATERAL) & 5 & 0,3 & SETORECTOMIA & 5 & 0,3 \\
\hline TIREOIDECTOMIA TOTAL & 5 & 0,3 & TIMPANOPLASTIA ( TIPO I - UNILATERAL ) & 5 & 0,3 \\
\hline $\begin{array}{l}\text { TRATAMENTO CIRÚRGICO DA INCONTINÊNCIA } \\
\text { URINÁRIA POR VIA VAGINAL }\end{array}$ & 5 & 0,3 & TORACOTOMIA EXPLORADORA & 5 & 0,3 \\
\hline COLONOSCOPIA & 4 & 0,3 & $\begin{array}{l}\text { TRATAMENTO CIRÚRGICO DA FRATURA DO } \\
\text { TORNOZ.UNIMALEOLAR }\end{array}$ & 5 & 0,3 \\
\hline CORREÇÃO PROLAPSO DE CÚPULA VAGINAL & 4 & 0,3 & URETROTOMIA INTERNA & 5 & 0,3 \\
\hline DEBRIDAMENTO DA FASCEITE NECROTIZANTE & 4 & 0,3 & AMIGDALECTOMIA & 4 & 0,3 \\
\hline $\begin{array}{l}\text { DERMOLIPECTOMIA ABDOMINAL NÃO } \\
\text { ESTÉTICA (PLÁSTICA ABDOMINAL) }\end{array}$ & 4 & 0,3 & ARTROPLASTIA PARCIAL DO QUADRIL & 4 & 0,3 \\
\hline DRENAGEM DE ABSCESSO ANAL & 4 & 0,3 & BIÓPSIA DA BOCA & 4 & 0,3 \\
\hline \begin{tabular}{|l|} 
DRENAGEM DE PLEURA \\
\end{tabular} & 4 & 0,3 & CISTOSCOPIA COM BIÓPSIA DE BEXIGA & 4 & 0,3 \\
\hline ENTERECTOMIA & 4 & 0,3 & COLOSTOMIA & 4 & 0,3 \\
\hline EXERESE DE TUMOR OU ADENOMA DA MAMA & 4 & 0,3 & $\begin{array}{l}\text { DERMOLIPECTOMIA ABDOMINAL NÃO } \\
\text { ESTÉTICA ( PLAST.ABD.) }\end{array}$ & 4 & 0,3 \\
\hline $\begin{array}{l}\text { EXTIRPAÇÃO E SUPRESSÃO DE LESÃO DA } \\
\text { PELEE E DO TECIDO }\end{array}$ & 4 & 0,3 & DRENAGEM DE ABSCESSO PÉLVICO & 4 & 0,3 \\
\hline $\begin{array}{l}\text { HISTERECTOMIA COM ANEXECTOMIA UNI OU } \\
\text { BILATERAL }\end{array}$ & 4 & 0,3 & ENXERTO ÓSSEO & 4 & 0,3 \\
\hline HISTERECTOMIA SUBTOTAL & 4 & 0,3 & EXERESE DE TUMOR OU ADENOMA DA MAMA & 4 & 0,3 \\
\hline $\begin{array}{l}\text { INCISÃO E DRENAGEM DE ABSCESSO DA } \\
\text { BOCA E ANEXOS }\end{array}$ & 4 & 0,3 & EXODONTIA DENTES INCLUSO & 4 & 0,3 \\
\hline $\begin{array}{l}\text { LAQUEADURA TUBÁRIA/ } \\
\text { VIDEOLAPAROSCÓPICA }\end{array}$ & 4 & 0,3 & $\begin{array}{l}\text { EXODONTIA MÚLTIPLA COM ALVEOLOPLASTIA } \\
\text { POR HEMI-ARCO }\end{array}$ & 4 & 0,3 \\
\hline $\begin{array}{l}\text { LARINGOSCOPIA/ TRAQUEOSCOPIA COM } \\
\text { DILATACÁO E ESTENOSE }\end{array}$ & 4 & 0,3 & HERNIORRAFIA INCISIONAL PEQUENA & 4 & 0,3 \\
\hline MIRINGOTOMIA & 4 & 0,3 & $\begin{array}{l}\text { HISTERECTOMIA COM ANEXECTOMIA UNI OU } \\
\text { BILATERAL }\end{array}$ & 4 & 0,3 \\
\hline ORQUIECTOMIA UNILATERAL & 4 & 0,3 & HISTERECTOMIA SUBTOTAL & 4 & 0,3 \\
\hline $\begin{array}{l}\text { REDUÇÃO INCRUENTA DA FRATURA DOS } \\
\text { OSSOS DO ANTEBRAÇO }\end{array}$ & 4 & 0,3 & HISTERECTOMIA VIDEOLAPAROSCÓPICA & 4 & 0,3 \\
\hline $\begin{array}{l}\text { REDUÇÃO INCRUENTA DA FRATURA } \\
\text { SUPRACONDILIANA DO ÚMERO }\end{array}$ & 4 & 0,3 & INCISÃO E DRENAGEM DE CELULITE & 4 & 0,3 \\
\hline $\begin{array}{l}\text { REDUÇÃO INCRUENTA DA FRATURA, LUX. OU } \\
\text { FRAT.-LUX.DO TORNOZELO }\end{array}$ & 4 & 0,3 & NEFRECTOMIA TOTAL & 4 & 0,3 \\
\hline $\begin{array}{l}\text { RETIRADA DE CORPO ESTRANHO } \\
\text { SUBCUTÂNEO }\end{array}$ & 4 & 0,3 & PANCREATECTOMIA PARCIAL & 4 & 0,3 \\
\hline SALPINGECTOMIA VIDEOLAPAROSCÓPICA & 4 & 0,3 & PASSAGEM DE SONDAS ENDOSCÓPICAS & 4 & 0,3 \\
\hline SEPTOPLASTIA (DESVIO DO SEPTO) & 4 & 0,3 & RETIRADA DE FIO OU PINO TRANSÓSSEO & 4 & 0,3 \\
\hline TENÓLISE & 4 & 0,3 & RETIRADA DE FIXADOR EXTERNO & 4 & 0,3 \\
\hline $\begin{array}{l}\text { TRAQUEOSTOMIA COM COLOCAÇÃO DE } \\
\text { ORTESE TRAQ. OU TRAQUEOBRON }\end{array}$ & 4 & 0,3 & SINUSOTOMIA MAXILAR & 4 & 0,3 \\
\hline $\begin{array}{l}\text { TRATAMENTO CIRÚRGICO DA FRATURA DA } \\
\text { EXTREM.PRÓX.DO ÚMERO }\end{array}$ & 4 & 0,3 & $\begin{array}{l}\text { TRATAMENTO CIRÚRGICO DA FRATURA } \\
\text { BIMAL.OU TRIMALEOLAR }\end{array}$ & 4 & 0,3 \\
\hline
\end{tabular}




\begin{tabular}{|c|c|c|c|c|c|}
\hline PROCEDIMENTO - 2007 & $\mathbf{N}$ & $\%$ & PROCEDIMENTO - 2008 & $\mathbf{N}$ & $\%$ \\
\hline TRATAMENTO CIRÚRGICO DA HIDROCELE & 4 & 0,3 & $\begin{array}{l}\text { TRATAMENTO CIRÚRGICO DA FRATURA DA } \\
\text { DIÁFISE DO ÚMERO }\end{array}$ & 4 & 0,3 \\
\hline URETEROLITOTOMIA & 4 & 0,3 & $\begin{array}{l}\text { TRATAMENTO CIRÚRGICO DA FRATURA DO } \\
\text { COLO DO FÊMUR } \\
\end{array}$ & 4 & 0,3 \\
\hline AMPUTAÇÃO DA PERNA & 3 & 0,2 & $\begin{array}{l}\text { TRATAMENTO CIRÚRGICOO DE FRATURA DAS } \\
\text { FALANGES, COM FIXAÇÃO }\end{array}$ & 4 & 0,3 \\
\hline AMPUTAÇÃO DO DEDO (CADA) & 3 & 0,2 & $\begin{array}{l}\text { TRATAMENTO CIRÚRGICO DO SOALHO DA } \\
\text { ÓRBITA }\end{array}$ & 4 & 0,3 \\
\hline $\begin{array}{l}\text { AMPUTAÇÃO OU DESARTICULAÇÃO DO(S) } \\
\text { PODODACTILO(S) }\end{array}$ & 3 & 0,2 & $\begin{array}{l}\text { VIDEOSCOPIA PARA DIAGNÓSTICO P/DREN. } \\
\text { TOAL.OU BIOP. P/REMOÇÃO }\end{array}$ & 4 & 0,3 \\
\hline APENDICECTOMIA VIDEOLAPAROSCÓPICA & 3 & 0,2 & ANASTOMOSE BILEODIGESTIVA & 3 & 0,2 \\
\hline $\begin{array}{l}\text { BRONCOSCOPIA COM OU SEM ASPIRADO } \\
\text { LAVADO BRÔNQUICO }\end{array}$ & 3 & 0,2 & BLEFAROPLASTIA & 3 & 0,2 \\
\hline $\begin{array}{l}\text { COLEDOCOTOMIA COM OU SEM } \\
\text { COLECISTECTOMIA }\end{array}$ & 3 & 0,2 & $\begin{array}{l}\text { CIRURGIA ORTOGNÁTICA PARA MAXILAR OU } \\
\text { MAXILO/MANDIBULAR }\end{array}$ & 3 & 0,2 \\
\hline COLOSTOMIA & 3 & 0,2 & $\begin{array}{l}\text { COLOCAÇAOO DE CATETER TOTALMENTE OU } \\
\text { SEMI IMPLANTÁVEL }\end{array}$ & 3 & 0,2 \\
\hline $\begin{array}{l}\text { COLPOPERINEOPLASTIA ANTERIOR E } \\
\text { POSTERIOR }\end{array}$ & 3 & 0,2 & COLONOSCOPIA & 3 & 0,2 \\
\hline COLPOPLASTIA ANTERIOR & 3 & 0,2 & CONIZAÇÃO COM CAF & 3 & 0,2 \\
\hline COLPOPLASTIA POSTERIOR & 3 & 0,2 & DEBRIDAMENTO DE ÚLCERA OU NECROSE & 3 & 0,2 \\
\hline DEBRIDAMENTO DE ULCERA OU NECROSE & 3 & 0,2 & ENXERTO COMPOSTO & 3 & 0,2 \\
\hline DRENAGEM COM BIÓPSIA DE PERICÁRDIO & 3 & 0,2 & EXCISÃO E SUTURA SIMPLES & 3 & 0,2 \\
\hline ENXERTO DERMO EPIDÉRMICO & 3 & 0,2 & EXERESE DE CISTO SEBÁCEO & 3 & 0,2 \\
\hline EXERESE DE CISTO TIREOGLOSSO & 3 & 0,2 & GASTROSTOMIA & 3 & 0,2 \\
\hline EXERESE DE TUMOR PALPEBRAL & 3 & 0,2 & $\begin{array}{l}\text { HERNIOPLASTIA HIATAL (CARDIOPLASTIA) } \\
\text { VIDEOLAPAROSCÓPICA }\end{array}$ & 3 & 0,2 \\
\hline GASTRORRAFIA & 3 & 0,2 & $\begin{array}{l}\text { IMPLANTE DE LENTE INTRAOCULAR EM } \\
\text { CÂMARA ANTERIOR }\end{array}$ & 3 & 0,2 \\
\hline $\begin{array}{l}\text { HISTERECTOMIA VAGINAL COM OU SEM } \\
\text { PROLAPSO DO ÚTERO }\end{array}$ & 3 & 0,2 & NEURÓLISE DE NERVO MEDIANO & 3 & 0,2 \\
\hline HISTERECTOMIA VIDEOLAPAROSCÓPICA & 3 & 0,2 & PLÁSTICA MAMÁRIA FEMININA NÃO ESTÉTICA & 3 & 0,2 \\
\hline INCISÃO E DRENAGEM DE CELULITE & 3 & 0,2 & PLÁSTICA TOTAL DO PÊNIS & 3 & 0,2 \\
\hline LOBECTOMIA PULMONAR & 3 & 0,2 & $\begin{array}{l}\text { SUTURA DE FERIMENTOS EXTENSOS, COM OU } \\
\text { SEM DEBRIDAMENTO }\end{array}$ & 3 & 0,2 \\
\hline MIOMECTOMIA & 3 & 0,2 & TENORRAFIA & 3 & 0,2 \\
\hline NEFRECTOMIA TOTAL & 3 & 0,2 & $\begin{array}{l}\text { TRAQUEOSTOMIA COM COLOCAÇÃO DE } \\
\text { ORT.TRAQ.OUTRAQUEOBRON }\end{array}$ & 3 & 0,2 \\
\hline NEFROLITOTOMIA & 3 & 0,2 & $\begin{array}{l}\text { TRATAMENTO CIRÚRGICO DA FRAT. DAS } \\
\text { EXTREM.PROX.E DIST.DA TÍBIA }\end{array}$ & 3 & 0,2 \\
\hline NEURORRAFIA MÚLTIPLA & 3 & 0,2 & $\begin{array}{l}\text { TRATAMENTO CIRÚRGICO DA FRATURA DO } \\
\text { CALCÂNEO }\end{array}$ & 3 & 0,2 \\
\hline REDUÇÃO INCRUENTA DA FRATURA DA TÍBIA & 3 & 0,2 & $\begin{array}{l}\text { TRATAMENTO CIRÚRGICO DA FRAT. SUPRA- } \\
\text { CONDILIANA DO ÚMERO }\end{array}$ & 3 & 0,2 \\
\hline $\begin{array}{l}\text { REDUĈÃO INCRUENTA DA LUXAÇÃO } \\
\text { CONGÊNITA COXO FEMORAL }\end{array}$ & 3 & 0,2 & $\begin{array}{l}\text { TRATAMENTO CIRÚRGICO DA FRAT. } \\
\text { TRANSTROCANTERIANA }\end{array}$ & 3 & 0,2 \\
\hline SETORECTOMIA & 3 & 0,2 & TRATAMENTO CIRÚRGICO DA HIDROCELE & 3 & 0,2 \\
\hline $\begin{array}{l}\text { SUTURA DE FERIMENTOS EXTENSOS, COM OU } \\
\text { SEM DEBRIDAMENTO }\end{array}$ & 3 & 0,2 & $\begin{array}{l}\text { TRATAMENTO CIRÚRGICO DE FRATURA } \\
\text { DIAFISÁRIA DO RÁDIO }\end{array}$ & 3 & 0,2 \\
\hline TIREOIDECTOMIA PARCIAL & 3 & 0,2 & $\begin{array}{l}\text { ABERTURA DE BAINHA TENDINOSA } \\
\text { (TENÓLISE) }\end{array}$ & 2 & 0,1 \\
\hline $\begin{array}{l}\text { TRATAMENTO CIRÚRGICO DE LUX.OU } \\
\text { FRAT.LUX.ACROMIO-CLAVICULAR }\end{array}$ & 3 & 0,2 & AMPUTAÇÃO TRANSFEMORAL & 2 & 0,1 \\
\hline $\begin{array}{l}\text { TRATAMENTO CIRÚRGICO DA } \\
\text { FRAT.BIMALEOLAR OU TRIMALEOLAR }\end{array}$ & 3 & 0,2 & AMPUTAÇÃO TRANSTIBIAL & 2 & 0,1 \\
\hline $\begin{array}{l}\text { TRATAMENTO CIRÚRGICO DA FRATURA DA } \\
\text { DIÁFISE DO ÚMERO }\end{array}$ & 3 & 0,2 & $\begin{array}{l}\text { ARTROPLASTIA TOTAL DO QUADRIL NÃO- } \\
\text { CIMENTADA OU HÍBRIDA }\end{array}$ & 2 & 0,1 \\
\hline $\begin{array}{l}\text { TRATAMENTO CIRÚRGICO DE FRATURA } \\
\text { DIAFISÁRIA DA ULNA }\end{array}$ & 3 & 0,2 & ARTROSCOPIA & 2 & 0,1 \\
\hline $\begin{array}{l}\text { TRATAMENTO CIRÚRGICO DE FRAT.NAS } \\
\text { EXTREM.DISTAIS/OSSOS DO ANTE }\end{array}$ & 3 & 0,2 & BARTOLINECTOMIA & 2 & 0,1 \\
\hline $\begin{array}{l}\text { ALONGAMENTO OU ENCURTAMENTO DE } \\
\text { TENDÃO }\end{array}$ & 2 & 0,1 & BIÓPSIA DA LÍNGUA & 2 & 0,1 \\
\hline $\begin{array}{l}\text { AMPUTAÇÃO / DESARTICULAÇÃO DO PÉ AO } \\
\text { NÍVEL METATÁRSICO }\end{array}$ & 2 & 0,1 & BIÓPSIA DE ENDOMÉTRIO - COLO-UTERINO & 2 & 0,1 \\
\hline ANASTOMOSE BILEODIGESTIVA & 2 & 0,1 & BIÓPSIA DE GÂNGLIO LINFÁTICO & 2 & 0,1 \\
\hline $\begin{array}{l}\text { ANEURISMECTOMIA DE AORTA ABDOMINAL } \\
\text { INFRARENAL }\end{array}$ & 2 & 0,1 & $\begin{array}{l}\text { BIÓPSIA DO FIGAADO POR LAPAROTOMIA OU } \\
\text { LAPAROSCOPIA }\end{array}$ & 2 & 0,1 \\
\hline ARTRODESE TRÍPLICE OU TRANSVERSA & 2 & 0,1 & $\begin{array}{l}\text { COLANGIOPANCREATROGRAFIA } \\
\text { RETRÓGRADA }\end{array}$ & 2 & 0,1 \\
\hline BARTOLINECTOMIA & 2 & 0,1 & $\begin{array}{l}\text { COLEDOCOSTOMIA COM OU SEM } \\
\text { COLECISTECTOMIA }\end{array}$ & 2 & 0,1 \\
\hline BIÓPSIA DA PAREDE ABDOMINAL & 2 & 0,1 & $\begin{array}{l}\text { COLEDOCOTOMIA COM OU SEM } \\
\text { COLECISTECTOMIA }\end{array}$ & 2 & 0,1 \\
\hline $\begin{array}{l}\text { BIÓPSIA DA PELE, TECIDO CELULAR OU } \\
\text { GÂNGLIO SUBCUTÂNEO }\end{array}$ & 2 & 0,1 & COLPOPLASTIA POSTERIOR & 2 & 0,1 \\
\hline BIÓPSIA DE PAVILHÃO AURICULAR & 2 & 0,1 & CONFECÇÃO DE FÍSTULA ARTERIOVENOSA & 2 & 0,1 \\
\hline BIÓPSIA DE PLEURA OU PLEUROSCOPIA & 2 & 0,1 & $\begin{array}{l}\text { DRENAGEM ABSCESSO DA MÃO (DORSO, } \\
\text { BAINHAS, ESPAC.PALM.) }\end{array}$ & 2 & 0,1 \\
\hline BIÓPSIA DO FÊMUR & 2 & 0,1 & DRENAGEM DE FLEIMAO & 2 & 0,1 \\
\hline
\end{tabular}




\begin{tabular}{|c|c|c|c|c|c|}
\hline PROCEDIMENTO - 2007 & $\mathbf{N}$ & $\%$ & PROCEDIMENTO - 2008 & $\mathbf{N}$ & $\%$ \\
\hline $\begin{array}{l}\text { CIRURGIA DE VARIZES DA SAFENA EXTERNA } \\
\text { UNILATERAL - EXCLUSIVO P }\end{array}$ & 2 & 0,1 & ENTERECTOMIA & 2 & 0,1 \\
\hline $\begin{array}{l}\text { CIRURGIA DE VARIZES DA SAFENA INTERNA E } \\
\text { EXTERNA UNILATERAL - E }\end{array}$ & 2 & 0,1 & ESFINCTEROPLASTIA ANAL & 2 & 0,1 \\
\hline $\begin{array}{l}\text { CIRURGIA DE VARIZES DA SAFENA INTERNA } \\
\text { UNILATERAL - EXCLUSIVO P }\end{array}$ & 2 & 0,1 & ESPLENECTOMIA & 2 & 0,1 \\
\hline COLECISTOSTOMIA & 2 & 0,1 & EXCISÃO DE GLÂNDULA SUBMAXILAR & 2 & 0,1 \\
\hline COLPOPERINEOPLASTIA & 2 & 0,1 & $\begin{array}{l}\text { EXCISÁO E SUTURA COM PLÁSTICA EM Z NA } \\
\text { PELE }\end{array}$ & 2 & 0,1 \\
\hline $\begin{array}{l}\text { DEBRIDAMENTO E CURATIVO DE ESCARA OU } \\
\text { ULCERAÇÃO }\end{array}$ & 2 & 0,1 & EXERESE DE GÂNGLIO LINFÁTICO & 2 & 0,1 \\
\hline DRENAGEM DE ABSCESSO PÉLVICO & 2 & 0,1 & EXERESE DE TUMOR DE PELE & 2 & 0,1 \\
\hline $\begin{array}{l}\text { DRENAGEM ESTEROTÁXICA - CISTOS, } \\
\text { HEMATOMAS OU ABSCESSOS }\end{array}$ & 2 & 0,1 & $\begin{array}{l}\text { FACOEMULSIFICAÇÃO COM IMPLANTE DE } \\
\text { LENTE INTRAOC.,VITREC. }\end{array}$ & 2 & 0,1 \\
\hline EXCISÃO DE RÂNULA & 2 & 0,1 & $\begin{array}{l}\text { GASTRECTOMIA PARCIAL SEM } \\
\text { LINFADENECTOMIA }\end{array}$ & 2 & 0,1 \\
\hline $\begin{array}{l}\text { EXCISÃO E SUTURA DE LESÃO CIRCULAR COM } \\
\text { ROTACCÃO DE RETALHO }\end{array}$ & 2 & 0,1 & GASTROENTEROANASTOMOSE & 2 & 0,1 \\
\hline EXCISÅO E SUTURA SIMPLES & 2 & 0,1 & GASTRORRAFIA & 2 & 0,1 \\
\hline EXERESE DE COLATERAIS & 2 & 0,1 & $\begin{array}{l}\text { HERNIORRAFIA DIAFRAGMÁTICA (VIA } \\
\text { ABDOMINAL) }\end{array}$ & 2 & 0,1 \\
\hline $\begin{array}{l}\text { EXERESE E PLÁSTICA DE CISTO } \\
\text { SACROCOCCÍGEO }\end{array}$ & 2 & 0,1 & $\begin{array}{l}\text { LAQUEADURA TUBÁRIA/ } \\
\text { VIDEOLAPAROSCÓPICA } \\
\end{array}$ & 2 & 0,1 \\
\hline $\begin{array}{l}\text { FACECTOMIA SEM IMPLANTE DE LENTE INTRA- } \\
\text { OCULAR }\end{array}$ & 2 & 0,1 & $\begin{array}{l}\text { LINFADENECTOMIA RADICAL INGUINAL } \\
\text { UNILATERAL }\end{array}$ & 2 & 0,1 \\
\hline HIPOSPADIA (1 TEMPO) & 2 & 0,1 & LOBECTOMIA PULMONAR & 2 & 0,1 \\
\hline ILEOSTOMIAS & 2 & 0,1 & MEDIASTINOSCOPIA & 2 & 0,1 \\
\hline INCISÁO E DRENAGEM DE HEMATOMA & 2 & 0,1 & MICRONEURORRAFIA & 2 & 0,1 \\
\hline $\begin{array}{l}\text { MANIPULAÇÃO DO JOELHO SOB ANESTESIA } \\
\text { GERAL }\end{array}$ & 2 & 0,1 & ORQUIDOPEXIA UNILATERAL & 2 & 0,1 \\
\hline \begin{tabular}{|l|} 
MICRONEURORRAFIA \\
\end{tabular} & 2 & 0,1 & PLEURECTOMIA & 2 & 0,1 \\
\hline NEURÓLISE DE NERVO MEDIANO & 2 & 0,1 & REDUÇÃO INCRUENTA DA FRATURA DA TÍBIA & 2 & 0,1 \\
\hline ORQUIECTOMIA BILATERAL & 2 & 0,1 & $\begin{array}{l}\text { REDUÇÃO INCRUENTA DE FRATURA DO } \\
\text { JOELHO }\end{array}$ & 2 & 0,1 \\
\hline OSTEOTOMIA NO JOELHO & 2 & 0,1 & $\begin{array}{l}\text { RESSECÇÃO ENDOSCÓPICA DE PÓLIPOS } \\
\text { VESICAIS }\end{array}$ & 2 & 0,1 \\
\hline OSTEOTOMIA DIAFISÁRIA DA TÍBIA & 2 & 0,1 & $\begin{array}{l}\text { RETIRADA DE CORPO ESTRANHO } \\
\text { INTRAMUSCULAR }\end{array}$ & 2 & 0,1 \\
\hline REPARO DE ROTURA DO MANGUITO ROTADOR & 2 & 0,1 & $\begin{array}{l}\text { RETIRADA DE CORPO ESTRANHO } \\
\text { SUBCUTÂNEO }\end{array}$ & 2 & 0,1 \\
\hline $\begin{array}{l}\text { RETIRADA CORPO ESTRANHO EM C.A.E., SOB } \\
\text { ANEST.GERAL }\end{array}$ & 2 & 0,1 & $\begin{array}{l}\text { RETIRADA DE PRÓTESE DE SUBSTIT.EM } \\
\text { PEQU.E MEDIAS ARTIC. }\end{array}$ & 2 & 0,1 \\
\hline SALPINGECTOMIA UNI OU BILATERAL & 2 & 0,1 & SALPINGECTOMIA UNI OU BILATERAL & 2 & 0,1 \\
\hline SIMPATECTOMIA & 2 & 0,1 & SINUSOTOMIA ETMOIDAL & 2 & 0,1 \\
\hline SINUSOTOMIA MAXILAR & 2 & 0,1 & TIMPANOTOMIA PARA TUBO DE VENTILAÇÃO & 2 & 0,1 \\
\hline TAMPONAMENTO NASAL ANTERIOR & 2 & 0,1 & $\begin{array}{l}\text { TRATAMENTO CIRÚRGICO DE LUX.E FRAT.- } \\
\text { LUX.DO COTOVELO }\end{array}$ & 2 & 0,1 \\
\hline $\begin{array}{l}\text { TENÓLISE FLEXORA OU EXTENS.AO NIVVEL DA } \\
\text { MÃO E DEDOS POR TENDÃO }\end{array}$ & 2 & 0,1 & $\begin{array}{l}\text { TRATAMENTO CIRÚRGICO DA FRATURA DOS } \\
\text { METACARP.C/ FIX. }\end{array}$ & 2 & 0,1 \\
\hline $\begin{array}{l}\text { TENOSSINOVECTOMIA OU TENÓLISE AO NÍVEL } \\
\text { DO PUNHO }\end{array}$ & 2 & 0,1 & $\begin{array}{l}\text { TRATAMENTO CIRÚRGICO DA LUXAÇÃO E } \\
\text { FRAT.-LUX.INTER-FALANG. } \\
\text { FRALA }\end{array}$ & 2 & 0,1 \\
\hline TORACOTOMIA COM DRENAGEM FECHADA & 2 & 0,1 & $\begin{array}{l}\text { TRATAMENTO CIRÚRGICO DE ARTRITE INFEC. } \\
\text { DAS PEQ. ARTIC. }\end{array}$ & 2 & 0,1 \\
\hline TORACOTOMIA EXPLORADORA & 2 & 0,1 & $\begin{array}{l}\text { TRATAMENTO CIRÚRGICO DE FRAT.NAS } \\
\text { EXTR..DIST.DOS OS.DO ANTE }\end{array}$ & 2 & 0,1 \\
\hline $\begin{array}{l}\text { TRATAMENTO CIRÚRGICO DE LUXAÇÃO E } \\
\text { FRATURA-LUXAÇÃO DO COTOVELO }\end{array}$ & 2 & 0,1 & TRATAMENTO CIRÚRGICO DO ESTRABISMO & 2 & 0,1 \\
\hline $\begin{array}{l}\text { TRATAMENTO CIRÚRGICO DA FRATURA DAS } \\
\text { EXTREM.PROX. E DIST.DA TÍBIA }\end{array}$ & 2 & 0,1 & $\begin{array}{l}\text { TRATAMENTO CIRÚRGICO NÂO-ESTÉTICO DA } \\
\text { ORELHA }\end{array}$ & 2 & 0,1 \\
\hline $\begin{array}{l}\text { TRATAMENTO CIRÚRGICO DA FRATURA DO } \\
\text { PILÃO TIBIAL }\end{array}$ & 2 & 0,1 & $\begin{array}{l}\text { VIDEOSCOPIA PARA RECONSTRUC.OU } \\
\text { TRANSPL.DE ESTR. EM ARTIC. }\end{array}$ & 2 & 0,1 \\
\hline $\begin{array}{l}\text { TRATAMENTO CIRÚRGICO DA FRATURA DOS } \\
\text { METACARPIANOS COM FIXAÇÃO }\end{array}$ & 2 & 0,1 & AMIDALECTOMIA DAS PALATINAS & 1 & 0,1 \\
\hline $\begin{array}{l}\text { TRATAMENTO CIRÚRGICO DA FRATURA } \\
\text { SUPRA-CONDILIANA DO ÚMERO }\end{array}$ & 2 & 0,1 & AMPUTAÇÃO DA COXA & 1 & 0,1 \\
\hline $\begin{array}{l}\text { TRATAMENTO CIRÚRGICO DE FRATURA DA } \\
\text { PATELA POR FIX.INTERNA }\end{array}$ & 2 & 0,1 & AMPUTAÇÃO DA PERNA & 1 & 0,1 \\
\hline $\begin{array}{l}\text { TRATAMENTO CIRÚRGICO DE FRATURA DO } \\
\text { PLANALTO TIBIAL }\end{array}$ & 2 & 0,1 & AMPUTAÇÃO DO PÊNIS & 1 & 0,1 \\
\hline URETROTOMIA INTERNA & 2 & 0,1 & ANTROSTOMIA MAXILAR INTRA-NASAL & 1 & 0,1 \\
\hline $\begin{array}{l}\text { LAPAROTOMIA EXPLORADORA, } \\
\text { APENDICECTOMIA }\end{array}$ & 1 & 0,1 & $\begin{array}{l}\text { ANTROTOMIA DA MASTÓIDE (DRENAGEM DE } \\
\text { OTITE NO LACTENTE) }\end{array}$ & 1 & 0,1 \\
\hline ABERTURA DE BAINHA TENDINOSA & 1 & 0,1 & ARTRODESE METACARPO-FALANGEANA & 1 & 0,1 \\
\hline $\begin{array}{l}\text { ABERTURA DE POLIA SINOVIAL DE BAINHA } \\
\text { TENDINOSA }\end{array}$ & 1 & 0,1 & $\begin{array}{l}\text { ARTROPLASTIA TOTAL DO QUADRIL } \\
\text { CIMENTADA }\end{array}$ & 1 & 0,1 \\
\hline ADENOIDECTOMIA & 1 & 0,1 & BIÓPSIA DA VULVA & 1 & 0,1 \\
\hline $\begin{array}{l}\text { ALONGAMENTO OU TRANSPORTAÇÃO ÓSSEA } \\
\text { AO NÍVEL DO FÊMUR }\end{array}$ & 1 & 0,1 & BIÓPSIA DE LESÃO ANAL & 1 & 0,1 \\
\hline $\begin{array}{l}\text { ALONGAMENTO OU TRANSPORTAÇÃO } \\
\text { OSSEACIRÚRGICO DO ÚMERO }\end{array}$ & 1 & 0,1 & BIÓPSIA DE LINFONODO & 1 & 0,1 \\
\hline
\end{tabular}




\begin{tabular}{|c|c|c|c|c|c|}
\hline PROCEDIMENTO - 2007 & $\mathbf{N}$ & $\%$ & PROCEDIMENTO - 2008 & $\mathbf{N}$ & $\%$ \\
\hline $\begin{array}{l}\text { AMIGDALECTOMIA COM OU SEM } \\
\text { ADENOIDECTOMIA, TIMPANOPLASTIA }\end{array}$ & 1 & 0,1 & BIÓPSIA DE TESTíCULO & 1 & 0,1 \\
\hline $\begin{array}{l}\text { AMPUTAÇÃO / DESARTICULAÇÄO DO PE AO } \\
\text { NIIVEL METATÁRSICO }\end{array}$ & 1 & 0,1 & BIÓPSIA DO CAVUM & 1 & 0,1 \\
\hline $\begin{array}{l}\text { AMPUTAÇÃO / DESARTICULAÇÃO DO PE AO } \\
\text { NÍVEL DO TARSO }\end{array}$ & 1 & 0,1 & $\begin{array}{l}\text { IIÓPSIA DO FÍGADO POR ASPIRAÇÃO OU } \\
\text { PUNCCÃO }\end{array}$ & 1 & 0,1 \\
\hline AMPUTAÇÃO A NIVELL DA MÃO & 1 & 0,1 & BIÓPSIA DO JOELHO & 1 & 0,1 \\
\hline AMPUTAÇÃO DO RETO POR PROCIDÊNCIA & 1 & 0,1 & $\begin{array}{l}\text { BIÓPSIA/PUNÇÃO DE TUMORES SUPERFICIAIS } \\
\text { DE PELE }\end{array}$ & 1 & 0,1 \\
\hline $\begin{array}{l}\text { ANASTOMOSE BILEODIGESTIVA, RESSUTURA } \\
\text { DE PAREDE ABDOMINAL }\end{array}$ & 1 & 0,1 & $\begin{array}{l}\text { BIÓPSIAS MÚLTIPLAS PARA AVALIAÇÃO DE } \\
\text { EXTENSÃO DE DOENÇA }\end{array}$ & 1 & 0,1 \\
\hline ARTRODESE DO JOELHO & 1 & 0,1 & BLEFAROCALASE & 1 & 0,1 \\
\hline ARTRODESE DO PUNHO (RÁDIO CÁRPICA) & 1 & 0,1 & $\begin{array}{l}\text { BRONCOSCOPIA COM COLETA APARELHADA } \\
\text { DE MATERIAL }\end{array}$ & 1 & 0,1 \\
\hline ARTRODESE INTERFALANGEANA MÃO & 1 & 0,1 & $\begin{array}{l}\text { CIRURGIA DE VARIZES DA SAFENA EXTER. } \\
\text { UNILATERAL - EXCLUSIVO P }\end{array}$ & 1 & 0,1 \\
\hline $\begin{array}{l}\text { ARTRODESE METATARSO-FALANGIANA OU } \\
\text { INTERFALANGIANA }\end{array}$ & 1 & 0,1 & $\begin{array}{l}\text { CIRURGIA DE VARIZES DA SAFENA INTER. E } \\
\text { EXTERNA UNILATERAL - E }\end{array}$ & 1 & 0,1 \\
\hline ARTRODESE SUBTALAR OU TALO-NVICULAR & 1 & 0,1 & $\begin{array}{l}\text { CIRURGIA DE VARIZES DA SAFENA INTER. } \\
\text { UNILATERAL - EXCLUSIVO P }\end{array}$ & 1 & 0,1 \\
\hline ARTROPLASTIA DO PUNHO & 1 & 0,1 & $\begin{array}{l}\text { CIRURGIA DOS ANEURISMAS DAS ARTÉRIAS } \\
\text { VISCERAIS }\end{array}$ & 1 & 0,1 \\
\hline ARTROPLASTIA PARCIAL DO QUADRIL & 1 & 0,1 & $\begin{array}{l}\text { CIRURGIA LESÖES VASCULARES TRAUMA. DE } \\
\text { MEMBRO INF.UNIL }\end{array}$ & 1 & 0,1 \\
\hline ARTROTOMIA DE COTOVELO & 1 & 0,1 & CISTORRAFIA & 1 & 0,1 \\
\hline BIÓPSIA CIRÚRGICA DE OSSOS DO PE & 1 & 0,1 & $\begin{array}{l}\text { COLECISTECTOMIA, COLECTOMIA, } \\
\text { ENTERECTOMIA }\end{array}$ & 1 & 0,1 \\
\hline BIÓPSIA DA ARTÉRIA E OU VEIA & 1 & 0,1 & COLECISTOSTOMIA & 1 & 0,1 \\
\hline BIÓPSIA DA ARTÉRIA TEMPORAL & 1 & 0,1 & $\begin{array}{l}\text { COLOCAÇÃO PERCUTÂNEA DE FILTRO DE } \\
\text { VEIA CAVA NA TROMB.VEN. }\end{array}$ & 1 & 0,1 \\
\hline BIÓPSIA DA ARTICULAÇÃO SACRO-ILÍACA & 1 & 0,1 & COLPOPERINEOPLASTIA & 1 & 0,1 \\
\hline BIÓPSIA DA PARATIREÓIDE & 1 & 0,1 & CORREÇÃO PROLAPSO DE CÚPULA VAGINAL & 1 & 0,1 \\
\hline BIÓPSIA DA TIREÓIDE & 1 & 0,1 & $\begin{array}{l}\text { CURATIVO CIRÚRGICO SOB ANESTESIA } \\
\text { SUBSEQ.A TRAT.CIR.E PRO }\end{array}$ & 1 & 0,1 \\
\hline BIÓPSIA DA VULVA & 1 & 0,1 & $\begin{array}{l}\text { DESCONEXÃO AZIGO-PORTAL (TRAT.CIR.DE } \\
\text { VARIZES ESOFAG.) }\end{array}$ & 1 & 0,1 \\
\hline BIÓPSIA DE GLÂNDULA SALIVAR & 1 & 0,1 & DESCORTICAÇÃO PULMONAR & 1 & 0,1 \\
\hline BIÓPSIA DE LESÃO ANAL & 1 & 0,1 & $\begin{array}{l}\text { DILATAÇÃO INSTRUMENTAL DE } \\
\text { ESTREITAMENTO DO RETO }\end{array}$ & 1 & 0,1 \\
\hline BIÓPSIA DE LINFONODO & 1 & 0,1 & DRENAGEM ABSCESSO DE DEDO DA MÃO & 1 & 0,1 \\
\hline $\begin{array}{l}\text { BIÓPSIA DO FIGADO POR LAPAROTOMIA OU } \\
\text { LAPAROSCOPIA }\end{array}$ & 1 & 0,1 & DRENAGEM COM BIÓPSIA DE PERICÁRDIO & 1 & 0,1 \\
\hline BIÓPSIA RENAL POR PUNÇÃO & 1 & 0,1 & $\begin{array}{l}\text { DRENAGEM DE ABSCESSO DA BOLSA } \\
\text { ESCROTAL }\end{array}$ & 1 & 0,1 \\
\hline $\begin{array}{l}\text { BRONCOSCOPIA COM COLETA APARELHADA } \\
\text { DE MATERIAL }\end{array}$ & 1 & 0,1 & DRENAGEM DE ABSCESSO DA MAMA & 1 & 0,1 \\
\hline CIRURGIA DE VARIZES UNILATERAL & 1 & 0,1 & DRENAGEM DE ABSCESSO DA PARÓTIDA & 1 & 0,1 \\
\hline $\begin{array}{l}\text { CIRURGIA PARA ENUCLEAÇÃO DE CISTO } \\
\text { BUCO MAXILAR }\end{array}$ & 1 & 0,1 & DRENAGEM DE PLEURA & 1 & 0,1 \\
\hline CISTECTOMIA TOTAL & 1 & 0,1 & $\begin{array}{l}\text { DRENAGEM ESTEROTÁXICA - CISTOS, } \\
\text { HEMATOMAS OU ABSCESSOS }\end{array}$ & 1 & 0,1 \\
\hline CISTOLITOTOMIA & 1 & 0,1 & ESÔFAGO CARDIOPLASTIA & 1 & 0,1 \\
\hline $\begin{array}{l}\text { CISTOLITOTOMIA, RESSECÇÃO ENDOSCÓPICA } \\
\text { DE PRÓSTATA }\end{array}$ & 1 & 0,1 & $\begin{array}{l}\text { ESOFAGOSCOPIA E RETIRADA DE CORPO } \\
\text { ESTRANHO }\end{array}$ & 1 & 0,1 \\
\hline CISTOLITOTOMIA, URETEROLITOTOMIA & 1 & 0,1 & EXCISÁO DE PAPILA HEMORROIDÁRIA & 1 & 0,1 \\
\hline $\begin{array}{l}\text { COLANGIOPANCREATROGRAFIA } \\
\text { RETRÓGRADA }\end{array}$ & 1 & 0,1 & EXCISÃO DE TUMOR DE GLÂNDULA PARÓTIDA & 1 & 0,1 \\
\hline $\begin{array}{l}\text { COLECISTECTOMIA, HERNIORRAFIA } \\
\text { EPIGÁSTRICA }\end{array}$ & 1 & 0,1 & $\begin{array}{l}\text { EXCISÃO DE TUMOR DE GLÂNDULA } \\
\text { SUBMAXILAR }\end{array}$ & 1 & 0,1 \\
\hline $\begin{array}{l}\text { COLECISTECTOMIA, PERITONIOSTOMIA C/ } \\
\text { TELA INORGÂNICA }\end{array}$ & 1 & 0,1 & EXCISÃO E SUTURA DE LESÃO DA BOCA & 1 & 0,1 \\
\hline COLECTOMIA VIDEOLAPAROSCÓPICA & 1 & 0,1 & $\begin{array}{l}\text { EXCISÃO E SUTURA DE LINFANGIOMA OU } \\
\text { NEVUS }\end{array}$ & 1 & 0,1 \\
\hline $\begin{array}{l}\text { COLOCAÇÃO DE MOLDE BRÔNQUICO POR } \\
\text { TORACOTOMIA } \\
\end{array}$ & 1 & 0,1 & EXERESE DE CISTO BRANQUIAL & 1 & 0,1 \\
\hline $\begin{array}{l}\text { COLPOPLASTIA POSTERIOR,HERNIORRAFIA } \\
\text { INCISIONAL GRANDE }\end{array}$ & 1 & 0,1 & EXERESE DE CISTO DERMÓIDE & 1 & 0,1 \\
\hline COLPOTOMIA & 1 & 0,1 & EXERESE DE CISTO TIREOGLOSSO & 1 & 0,1 \\
\hline CONIZAĈÃO COM CAF & 1 & 0,1 & EXERESE DE TUMOR BENIGNO DE C.A.E. & 1 & 0,1 \\
\hline $\begin{array}{l}\text { CORREÇÁO DA PERSISTÊNCIA DO CANAL } \\
\text { ARTERIAL NO REC.NASC. }\end{array}$ & 1 & 0,1 & EXERESE DE TUMOR DE CONJUNTIVA & 1 & 0,1 \\
\hline $\begin{array}{l}\text { CURATIVO CIRÚRGICO SOB ANEST. } \\
\text { SUBSEQUENTE A TRAT.CIRURG. DE PRO }\end{array}$ & 1 & 0,1 & EXERESE DE TUMOR PALPEBRAL & 1 & 0,1 \\
\hline $\begin{array}{l}\text { CURATIVO CIRÚRGICO SOB ANEST. } \\
\text { SUBSEQUENTE A TRAT.CIRURG } \\
\end{array}$ & 1 & 0,1 & $\begin{array}{l}\text { EXERESE E PLÁSTICA DE CISTO SACRO } \\
\text { COCCÍGEO }\end{array}$ & 1 & 0,1 \\
\hline DERMOLIPECTOMIA & 1 & 0,1 & $\begin{array}{l}\text { EXPLORAÇÃO OU TOALETE ARTICULAR C/ OU } \\
\text { S/ SINOV. DA COXO-FEM. }\end{array}$ & 1 & 0,1 \\
\hline $\begin{array}{l}\text { DERMOLIPECTOMIA BRAQUIAL POS } \\
\text { GASTROPLASTIA }\end{array}$ & 1 & 0,1 & $\begin{array}{l}\text { EXPLORAÇÁO OU TOALETE ARTICULAR C/ OU } \\
\text { S/ SINOV.DO COTOVELO }\end{array}$ & 1 & 0,1 \\
\hline
\end{tabular}




\begin{tabular}{|c|c|c|c|c|c|}
\hline PROCEDIMENTO - 2007 & $\mathbf{N}$ & $\%$ & PROCEDIMENTO - 2008 & $\mathbf{N}$ & $\%$ \\
\hline DESARTICULAÇÃO AO NÍVEL DO JOELHO & 1 & 0,1 & $\begin{array}{l}\text { EXPLORAÇÃO OU TOALETE ARTICULAR C/ OU } \\
\text { S/ SINOV.DO PUNHO }\end{array}$ & 1 & 0,1 \\
\hline DESCORTICAÇÃO PULMONAR & 1 & 0,1 & $\begin{array}{l}\text { EXPLORAÇÃO OU TOALETE ARTICULAR C/ OU } \\
\text { S/ SINOV.ESCAP.UMER. }\end{array}$ & 1 & 0,1 \\
\hline DRENAGEM CIRÚRGICA DO PSOAS & 1 & 0,1 & EXTIRPAÇÃO DE NEUROMA & 1 & 0,1 \\
\hline $\begin{array}{l}\text { DRENAGEM DE ABSCESSO DA BOLSA } \\
\text { ESCROTAL }\end{array}$ & 1 & 0,1 & $\begin{array}{l}\text { EXTIRPAÇÁO E SUPRESSÃO DE LESÃO DA } \\
\text { PELEE E DO TECIDO }\end{array}$ & 1 & 0,1 \\
\hline DRENAGEM DE ABSCESSO DA MAMA & 1 & 0,1 & EXTRAÇÃO DE CORPO ESTRANHO DA BEXIGA & 1 & 0,1 \\
\hline DRENAGEM DE ABSCESSO DA PARÓTIDA & 1 & 0,1 & $\begin{array}{l}\text { FACECTOMIA SEM IMPLANTE DE LENTE } \\
\text { INTRA-OCULAR }\end{array}$ & 1 & 0,1 \\
\hline DRENAGEM DE ABSCESSO ISQUIORRETAL & 1 & 0,1 & $\begin{array}{l}\text { FACECTOMIA SEM IMPLANTE DE LENTE } \\
\text { INTRA-OCULAR, VITRECTOMIA }\end{array}$ & 1 & 0,1 \\
\hline $\begin{array}{l}\text { DRENAGEM DE ABSCESSO LINGUAL E } \\
\text { SUBLINGUAL }\end{array}$ & 1 & 0,1 & FECHAMENTO DE FISTULA RETAL & 1 & 0,1 \\
\hline DRENAGEM DE ABSCESSO PERIURETRAL & 1 & 0,1 & GLOSSECTOMIA PARCIAL & 1 & 0,1 \\
\hline $\begin{array}{l}\text { DRENAGEM DE ABSCESSO RENAL OU PERI- } \\
\text { RENAL }\end{array}$ & 1 & 0,1 & HEPATECTOMIA PARCIAL & 1 & 0,1 \\
\hline $\begin{array}{l}\text { DRENAGEM DE HEMATOMA OU ABSCESSO } \\
\text { RETRO RETAL }\end{array}$ & 1 & 0,1 & $\begin{array}{l}\text { HERNIORRAFIA INGUINAL } \\
\text { VIDEOLAPAROSCÓPICA } \\
\end{array}$ & 1 & 0,1 \\
\hline $\begin{array}{l}\text { DRENAGEM TUBULAR ABERTA DE CAVIDADE } \\
\text { PULMONAR }\end{array}$ & 1 & 0,1 & $\begin{array}{l}\text { HERNIORRAFIA SEM RESSECÇÃO INTESTINAL } \\
\text { (ESTRANGULADA) }\end{array}$ & 1 & 0,1 \\
\hline ELETRO COAGULAÇÃO DE LESÃO CUTÂNEA & 1 & 0,1 & HIPOSPADIA (1 TEMPO) & 1 & 0,1 \\
\hline EMBOLECTOMIA ARTERIAL & 1 & 0,1 & HIPOSPADIA (2 TEMPOS) & 1 & 0,1 \\
\hline $\begin{array}{l}\text { ENTERECTOMIA, ENTEROANASTOMOSE } \\
\text { (QUALQUER SEGMENTO) }\end{array}$ & 1 & 0,1 & HISTERECTOMIA TOTAL & 1 & 0,1 \\
\hline ENTERECTOMIA,ENTEROANASTOMOSE & 1 & 0,1 & JEJUNOSTOMIA & 1 & 0,1 \\
\hline $\begin{array}{l}\text { ENTEROANASTOMOSE (QUALQUER } \\
\text { SEGMENTO) }\end{array}$ & 1 & 0,1 & $\begin{array}{l}\text { LARINGOSCOPIA/TRAQUEOSCOPIA C/EXE.DE } \\
\text { PÓLIPO, NÓD./ PAPIL. }\end{array}$ & 1 & 0,1 \\
\hline $\begin{array}{l}\text { ENTEROANASTOMOSE, REPAR.DE HÉRNIAS, } \\
\text { COLECTOMIA PARCIAL }\end{array}$ & 1 & 0,1 & LIBERAÇÃO DE ADERÊNCIAS INTESTINAIS & 1 & 0,1 \\
\hline $\begin{array}{l}\text { ENTERORRAFIA (QUALQUER SEGMENTO) } \\
\text { FECH.DE FÍSTULA CÓLICA } \\
\end{array}$ & 1 & 0,1 & LINFADENECTOMIA PÉLVICA & 1 & 0,1 \\
\hline ENXERTO ÓSSEO & 1 & 0,1 & $\begin{array}{l}\text { MASTECTOMIA RADICAL COM } \\
\text { LINFONODECTOMIA }\end{array}$ & 1 & 0,1 \\
\hline EPIDÍDIMO DEFERENTE NEOSTOMIA & 1 & 0,1 & MASTOIDECTOMIA SUBTOTAL & 1 & 0,1 \\
\hline ESFINCTEROPLASTIA ANAL & 1 & 0,1 & NEFROSTOMIA SEM OU COM DRENAGEM & 1 & 0,1 \\
\hline ESOFAGOPLASTIA (QUALQUER TÉCNICA) & 1 & 0,1 & ORQUIDOPEXIA BILATERAL & 1 & 0,1 \\
\hline ESPLENECTOMIA & 1 & 0,1 & $\begin{array}{l}\text { OSTEOTOMIA PARA COR.DE DEFORM.DE } \\
\text { OSSO METACARP.OU FALAN. }\end{array}$ & 1 & 0,1 \\
\hline $\begin{array}{l}\text { ESPLENECTOMIA, DECONEXÃO AZIGO- } \\
\text { PORTAL }\end{array}$ & 1 & 0,1 & PALATOPLASTIA PARCIAL & 1 & 0,1 \\
\hline EXCISÄO DE GLÂNDULA SUBMAXILAR & 1 & 0,1 & PERITONIOSCOPIA OU LAPAROSCOPIA & 1 & 0,1 \\
\hline $\begin{array}{l}\text { EXCISÃO DE TUMOR DE GLÂNDULA } \\
\text { SUBLINGUAL }\end{array}$ & 1 & 0,1 & $\begin{array}{l}\text { PLASTIA ARTERIAL COM REMENDO, } \\
\text { QUALQUER TÉCNICA }\end{array}$ & 1 & 0,1 \\
\hline $\begin{array}{l}\text { EXCISÃO E ENXERTO DE PELE (HEMANGIOMA, } \\
\text { NEVUS OU TUMOR) }\end{array}$ & 1 & 0,1 & $\begin{array}{l}\text { PLÁSTICA MAMÁRIA MASCULINA } \\
\text { (GINECOMASTIA) }\end{array}$ & 1 & 0,1 \\
\hline EXCISÃO E SUTURA DE HEMANGIOMA & 1 & 0,1 & PNEUMOMECTOMIA & 1 & 0,1 \\
\hline EXERESE DE CALO & 1 & 0,1 & POLIPECTOMIA DE CÓLON & 1 & 0,1 \\
\hline EXERESE DE CISTO SEBÁCEO & 1 & 0,1 & PREPARO DE RETALHO & 1 & 0,1 \\
\hline EXERESE DE GÂNGLIO LINFÁTICO & 1 & 0,1 & PROCTOCOLECTOMIA & 1 & 0,1 \\
\hline EXERESE DE TUMOR DE CONJUNTIVA & 1 & 0,1 & PTOSE E COLOBOMA DE PÁLPEBRA & 1 & 0,1 \\
\hline EXERESE DO MAMILO & 1 & 0,1 & $\begin{array}{l}\text { RECONSTRUÇÃO COM RETALHO MIO } \\
\text { CUTÂNEO EM CIRURGIA ONCOLOG. }\end{array}$ & 1 & 0,1 \\
\hline $\begin{array}{l}\text { EXPLORAÇÃO OU TOALETE ARTICULAR C/OU } \\
\text { SEM SINOVECT.DO JOELHO }\end{array}$ & 1 & 0,1 & $\begin{array}{l}\text { RECONSTRUÇÃO PARCIAL DO LÁBIO } \\
\text { TRAUMATIZADO }\end{array}$ & 1 & 0,1 \\
\hline EXTRAÇÃO DE CORPO ESTRANHO DA BEXIGA & 1 & 0,1 & $\begin{array}{l}\text { REDUÇÃO INCRUENTA DA DA LUX. OU FRAT.- } \\
\text { LUX. AO NIVEL DO PUNHO }\end{array}$ & 1 & 0,1 \\
\hline $\begin{array}{l}\text { EXTRAÇÃO DE CORPO ESTRANHO OU } \\
\text { CALC.NA URETRA C/ CISTOSCOPIA }\end{array}$ & 1 & 0,1 & $\begin{array}{l}\text { REDUÇÃO INCRUENTA DA LUX.E FRAT.-LUX. } \\
\text { INTER-FALANGIANA }\end{array}$ & 1 & 0,1 \\
\hline $\begin{array}{l}\text { FACECTOMIA PARA IMPLANTE DE LENTE } \\
\text { INTRA-OC. VITRECTOMIA ANTERIOR }\end{array}$ & 1 & 0,1 & $\begin{array}{l}\text { REDUÇÄO INCRUENTA DA LUX. OU } \\
\text { FRAT.LUX.CARPO -METACARP. }\end{array}$ & 1 & 0,1 \\
\hline $\begin{array}{l}\text { FACECTOMIA PARA IMPLANTE DE LENTE } \\
\text { INTRA-OCULAR,VITRECTOMIA }\end{array}$ & 1 & 0,1 & $\begin{array}{l}\text { REDUÇÃO INCRUENTA DE FRATURA DA } \\
\text { DIÁFISE DO ÚMERO }\end{array}$ & 1 & 0,1 \\
\hline FASCIOTOMIA PALMAR & 1 & 0,1 & $\begin{array}{l}\text { REDUÇÃO INCRUENTA DE FRATURA DO(S) } \\
\text { OSSO(S) DO TARSO }\end{array}$ & 1 & 0,1 \\
\hline FASCIOTOMIAS & 1 & 0,1 & $\begin{array}{l}\text { REMOÇAिO DE CORPO ESTRANHO DA REGIÃO } \\
\text { BUCO-MAXILO-FACIAL }\end{array}$ & 1 & 0,1 \\
\hline GASTRECTOMIA COM LINFADENECTOMIA & 1 & 0,1 & $\begin{array}{l}\text { REPARAÇÃO OUTRAS HÉRNIAS (INCLUI } \\
\text { HERNIORRAFIA MUSCULAR) }\end{array}$ & 1 & 0,1 \\
\hline GASTROENTEROANASTOMOSE & 1 & 0,1 & $\begin{array}{l}\text { REPARO DE ROTURA DO MANGUITO } \\
\text { ROTADOR }\end{array}$ & 1 & 0,1 \\
\hline $\begin{array}{l}\text { GASTROENTEROANASTOMOSE, } \\
\text { GASTRECTOMIA, COLECISTECTOMIA }\end{array}$ & 1 & 0,1 & $\begin{array}{l}\text { REPARO DE ROTURA DO MANGUITO ROT. } \\
\text { INCL. PROC.DESCOMP. }\end{array}$ & 1 & 0,1 \\
\hline GASTROSTOMIA & 1 & 0,1 & $\begin{array}{l}\text { REPARO LIGAMENTAR AO NÍVEL DO } \\
\text { CARPO(RADIO-ULNAR DIST. }\end{array}$ & 1 & 0,1 \\
\hline $\begin{array}{l}\text { GASTROSTOMIA, HERNIOPLASTIA HIATAL } \\
\text { VIDEOLAPAROSCÓPICA }\end{array}$ & 1 & 0,1 & $\begin{array}{l}\text { RESSECÇÃO DE PARTES MOLES DAS EXTR.C/ } \\
\text { RECONSTRUÇÃOO }\end{array}$ & 1 & 0,1 \\
\hline GLOSSECTOMIA PARCIAL & 1 & 0,1 & $\begin{array}{l}\text { RESSECĈÃO DE TUMOR UROTELIAL } \\
\text { MULTICÊNTRICO E SINCRÔNICO }\end{array}$ & 1 & 0,1 \\
\hline
\end{tabular}




\begin{tabular}{|c|c|c|c|c|c|}
\hline PROCEDIMENTO - 2007 & $\mathbf{N}$ & $\%$ & PROCEDIMENTO - 2008 & $\mathbf{N}$ & $\%$ \\
\hline $\begin{array}{l}\text { HEMOSTASIA DE ESÖFAGO, ESTÔMAGO E } \\
\text { DUODENO, ENTERECTOMIA }\end{array}$ & 1 & 0,1 & $\begin{array}{l}\text { RESSECÇÃO DE TUMORES DA FACE, POR VIA } \\
\text { EXT.OU ENDOBUCAL/N }\end{array}$ & 1 & 0,1 \\
\hline $\begin{array}{l}\text { HERNIORRAFIA COM RESSECÇÃO INTESTINAL } \\
\text { (ESTRANGULADA) }\end{array}$ & 1 & 0,1 & RESSECÇÃO DO TUMOR DO MEDIASTINO & 1 & 0,1 \\
\hline HERNIORRAFIA CRURAL (UNILATERAL) & 1 & 0,1 & $\begin{array}{l}\text { RESSECÇÃO ENDOSCÓPICA DE TUMOR } \\
\text { VESICAL }\end{array}$ & 1 & 0,1 \\
\hline $\begin{array}{l}\text { HERNIORRAFIA DIAFRAGMÁTICA (VIA } \\
\text { ABDOMINAL) }\end{array}$ & 1 & 0,1 & $\begin{array}{l}\text { RESSECÇÃO RADICAL DE PARTES MOLES DA } \\
\text { COX. JOEL. PER., BRAC. }\end{array}$ & 1 & 0,1 \\
\hline $\begin{array}{l}\text { HERNIORRAFIA DIAFRAGMÁTICA (VIA } \\
\text { ABDOMINAL), ESPLENECTOMIA }\end{array}$ & 1 & 0,1 & RESSUTURA & 1 & 0,1 \\
\hline $\begin{array}{l}\text { HERNIORRAFIA INCISIONAL GRANDE, } \\
\text { ENTERCTOMIA }\end{array}$ & 1 & 0,1 & $\begin{array}{l}\text { RETIRADA DE CORPO ESTRANHO DO } \\
\text { ESÔFAGO, ESTÔM.E DUODENO }\end{array}$ & 1 & 0,1 \\
\hline $\begin{array}{l}\text { HERNIORRAFIA INGUINAL } \\
\text { VIDEOLAPAROSCÓPICA }\end{array}$ & 1 & 0,1 & $\begin{array}{l}\text { RETIRADA DE CORPO ESTRANHO NA } \\
\text { INTIMIDADE DOS OSSOS DA FACE } \\
\end{array}$ & 1 & 0,1 \\
\hline $\begin{array}{l}\text { HERNIORRAFIA INGUINAL( UNILATERAL) E } \\
\text { EPIGÁSTRICA }\end{array}$ & 1 & 0,1 & $\begin{array}{l}\text { RETIRADA DE CORPO ESTRANHO POR VIA } \\
\text { ESTERIOTÁXICA }\end{array}$ & 1 & 0,1 \\
\hline $\begin{array}{l}\text { IMPLANTE DE LENTE INTRAOCULAR EM } \\
\text { CÂMARA ANTERIOR }\end{array}$ & 1 & 0,1 & RETIRADA DE HASTE INTRAMEDULAR & 1 & 0,1 \\
\hline $\begin{array}{l}\text { INCISÃO E DRENAGEM DE ABSCESSO DA } \\
\text { PARÓTIDA }\end{array}$ & 1 & 0,1 & RETIRADA DE PARAFUSO & 1 & 0,1 \\
\hline INCISÃO E DRENAGEM DE FLEIMAO & 1 & 0,1 & $\begin{array}{l}\text { RETIRADA DE PRÓTESE INFECTADA EM } \\
\text { POSIÇÃO NÃO AÓRTICA }\end{array}$ & 1 & 0,1 \\
\hline $\begin{array}{l}\text { LAPAROTOMIA EXPLORADORA, } \\
\text { ENTERECTOMIA }\end{array}$ & 1 & 0,1 & $\begin{array}{l}\text { RETOSSIGMOIDOSCOPIA E RETIRADA DE } \\
\text { CORPO ESTRANHO }\end{array}$ & 1 & 0,1 \\
\hline $\begin{array}{l}\text { LAPAROTOMIA EXPLORADORA, } \\
\text { ENTERECTOMIA, COLECISTECTOMIA }\end{array}$ & 1 & 0,1 & $\begin{array}{l}\text { RETRAÇÃO CICATRICIAL - CORREÇÃO EM UM } \\
\text { ESTAGIO }\end{array}$ & 1 & 0,1 \\
\hline $\begin{array}{l}\text { LAPAROTOMIA EXPLORADORA, } \\
\text { HEPATORRAFIA }\end{array}$ & 1 & 0,1 & REVASCULARIZAÇÃO DO MEMBRO SUPERIOR & 1 & 0,1 \\
\hline $\begin{array}{l}\text { LAPAROTOMIA EXPLORADORA, ILEOSTOMIAS, } \\
\text { ENTERECTOMIA }\end{array}$ & 1 & 0,1 & SIMPATECTOMIA & 1 & 0,1 \\
\hline $\begin{array}{l}\text { LAPAROTOMIA EXPLORADORA, } \\
\text { APENDICECTOMIA }\end{array}$ & 1 & 0,1 & SINOVECTOMIA DE PUNHO & 1 & 0,1 \\
\hline $\begin{array}{l}\text { LAPAROTOMIA EXPLORADORA, BIÓPSIA DE } \\
\text { GÂNGLIO LINF., APENDIC. }\end{array}$ & 1 & 0,1 & SINUSOTOMIA MAXILAR UNILATERAL & 1 & 0,1 \\
\hline $\begin{array}{l}\text { LAPAROTOMIA EXPLORADORA,COLECTOMIA } \\
\text { PARCIAL, ILEOSTOMIAS }\end{array}$ & 1 & 0,1 & SONDAGEM DE VIAS LACRIMAIS & 1 & 0,1 \\
\hline $\begin{array}{l}\text { LAPAROTOMIA } \\
\text { EXPLORADORA,ENTERORRAFIA (QUALQUER } \\
\text { SEGMENTO) }\end{array}$ & 1 & 0,1 & SUTURA DE CÓRNEA & 1 & 0,1 \\
\hline $\begin{array}{l}\text { LAPAROTOMIA EXPLORADORA, } \\
\text { GASTRORRAFIA }\end{array}$ & 1 & 0,1 & TENOPLASTIA OU ENXERTO DE TENDÃO & 1 & 0,1 \\
\hline LAPAROTOMIA EXPLORADORA, ILEOSTOMIAS & 1 & 0,1 & $\begin{array}{l}\text { TENORRAFIA EM TÚNEL OSTEOFIBROSO POR } \\
\text { DEDO }\end{array}$ & 1 & 0,1 \\
\hline $\begin{array}{l}\text { LAPAROTOMIA EXPLORADORA, } \\
\text { TRAQUEOPLASTIA }\end{array}$ & 1 & 0,1 & TENOTOMIA & 1 & 0,1 \\
\hline $\begin{array}{l}\text { LARINGOSCOPIA/TRAQUEOSCOPIA COM } \\
\text { LASER PARA EXE.DE PAPILOMA }\end{array}$ & 1 & 0,1 & TIREOIDECTOMIA PARCIAL & 1 & 0,1 \\
\hline LARINGOSCOPIA COM EXERESE DE PAPILOMA & 1 & 0,1 & TORACOCENTESE & 1 & 0,1 \\
\hline $\begin{array}{l}\text { LARINGOSCOPIA DIRETA PARA RETIRADA DE } \\
\text { CORPO ESTRANHO }\end{array}$ & 1 & 0,1 & TORACOTOMIA COM DRENAGEM FECHADA & 1 & 0,1 \\
\hline $\begin{array}{l}\text { LARINGOSCOPIA/TRAQUEOSCOPIA COM } \\
\text { EXE.DE PÓLIPO, NÓD./ PAPILOMA }\end{array}$ & 1 & 0,1 & TRABECULECTOMIA COM MITOMICINA C & 1 & 0,1 \\
\hline $\begin{array}{l}\text { LARINGOSCOPIA/TRAQUEOSCOPIA PARA } \\
\text { DIAGNOSTICO E BIÓPSIA }\end{array}$ & 1 & 0,1 & TRAÇÃO TRANSESQUELÉTICA - POR MEMBRO & 1 & 0,1 \\
\hline LINFADENECTOMIA RETROPERITONIAL & 1 & 0,1 & TRAQUEOPLASTIA (QUALQL & 1 & 0,1 \\
\hline LOBECTOMIA & 1 & 0,1 & $\begin{array}{l}\text { TRATAMENTO CIRÚ'RGICO DA FRATURA SUB- } \\
\text { TROCANTERIANA }\end{array}$ & 1 & 0,1 \\
\hline MASTOIDECTOMIA RADICAL & 1 & 0,1 & $\begin{array}{l}\text { TRATAMENTO CIRÚRGICO DA FRAT.DA } \\
\text { EXTREM.PROX. DO ÚMERO }\end{array}$ & 1 & 0,1 \\
\hline MEATOTOMIA, URETROTOMIA INTERNA & 1 & 0,1 & $\begin{array}{l}\text { TRATAMENTO CIRÚRGICO DA FRATURA DO } \\
\text { OSSOS DO MÉDIO-PÉ }\end{array}$ & 1 & 0,1 \\
\hline MICRONEURÓLISE & 1 & 0,1 & $\begin{array}{l}\text { TRATAMENTO CIRÚRGICO DA FRATURA DO } \\
\text { PILÃO TIBIAL }\end{array}$ & 1 & 0,1 \\
\hline NEFROLITOTOMIA PERCUTÂNEA & 1 & 0,1 & $\begin{array}{l}\text { TRATAMENTO CIRÚRGICO DA FRATURA DO(S) } \\
\text { PODODACTILO(S), }\end{array}$ & 1 & 0,1 \\
\hline NEURÓLISE & 1 & 0,1 & $\begin{array}{l}\text { TRATAMENTO CIRÚRGICO DA LUX.OU FRAT.- } \\
\text { LUX. CARPO-METACARP. }\end{array}$ & 1 & 0,1 \\
\hline OOFORECTOMIA UNI OU BILATERAL & 1 & 0,1 & $\begin{array}{l}\text { TRATAMENTO CIRÚRGICO DA LUX.OU FRAT.- } \\
\text { LUX. METATARSO-FALANG. }\end{array}$ & 1 & 0,1 \\
\hline $\begin{array}{l}\text { OOFORECTOMIA UNI OU BILATERAL, } \\
\text { MIOMECTOMIA }\end{array}$ & 1 & 0,1 & $\begin{array}{l}\text { TRATAMENTO CIRÚRGICO DA OSTEOMIELITE } \\
\text { DOS OSSOS DA MÃO }\end{array}$ & 1 & 0,1 \\
\hline ORQUIDOPEXIA BILATERAL & 1 & 0,1 & $\begin{array}{l}\text { TRATAMENTO CIRÚRGICO DA PSEUDO- } \\
\text { ARTROSE, RETARDO DE CONSOL. }\end{array}$ & 1 & 0,1 \\
\hline $\begin{array}{l}\text { OSTECTOMIA, CURETAGEM OU EXCISÃO DE } \\
\text { LESÃO NOS OSSOS DO PE }\end{array}$ & 1 & 0,1 & $\begin{array}{l}\text { TRATAMENTO CIRÚRGICO DA TORC.DO } \\
\text { TESTIC.OU DO CORDÃO ESPERM. }\end{array}$ & 1 & 0,1 \\
\hline OSTEOTOMIA AO NÍVEL DA PELVE & 1 & 0,1 & $\begin{array}{l}\text { TRATAMENTO CIRÚRGICO DE FRATURA DA } \\
\text { CLAVÍ́CULA }\end{array}$ & 1 & 0,1 \\
\hline OSTEOTOMIA DA DIÁFISE DO FÊMUR & 1 & 0,1 & $\begin{array}{l}\text { TRATAMENTO CIRÚRGICO DE FRAT. OU } \\
\text { DESLOC. EPIFIS.DOS COND. E T }\end{array}$ & 1 & 0,1 \\
\hline
\end{tabular}




\begin{tabular}{|c|c|c|c|c|c|}
\hline PROCEDIMENTO - 2007 & $\mathbf{N}$ & $\%$ & PROCEDIMENTO - 2008 & $\mathbf{N}$ & $\%$ \\
\hline $\begin{array}{l}\text { PALATO LABIOPLASTIA UNI OU BILATERAL } \\
\text { (POR ESTAGIO) }\end{array}$ & 1 & 0,1 & TRATAMENTO CIRÚRGICO DE HIPERTROPIAS & 1 & 0,1 \\
\hline PALATOPLASTIA COM ENXERTO ÓSSEO & 1 & 0,1 & $\begin{array}{l}\text { TRATAMENTO CIRÚRGICO DE LESÃO LIGAM. } \\
\text { AG.DO TORNOZELO }\end{array}$ & 1 & 0,1 \\
\hline PANCREATECTOMIA PARCIAL & 1 & 0,1 & $\begin{array}{l}\text { TRATAMENTO CIRÚRGICO DO HALUX VALGUS } \\
\text { C/OSTEOT.OSSO METAT }\end{array}$ & 1 & 0,1 \\
\hline PERITONIOSCOPIA OU LAPAROSCOPIA & 1 & 0,1 & $\begin{array}{l}\text { TRATAMENTO CONSERVADOR DA FRAT.DOS } \\
\text { OSSOS DO NARIZ }\end{array}$ & 1 & 0,1 \\
\hline PIELOPLASTIA & 1 & 0,1 & $\begin{array}{l}\text { TRATAMENTO DE EMERGÊNCIA, } \\
\text { FRAT.ALVE.DENTÁRIA REDUÇÃO C }\end{array}$ & 1 & 0,1 \\
\hline PIELOTOMIA & 1 & 0,1 & $\begin{array}{l}\text { TREPANAÇÃO, OSTECTOMIA, CURETAGEM OU } \\
\text { SAUCERIZAÇÃO EM OSS }\end{array}$ & 1 & 0,1 \\
\hline $\begin{array}{l}\text { PLÁSTICA MAMÁRIA RECONSTRUTIVA, } \\
\text { C/IMPL.DE PRÓTESE MAM. }\end{array}$ & 1 & 0,1 & VITRECTOMIA ANTERIOR & 1 & 0,1 \\
\hline $\begin{array}{l}\text { PLÁSTICA MAMÁRIA RECONSTRUTIVA, POS } \\
\text { MASTEC.C/IMPLANTE DE PROT. }\end{array}$ & 1 & 0,1 & TOTAL & 1.455 & 100,0 \\
\hline PLÁSTICA TOTAL DO PÊNIS & 1 & 0,1 & & & \\
\hline PLEURODESE & 1 & 0,1 & & & \\
\hline PREPARO DE RETALHO, EXERESE DE LIPOMA & 1 & 0,1 & & & \\
\hline PROSTATECTOMIA & 1 & 0,1 & & & \\
\hline PROSTATECTOMIA SUPRA PÚBICA & 1 & 0,1 & & & \\
\hline RECONSTRUÇÂO DE HÉLIX DA ORELHA & 1 & 0,1 & & & \\
\hline $\begin{array}{l}\text { RECONSTRUÇÁO DE TENDÂO PATELAR OU } \\
\text { TENDÃO QUADRICIPITAL }\end{array}$ & 1 & 0,1 & & & \\
\hline RECONSTRUÇÃO DO ASSOALHO PÉLVICO & 1 & 0,1 & & & \\
\hline $\begin{array}{l}\text { RECONSTRUÇÃO DO PÓLO SUPERIOR DA } \\
\text { ORELHA }\end{array}$ & 1 & 0,1 & & & \\
\hline $\begin{array}{l}\text { RECONSTRUÇÃO LIGAMENTAR INTRA- } \\
\text { ARTICULAR DO JOELHO }\end{array}$ & 1 & 0,1 & & & \\
\hline $\begin{array}{l}\text { RECONSTRUÇÃO TOTAL DA ORELHA } \\
\text { (MÚLTIPLOS ESTÁGIOS) }\end{array}$ & 1 & 0,1 & & & \\
\hline $\begin{array}{l}\text { REDUÇÃO CIRÚRGICA DA LUXAĈÁO } \\
\text { TEMPOROMANDIBULAR (RECIDIVANTE) }\end{array}$ & 1 & 0,1 & & & \\
\hline $\begin{array}{l}\text { REDUÇÃO INCRUENTA DA(S) FRATURA(S) DO } \\
\text { (S) OSSO(S) DO PUNHO }\end{array}$ & 1 & 0,1 & & & \\
\hline $\begin{array}{l}\text { REDUÇÃO INCRUENTA DE FRATURA DO(S) } \\
\text { METACARPIANO(S) }\end{array}$ & 1 & 0,1 & & & \\
\hline REPARO DE ROTURA DO MANGUITO ROTADOR & 1 & 0,1 & & & \\
\hline REPARO LIGAMENTAR AO NÍVEL DO CARPO & 1 & 0,1 & & & \\
\hline RESSECÇÃO CISTO SINOVIAL & 1 & 0,1 & & & \\
\hline RESSECÇÃO DE CISTO SINOVIAL & 1 & 0,1 & & & \\
\hline RESSECÇÃO DE EXOSTOSE & 1 & 0,1 & & & \\
\hline $\begin{array}{l}\text { RESSECÇÂO ENDOSCÓPICA DE TUMOR } \\
\text { VESICAL }\end{array}$ & 1 & 0,1 & & & \\
\hline $\begin{array}{l}\text { RESSECÇÄO RADICAL DE PARTES MOLES DA } \\
\text { COXA, JOELHO, PERNA, BRAÇO }\end{array}$ & 1 & 0,1 & & & \\
\hline $\begin{array}{l}\text { RESSUTURA DE PAREDE ABDOMINAL } \\
\text { (DEISCÊNCIA TOT.OU EVISCERAÇÃO) }\end{array}$ & 1 & 0,1 & & & \\
\hline RETIRADA DE FIO OU PINO TRANSÓSSEO & 1 & 0,1 & & & \\
\hline RETIRADA DE FIXADOR EXTERNO & 1 & 0,1 & & & \\
\hline $\begin{array}{l}\text { RETOSSIGMOIDECTOMIA ABDOMINO } \\
\text { PERINEAL, APENDICECTOMIA }\end{array}$ & 1 & 0,1 & & & \\
\hline $\begin{array}{l}\text { RETRAÇÃO CICATRICIAL - CORREÇÃO EM UM } \\
\text { ESTAGIO }\end{array}$ & 1 & 0,1 & & & \\
\hline $\begin{array}{l}\text { REVASCULARIZAÇÃO POR } \\
\text { PONTE/TROMBOENDARTERECTOMIA }\end{array}$ & 1 & 0,1 & & & \\
\hline $\begin{array}{l}\text { REVISÃO CIRÚRGICA DO PE TORTO } \\
\text { CONGÊNITO }\end{array}$ & 1 & 0,1 & & & \\
\hline REVISÂO DE COTO AMPUTADO (COXA) & 1 & 0,1 & & & \\
\hline $\begin{array}{l}\text { RINOPLASTIA PARA DEFEITO(S) PÓS- } \\
\text { TRAUMÁTICO(S) }\end{array}$ & 1 & 0,1 & & & \\
\hline $\begin{array}{l}\text { SEPTOPLASTIA (DESVIO DO SEPTO), } \\
\text { TURBINECTOMIA }\end{array}$ & 1 & 0,1 & & & \\
\hline SINUSOTOMIA ESFENOIDAL, MAXILAR & 1 & 0,1 & & & \\
\hline SINUSOTOMIA ETMOIDAL E MAXILAR & 1 & 0,1 & & & \\
\hline SONDAGEM DE VIAS LACRIMAIS & 1 & 0,1 & & & \\
\hline TAMPONAMENTO NASAL ANT.TURBINECTOMIA & 1 & 0,1 & & & \\
\hline TENÓLISE OU TENODESE & 1 & 0,1 & & & \\
\hline $\begin{array}{l}\text { TENOTOMIA OU TENOPLASTIAS AO NÍVEL DO } \\
\text { PE }\end{array}$ & 1 & 0,1 & & & \\
\hline $\begin{array}{l}\text { TIREOIDECTOMIA TOTAL COM ESVAZIAMENTO } \\
\text { GANGLIONAR }\end{array}$ & 1 & 0,1 & & & \\
\hline $\begin{array}{l}\text { TORACOTOMIA C/ DRENAGEM } \\
\text { FECHADA,BIOP.DE PLEURA }\end{array}$ & 1 & 0,1 & & & \\
\hline $\begin{array}{l}\text { TORACOTOMIA COM DRENAGEM FECHADA, } \\
\text { DECORTICAÇÃO PULMONAR }\end{array}$ & 1 & 0,1 & & & \\
\hline $\begin{array}{l}\text { TORACOTOMIA COM DRENAGEM } \\
\text { FECHADA,PLEURECTOMIA }\end{array}$ & 1 & 0,1 & & & \\
\hline $\begin{array}{l}\text { TORACOTOMIA COM DRENAGEM } \\
\text { FECHADA,TORACOTOMIA EXPLORADORA }\end{array}$ & 1 & 0,1 & & & \\
\hline
\end{tabular}




\begin{tabular}{|c|c|c|c|c|c|}
\hline PROCEDIMENTO - 2007 & $\mathbf{N}$ & $\%$ & PROCEDIMENTO - 2008 & $\mathbf{N}$ & $\%$ \\
\hline $\begin{array}{l}\text { TRAQUEOSTOMIA COM COLOCAÇÃO DE } \\
\text { ORTESE TRAQUEAL }\end{array}$ & 1 & 0,1 & & & \\
\hline $\begin{array}{l}\text { TRAQUEOSTOMIA COM COLOCAÇÃO DE } \\
\text { ORTESE TRAQUEOBRON }\end{array}$ & 1 & 0,1 & & & \\
\hline TRAQUEOTOMIA (INCLUSIVE CURATIVOS) & 1 & 0,1 & & & \\
\hline $\begin{array}{l}\text { TRATAMENTO CIRURG.DA INCONTINÊNCIA } \\
\text { URINÁRIA POR V.VAGINAL }\end{array}$ & 1 & 0,1 & & & \\
\hline $\begin{array}{l}\text { TRATAMENTO CIRÚRGICO DA FRATURA DO(S) } \\
\text { METATARSIANO(S) }\end{array}$ & 1 & 0,1 & & & \\
\hline $\begin{array}{l}\text { TRATAMENTO CIRÚRGICO DA ARTRITE } \\
\text { PIOGÊNICA COXO FEMORAL }\end{array}$ & 1 & 0,1 & & & \\
\hline $\begin{array}{l}\text { TRATAMENTO CIRÚRGICO DA FRATURA DO } \\
\text { ACETÁBULO }\end{array}$ & 1 & 0,1 & & & \\
\hline $\begin{array}{l}\text { TRATAMENTO CIRÚRGICO DA FRATURA DO } \\
\text { CALCÂNEO }\end{array}$ & 1 & 0,1 & & & \\
\hline $\begin{array}{l}\text { TRATAMENTO CIRÚRGICO DA FRATURA DO(S) } \\
\text { PODODÁCTILO(S), }\end{array}$ & 1 & 0,1 & & & \\
\hline $\begin{array}{l}\text { TRATAMENTO CIRÚRGICO DA IMPERFURAÇÃO } \\
\text { MEMBRANOSA DO ÂNUS }\end{array}$ & 1 & 0,1 & & & \\
\hline $\begin{array}{l}\text { TRATAMENTO CIRÚRGICO DA LUX. E } \\
\text { FRAT.LUXACÃO METACARPO-FALANG. }\end{array}$ & 1 & 0,1 & & & \\
\hline $\begin{array}{l}\text { TRATAMENTO CIRÚRGICO DA OSTEOMIELITE } \\
\text { DA PELVE }\end{array}$ & 1 & 0,1 & & & \\
\hline $\begin{array}{l}\text { TRATAMENTO CIRÚRGICO DA POLIDACTILIA } \\
\text { NAO ARTICULADA }\end{array}$ & 1 & 0,1 & & & \\
\hline $\begin{array}{l}\text { TRATAMENTO CIRÚRGICO DA PSEUDO- } \\
\text { ARTROSE }\end{array}$ & 1 & 0,1 & & & \\
\hline $\begin{array}{l}\text { TRATAMENTO CIRÚRGICO DA PSEUDO- } \\
\text { ARTR.ESCAFÓIDE }\end{array}$ & 1 & 0,1 & & & \\
\hline $\begin{array}{l}\text { TRATAMENTO CIRÚRGICO DA PSEUDO- } \\
\text { ARTROSE, RETARDO DE CONS. }\end{array}$ & 1 & 0,1 & & & \\
\hline TRATAMENTO CIRÚRGICO DA VARICOCELE & 1 & 0,1 & & & \\
\hline $\begin{array}{l}\text { TRATAMENTO CIRÚRGICO DAS } \\
\text { DEFORMIDADES DO PE,RETR.ENO-CAPSUL. }\end{array}$ & 1 & 0,1 & & & \\
\hline TRATAMENTO CIRÚRGICO DE CISTO SINOVIAL & 1 & 0,1 & & & \\
\hline $\begin{array}{l}\text { TRATAMENTO CIRÚRGICO DE FRATURA DA } \\
\text { CLAVÍCULA }\end{array}$ & 1 & 0,1 & & & \\
\hline $\begin{array}{l}\text { TRATAMENTO CIRÚRGICO DE FRATURA NAS } \\
\text { EXTR.DIST.DOS OSSOS DO ANTE }\end{array}$ & 1 & 0,1 & & & \\
\hline $\begin{array}{l}\text { TRATAMENTO CIRÚRGICO DE LESÃO } \\
\text { LIGAMENTAR AGUDA DO TORNOZELO - }\end{array}$ & 1 & 0,1 & & & \\
\hline $\begin{array}{l}\text { TRATAMENTO CIRÚRGICO DE OSTEOMIELITE } \\
\text { DO(S) OSSO(S) DA FACE }\end{array}$ & 1 & 0,1 & & & \\
\hline $\begin{array}{l}\text { TRATAMENTO CIRÚRGICO DE PE TALO } \\
\text { VERTICAL }\end{array}$ & 1 & 0,1 & & & \\
\hline $\begin{array}{l}\text { TRATAMENTO CIRÚRGICO DO DEDO EM } \\
\text { MARTELO OU EM GARRA }\end{array}$ & 1 & 0,1 & & & \\
\hline TRATAMENTO CIRÚRGICO DO ESTRABISMO & 1 & 0,1 & & & \\
\hline $\begin{array}{l}\text { TRATAMENTO CIRÚRGICO DO HALUX VALGUS } \\
\text { COM OSTEOT.DO OSSO METAT }\end{array}$ & 1 & 0,1 & & & \\
\hline TRATAMENTO CIRÚRGICO DO PRIAPRISMO & 1 & 0,1 & & & \\
\hline $\begin{array}{l}\text { TRATAMENTO CIRÚRGICO LESÕES } \\
\text { VASCULARES TRAUM.DA REGIÃO CERV. }\end{array}$ & 1 & 0,1 & & & \\
\hline $\begin{array}{l}\text { TRATAMENTO CIRÚRGICO LESÕES } \\
\text { VASCULARES TRAUM.DE MEMB.INFE.UNIL. }\end{array}$ & 1 & 0,1 & & & \\
\hline $\begin{array}{l}\text { TRATAMENTO CIRÚRGICO NÁO ESTÉTICO DA } \\
\text { ORELHA }\end{array}$ & 1 & 0,1 & & & \\
\hline $\begin{array}{l}\text { TRATAMENTO CONSERVADOR DE } \\
\text { OSTEOMIELITE }\end{array}$ & 1 & 0,1 & & & \\
\hline $\begin{array}{l}\text { TRATAMENTO DA GINECOMASTIA EM PAC.C/ } \\
\text { LIPODISTR. DECOR.DO USO }\end{array}$ & 1 & 0,1 & & & \\
\hline $\begin{array}{l}\text { TREPANACAO, OSTECTOMIA, CURET. } \\
\text { SEQUESTREC. OU SAUCER. EM OSS. }\end{array}$ & 1 & 0,1 & & & \\
\hline TURBINECTOMIA SEPTOPLASTIA & 1 & 0,1 & & & \\
\hline $\begin{array}{l}\text { VIDEOSCOPIA P/ RECONSTRUÇÃO OU } \\
\text { TRANSPL.DE ESTRUTURAS DA COL. }\end{array}$ & 1 & 0,1 & & & \\
\hline TOTAL & 1.581 & & & & \\
\hline
\end{tabular}


ANEXOS 
Anexo 1 - Manual para o treinamento do Sistema de Gestão de Materiais - SGM (Centro Cirúrgico)

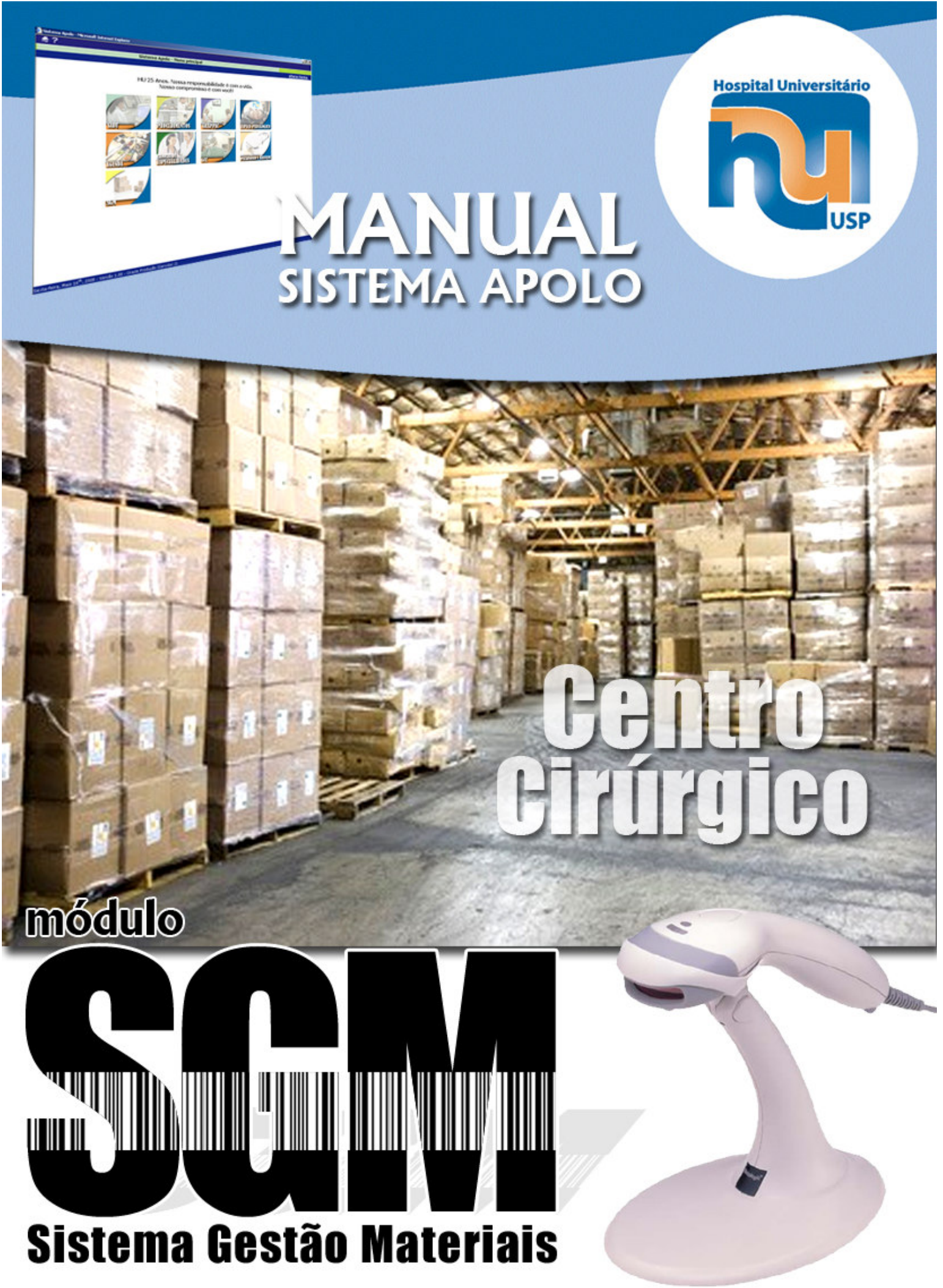




\section{Capítulo 2: Solicitação, Montagem de Kit Cirúrgico e Anestésico, Devolução e MANUTENÇÃo do Produto (ESTOQUe SUPRIMENTOS)}

\section{1 - Descrição}

Neste capítulo, vamos aprender quatro procedimentos fundamentais: 1)como se solicita a montagem do kit cirúrgico; 2) como se monta um kit para uma determinada cirurgia;3) como se efetua a devolução dos itens não usados nos kits para o estoque suprimentos do Centro Cirúrgico; 4) como se dá a manutenção do produto, ou seja, inclusão de algum item quando o kit já está montado.

Os kits são específicos, de acordo com o tipo de cirurgia a ser realizado. São montados kits cirúrgicos e anestésicos, tanto para adulto quanto para infantil.

\section{2 - A quem se destina}

\begin{tabular}{|c|c|}
\hline Perfil & Função no sistema \\
\hline Administrativos e técnicos em geral & Inclui / Consulta/ Exclui \\
\hline
\end{tabular}

\section{3 - Como fazer}

Para se solicitar a montagem de um ou mais kits, vá ao Sistema Apolo, módulo SGM.

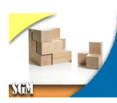

Kit - Vá ao menu Kit, opção Solicitação. Forneça: Setor, Período da cirurgia e

Solicitaçẫo a sua data prevista. A seguir, clique em "Adicionar Itens".

Na tela abaixo, o funcionário irá executar a solicitação da montagem dos kits cirúrgicos e anestésicos, conforme o relatório de intenção cirúrgica obtido anteriormente. Neste relatório, constam os procedimentos cirúrgicos a serem realizados. Baseado nisto, o funcionário monta a solicitação. O sistema irá gerar um número desta lista de solicitação, que será usado na montagem dos kits.

O funcionário que está montando o kit informa:

1) $O$ tipo de procedimento a ser realizado;

2) A matrícula do paciente (ao qual está destinado o kit); 3) A quantidade de kits montados.

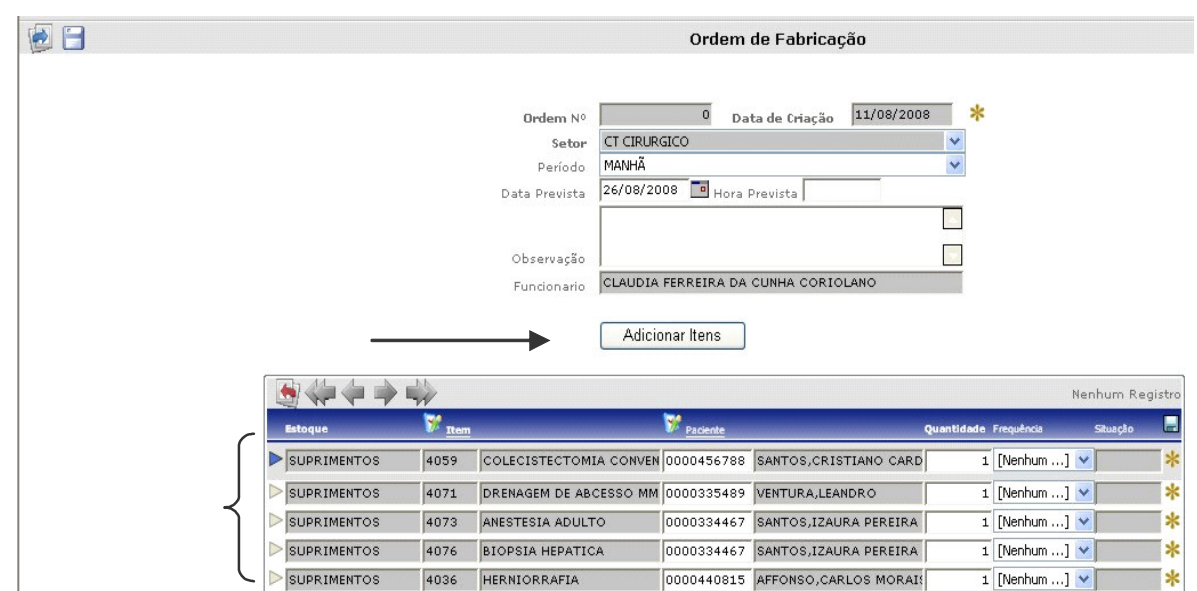

Observação: É opcional informar ou não a matrícula do paciente nesta hora da montagem do kit. Pode-se apenas deixar o kit montado e liberá-lo para o paciente no dia da cirurgia. A cada kit gerado, o sistema irá chamar de "Produto" e este terá uma numeração única. 


\section{PESQUISA POR PROCEDIMENTO}

Quando está se montando a solicitação do kit e clica-se em "Adicionar itens", surge uma tela de pesquisa por procedimento. Basta escolher o estoque: "Suprimentos" e usar os atalhos de busca para se achar o procedimento desejado. Por exemplo, digitando o nome parcial do procedimento, como: DRENA, HERNIO, COLE, etc. O sistema filtra e traz os dados encontrados. Dê um duplo clic no procedimento desejado e pronto!

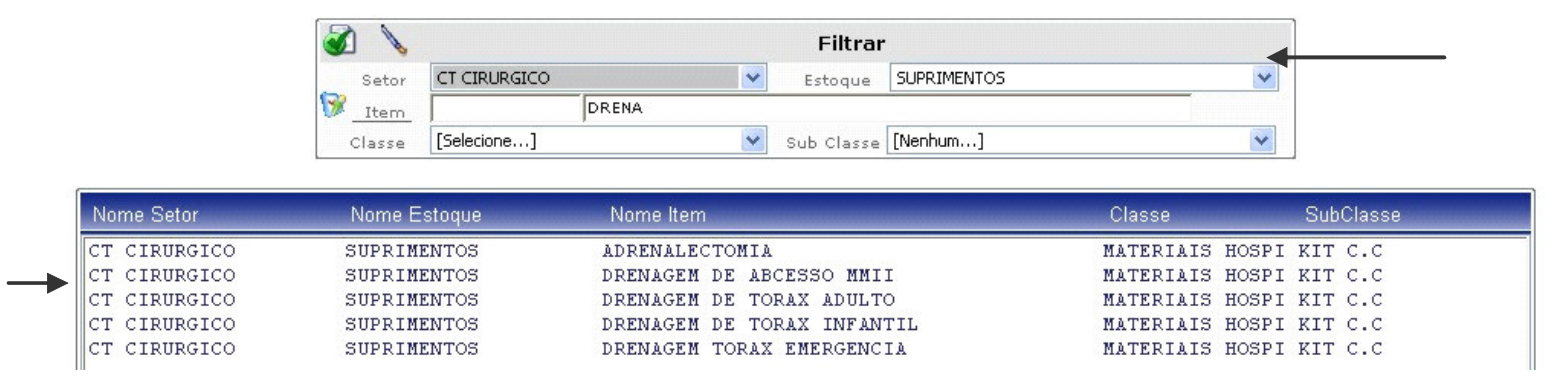

\subsection{1 - Montagem do Kit}

Kit - Vá ao menu Kit, opção Lista. Você verá a lista das solicitações da Solicitaçẫo montagem dos kits.

\section{Lista}

Devoluçẫo

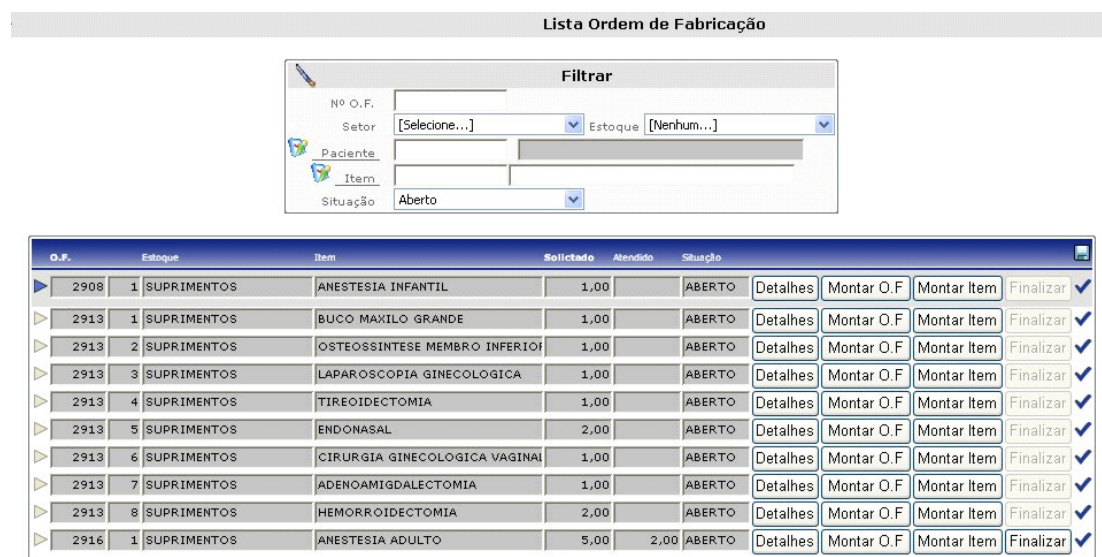

Vamos entender melhor como funciona esta tela.

Botão "Detalhes" - Permite deletar o produto (kit) da lista. Clica-se na linha desejada (ficando setada em azul) e depois no ícone de "exclusão de registro". Salve as alterações e pronto.

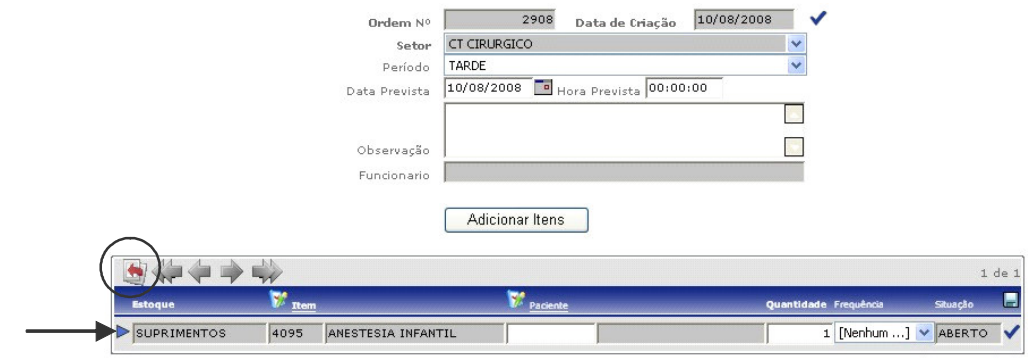


Botão O.F. (Ordem de Fabricação) - Permite a montagem simultânea de vários kits. Quando se salva a montagem de um determinado kit, o sistema já exibe na tela o próximo procedimento que deverá ser montado o kit, daquela ordem de fabricação.

\section{Passos para o preenchimento da tela de montagem dos kits:}

1. Selecionar setor: Centro Cirúrgico;

2. Selecionar estoque: Suprimentos;

3. O sistema informa o saldo total do item no estoque;

4. O sistema sugere uma quantidade para a montagem do kit;

5. O usuário preenche a quantidade desejada no retângulo em branco;

6. Se desejar, o usuário pode substituir determinado item, basta clicar no botão "Substituir";

7. O usuário deverá salvar essa tela. Ao salvar, o sistema emite uma etiqueta, gerando o número do kit (produto) montado. Cola-se a etiqueta na caixa, identificando-o.

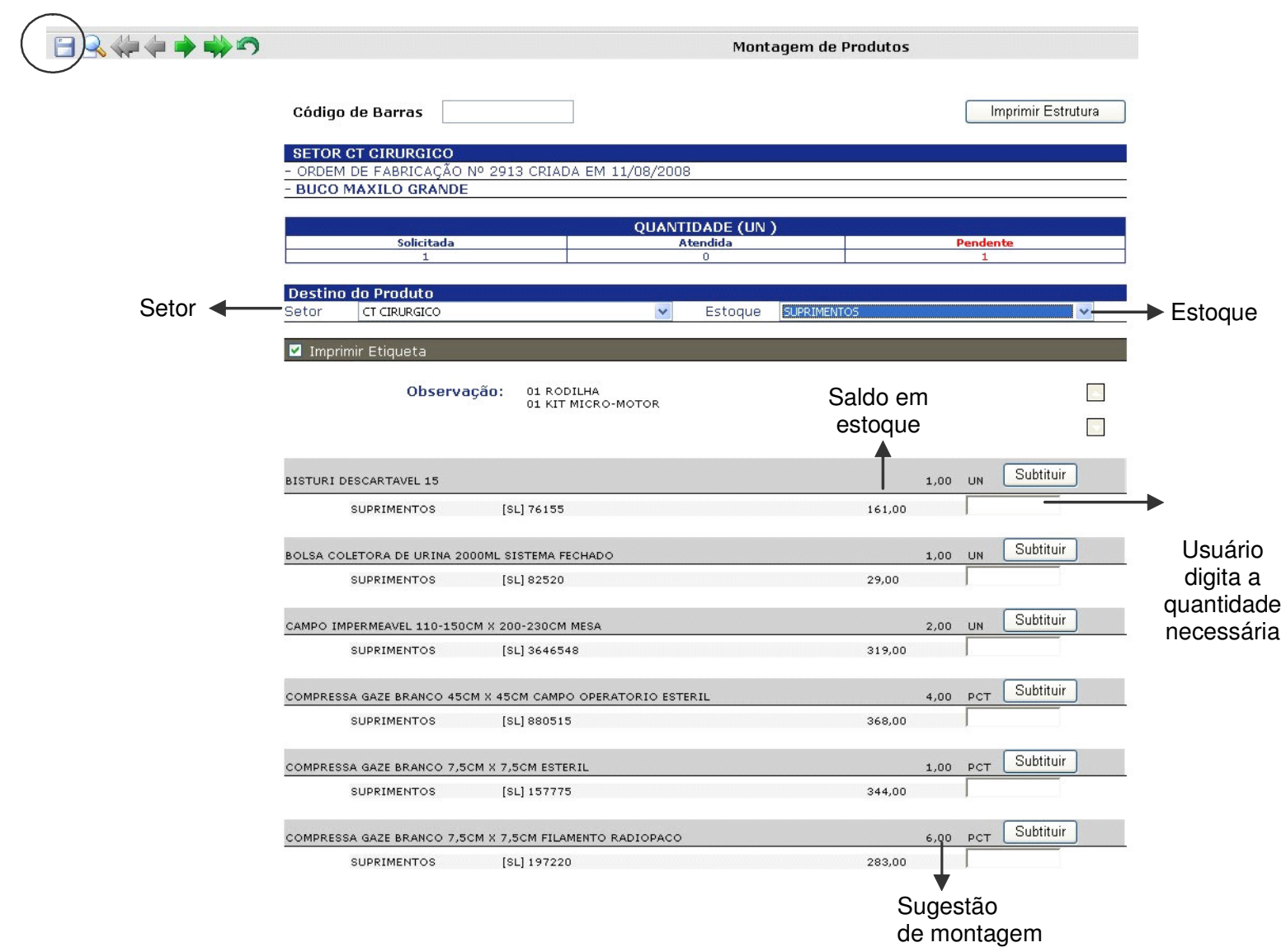

Montar Item - Permite a montagem de um único kit. Seguem os mesmos passos da montagem da OF, porém é para somente um procedimento. Sempre salve no final as alterações. O sistema gera uma etiqueta do kit (produto), que deverá ser colada na caixa correspondente.

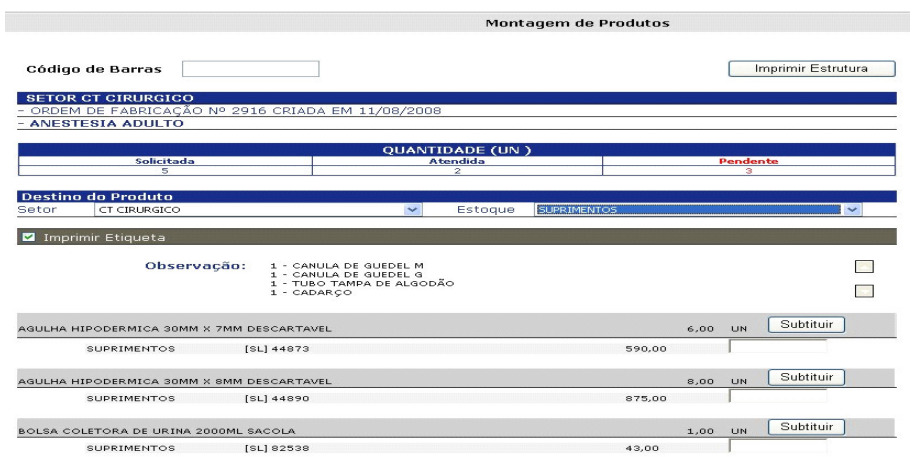


Finaliza - Exclui uma sequência de um determinado produto (kit) que esteja em andamento.

Como exemplo, temos a situação da tela abaixo. Existem previamente criados 10 produtos (kits) de ANESTESIA ADULTO. Foram fornecidos 4 produtos (kits). A situação dos produtos restantes (6 kits) continua em "aberto".

Caso queira encerrar esse andamento do sistema (ou seja, excluir os 6 produtos restantes de Anestesia Adulto), basta clicar no botão "Finalizar" que este cadastro some da tela.

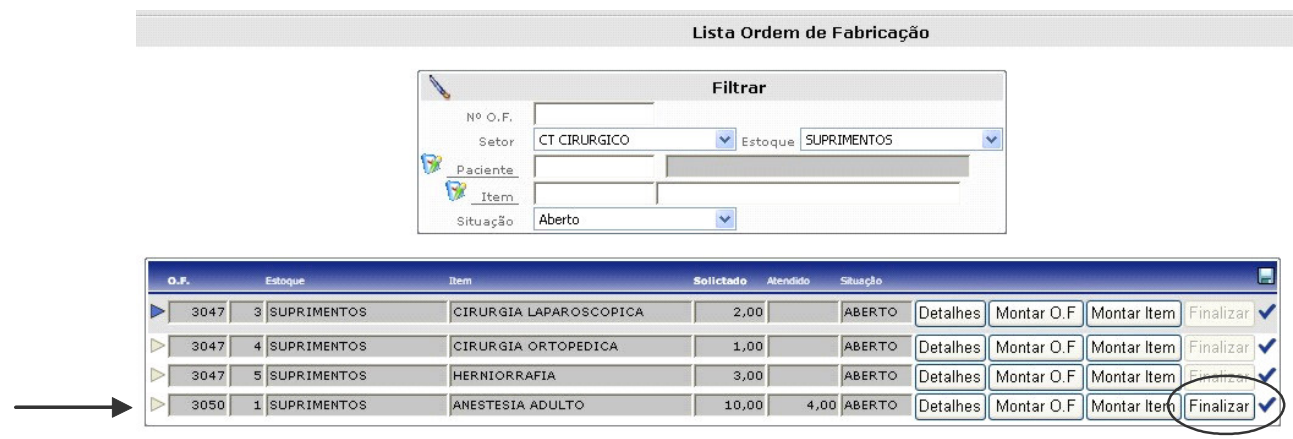

\subsection{2 - Devolução total ou parcial do Kit (produto)}

Se caso a cirurgia for suspensa, pode-se estornar todo o kit, que fica disponível e já montado para um próximo procedimento.

Também pode acontecer de todo o material que compõe o kit não ser usado na cirurgia. Assim o usuário informa ao sistema quais foram os itens que "sobraram" na caixa, dando entrada no sistema como devolução.

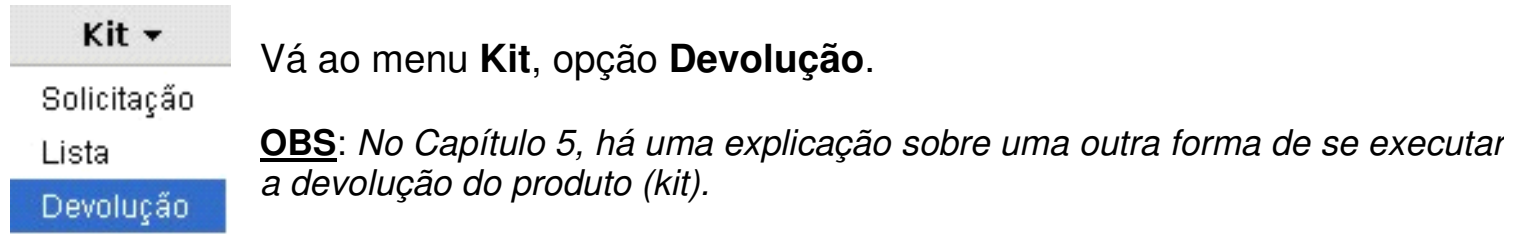

\section{Informe:}

1) Setor: Centro Cirúrgico

2) Estoque: Suprimentos

3) O número do produto (kit) ou da O.F.

4) Digite a quantidade devolvida e salve.

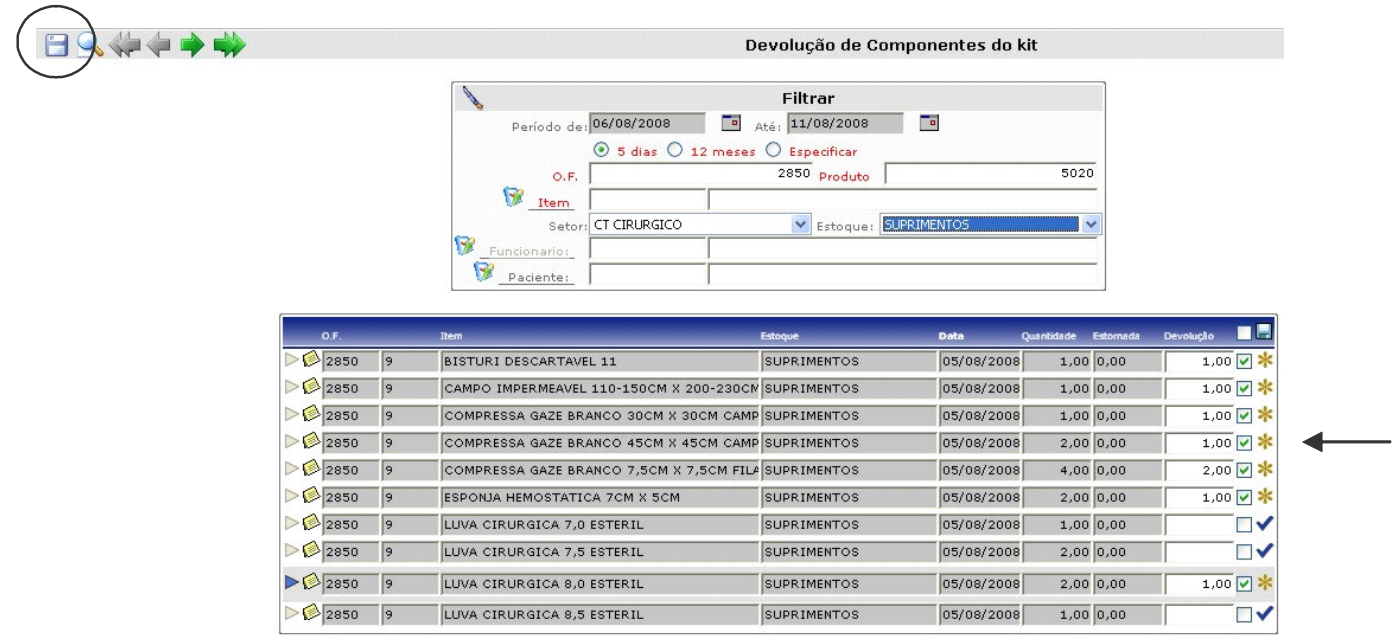


Manual SGM - Centro Cirúrgico

\subsection{3 - Manutenção do Produto (kit)}

Permite a inclusão de itens num produto (kit) já montado.

Vá ao menu Estoque / Itens / Baixa / Baixa Item.

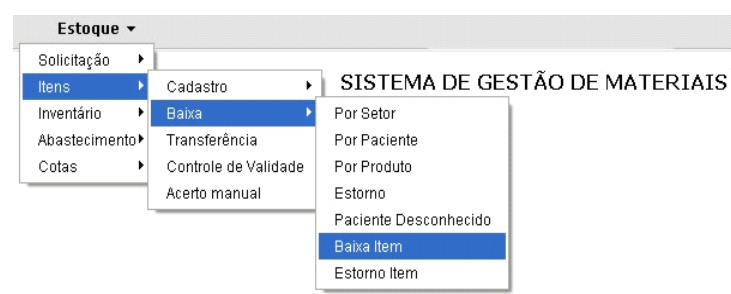

\section{Passos para inclusão do item no Kit:}

1. Selecionar o Setor (no caso, Centro Cirúrgico);

2. Selecionar estoque suprimentos;

3. Clicar no quadradinho Manutenção;

4. Digitar o número do item a ser inserido no kit ou realizar a busca pelo nome e ENTER;

5. Digitar o número do produto (kit) a ser inserido no item;

6. Digitar a quantidade desejada e salvar.

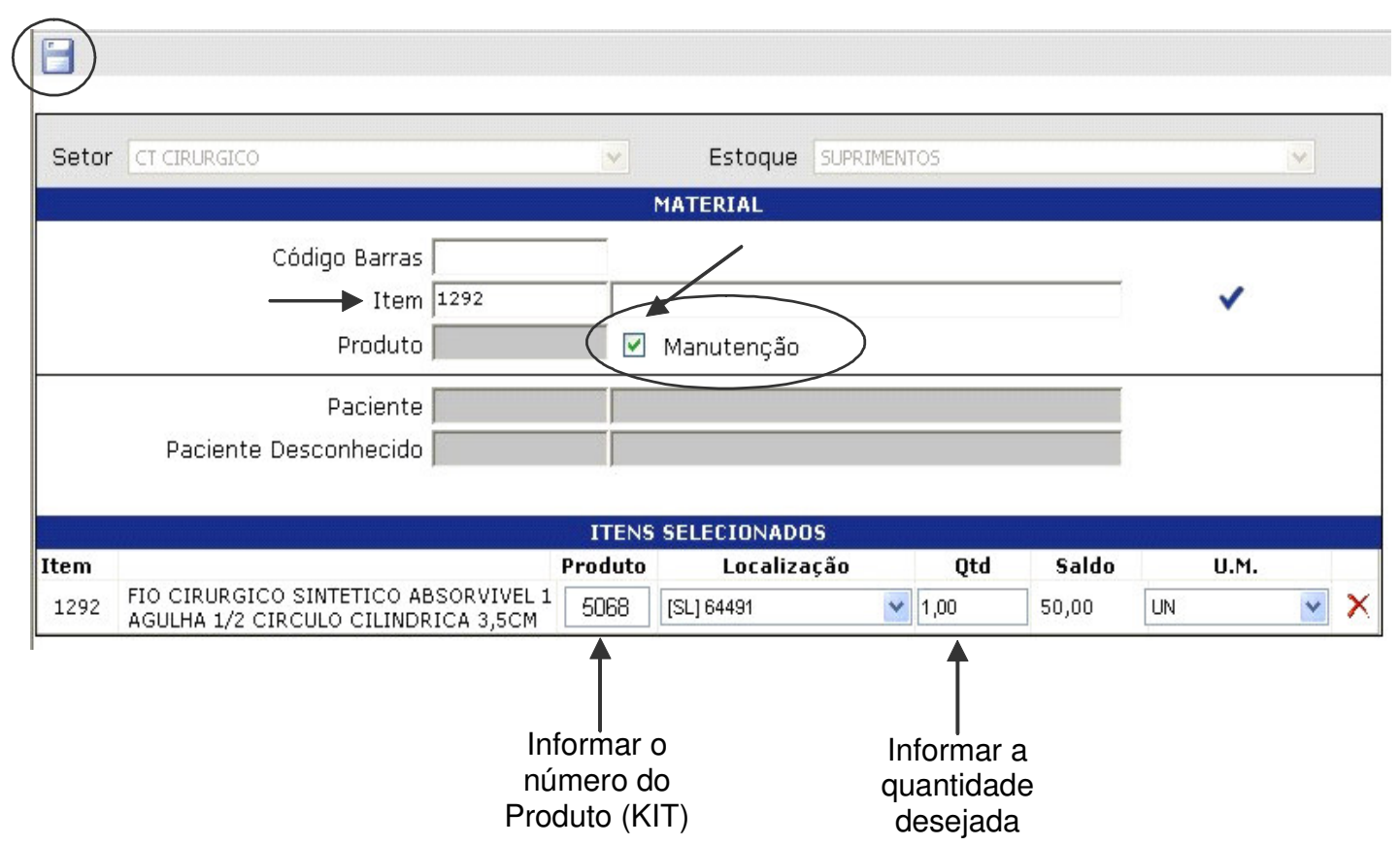


Manual SGM - Centro Cirúrgico

\section{CAPÍtUlo 3: FoRneCIMENTO de KIT CIRÚRGICO E ANESTÉSICO (ESTOQUE SUPRIMENTOS)}

\section{1 - Descrição}

Neste capítulo, vamos aprender como se realiza a distribuição dos kits cirúrgicos e anestésicos, produzidos pelo estoque suprimentos do setor Centro Cirúrgico.

\section{2 - A quem se destina}

\begin{tabular}{|c|c|}
\hline Perfil & Função no sistema \\
\hline Administrativos e técnicos em geral & Fornece / Consulta / Baixa \\
\hline
\end{tabular}

\section{3 - Como fazer}

Para se fornecer kits cirúrgicos e anestésicos, vá ao módulo SGM.

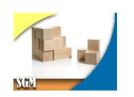

Vá ao menu Estoque / Itens /

Baixa / Baixa Item, conforme mostra a imagem ao lado.

\section{Passos da tela de baixa do kit:}

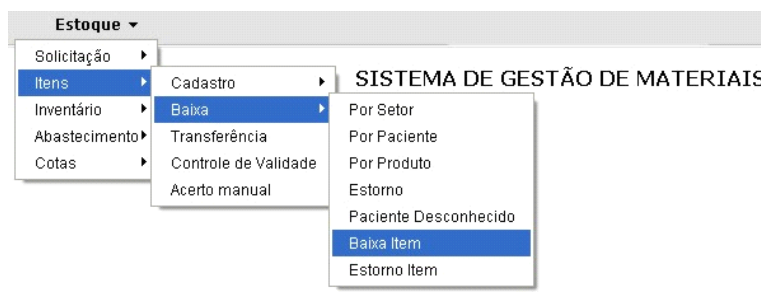

1. Selecionar o setor (no caso, Centro Cirúrgico);

2. Selecionar de qual estoque do Centro Cirúrgico este kit está saindo (no caso, de suprimentos);

3. Informar o número do produto (kit) criado no SGM, na linha "Produto". Pode ser fornecido mais que um kit por paciente, conforme ilustra a imagem abaixo;

4. Informar a matrícula do paciente, ao qual irá utilizar o (s) kit (s) solicitado (s). O sistema traz como quantidade, padrão "01" kit (adulto, anestésico, infantil, etc). Se necessário, alterar a quantidade. Salve as informações, clicando no disquete.

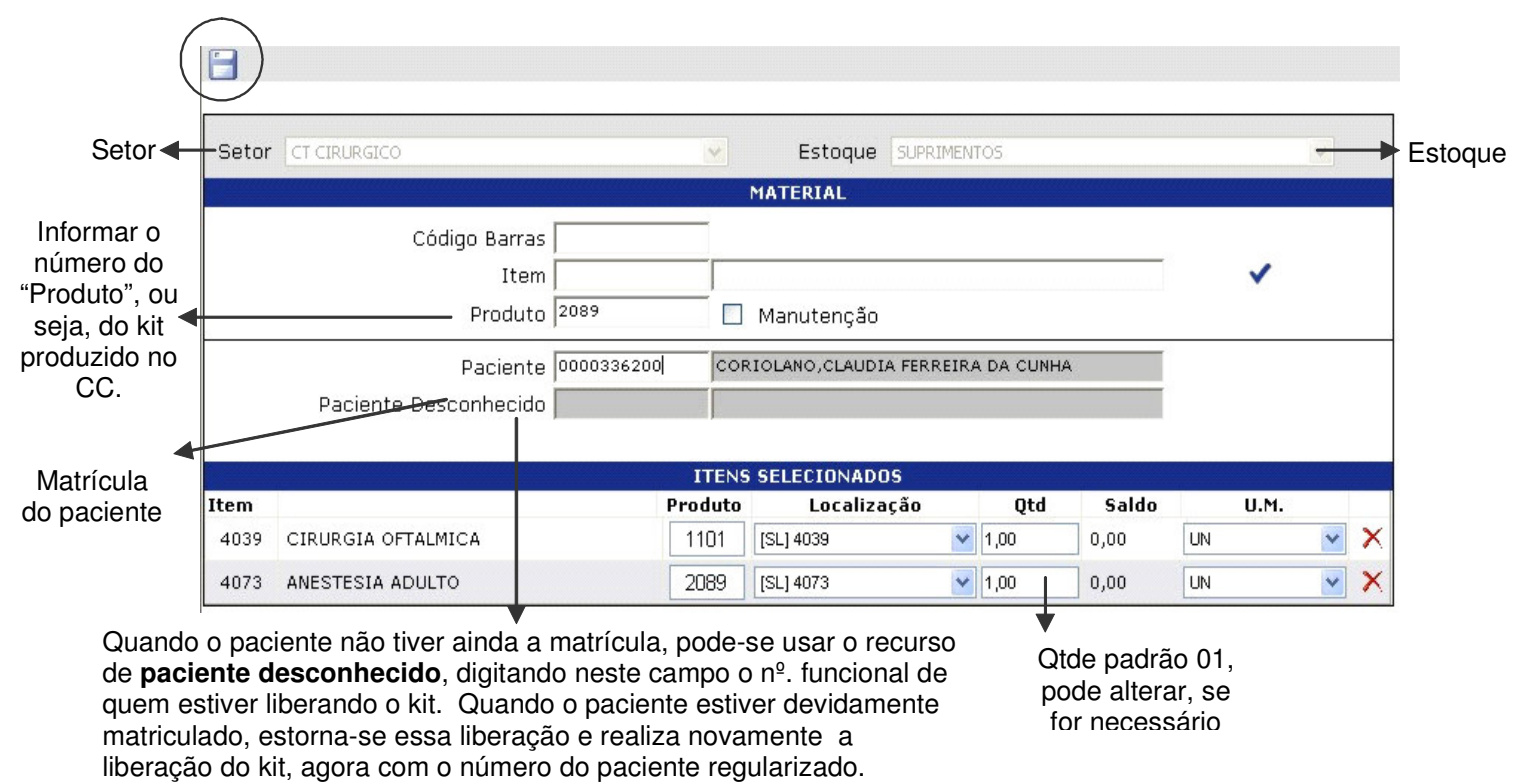


Manual SGM - Centro Cirúrgico

\section{CAPítulo 4: Fornecimento de ITEM AVULSO (eStOQUe SUPRIMENTOS E RECUPERAÇÃo)}

\section{1 - Descrição}

Neste capítulo, vamos aprender como se realiza a distribuição e a baixa do item que é solicitado no balcão do estoque suprimentos do setor Centro Cirúrgico.

\section{2 - A quem se destina}

\begin{tabular}{|c|c|}
\hline Perfil & Função no sistema \\
\hline Administrativos e técnicos em geral & Fornece / Consulta / Baixa \\
\hline
\end{tabular}

\section{3 - Como fazer}

Para se fornecer materiais cirúrgicos avulsos, vá ao módulo SGM.

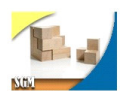

\section{Vá ao menu Estoque / Itens \\ / Baixa / Baixa Item, conforme mostra a imagem ao lado.}

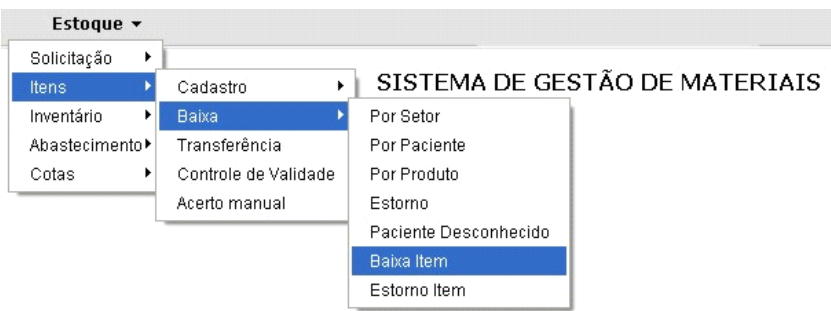

\section{Passos da tela de baixa:}

1. Selecionar o Setor (no caso, Centro Cirúrgico);

2. Selecionar de qual estoque do Centro Cirúrgico este material está saindo (suprimentos ou recuperação);

3. Informar o número do item cadastrado no SGM ou realizar uma busca pelo seu nome;

4. Informar a matrícula do paciente, que será utilizado para o(s) item(s) solicitado(s);

5. O sistema traz como quantidade, padrão "01" (unidade, pacote, etc.). Se necessário alterar a quantidade. Salve as informações, clicando no disquete.

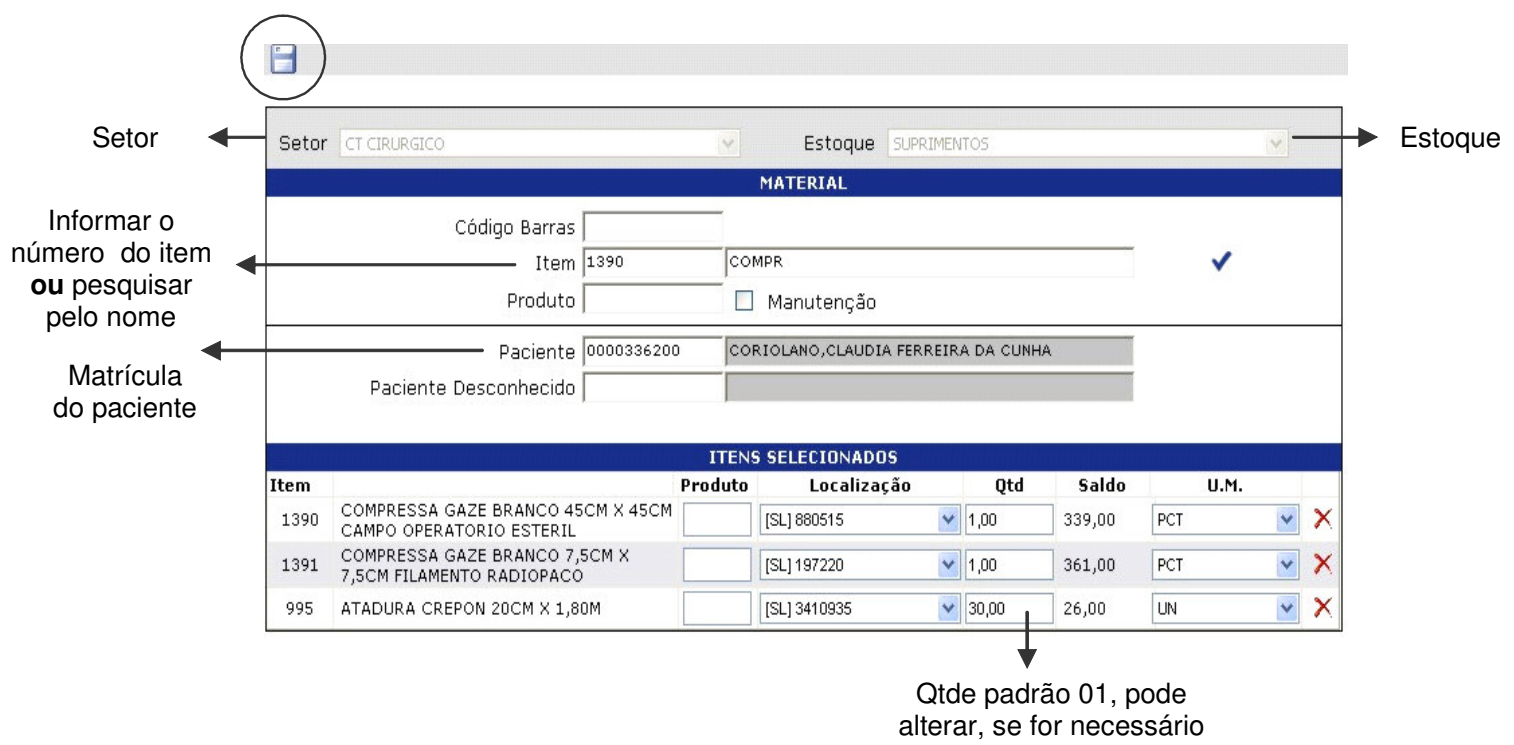




\section{Capítulo 5: Devolução de Kit (estoque suprimentos)}

\section{1 - Descrição}

Neste capítulo, vamos aprender como se realiza a devolução dos materiais que tiveram a cirurgia suspensa ou que restaram nos kits cirúrgicos e anestésicos, produzidos pelo estoque suprimentos do setor Centro Cirúrgico.

\section{2- A quem se destina}

\begin{tabular}{|c|c|}
\hline Perfil & Função no sistema \\
\hline Administrativos e técnicos em geral & Consulta / Baixa \\
\hline
\end{tabular}

\section{3 - Como fazer}

Para a devolução de materiais cirúrgicos dos kits, vá ao módulo SGM.

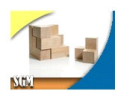

\section{Vá ao menu Estoque / Itens / Baixa / Estorno Item.}

\section{Passos da tela de estorno:}

1. Selecionar o Setor;

2. Selecionar o estoque do Centro

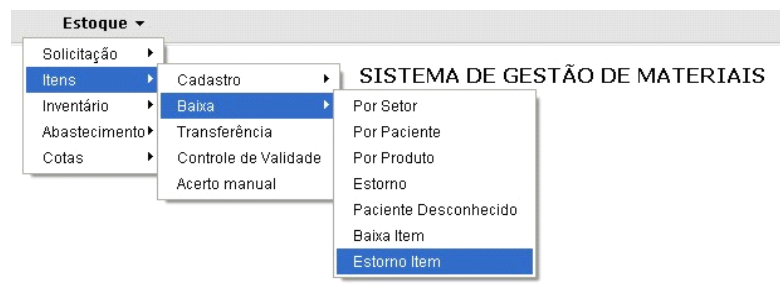

Cirúrgico, para o qual os materiais que restaram no kit estão voltando (no caso, suprimentos); 3. Informar o número do produto gerado (kit) no SGM ou a matrícula do paciente. Se você informar o número do kit, os itens avulsos não aparecerão na tela. A melhor opção é a matrícula do paciente, assim aparece tudo que foi criado e pedido para ele!!;

4. O sistema exibe, nos últimos 30 dias, o que foi gerado para o paciente em questão. Se necessário, mude o período de "Data de" e "até";

5. A tela exibe 4 tipos de cores de linhas. As linhas amarelas claras são os kits produzidos para aquele determinado procedimento. As linhas amarelas escuras significam que aquele Produto não foi consumido, podendo voltar o kit inteiro ao estoque. As linhas, com fundo cinza e branco, representam itens que foram solicitados de forma avulsa para a cirurgia.

6. Basta digitar o número da quantidade do item que voltou. Seja por kit ou avulso. Salve as informações, clicando no disquete.

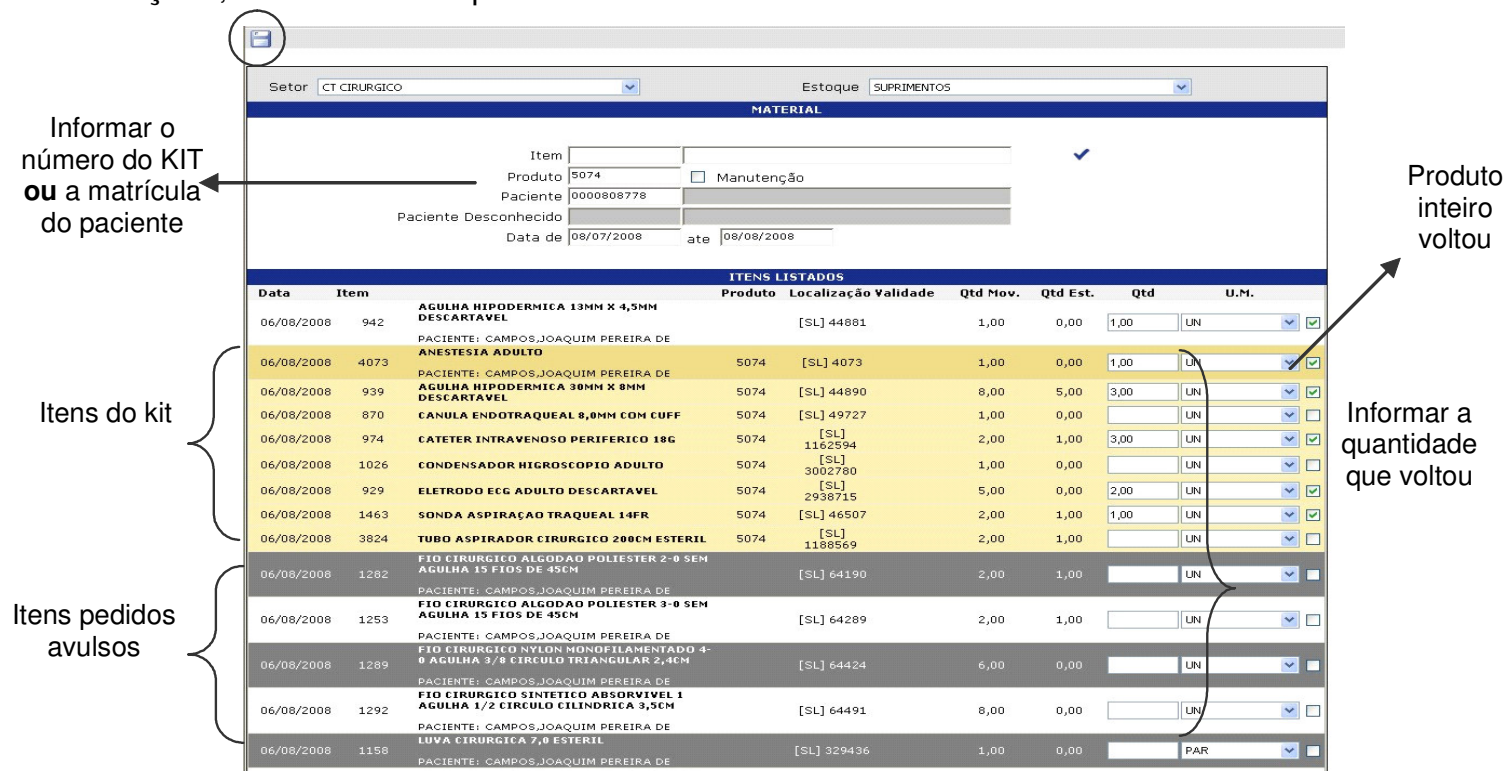


Manual SGM - Centro Cirúrgico

\section{Capítulo 6: DeVoluÇão de ITEM AVULSo (estoque suprimentos e ReCUPERAÇÃo)}

\section{1 - Descrição}

Neste capítulo, vamos aprender como se realiza a devolução dos materiais que foram solicitados de forma avulsa para o estoque Suprimentos e Recuperação do setor Centro Cirúrgico.

\section{2 - A quem se destina}

\begin{tabular}{|c|c|}
\hline Perfil & Função no sistema \\
\hline Administrativos e técnicos em geral & Consulta / Baixa \\
\hline
\end{tabular}

\section{3 - Como fazer}

Para a devolução de materiais cirúrgicos avulsos, vá ao módulo SGM.

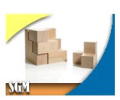

Vá ao menu Estoque /

Itens / Baixa / Estorno

Item, conforme mostra a imagem ao lado.

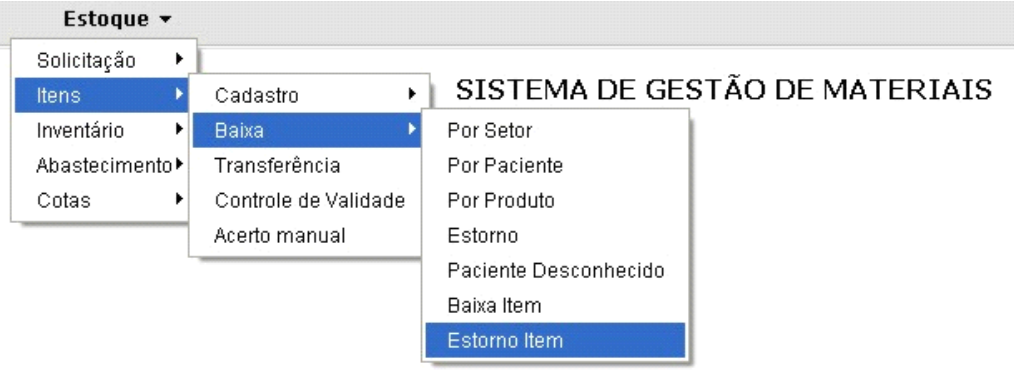

\section{Passos da tela de estorno:}

1. Selecionar o Setor (no caso, Centro Cirúrgico);

2. Selecionar o estoque do Centro Cirúrgico, para o qual os materiais estão voltando (no caso, Suprimentos ou Recuperação);

3. Informar o número do item no SGM e a matrícula do paciente;

4. O sistema exibe, nos últimos 30 dias, o que foi gerado para o paciente em questão. Se necessário, mude o período de "Data de" e "até";

5. Basta digitar o número da quantidade do item que voltou. Salve as informações, clicando no disquete.

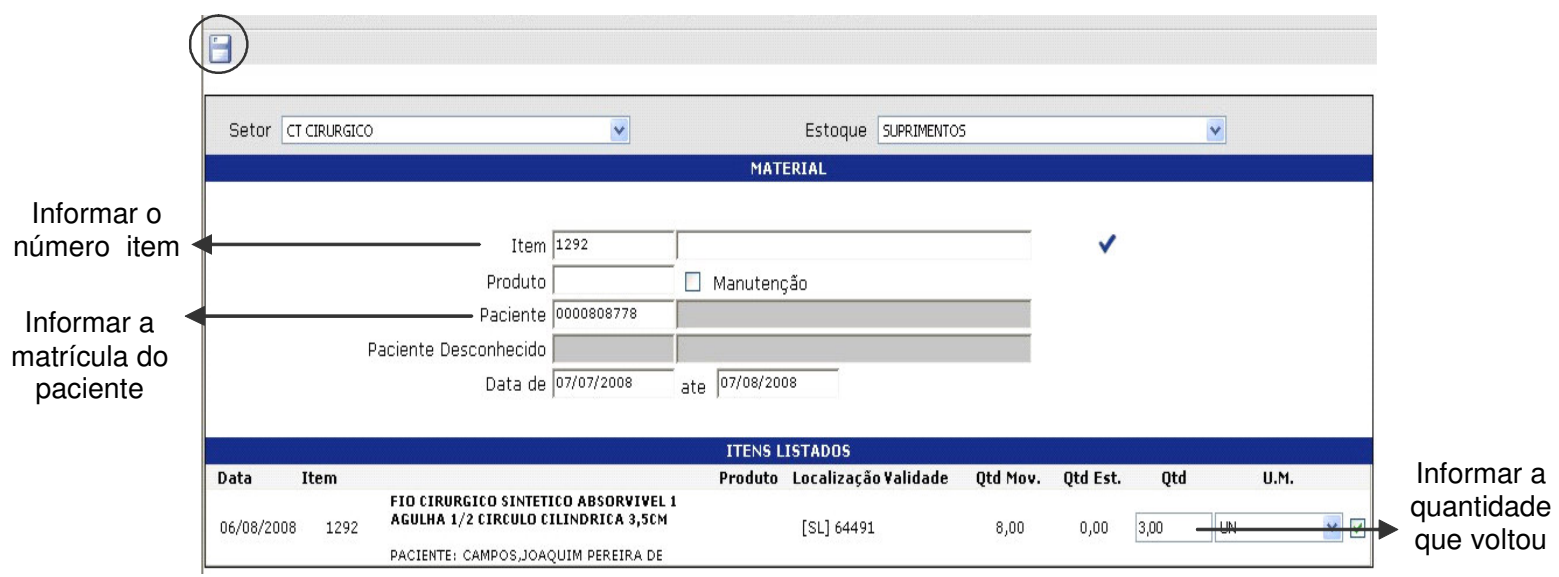




\section{Anexo 2 - Relação de materiais e seus custos unitários}

\begin{tabular}{|c|c|}
\hline NOME DO ITEM & $\begin{array}{l}\text { VALOR } \\
\text { UNITÁRIO }\end{array}$ \\
\hline ABSORVENTE HIGIÊNICO 10CM X 37CM TIPO HOSPITALAR & 4,38 \\
\hline ADESIVO TISSULAR 0,5ML & 70,99 \\
\hline ÁGUA DESTILADA 2.000ML ESTÉRIL COM TAMPA TWIST OFF & 4,39 \\
\hline ÁGUA DESTILADA 250ML ESTÉRIL COM TAMPA TWIST OFF & 0,69 \\
\hline ÁGUA OXIGENADA SOLUÇÃO 10 VOL 100ML & 0,75 \\
\hline AGULHA BIÓPSIA HEPÁTICA 18G X 16CM & 70,11 \\
\hline AGULHA BIÓPSIA HEPATICA 20G X 16CM & 70,11 \\
\hline AGULHA HIPODÉRMICA 13MM X 4,5MM DESCARTÁVEL & 0,06 \\
\hline AGULHA HIPODÉRMICA 20MM X 5MM DESCARTÁVEL & 0,11 \\
\hline AGULHA HIPODÉRMICA 25MM X 6MM DESCARTÁVEL & 0,09 \\
\hline AGULHA HIPODÉRMICA 30MM X 7MM DESCARTÁVEL & 0,06 \\
\hline AGULHA HIPODÉRMICA 30MM X 8MM DESCARTÁVEL & 4,14 \\
\hline AGULHA ODONTOLÓGICA 27G & 0,22 \\
\hline AGULHA ODONTOLÓGICA 30G & 0,19 \\
\hline AGULHA PUNÇÃO LOMBAR 25G X 3 1/2"/0,5MM X 89MM BISEL TIPO PONTA DE LÁPIS & 12,85 \\
\hline AGULHA PUNÇÃO LOMBAR 27G X 3 1/2"/0,4MM X 89MM BISEL TIPO PONTA DE LÁPIS & 14,99 \\
\hline AGULHA PUNÇÃO LOMBAR 27G X 411/16"/0,4MM X 11,9MM BISEL TIPO PONTA DE LÁPIS & 20,89 \\
\hline AGULHA VERESS 14G X 120MM PNEUMOPERITONEO & 87,00 \\
\hline ALG. HIDRÓFILO C/ 500G & 4,42 \\
\hline ALGODÃO HIDRÓFILO BRANCO 5CM X 6CM FORMATO QUADRADO & 2,09 \\
\hline ATADURA ALGODÃO ORTOPÉDICO 10CM X 1,80M & 0,18 \\
\hline ATADURA ALGODÃO ORTOPÉDICO 15CM X 1,80M & 0,28 \\
\hline ATADURA ALGODÃO ORTOPÉDICO 20CM X 1,80M & 0,30 \\
\hline ATADURA ALGODÃO ORTOPÉDICO 6CM X 1,80M & 0,12 \\
\hline ATADURA BORRACHA 06CM FAIXA DE SMARCH & 10,69 \\
\hline ATADURA BORRACHA 10CM FAIXA DE SMARCH & 1,04 \\
\hline ATADURA BORRACHA 15CM FAIXA DE SMARCH & 19,61 \\
\hline ATADURA CREPON 15CM X 1,80M & 0,42 \\
\hline ATADURA CREPON 20CM X 1,80M & 0,57 \\
\hline ATADURA CREPON 25CM X 1,80M & 0,80 \\
\hline ATADURA CREPON $6 \mathrm{CM} \times 1,80 \mathrm{M}$ & 0,15 \\
\hline ATADURA ELÁSTICA 5CM X 4,50M ADESIVA & 27,28 \\
\hline ATADURA GESSADA 10CM X 3,0M & 0,54 \\
\hline ATADURA GESSADA $15 \mathrm{CM} \times 3,0 \mathrm{M}$ & 1,03 \\
\hline ATADURA GESSADA 20CM X 3,0M & 1,37 \\
\hline ATADURA GESSADA 6CM X 3,0M & 0,42 \\
\hline ATADURA RAYON 7CM X 20CM & 0,65 \\
\hline ATADURA RAYON 7CM X 50CM & 0,90 \\
\hline ATADURA RAYON 7CM X 5,0M & 1,48 \\
\hline ATROPINA INJETÁVEL 0,50MG/ML 1ML & 0,26 \\
\hline AVENTAL CIRÚRGICO EXTRAGRANDE ULTRA PROTEÇÃO & 18,00 \\
\hline BANDAGEM ELÁSTICA AZUL 5CM X 450CM & 13,18 \\
\hline BASKET 2,4FR X 115CM RETIRADA DE CALCULO BILIAR & $1.845,45$ \\
\hline BISTURI DESCARTÁVEL 11 & 3,32 \\
\hline BISTURI DESCARTÁVEL 15 & 3,30 \\
\hline BISTURI DESCARTÁVEL 23 & 3,30 \\
\hline BOLSA COLETORA DE URINA 2.000ML SACOLA & 0,18 \\
\hline BOLSA COLETORA DE URINA 2.000ML SISTEMA FECHADO & 17,37 \\
\hline CADARÇO ALGODÃO HIPOALERGÊNICO BRANCA 5MM LARGURA APRESENTANDO EM ROLO COM 10M & 1,95 \\
\hline CAMPO CIRÚRGICO 60CM X 36CM IODOFORADO & 512,21 \\
\hline CAMPO CIRÚRGICO 90CM X 45CM IODOFORADO & 832,00 \\
\hline CAMPO IMPERMEÁVEL 110-150CM X 200-230CM MESA & 5,09 \\
\hline CANETA MARCAÇÃO DE VARIZES PRETA & 17,11 \\
\hline CÂNULA ENDOBRONQUIAL 35 TIPO ROBERT SHAW LADO ESQUERDO & 225,17 \\
\hline CÂNULA ENDOBRONQUIAL 37 TIPO ROBERT SHAW LADO ESQUERDO & 215,93 \\
\hline CÂNULA ENDOTRAQUEAL ARAMADA 4,0MM COM CUFF & 35,00 \\
\hline CÂNULA ENDOTRAQUEAL ARAMADA 4,5MM COM CUFF & 53,90 \\
\hline
\end{tabular}




\begin{tabular}{|c|c|}
\hline NOME DO ITEM & $\begin{array}{l}\text { VALOR } \\
\text { UNITÁRIO }\end{array}$ \\
\hline CÂNULA ENDOTRAQUEAL ARAMADA 5,0MM COM CUFF & 47,33 \\
\hline CÂNULA ENDOTRAQUEAL ARAMADA 5,5MM COM CUFF & 25,42 \\
\hline CÂNULA ENDOTRAQUEAL ARAMADA 6,0MM COM CUFF & 24,87 \\
\hline CÂNULA ENDOTRAQUEAL ARAMADA 6,5MM COM CUFF & 28,08 \\
\hline CÂNULA ENDOTRAQUEAL 2,5MM SEM CUFF & 3,42 \\
\hline CÂNULA ENDOTRAQUEAL 3,0MM COM CUFF & 13,00 \\
\hline CÂNULA ENDOTRAQUEAL 3,0MM SEM CUFF & 3,41 \\
\hline CÂNULA ENDOTRAQUEAL 3,5MM COM CUFF & 5,95 \\
\hline CÂNULA ENDOTRAQUEAL 3,5MM SEM CUFF & 3,84 \\
\hline CÂNULA ENDOTRAQUEAL 4,0MM COM CUFF & 6,50 \\
\hline CÂNULA ENDOTRAQUEAL 4,0MM SEM CUFF & 3,88 \\
\hline CÂNULA ENDOTRAQUEAL 4,5MM COM CUFF & 5,99 \\
\hline CÂNULA ENDOTRAQUEAL 4,5MM SEM CUFF & 3,48 \\
\hline CÂNULA ENDOTRAQUEAL 5,0MM COM CUFF & 3,76 \\
\hline CÂNULA ENDOTRAQUEAL 5,0MM SEM CUFF & 3,77 \\
\hline CÂNULA ENDOTRAQUEAL 5,5MM COM CUFF & 3,10 \\
\hline CÂNULA ENDOTRAQUEAL 5,5MM SEM CUFF & 3,15 \\
\hline CÂNULA ENDOTRAQUEAL 6,0MM COM CUFF & 2,95 \\
\hline CÂNULA ENDOTRAQUEAL 6,0MM SEM CUFF & 3,12 \\
\hline CÂNULA ENDOTRAQUEAL 6,5 COM CUFF & 3,14 \\
\hline CÂNULA ENDOTRAQUEAL 6,5MM SEM CUFF & 3,20 \\
\hline CÂNULA ENDOTRAQUEAL 7,0MM ARAMADA COM CUFF & 33,61 \\
\hline CÂNULA ENDOTRAQUEAL 7,0MM COM CUFF & 2,21 \\
\hline CÂNULA ENDOTRAQUEAL 7,0MM SEM CUFF & 4,47 \\
\hline CÂNULA ENDOTRAQUEAL 7,5MM ARAMADA COM CUFF & 28,21 \\
\hline CÂNULA ENDOTRAQUEAL 7,5MM COM CUFF & 2,25 \\
\hline CÂNULA ENDOTRAQUEAL 8,0MM ARAMADA COM CUFF & 28,10 \\
\hline CÂNULA ENDOTRAQUEAL 8,0MM COM CUFF & 3,14 \\
\hline CÂNULA ENDOTRAQUEAL 8,5MM ARAMADA COM CUFF & 31,15 \\
\hline CÂNULA ENDOTRAQUEAL 8,5MM COM CUFF & 2,28 \\
\hline CÂNULA ENDOTRAQUEAL 9,0MM COM CUFF & 6,86 \\
\hline CÂNULA TRAQUEOSTOMIA 7,0MM DESCARTÁVEL COM CUFF & 37,70 \\
\hline CÂNULA TRAQUEOSTOMIA 8,0 DESCARTÁVEL COM CUFF & 26,22 \\
\hline CÂNULA TRAQUEOSTOMIA 9,0MM DESCARTÁVEL COM CUFF & 44,20 \\
\hline CAPA LAPAROSCÓPIO ESTÉRIL & 2,80 \\
\hline CARGA GRAMPO GRAMPEADOR CURVO 40MM RECARREGÁVEL & $1.200,00$ \\
\hline CARGA GRAMPO GRAMPEADOR LINEAR RECARREGÁVEL 55MM & 273,00 \\
\hline CARGA GRAMPO GRAMPEADOR LINEAR RECARREGÁVEL 75MM & 281,63 \\
\hline CARGA GRAMPO GRAMPEADOR LINEAR 45MM TECIDO VASCULAR & 950,00 \\
\hline CATETER COLANGIOGRAFIA 5 FRX50CM & 123,75 \\
\hline CATETER EMBOLECTOMIA ARTERIAL 3FR X 80CM TIPO FOGARTY & 96,33 \\
\hline CATETER EMBOLECTOMIA ARTERIAL 4FR X 80CM TIPO FOGARTY & 104,00 \\
\hline CATETER EMBOLECTOMIA ARTERIAL 5FR X 80CM TIPO FOGARTY & 96,33 \\
\hline CATETER INTRAVENOSO CENTRAL 16G X 30,5CM MONOLÚMEN & 26,60 \\
\hline CATETER INTRAVENOSO CENTRAL 16G X 61CM MONOLÚMEN & 9,70 \\
\hline CATETER INTRAVENOSO CENTRAL 19G X 30,5CM MONOLÚMEN & 25,65 \\
\hline CATETER INTRAVENOSO CENTRAL 7FR X 20CM DUPLO LÚMEN & 62,00 \\
\hline CATETER INTRAVENOSO CENTRAL 7FR X 20CM TRIPLO LÚMEN & 90,00 \\
\hline CATETER INTRAVENOSO PERIFÉRICO 14G & 2,92 \\
\hline CATETER INTRAVENOSO PERIFÉRICO 16G & 1,68 \\
\hline CATETER INTRAVENOSO PERIFÉRICO 18G & 1,73 \\
\hline CATETER INTRAVENOSO PERIFÉRICO 20G & 1,76 \\
\hline CATETER INTRAVENOSO PERIFÉRICO 22G & 2,86 \\
\hline CATETER INTRAVENOSO PERIFÉRICO 24G & 7,42 \\
\hline CATETER NASAL OXIGÊNIO ADULTO TIPO ÓCULOS & 0,66 \\
\hline CERA PARA OSSO 2,5 GRAMAS & 7,50 \\
\hline CICLOPENTOLATO COLÍRIO 1\% 3ML CONTROLADO & 5,72 \\
\hline CLIP LAQUEAÇÃO MECÂNICA GRANDE LIGA CLIP & 60,17 \\
\hline CLIPS LIGADURA VASCULAR 10MM & 221,48 \\
\hline CLIPS LIGADURA VASCULAR 17MM & 275,00 \\
\hline CLIPS LIGADURA VASCULAR 7MM & 221,48 \\
\hline CLOREXIDINA ALCOÓLICA SOLUÇÃO 0,5\% 100ML & 2,15 \\
\hline
\end{tabular}




\begin{tabular}{|c|c|}
\hline NOME DO ITEM & $\begin{array}{l}\text { VALOR } \\
\text { UNITÁRIO }\end{array}$ \\
\hline CLOREXIDINA DEGERMANTE SOLUÇÃO 2\% 100ML & 1,97 \\
\hline COLETOR ARTIGO DESCARTÁVEL 3 LITROS & 1,35 \\
\hline COLETOR ARTIGO DESCARTÁVEL 7 LITROS & 1,62 \\
\hline COLETOR UNIVERSAL ESTÉRIL DESCARTÁVEL, TAMPA VERMELHA & 0,18 \\
\hline COLETOR UNIVERSAL NÃO-ESTÉRIL DESCARTÁVEL, TAMPA BRANCA & 0,15 \\
\hline COLETOR URINA INFANTIL UNISSEX & 0,30 \\
\hline COMPRESSA GAZE BRANCO 15CM X 10CM ESTÉRIL & 0,77 \\
\hline COMPRESSA GAZE BRANCO 30CM X 30CM CAMPO OPERATÓRIO & 4,79 \\
\hline COMPRESSA GAZE BRANCO 45CM X 45CM CAMPO OPERATÓRIO ESTÉRIL & 7,18 \\
\hline COMPRESSA GAZE BRANCO 7,5CM X 6CM OCULAR & 0,70 \\
\hline COMPRESSA GAZE BRANCO 7,5CM X 7,5CM ESTÉRIL & 0,25 \\
\hline COMPRESSA GAZE BRANCO 7,5CM X 7,5CM FILAMENTO RADIOPACO & 0,62 \\
\hline COMPRESSA GAZE BRANCO 90CM X 100CM ESTÉRIL & 0,54 \\
\hline CONDENSADOR HIGROSCÓPIO ADULTO & 8,32 \\
\hline CONJUNTO ANESTESIA DE PLEXO 22G X 2"/0,70MM X 50MM & 72,36 \\
\hline CONJUNTO ANESTESIA EPIDURAL AGULHA 16G PU 17G & 52,00 \\
\hline CONJUNTO ANESTESIA EPIDURAL 18G & 28,70 \\
\hline CONJUNTO ANESTESIA RAQUIDIANA/EPIDURAL DUPLO BLOQUEIO & 140,00 \\
\hline CONJUNTO DRENAGEM VESICAL 10 AGULHA 12CM & 81,66 \\
\hline CONJUNTO DRENAGEM VESICAL 10 AGULHA 8CM & 93,00 \\
\hline CONJUNTO DRENAGEM VESICAL 12 COM BALÃO & 166,11 \\
\hline CONJUNTO EXTRATOR DE VARIZES & 30,00 \\
\hline CONJUNTO LENTE INTRA OCULAR & 459,59 \\
\hline CONJUNTO MONITORIZARÃO DE PRESSÃO ARTERIAL & 46,68 \\
\hline CONJUNTO TROCARTE 10/12MM LAPAROSCOPIA & 169,23 \\
\hline CONJUNTO TROCARTE 5MM LAPAROSCOPIA & 171,31 \\
\hline CURATIVO HIDROATIVO 10CM X 10CM & 9,65 \\
\hline CURATIVO HIDROATIVO 10CM X 10CM EXTRA FINO & 11,40 \\
\hline CURATIVO TRAQUEOSTOMIA 9 CMX9CM & 20,69 \\
\hline DEXAMETASONA INJETÁVEL 4 MG/ML 2,5 ML & 4,75 \\
\hline DIATRIZOATO DE MEGLUMINA 60\%20 ML (280 MG/ML DE IODO) & 12,00 \\
\hline DISPOSITIVO INFUSÃO VENOSA 19G & 0,74 \\
\hline DISPOSITIVO INFUSÃO VENOSA 21G & 0,56 \\
\hline DISPOSITIVO INFUSÃO VENOSA 23G & 0,56 \\
\hline DISPOSITIVO INFUSÃO VENOSA 25G & 0,56 \\
\hline DISPOSITIVO INFUSÃO VENOSA 27G & 0,56 \\
\hline DRENO KERR 10 & 36,74 \\
\hline DRENO KERR 12 & 36,74 \\
\hline DRENO KERR 14 & 36,74 \\
\hline DRENO KERR 16 & 36,74 \\
\hline DRENO OTOLÓGICO 1ML X 2,4ML & 90,00 \\
\hline DRENO PENROSE 1 & 0,84 \\
\hline DRENO PENROSE 2 & 1,14 \\
\hline DRENO PENROSE 3 & 1,69 \\
\hline DRENO SUCÇÃO DE FERIDA FECHADA AGULHA 3,2MM & 127,00 \\
\hline DRENO SUCÇÃO DE FERIDA FECHADA AGULHA 4,8MM & 127,00 \\
\hline DRENO SUCÇÃO DE FERIDA FECHADA AGULHA 6,4MM & 127,00 \\
\hline DRENO TÓRAX TUBULAR 20FR PVC & 20,43 \\
\hline DRENO TÓRAX TUBULAR 28FR PVC & 24,50 \\
\hline DRENO TÓRAX TUBULAR 36FR PVC & 24,00 \\
\hline ELETRODO ECG ADULTO DESCARTÁVEL & 0,19 \\
\hline ELETRODO ECG INFANTIL DESCARTÁVEL & 0,19 \\
\hline EPINEFRINA INJETÁVEL 1 MG/ML 1 ML & 0,29 \\
\hline EQUIPO ANESTESIA ENDOVENOSA LIFESHIELD COM SERINGA & 91,50 \\
\hline EQUIPO ANESTESIA ENDOVENOSA LIFESHIELD CONVENCIONAL & 91,50 \\
\hline EQUIPO CISTOSCOPIA & 8,98 \\
\hline EQUIPO EPIDURAL BOMBA APM & 92,00 \\
\hline EQUIPO IRRIGAÇÃO VESICAL 2 VIAS & 8,56 \\
\hline EQUIPO MACROGOTAS & 1,49 \\
\hline EQUIPO MICROGOTAS & 2,15 \\
\hline EQUIPO MICROGOTAS RESERVATÓRIO GRADUADO & 11,05 \\
\hline EQUIPO PARA BOMBA DE ARTROSCOPIA & 475,00 \\
\hline
\end{tabular}




\begin{tabular}{|c|c|}
\hline NOME DO ITEM & $\begin{array}{l}\text { VALOR } \\
\text { UNITÁRIO }\end{array}$ \\
\hline EQUIPO TRANSFUSÃO DE SANGUE CÂMARA DUPLA & 1,36 \\
\hline EQUIPO TRANSFUSÃO DE SANGUE RESERVATÓRIO GRADUADO & 5,70 \\
\hline ESCOVA ASSEPSIA SECA & 0,55 \\
\hline ESPARADRAPO IMPERMEÁVEL BRANCO 10CM X 4,5M & 2,85 \\
\hline ESPARADRAPO RAYON BRANCO 5 CM X 4,5M & 3,30 \\
\hline ESPONJA HEMOSTÁTICA 7CM X 5CM & 107,08 \\
\hline FENILEFRINA COLÍRIO 10\% 5ML & 4,90 \\
\hline FILTRO ANTIMICROBIANO APARELHO ANESTESIA DRAGER & 272,18 \\
\hline FIO CIRÚRGICO AÇO 0 SEM AGULHA 3 FIOS DE 60CM & 3,79 \\
\hline FIO CIRÚRGICO AÇO 1 SEM AGULHA 3 FIOS DE 60CM & 4,40 \\
\hline FIO CIRÚRGICO AÇO 2-0 SEM AGULHA 3 FIOS DE 60CM & 4,42 \\
\hline FIO CIRÚRGICO AÇO 4 AGULHA COM 1/2 CÍRCULO CILÍNDRICA 4,7CM & 18,82 \\
\hline FIO CIRÚRGICO ALGODÃO BRANCO 0,03CM X 0,35CM X 80CM FITA CARDÍACA & 3,69 \\
\hline FIO CIRÚRGICO ALGODÃO POLIÉSTER 0 SEM AGULHA 15 FIOS DE 45 CM & 3,23 \\
\hline FIO CIRÚRGICO ALGODÃO POLIÉSTER 2-0 AGULHA 1/2 CÍRCULO CILÍNDRICA 2,5CM & 2,58 \\
\hline FIO CIRÚRGICO ALGODÃO POLIÉSTER 2-0 SEM AGULHA 15 FIOS DE 45CM & 0,70 \\
\hline FIO CIRÚRGICO ALGODÃO POLIÉSTER 3-0 AGULHA 1/2 CÍRCULO CILÍNDRICA 2,5CM & 3,25 \\
\hline FIO CIRÚRGICO ALGODÃO POLIÉSTER 3-0 SEM AGULHA 15 FIOS DE 45CM & 2,50 \\
\hline FIO CIRÚRGICO ALGODÃO POLIÉSTER 4-0 AGULHA 1/2 CÍRCULO CILÍNDRICA 2,5CM & 3,25 \\
\hline FIO CIRÚRGICO ALGODÃO POLIÉSTER 4-0 SEM AGULHA 15 FIOS DE 45CM & 2,65 \\
\hline FIO CIRÚRGICO CATIGUTE CROMADO 1 AGULHA 1/2 CÍRCULO CILÍNDRICA 5,0CM & 2,50 \\
\hline FIO CIRÚRGICO CATIGUTE CROMADO 2-0 AGULHA 1/2 CÍRCULO CILÍNDRICA 2,5CM & 2,66 \\
\hline FIO CIRÚRGICO CATIGUTE CROMADO 2-0 AGULHA 1/2 CÍRCULO CILÍNDRICA 3,5CM & 5,76 \\
\hline FIO CIRÚRGICO CATIGUTE CROMADO 3-0 AGULHA 1/2 CÍRCULO CILÍNDRICA 2,5CM & 4,00 \\
\hline FIO CIRÚRGICO CATIGUTE CROMADO 4-0 AGULHA 1/2 CÍRCULO CILÍNDRICA 2,0CM & 4,41 \\
\hline FIO CIRÚRGICO CATIGUTE CROMADO 5-0 AGULHA 1/2 CÍRCULO CILÍNDRICA 1,5CM & 3,38 \\
\hline 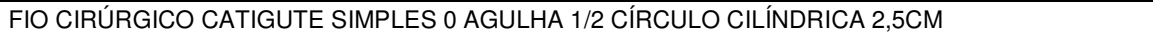 & 3,10 \\
\hline FIO CIRÚRGICO CATIGUTE SIMPLES 2-0 AGULHA 1/2 CíRCULO CILÍNDRICA 2,5CM & 1,55 \\
\hline FIO CIRÚRGICO CATIGUTE SIMPLES 2-0 AGULHA 1/2 CíRCULO CILÍNDRICA 3,5CM & 1,55 \\
\hline FIO CIRÚRGICO CATIGUTE SIMPLES 2-0 AGULHA 3/8 CÍRCULO CILÍNDRICA 2,0CM & 2,19 \\
\hline FIO CIRÚRGICO CATIGUTE SIMPLES 2-0 SEM AGULHA 150CM & 2,30 \\
\hline FIO CIRÚRGICO CATIGUTE SIMPLES 3-0 AGULHA 1/2 CÍRCULO CILÍNDRICA 2,0CM & 2,41 \\
\hline FIO CIRÚRGICO CATIGUTE SIMPLES 3-0 AGULHA 1/2 CíRCULO CILÍNDRICA 3,5CM & 2,69 \\
\hline FIO CIRÚRGICO CATIGUTE SIMPLES 3-0 SEM AGULHA 150CM & 2,30 \\
\hline FIO CIRÚRGICO CATIGUTE SIMPLES 4-0 AGULHA 1/2 CÍRCULO CILÍNDRICA 2,0CM & 2,30 \\
\hline FIO CIRÚRGICO CATIGUTE SIMPLES 4-0 SEM AGULHA 150CM & 4,19 \\
\hline FIO CIRÚRGICO CATIGUTE SIMPLES 5-0 AGULHA 1/2 CÍRCULO CILÍNDRICA 2,0CM & 2,40 \\
\hline FIO CIRÚRGICO NYLON MONOFILAMENTADO 10-0 2 AGULHAS 1/2 CÍRCULO ESPATULADA 0,7CM & 13,51 \\
\hline FIO CIRÚRGICO NYLON MONOFILAMENTADO 2-0 AGULHA 3/8 CíRCULO TRIANGULAR 2,0CM & 2,50 \\
\hline FIO CIRÚRGICO NYLON MONOFILAMENTADO 3-0 AGULHA 3/8 CÍRCULO CILÍNDRICA 2,0CM & 2,50 \\
\hline FIO CIRÚRGICO NYLON MONOFILAMENTADO 4-0 AGULHA 3/8 CÍRCULO TRIANGULAR 2,0CM & 2,50 \\
\hline FIO CIRÚRGICO NYLON MONOFILAMENTADO 4-0 AGULHA 3/8 CÍRCULO TRIANGULAR 2,4CM & 1,68 \\
\hline FIO CIRÚRGICO NYLON MONOFILAMENTADO 5-0 AGULHA 3/8 CÍRCULO TRIANGULAR 2,0CM & 2,50 \\
\hline FIO CIRÚRGICO NYLON MONOFILAMENTADO 6-0 AGULHA 1/2 CÍRCULO CILÍNDRICA 1,5CM & 1,90 \\
\hline FIO CIRÚRGICO POLIDIOXANONA 3-0 AGULHA 1/2 CÍRCULO CILÍNDRICA 2,6CM & 17,37 \\
\hline FIO CIRÚRGICO POLIDIOXANONA 6-0 2 AGULHAS 3/8 CÍRCULO CILÍNDRICA 1,3CM & 27,50 \\
\hline FIO CIRÚRGICO POLIDIOXANONA 7-0 2 AGULHAS 3/8 CÍRCULO CILÍNDRICA 0,9CM & 34,50 \\
\hline FIO CIRÚRGICO POLIÉSTER 2 AGULHA 1/2 CÍRCULO TRIANGULAR 4,0CM & 10,65 \\
\hline FIO CIRÚRGICO POLIÉSTER 2-0 2 AGULHAS 1/2 CíRCULO CILÍNDRICAS 2,0CM & 4,27 \\
\hline FIO CIRÚRGICO POLIÉSTER 5 AGULHA 1/2 CíRCULO TRIANGULAR 4,7CM & 23,91 \\
\hline FIO CIRÚRGICO POLIGLECAPRONE 0 AGULHA 1/2 CÍRCULO CILÍNDRICA 4,0CM & 5,41 \\
\hline FIO CIRÚRGICO POLIGLECAPRONE 1 AGULHA 1/2 CÍRCULO CILÍNDRICA 4,0CM & 6,90 \\
\hline FIO CIRÚRGICO POLIGLECAPRONE 2-0 AGULHA 1/2 CÍRCULO CILÍNDRICA 2,5CM & 6,25 \\
\hline FIO CIRÚRGICO POLIGLECAPRONE 3-0 AGULHA 1/2 CíRCULO CILÍNDRICA 2,5CM & 8,20 \\
\hline FIO CIRÚRGICO POLIGLECAPRONE 4-0 AGULHA 1/2 CÍRCULO CILÍNDRICA 2,5CM & 5,65 \\
\hline FIO CIRÚRGICO POLIGLECAPRONE 4-0 AGULHA 3/8 CÍRCULO TRIANGULAR 1,95CM & 9,21 \\
\hline FIO CIRÚRGICO POLIGLECAPRONE 5-0 AGULHA 3/8 CÍRCULO TRIANGULAR 1,65CM & 12,10 \\
\hline FIO CIRÚRGICO POLIPROPILENO 2 AGULHA 3/8 CíRCULO CILÍNDRICA 7,5CM & 20,53 \\
\hline FIO CIRÚRGICO POLIPROPILENO 2-0 AGULHA 1/2 CíRCULO CILÍNDRICA 2,5CM & 4,10 \\
\hline FIO CIRÚRGICO POLIPROPILENO 3-0 2 AGULHAS 1/2 CÍRCULO CILÍNDRICAS 3,0CM & 7,25 \\
\hline FIO CIRÚRGICO POLIPROPILENO 4-0 2 AGULHAS 1/2 CÍRCULO CILÍNDRICA 2,0CM & 8,20 \\
\hline FIO CIRÚRGICO POLIPROPILENO 4-0 2 AGULHAS 1/2 CÍRCULO CILÍNDRICAS 1,5CM & 7,45 \\
\hline
\end{tabular}




\begin{tabular}{|c|c|}
\hline NOME DO ITEM & $\begin{array}{c}\text { VALOR } \\
\text { UNITÁRIO }\end{array}$ \\
\hline FIO CIRÚRGICO POLIPROPILENO 5-0 2 AGULHAS 1/2 CÍRCULO CILÍNDRICA 1,50CM & 6,63 \\
\hline FIO CIRÚRGICO POLIPROPILENO 6-0 2 AGULHAS 3/8 CÍRCULO CILÍNDRICAS 1,3CM & 11,00 \\
\hline FIO CIRÚRGICO POLIPROPILENO 7-0 2 AGULHAS 3/8 CÍRCULO CILÍNDRICAS 1,0CM & 11,75 \\
\hline FIO CIRÚRGICO SEDA 4-0 AGULHA 3/8 CÍRCULO TRIANGULAR 1,3CM & 6,00 \\
\hline FIO CIRÚRGICO SINTÉTICO ABSORVÍVEL OFTÁLMICO COLORIDO 6-0 2 AG.1/4 CIRC.ESPAT.0,65CM & 51,00 \\
\hline FIO CIRÚRGICO SINTÉTICO ABSORVÍVEL 0 AGULHA 1/2 CÍRCULO CILÍNDRICA 3,5CM & 6,61 \\
\hline FIO CIRÚRGICO SINTÉTICO ABSORVÍVEL 0 AGULHA 1/2 CÍRCULO CILÍNDRICA 5,0CM & 6,70 \\
\hline FIO CIRÚRGICO SINTÉTICO ABSORVÍVEL 0 AGULHA 3/8 CíRCULO CILÍNDRICA 3,0CM & 4,89 \\
\hline FIO CIRÚRGICO SINTÉTICO ABSORVÍVEL 1 AGULHA 1/2 CÍRCULO CILÍNDRICA 3,5CM & 7,07 \\
\hline FIO CIRÚRGICO SINTÉTICO ABSORVIIVEL 1 AGULHA 1/2 CíRCULO CILÍNDRICA 5,0CM & 4,00 \\
\hline FIO CIRÚRGICO SINTÉTICO ABSORVÍVEL 2-0 AGULHA 1/2 CíRCULO CILÍNDRICA 2,5CM & 6,15 \\
\hline FIO CIRÚRGICO SINTÉTICO ABSORVÍVEL 2-0 AGULHA 1/2 CíRCULO CILÍNDRICA 5,0CM & 7,07 \\
\hline FIO CIRÚRGICO SINTÉTICO ABSORVÍVEL 2-0 AGULHA 3/8 CÍRCULO CILÍNDRICA 3,0CM & 4,90 \\
\hline FIO CIRÚRGICO SINTÉTICO ABSORVÍVEL 3-0 AGULHA 1/2 CÍRCULO CILÍNDRICA 2,5CM & 6,42 \\
\hline FIO CIRÚRGICO SINTÉTICO ABSORVÍVEL 4-0 AGULHA 1/2 CíRCULO CILÍNDRICA 2,0CM & 5,50 \\
\hline FIO CIRÚRGICO SINTÉTICO ABSORVÍVEL 4-0 AGULHA 3/8 CíRCULO CUTICULAR & 6,70 \\
\hline FIO CIRÚRGICO SINTÉTICO ABSORVÍVEL 5-0 AGULHA 3/8 CíRCULO TRIANGULAR 2,0CM & 6,70 \\
\hline FIO CIRÚRGICO 2-0 SEM AGULHA PARA ARTROSCOPIA & 194,00 \\
\hline FIO GUIA 0,035" X 150CM HIDROFíLICO & 240,00 \\
\hline FITA ADESIVA MICROPOROSA BRANCO 12MM X 100MM SUTURA DE PELE & 2,38 \\
\hline $\begin{array}{l}\text { FITA ADESIVA MICROPOROSA BRANCO 6MM X 38MM SUTURA DE PELE } \\
\end{array}$ & 2,05 \\
\hline FITA CIRÚRGICA MICROPOROSA BRANCO 100MM X 10MT HIPOALÉRGICA & 4,50 \\
\hline FITA CIRÚRGICA MICROPOROSA BRANCO 12MM X 10MT HIPOALÉRGICA & 0,89 \\
\hline FITA CIRÚRGICA MICROPOROSA BRANCO 25MM X 10MT HIPOALÉRGICA & 1,19 \\
\hline FITA CIRÚRGICA MICROPOROSA BRANCO 50MM X 10MT HIPOALÉRGICA & 2,96 \\
\hline FITA CREPE BRANCO 16MM X 50MT HIPOALÉRGICA & 1,14 \\
\hline FITA PROLENE 1,1CM X 45CM INABSORVÍVEL POLIPROPILENO & $2.400,00$ \\
\hline FRAGMENTADOR DE TECIDOS 15MM LAPAROSCÓPICO & $2.800,00$ \\
\hline FRALDA DESCARTÁVEL ADULTO & 1,80 \\
\hline $\begin{array}{l}\text { FRALDA DESCARTÁVEL ATE 5KG } \\
\end{array}$ & 0,24 \\
\hline FRASCO BRANCO 67ML COM TAMPA & 1,40 \\
\hline FRASCO DE VIDRO BRANCO CAPACIDADE 250ML DIÂMETRO DE 3CM - COM TAMPA & 1,68 \\
\hline FRASCO DRENAGEM DE TÓRAX 2000MIL & 7,30 \\
\hline FRASCO DRENAGEM DE TÓRAX 500MIL & 16,30 \\
\hline GENTAMICINA INJETÁVEL 40 MG/ML 2ML & 0,23 \\
\hline GRAMPEADOR CIRÚRGICO CURVO 21MM INTRALUMINAL DESCARTÁVEL & $1.086,00$ \\
\hline GRAMPEADOR CIRÚRGICO CURVO 25MM INTRALUMINAL DESCARTÁVEL & $1.065,00$ \\
\hline GRAMPEADOR CIRÚRGICO CURVO 28/29MM INTRALUMINAL DESCARTÁVEL & $1.065,00$ \\
\hline GRAMPEADOR CIRÚRGICO CURVO 33/34MM INTRALUMINAL DESCARTÁVEL & $1.065,00$ \\
\hline GRAMPEADOR CIRÚRGICO CURVO 40MM INTRALUMINAL RECARREGÁVEL & $2.100,00$ \\
\hline GRAMPEADOR CIRÚRGICO LINEAR 45MM ARTICULADO INTRALUMINAL DESCARTÁVEL & $2.263,00$ \\
\hline GRAMPEADOR CIRÚRGICO LINEAR 55MM INTRALUMINAL DESCARTÁVEL & $1.150,83$ \\
\hline GRAMPEADOR LINEAR RECARREGÁVEL 75MM CIRÚRGICO LINEAR 75MM RECARREGÁVEL DESC. & $1.165,92$ \\
\hline GUIA ENTUBAÇÃO 2,5MM X 4,5MM & 16,70 \\
\hline GUIA ENTUBAÇÃO 4,0MM 10FR & 14,40 \\
\hline GUIA ENTUBAÇÃO 5,0MM 14FR & 6,15 \\
\hline HIALURONIDASE INJETÁVEL 2.000 UTR COM DILUENTE DE 5ML & 12,00 \\
\hline LÂMINA BARBEAR & 0,14 \\
\hline LENÇOL ABSORVENTE 80CM X 150CM DRY GEL & 1,42 \\
\hline LENTE AVULSA CIRURGIA EXTRA CAPSULAR & 115,20 \\
\hline LIDOCAÍNA GELÉIA 2\% (20 MG/ML) 30ML ESTÉRIL & 1,22 \\
\hline LIDOCAÍNA SEM VASOCONSTRICTOR 2\% (20 MG/ML) 5ML & 0,43 \\
\hline LIDOCAÍNA SEM VASOCONSTRITOR 2\% (20 MG/ML) 20ML & 1,80 \\
\hline LIXA BISTURI ELÉTRICO & 2,97 \\
\hline LUVA CIRÚRGICA 6,5 ESTÉRIL & 0,44 \\
\hline LUVA CIRÚRGICA 7,0 ESTÉRIL & 0,44 \\
\hline LUVA CIRÚRGICA 7,5 ESTÉRIL & 0,44 \\
\hline LUVA CIRÚRGICA 8,0 ESTÉRIL & 0,44 \\
\hline LUVA CIRÚRGICA 8,5 ESTÉRIL & 0,45 \\
\hline LUVA PLÁSTICA ESTÉRIL & 0,04 \\
\hline LUVA PROCEDIMENTO MÉDIO ESTÉRIL & 0,40 \\
\hline LUVA PROCEDIMENTO MÉDIO NÃO ESTÉRIL & 10,45 \\
\hline
\end{tabular}




\begin{tabular}{|c|c|}
\hline NOME DO ITEM & $\begin{array}{l}\text { VALOR } \\
\text { UNITÁRIO }\end{array}$ \\
\hline MALHA TUBULAR 10CM X 25M & 5,50 \\
\hline MALHA TUBULAR 20CM X 25M & 11,05 \\
\hline MANTA TÉRMICA ADULTO 90-130CM X 200-240CM & 45,00 \\
\hline MANTA TÉRMICA INFERIOR 90-110CM X 140-160CM & 45,00 \\
\hline MANTA TÉRMICA PEDIÁTRICA 60-105CM X 100-155CM & 45,00 \\
\hline MANTA TÉRMICA SUPERIOR 60-80CM X 180-200CM & 44,99 \\
\hline MASCARA CIRÚRGICA DESCARTÁVEL & 0,07 \\
\hline METILCELULOSE INTRAOCULAR 2\% 1,5ML & 35,50 \\
\hline NITROFURAZONA SOLUÇÃO 0,2\% 20ML ESTÉRIL & 13,60 \\
\hline PASTA CONDUTORA ELETRODO & 1,07 \\
\hline PELÍCULA ADESIVA 10CM X 12CM PROTETORA & 1,61 \\
\hline PELÍCULA ADESIVA 25CM X 10CM PROTETORA & 6,37 \\
\hline $\begin{array}{l}\text { PELÍCULA ADESIVA 7CM X 9CM PROTETORA } \\
\end{array}$ & 2,69 \\
\hline PILOCARPINA COLÍRIO 2\%10ML & 11,71 \\
\hline PLACA BISTURI ELÉTRICO ADULTO & 15,90 \\
\hline PLACA BISTURI ELÉTRICO INFANTIL & 15,00 \\
\hline PROPE DESCARTÁVEL & 0,14 \\
\hline PROXIMETACAINA COLÍRIO 0,5\% 5ML & 4,86 \\
\hline PVP-I DEGERMANTE SOLUÇÃO 10\% 100ML & 9,40 \\
\hline PVP-I TINTURA SOLUÇÃO $10 \% 100 \mathrm{ML}$ & 2,30 \\
\hline PVP-I TÓPICO SOLUÇÃO 10\% 100 ML & 1,84 \\
\hline SABONETE GLICERINA 20 GRAMAS & 0,23 \\
\hline SACO P/ LIXO 15 L BRANCA 39X 59 CM DE ACORDO COM NBR9191/130 56/14474/7500 & 0,17 \\
\hline SACO P/ LIXO 30 L BRANCA 59X 62CM DE ACORDO COM NBR9191/130 56/14474/7500 & 0,26 \\
\hline SACO P/ LIXO 90 L BRANCA 92X 90CM DE ACORDO COM NBR9191/130 56/14474/7500 & 0,99 \\
\hline SACO PLÁSTICO BRANCO LEITOSO 20 CM X 40 CM PLACENTA & 0,16 \\
\hline SERINGA GASOMETRIA 2ML & 1,53 \\
\hline SERINGA 1ML DESCARTÁVEL & 0,18 \\
\hline SERINGA 10ML DESCARTÁVEL & 0,16 \\
\hline SERINGA 20ML DESCARTÁVEL & 0.28 \\
\hline SERINGA 3ML DESCARTÁVEL & 0,09 \\
\hline SERINGA 5ML DESCARTÁVEL & 0,10 \\
\hline SERINGA 60ML DESCARTÁVEL & 3,00 \\
\hline SOLUÇÃO SALINA PARA IRRIGAÇÃO OCULAR 250 ML ESTÉRIL & 14,00 \\
\hline SONDA ASPIRAÇÃO TRAQUEAL 10FR & 0,45 \\
\hline SONDA ASPIRAÇÃO TRAQUEAL 12FR & 0,45 \\
\hline SONDA ASPIRAÇÃO TRAQUEAL 14FR & 0,42 \\
\hline SONDA ASPIRAÇÃO TRAQUEAL 6FR & 0,57 \\
\hline SONDA ASPIRAÇÃO TRAQUEAL 8FR & 0,61 \\
\hline SONDA FOLEY 122 VIAS & 0,81 \\
\hline SONDA FOLEY 142 VIAS & 0,71 \\
\hline SONDA FOLEY 162 VIAS & 1,16 \\
\hline SONDA FOLEY 182 VIAS & 0,82 \\
\hline SONDA FOLEY 183 VIAS & 3,86 \\
\hline SONDA FOLEY 202 VIAS & 1,18 \\
\hline SONDA FOLEY 203 VIAS & 4,56 \\
\hline SONDA FOLEY 222 VIAS & 0,83 \\
\hline SONDA FOLEY 223 VIAS & 4,59 \\
\hline SONDA FOLEY 8 SILICONE 2 VIAS & 18,20 \\
\hline SONDA GÁSTRICA 10 TIPO LEVINE & 0,47 \\
\hline SONDA GÁSTRICA 12 TIPO LEVINE & 0,45 \\
\hline SONDA GÁSTRICA 14 TIPO LEVINE & 0,38 \\
\hline SONDA GÁSTRICA 16 TIPO LEVINE & 0,81 \\
\hline SONDA GÁSTRICA 18 TIPO LEVINE & 0,85 \\
\hline SONDA GÁSTRICA 8 TIPO LEVINE & 0,33 \\
\hline SONDA GASTROSTOMIA 14FR COM BALÃO 3 VIAS & 210,00 \\
\hline SONDA GASTROSTOMIA 16FR COM BALÃO 3 VIAS & 106,00 \\
\hline SONDA PARA NUTRIÇÃO ENTERAL 12FR - 105 A 120CM & 27,29 \\
\hline SONDA RETAL 26 & 0,58 \\
\hline SONDA RETAL 28 & 0,46 \\
\hline SONDA URETRAL DESC. CAL. 04. URETRAL 4 & 0,29 \\
\hline SONDA URETRAL DESC. CAL. 10. URETRAL 10 & 0,31 \\
\hline
\end{tabular}




\begin{tabular}{|c|c|}
\hline NOME DO ITEM & $\begin{array}{l}\text { VALOR } \\
\text { UNITÁRIO }\end{array}$ \\
\hline SONDA URETRAL DESC. CAL. 12. URETRAL 12 & 0,33 \\
\hline SONDA URETRAL DESC. CAL. 14. URETRAL 14 & 0,35 \\
\hline SONDA URETRAL 12 NELATON REUSÁVEL & 13,50 \\
\hline SONDA URETRAL 14 NELATON REUSÁVEL & 13,70 \\
\hline SONDA URETRAL 16 NELATON REUSÁVEL & 13,50 \\
\hline SONDA URETRAL 6 & 0,31 \\
\hline SONDA URETRAL 8 & 0,31 \\
\hline TALA IMOBILIZAÇÃO PROVISÓRIA 10CM X 2CMDEDO & 0,51 \\
\hline TALA IMOBILIZACCÃO PROVISÓRIA 30CM X 8CM X 2CM & 4,76 \\
\hline TALA IMOBILIZAÇÃO PROVISÓRIA 53CM X 8CM X 2CM & 7,53 \\
\hline TALA IMOBILIZAÇÃO PROVISÓRIA 63CM X 8CM X 2CM & 10,98 \\
\hline TALA IMOBILIZAÇÃO PROVISÓRIA 86CM X 9CM X 2CM & 16,80 \\
\hline TELA CIRÚRGICA 15CM X 15CM INABSORVÍVEL POLIPROPILENO & 136,00 \\
\hline TELA CIRÚRGICA 15CM X 15CM PARCIALMENTE ABSORVÍVEL POLIPROPILENO & 211,89 \\
\hline TELA CIRÚRGICA 30,5CM X 30,5CM INABSORVÍVEL POLIPROPILENO & 114,80 \\
\hline TIRA REAGENTE PARA DETERMINAÇÃO DE GLICOSE NO SANGUE & 0,83 \\
\hline TINTURA DE BENJOIM 20\% 100ML & 2,70 \\
\hline TORNEIRA 3 VIAS PLÁSTICO & 0,66 \\
\hline TOUCA DESCARTÁVEL & 0,06 \\
\hline TROPICAMIDA COLÍRIO 1\% 5ML & 7,25 \\
\hline TUBO ASPIRADOR CIRÚRGICO 200CM ESTÉRIL & 1,49 \\
\hline TUBO COLETA DE SANGUE A VÁCUO TAMPA AZUL $1,8 \mathrm{ML}$ CITRATO & 0,32 \\
\hline TUBO COLETA DE SANGUE A VÁCUO TAMPA ROXA 3 A 4ML EDTA & 0,20 \\
\hline TUBO COLETA DE SANGUE A VÁCUO TAMPA VERMELHA 9 A 10ML SEM GEL & 0,30 \\
\hline TUBO EXTENSOR 120CM CONEXÃO LUER LOCK & 1,95 \\
\hline TUBO EXTENSOR 20CM CONEXÃO LUER LOCK & 1,97 \\
\hline TUBO EXTENSOR 60CM CONEXÃO LUER LOCK & 0,48 \\
\hline TUBO LÁTEX DIÂMETRO INTERNO 3MM GARROTE & 7,75 \\
\hline $\begin{array}{l}\text { TUBO PARA COLETA A VÁCUO COM GEL TAMPA DE COR AMARELO OU VERMELHO 13MM X 100MM, DE } \\
5 \mathrm{~A} 6 \mathrm{ML}\end{array}$ & 0,28 \\
\hline $\begin{array}{l}\text { TUBO PARA COLETA A VÁCUO FLUORETO DE SÓDIO E EDTA TAMPA DE COR CINZA 13MMX } 75 \text { MM DE } \\
\text { 2ML A 3ML }\end{array}$ & 0,35 \\
\hline $\begin{array}{l}\text { TUBO PARA MICROCOLETA DE SANGUE CAPILAR C/ TAMPA AMAR.OU VERM. } 600 \text { MICROLIT (0,6ML) A } \\
1000 \text { MICROLIT }\end{array}$ & 1,30 \\
\hline TUBO VACUTAINER FLUORETO DE SÓDIO 3ML & 0,35 \\
\hline VASELINA LÍQUIDA 20ML ESTÉRIL & 6,30 \\
\hline
\end{tabular}




\section{Anexo 3 - Aprovação da Câmara de Pesquisa do HU-USP}
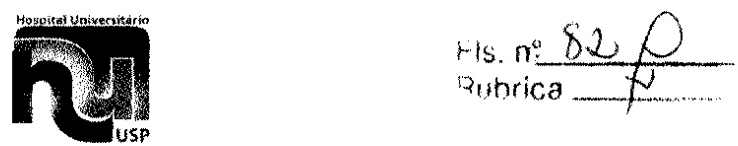

São Paulo, 28 de agosto de 2007.

$I^{\text {mo(a) }} . S^{\text {(a) }}$.

Dra. Valéria Castilho

Departamento de Orientação Profissional

Escola de Enfermagem

UNIVERSIDADE DE SÃO PAULO

REFERENTE: Projeto de Pesquisa "Estudo dos custos dos materiais após a reestruturação do modelo de gerenciamento de materiais do Centro Cirúrgico do Hospital Universitário da USP" - Co-Autor(es): Maria Lúcia Habib Paschoal Registro CEP-HU/USP: 771/07

Prezado(a) Senhor(a)

A Câmara de Pesquisa do Hospital Universitário da Universidade de São Paulo, em 24 de agosto de 2007 analisou o projeto de pesquisa acima citado, considerando-o como APROVADO.

Solicitamos que ao final do trabalho seja apresentado a esta Câmara de Pesquisa, relatório final consubstanciado dos resultados e conclusões.

Atenciosamente,

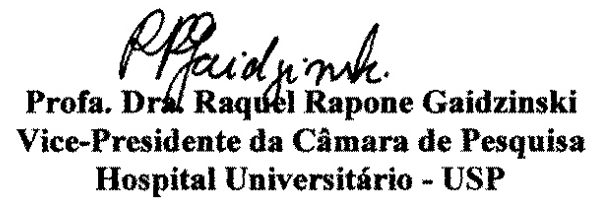

CAMARA DE PESOUISA DO HOSPTTAL UNTVERSTARIO DA USP Avea ida Protessor Lineu Prestes, 2865 - Cldade Universithria - 05508-900 Sto Paulo - SP

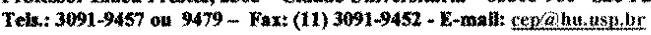

